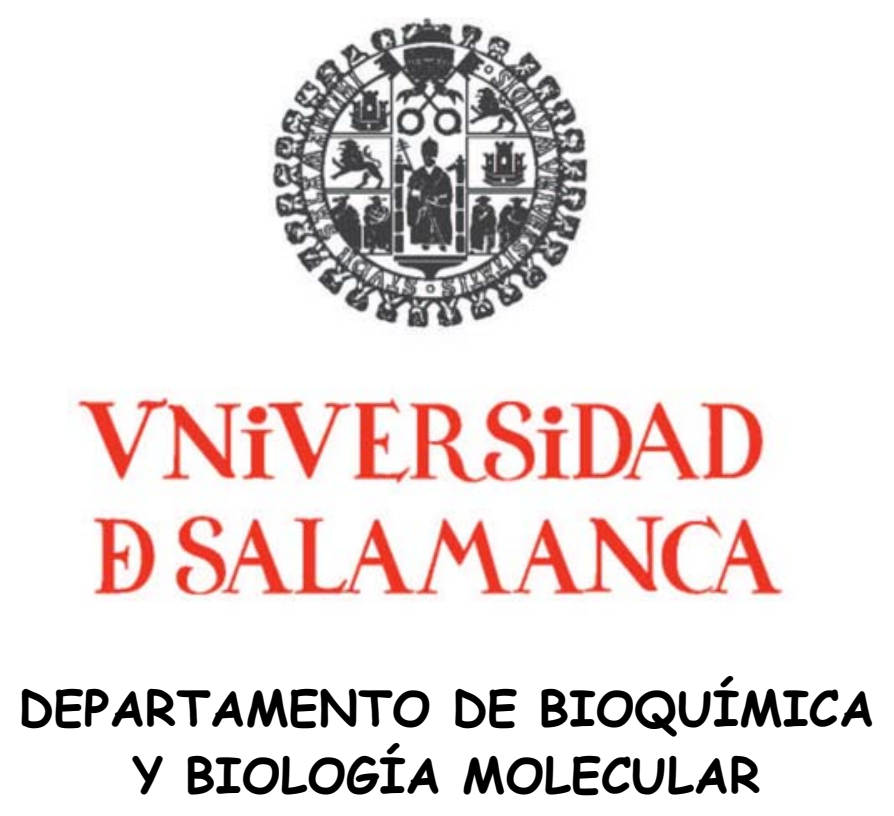

\title{
TESíS DOCTORAL
}

Efecto de la quercetina y la rutina frente al daño oxidativo inducido en eritrocitos con distintos contenidos de colesterol.

JOSÉ IGNACiO SÁNCHEZ GALLEGO 
MARCIAL LLANILLO ORTEGA, Profesor Titular de Universidad del Departamento de Bioquímica y Biología Molecular de la Universidad de Salamanca,

HAGO CONSTAR,

Que la presente Memoria de Tesis Doctoral titulada "Efecto de la quercetina y la rutina frente al daño oxidativo inducido en eritrocitos con distintos contenidos de colesterol', de la que es autor D. José Ignacio SÁNCHEZ GALLEGO y que presenta para optar al Grado de Doctor en Biología, ha sido realizada bajo mi dirección en el Departamento de Bioquímica y Biología Molecular de la Universidad de Salamanca. Considero que dicha Tesis Doctoral se halla concluida, y por tanto, autorizo su presentación para que sea juzgada por el Tribunal correspondiente.

Y para que así conste, firmo el presente documento en Salamanca a diecisiete de febrero de dos mil nueve. 
JOSÉ IGNACIO SÁNCHEZ GALLEGO, licenciado en Biología y Bioquímica por la Universidad de Salamanca,

\section{HAGO CONSTAR,}

Que soy autor de la Tesis Doctoral titulada "Efecto de la quercetina y la rutina frente al daño oxidativo inducido en eritrocitos con distintos contenidos de colesterol", realizada en el Departamento de Bioquímica y Biología Molecular de la Universidad de Salamanca bajo la dirección del Profesor Dr. Marcial Llanillo.

Y para que así conste, firmo el presente documento en Salamanca a diecisiete de febrero de dos mil nueve. 


\section{NOTA PRELIMINAR}

Este trabajo de investigación ha sido financiado con cargo a los proyectos subvencionados por el Ministerio de Ciencia y Tecnología (Plan I+D+i, "Efecto de la peroxidación sobre la estructura-función de los eritrocitos enriquecidos en colesterol" Ref. BMC2000-1132), la Universidad de Salamanca ("Protecciones aportadas por quercetina y rutina frente al daño oxidativo inducido por radicales libres de oxígeno en eritrocitos modificados en sus contenidos de colesterol" Ref. USAL2005B1-13) y la Junta de Castilla y León (Ref. SA058A07).

El autor de la Memoria ha disfrutado de una Beca de Investigación de la Junta de Castilla y León (Junio 2003-Junio 2007).

Los resultados recogidos en esta Memoria han sido en parte publicados en un artículo y presentados en los siguientes Congresos:

\section{Artículo:}

López-Revuelta, A., Sánchez-Gallego, J.I., Hernández-Hernández, A., SánchezYagüe, J. y Llanillo, M.

Membrane cholesterol contents influence the protective effects of quercetin and rutin in erythrocytes damaged by oxidative stress

Chemico-Biological Interactions 161(2006)79-91

\section{Congresos:}

1. II Congreso Nacional de Ciencia y Tecnología de los Alimentos, Orihuela (Alicante, España), 3-6 de Junio de 2003. "Actividad biológica de la quercetina y la rutina frente al daño oxidativo en eritrocitos enriquecidos en colesterol". Volumen 1, pág 109-112. 
2. XXVII Congreso de la Sociedad Española de Bioquímica y Biología Molecular, Lleida (España), 12-15 de Septiembre de 2004. "Relación entre el contenido en colesterol de los eritrocitos y su susceptibilidad al daño oxidativo inducido por hidroperóxido de ter-butilo. Protección por antioxidantes". Resumen P12-3, pág 216.

3. XXX Congreso de la Sociedad Española de Bioquímica y Biología Molecular, Málaga (España), 12-15 de Septiembre de 2007. "Influencia del colesterol en la disposición asimétrica de los aminofosfolípidos de membrana en eritrocitos oxidados con hidroperóxido de ter-butilo. Efectos protectores de quercetina y rutina. Resumen T06-16, pág 152. 
Abreviaturas 
APLT: Aminofosfolípido translocasa.

Anexina V-FITC: Proteína anticoagulante anexina $\mathrm{V}$ conjugada con el compuesto fluorescente isotiocianato de fluoresceina.

BCD: $\beta$-ciclodextrina.

BHA: 3-t-butil-4-hidroxianisolona.

BHT: Hidroxitoluenobutilado.

BSA: Seroalbúmina bovina.

BSF: Suero bovino fetal.

Ch: Colesterol.

COMT: Catecol-O-metiltransferasa

CPD-A $\mathbf{1}$ : Anticoagulante citrato/fosfato/glucosa/adenina.

DCF: 2',7'-diclorofluoresceina.

DCFDA: Diacetato de diclorodihidrofluoresceina.

DCFH $_{2}$ : 2', 7 '-diclorodihidrofluoresceina.

D.E.: Desviación estándar de la media.

DHEAS: Dehidroandrosterona 3-sulfato.

DMSO: Dimetilsulfósido.

DPG: Difosfatidilglicerol ó Cardiolipina.

DPH: 1,6-difenil-1,3,5-hexatrieno.

DTNB: 5-5' -dithiobis(2-ácido nitrobenzoico).

FAME: Ésteres metílicos de ácidos grasos.

FID: Detector de ionización de llama.

FITC: Isotiocianato de fluoresceina.

F-OH: Flavonoide

FSC: Forward scatter (dispersión frontal de luz)

GC: Cromatografía en fase gaseosa.

GC-MS: Cromatografía en fase gaseosa acoplada a espectrometría de masas.

GSH: Glutation reducido.

GSSG: Glutation oxidado.

Hb: Hemoglobina.

HBS $_{1}$ : Disolución amortiguadora de HEPES 10 mM, $\mathrm{KCl} 150$ mM, pH 7,4.

HBS $_{2}$ : Disolución amortiguadora de HEPES 10 mM, NaCl 145 mM, pH 7,4.

HEPES: Ácido N-[2-hidroxietil]piperacina-N'-[2-etanosulfónico].

HOO०: Radical perhidroxilo.

IAA: Ácido indolacético.

LDL: Lipoproteínas de baja densidad

MBCD: Metil- $\beta$-ciclodextrina.

MDA: Malonildialdehído. 
MetHb: Metahemoglobina.

MS: Espectrometría de masas.

NBD-PS: 1-Palmitoil-2-[6-[(7-nitro-2-1,3-benzoxadiazol-4-il)amino]hexanoil]sn-glycero-3-phosphoserine

NEM: N-etilmaleimida.

$\mathbf{O}_{2}{ }^{\bullet-}$ : Radical superóxido.

$\mathbf{O H}^{\bullet}$ : Radical hidroxilo.

P: Polarización de fluorescencia.

PA: Ácido fosfatídico.

PBS: Disolución amortiguadora de fosfato sódico 5 mM, NaCl 150 mM, pH 7,5.

PC: Fosfatidilcolina.

PDE: Fosfodiesterasa

PE: Fosfatidiletanolamina.

Pi: Fósforo inorgánico (procedente de lípidos).

PI: Fosfatidilinositol.

PL: Fosfolípido.

PMSF: Fluoruro de fenilmetilsulfonilo.

PRP: Plasma rico en plaquetas.

PS: Fosfatidilserina.

PUFA: Ácidos grasos poliinsaturados.

$\mathbf{p} / \mathbf{v}$ : Peso/volumen.

PVP: Polivinilpirrolidona.

Q: Quercetina

Rf: Coeficiente de reparto.

$\mathbf{R}^{\bullet}$ : Radical libre

RNS: Especies reactivas de nitrógeno

RO•: Radical alcoxilo

ROO•: Radical peroxilo.

ROOH: Hidroperóxido lipídico.

ROS: Especies reactivas de oxígeno.

$\mathbf{r}_{\mathbf{s}}$ : Anisotropía de fluorescencia.

Ru: Rutina

SBF: Suero bovino fetal

SDS: Lauril sulfato sódico.

SM: Esfingomielina.

SOD: Superóxido dismutasa.

SSC: Side scatter (dispersión lateral de luz).

TBA: Ácido tíobarbitúrico. 
TBARS: Sustancias reaccionantes con el ácido tiobarbitúrico.

tBHP: Hidroperóxido de ter-butilo.

t-BuO': Radical butoxilo.

TCA: Ácido tricloroacético.

TEAC: Actividad antioxidante equivalente en Trolox

THF: Tetrahidrofurano.

TLC: Cromatografía en capa fina.

TMA-DPH: 1-[4-(trimetilamonio)-fenil]-6-fenil-1,3,5-hexatrieno.

TRIS: tris[hidroximetil]aminometano.

UFR: Unidades de fluorescencia relativa

UV: Ultravioleta

$\mathbf{v} / \mathbf{v}$ :Volumen/volumen. 
Índice 



\section{CAPÍTULO I: INTRODUCCIÓN}

1. LOS ERITROCITOS. GENERALIDADES

2. ORGANIZACIÓN ESTRUCTURAL Y FUNCIONAL DE LA MEMBRANA ERITROCITARIA

2.1. COMPOSICIÓN QUÍMICA. ORGANIZACIÓN ESTRUCTURAL DE LA BICAPA LIPÍDICA

2.2. ESTADO FÍSICO DE LA BICAPA LIPÍDICA .........................................15

2.3. INFLUENCIA DE LA ASIMETRÍA LIPÍDICA EN EL FUNCIONAMIENTO DE

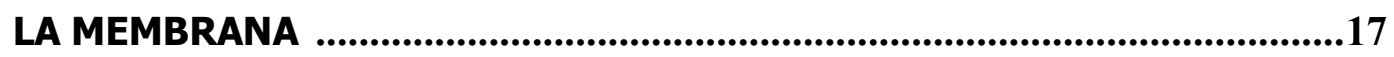

3. PROCESOS OXIDATIVOS EN LAS MEMBRANAS CELULARES ...................20

3.1. RADICALES LIBRES Y ESTRÉS OXIDATIVO ............................................20

3.2. IMPLICACIONES DEL ESTRÉS OXIDATIVO SOBRE LA ESTRUCTURA-

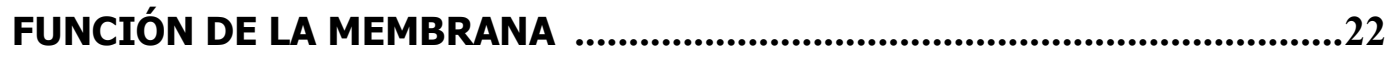

3.2.1. Efecto sobre la composición lipídica .....................................................23

3.2.2. Influencia sobre el estado físico y la asimetría lipídica de la membrana

3.2.3. Implicaciones fisiológicas del daño oxidativo. Repercusiones en el eritrocito

4. SISTEMAS INTRACELULARES DE DEFENSA FRENTE AL DAÑO OXIDATIVO

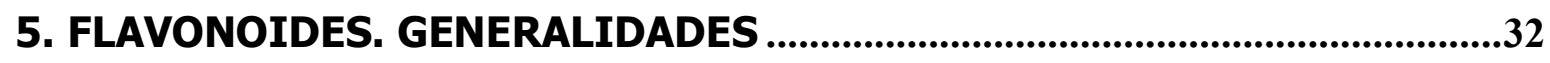

5.1. ESTRUCTURA QUÍMICA Y CLASIFICACIÓN ..............................................33

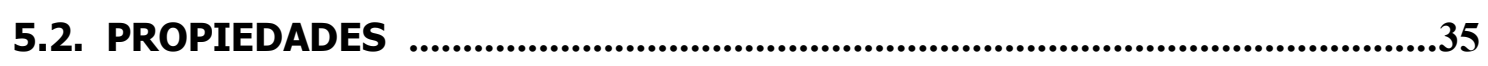

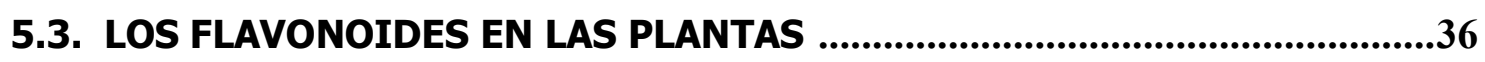

5.3.1. Biosíntesis y regulación ..................................................................37

5.3.2. Funciones en las plantas ...................................................................................38

5.4. FLAVONOIDES EN LA DIETA ...............................................................40

5.4.1. Distribución ........................................................................................40

5.4.2. Bioasimilación y metabolismo de los flavonoides ....................................42

5.5. ACTIVIDADES BIOLÓGICAS DE LOS FLAVONOIDES ...................................45

5.5.1. Propiedades antioxidantes en relación con su estructura ......................45

5.5.1.1. Propiedades de quelación ....................................................................49

5.5.1.2. Interacciones de los flavonoides con biomembranas ............................50

5.5.2. Propiedades pro-oxidantes de los flavonoides ....................................53

5.5.3. Otras actividades biológicas ...........................................................55 
CAPÍTULO III: MATERIALES Y MÉTODOS ......................................................69

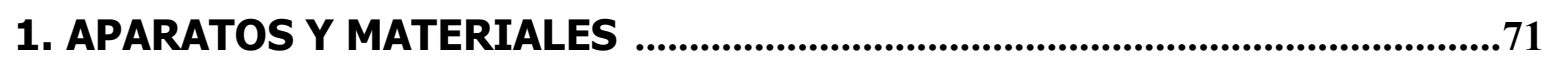

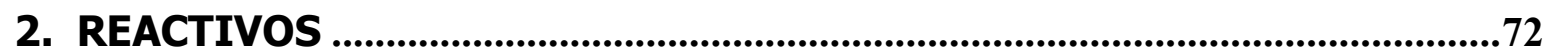

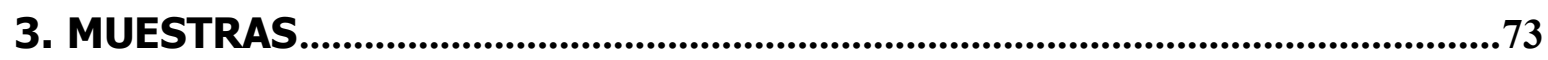

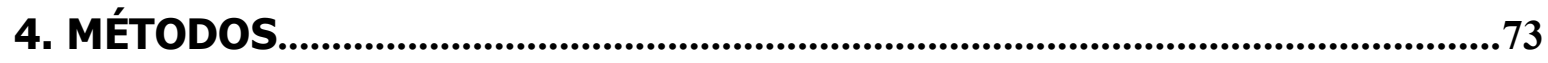

4.1. OBTENCIÓN DE LOS ERITROCITOS ………..........................................73

4.2. MODIFICACIÓN DE LOS CONTENIDOS DE COLESTEROL EN LOS

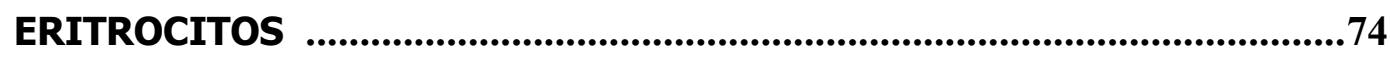

4.2.1. Enriquecimiento en colesterol ................................................................74

4.2.2. Empobrecimiento en colesterol …...........................................................74

4.3. OBTENCIÓN DE LAS MEMBRANAS DE LOS ERITROCITOS .........................75

4.4. DETERMINACIÓN DE HEMOGLOBINA Y METAHEMOGLOBINA ................75

4.4.1. Determinación de la hemoglobina (Hb) ..............................................75

4.4.2. Determinación de la metahemoglobina (MetHb) ....................................76

4.5. VALORACIÓN DE PROTEÍNAS ...................................................................77

4.6. DETERMINACIÓN DE GLUTATION REDUCIDO (GSH) ...............................77

4.7. MEDIDAS DE LA HEMÓLISIS Y DE LA ESTABILIDAD EN MEDIOS ISOTÓNICOS

4.7.1. Determinación de la hemólisis durante la modificación de los contenidos de colesterol ..............................................................................78

4.7.2. Determinación de la hemólisis durante el daño oxidativo.........................79

4.7.3. Determinación de la estabilidad en medios isotónicos ..............................79

4.8. INDUCCIÓN DEL DAÑO OXIDATIVO ...................................................79

4.8.1. En ausencia de antioxidante.................................................................79

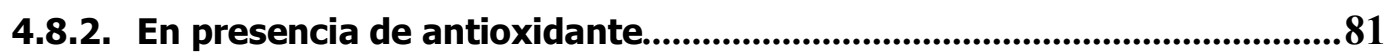

4.9. CUANTIFICACIÓN DEL DAÑo OXIDATIVO POR MEDIDA DE LAS SUSTANCIAS REACCIONANTES CON EL ÁCIDO TIOBARBITÚRICO (TBARS)

4.10. DETERMINACIÓN DEL CONTENIDO DE ESPECIES REACTIVAS DE OXÍGENO (ROS) EN AUSENCIA Y PRESENCIA DE ANTIOXIDANTE ........82

4.11. ESTUDIO DE LA COMPOSICIÓN LIPÍDICA …........................................83

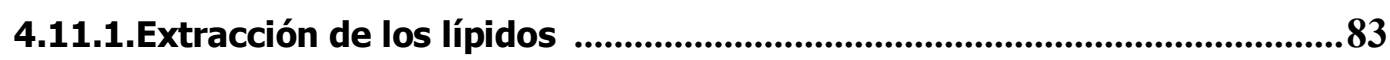

4.11.2.Valoración de los contenidos en fosfolípidos .......................................84

4.11.3.Valoración del contenido en colesterol .....................................................84

4.11.4.Separación y cuantificación de las diferentes clases de fosfolípidos ....85

4.11.5.Separación, identificación y cuantificación de los ácidos grasos mediante cromatografía en fase gaseosa (GC) acoplada a espectrometría de masas (MS) ..................................................................86 
4.12. ESTUDIO DE POLARIZACIÓN DE FLUORESCENICA

4.12.1. Condiciones de medida

4.13. ESTUDIOS SOBRE LA ORIENTACIÓN DE LOS FOSFOLIPIDOS EN LA MEMBRANA ERITROCITARIA ......................................................89

4.13.1. Mediante tratamiento con fosfolipasa $A_{2}$................................................89

4.13.2. Por citometría de flujo

4.14. DETERMINACIÓN DE LA ACTIVIDAD AMINOFOSFOLÍPIDO

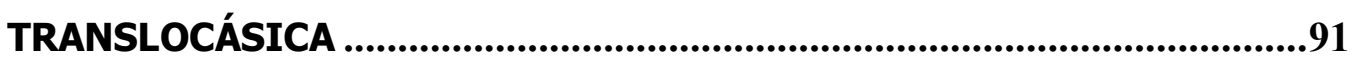

4.15. DETERMINACIÓN DE LA ERITROFAGOCITOSIS .....................................94

4.15.1. Cultivos celulares de macrófagos de ratón ...............................................94

4.15.2. Ensayo de la fagocitosis de los eritrocitos por macrófagos de ratón ...94

4.16. ESTUDIOS MORFOLÓGICOS …............................................................95

5. TRATAMIENTO ESTADÍSTICO DE LOS DATOS................................................96

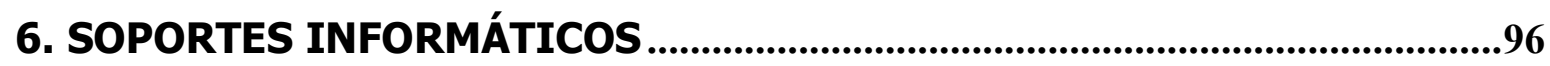

CAPÍTULO IV: RESULTADOS 97

1. MODIFICACIÓN DE LOS CONTENIDOS DE COLESTEROL EN LOS ERITROCITOS

2. ENSAYO DE LA ACTIVIDAD ANTIOXIDANTE DE DIFERENTES COMPUESTOS FRENTE AL DAÑO OXIDATIVO INDUCIDO POR EL TBHP EN ERITROCITOS CONTROLES

3. EFECTO PROTECTOR DE LOS ANTIOXIDANTES QUERCETINA Y RUTINA FRENTE AL DAÑO OXIDATIVO INDUCIDO POR EL TBHP EN LOS ERITROCITOS MODIFICADOS EN SUS CONTENIDOS DE COLESTEROL.

3.1. INFLUENCIA SOBRE LA PRODUCCIÓN DE ROS ….................................104

3.1. INFLUENCIA SOBRE LA PRODUCCIÓN DE TBARS .................................111

4. EFECTO PROTECTOR DE LOS FLAVONOIDES QUERCETINA Y RUTINA SOBRE LA OXIDACIÓN DE LA HEMOGLOBINA INDUCIDA POR TBHP

5. EFECTO PROTECTOR DE LOS FLAVONOIDES QUERCETINA Y RUTINA SOBRE LA OXIDACIÓN DEL GSH INDUCIDA POR tBHP.

6. PROTECCIÓN EJERCIDA POR LOS FLAVONOIDES QUERCETINA Y RUTINA SOBRE LA COMPOSICIÓN LIPÍDICA DE LOS DISTINTOS TIPOS DE ERITROCITOS TRAS LA OXIDACIÓN CON TBHP.

6.1. PROTECCIÓN SOBRE EL CONTENIDO EN LÍPIDOS TOTALES

6.2. PROTECCIÓN SOBRE LAS DIFERENTES CLASES DE FOSFOLÍPIDOS ...124 
6.3. PROTECCIÓN DE LOS CONTENIDOS EN ÁCIDOS GRASOS DE LOS LÍPIDOS TOTALES

7. ANÁLISIS DE LA PROTECCIÓN EJERCIDA POR QUERCETINA Y RUTINA SOBRE ESTADO FÍSICO DE LA MEMBRANA ERITROCITARIA SOMETIDA A OXIDACIÓN

8. ANÁLISIS DE LA PROTECCIÓN EJERCIDA POR QUERCETINA Y RUTINA SOBRE LA DISPOSICIÓN ASIMÉTRICA DE LOS FOSFOLÍPIDOS EN LA MEMBRANA ERITROCITARIA OXIDADA...............................................135

8.1. ANÁLISIS MEDIANTE HIDRÓLISIS CON FOSFOLIPASA $A_{2}$ DE LA DISPOSICIÓN ASIMÉTRICA DE LOS FOSFOLÍPIDOS ............................135

8.2. ANÁLISIS MEDIANTE CITOMETRÍA DE FLUJO DE LA EXTERIORIZACIÓN DE FOSFATIDILSERINA

8.2.1. Estudio de la integridad celular de los eritrocitos .138

8.2.2. Análisis porcentual de los eritrocitos marcados con anexina V-FITC 140

8.3. ESTUDIO DE LA FAGOCITOSIS EN LOS DIFERENTES TIPOS DE ERITROCITOS TRATADOS

9. CUANTIFICACIÓN DE LA ACTIVIDAD AMINOFOSFOLÍPIDO
A TRANSLOCÁSICA .149

10. ANÁLISIS MORFOLÓGICO Y DE ESTABILIDAD ISOTÓNICA 152

10.1. EFECTO SOBRE LA MORFOLOGÍA CELULAR 152

10.2. EFECTO SOBRE LA ESTABILIDAD ISOTÓNICA 156

10.2.1. Análisis del grado de hemólisis en ausencia y presencia de antioxidante 156

10.2.2. Análisis de la estabilidad isotónica en ausencia y presencia de antioxidante 
CAPÍTULO I: Introducción 



\section{LOS ERITROCITOS. GENERALIDADES}

El eritrocito (del griego erythrose, rojo y kytos, recipiente con depresión), también llamado hematíe, es la célula roja de la sangre. En pájaros, reptiles y camélidos tienen forma oval o elíptica. En el resto de los mamíferos, en su forma circulante y normal, presenta forma de disco flexible bicóncavo, lo que asegura la difusión rápida del oxígeno a las moléculas de hemoglobina situadas en el interior del eritrocito.

En la especie humana, su diámetro, que disminuye con la edad, es de 7,5 a $8,3 \mu \mathrm{m}$, su espesor aproximado es de $2 \mu \mathrm{m}$ en la periferia y $1 \mu \mathrm{m}$ en su parte central y el volumen medio es de $83 \mu \mathrm{m}^{3}$ con un área de aproximadamente $145 \mu \mathrm{m}^{2}$. El exceso de superficie en relación al volumen contribuye a su deformación, característica de gran trascendencia en este tipo de células, y al intercambio gaseoso con el entorno que les rodea. En el hombre, el número medio de glóbulos rojos por $\mathrm{mm}^{3}$ de sangre es de unos $5.400 .000 \pm 600.000$ y en la mujer de $4.600 .000 \pm 500.000$, aunque este valor varía con la edad, así como con la altitud del medio donde se habita y el ejercicio que se practica.

Los eritrocitos realizan la función de transportar los gases $\mathrm{O}_{2}$ y $\mathrm{CO}_{2}$ por medio de la hemoglobina (34 g/100 ml eritrocitos). El eritrocito tiene la capacidad de deformarse, deslizarse y circular a través de los vasos sanguíneos junto a otras células, sin que se produzca su agregación, fragmentación 0 fusión. La estructura bicóncava, la deformación y las propiedades de superficie del eritrocito vienen determinadas por tres componentes del mismo que interactúan entre sí: la membrana, la hemoglobina y los componentes no hemoglobínicos como sales, agua, enzimas, sustratos y cofactores.

El eritrocito se comporta como un osmómetro, contrayéndose en disoluciones hipertónicas, con lo que adquiere una forma aplanada, mientras que en disoluciones hipotónicas se hincha y adopta formas esféricas, llegando a producirse agujeros en su membrana plasmática, lo que ocasiona una salida de la hemoglobina al medio extracelular.

El eritrocito carece de algunos de los orgánulos que están presentes en sus células precursoras (los reticulocitos), como las mitocondrias, los ribosomas, 
el centríolo y las vesículas de Golgi, pero tiene toda la maquinaria enzimática necesaria para conservar la hemoglobina (Moraleda y Corral, 1996).

El proceso de formación de los eritrocitos (eritropoyesis) tiene por objeto mantener un número relativamente constante de eritrocitos circulantes, que aseguren el transporte de oxígeno a los tejidos. En las primeras etapas de la vida embrionaria en humanos, los glóbulos rojos primitivos se producen en el saco vitelino, siendo posteriormente el hígado, junto con el bazo y los ganglios linfáticos, los encargados de su producción. Durante el último periodo del embarazo y después del nacimiento hasta llegar a la adolescencia, se producen en la médula ósea, aunque a partir de los veinte años tan sólo lo hacen en la médula de los huesos membranosos (vértebras, esternón y costillas), ya que la médula ósea de los huesos largos se vuelve grasa, siendo incapaz de producir eritrocitos (Moraleda y Corral, 1996).

La vida media de los eritrocitos humanos en el torrente sanguíneo es aproximadamente de 100-120 días, para ser eliminados después. Se han propuesto varias hipótesis acerca de cómo acontece el reconocimiento y la eliminación de los eritrocitos senescentes, que en todos los casos implican alteraciones en su membrana, tales como: i) descenso de la densidad de carga superficial; ii) descenso de la deformación; iii) cambios en la asimetría lipídica, por exteriorización de la fosfatidilserina; iv) exposición de residuos (ej. B-Dgalactosil) que son reconocidos por receptores de los macrófagos celulares; v) exposición del "antígeno de célula senescente" y unión a su correspondiente anticuerpo (Bartosz, 1990; Kuypers y de Jong, 2004). Esta última hipótesis es ampliamente aceptada. La banda 3 se modificaría por asociación con hemicromos, actuando dicho conjunto como "antígeno de senescencia", que se unirá con alta afinidad a sus anticuerpos sanguíneos, activándose el complemento, y favoreciéndose así la fagocitosis de los eritrocitos alterados (Pantaleo et al, 2008). La eliminación de los eritrocitos de la circulación se realiza por tres vías distintas: i) a través del bazo, cuando el eritrocito presenta pequeñas alteraciones; ii) por medio del hígado y el bazo, si los cambios en el eritrocito son elevados; iii) en la propia circulación sanguínea, con liberación de sus componentes citoplasmáticos al plasma, cuando el eritrocito está muy deteriorado.

Para cumplir con eficacia su función y sobrevivir en la circulación durante 120 días, el eritrocito debe disponer de suficiente energía y de los componentes 
metabólicos adecuados, a pesar de que la captación, transporte y distribución de oxígeno no precisa de un gasto energético elevado. Los productos generados en el catabolismo que tiene lugar en el eritrocito permiten mantener: i) el hierro de la hemoglobina en forma divalente; ii) sus niveles de potasio altos y los de sodio bajos en el interior celular, contra el gradiente de concentración impuesto por los niveles plasmáticos; iii) el glutation y los grupos sulfhidrilos de la hemoglobina y otras proteínas eritrocitarias en estado reducido.

La glucosa representa la principal fuente de aporte energético en el eritrocito, la cual se metaboliza a través de dos rutas principales: glucólisis anaerobia y la ruta de las pentosas fosfato. La energía que le proporciona la glucosa al hematíe maduro se obtiene casi exclusivamente por la glucólisis anaerobia. El lactato y el piruvato formados por esta vía difunden fuera del eritrocito y se metabolizan en otros lugares. La función principal de la ruta de las pentosas fosfato consiste en proporcionar NADPH a través de la glucosa-6fosfato deshidrogenasa, que convierte la glucosa-6-fosfato en 6-fosfogluconato en un proceso dependiente de NADP ${ }^{+}$. El NADPH que se forma será utilizado en la reducción del glutation oxidado (GSSG) de los eritrocitos por medio de la glutation reductasa. Este glutation reducido es un potente agente antioxidante, y se encarga también de mantener reducidos los grupo tioles de la hemoglobina y de las proteínas eritrocitarias (Williams et al, 1975; Gaetani et al, 1989).

El eritrocito también es capaz de utilizar otros sustratos diferentes a la glucosa para obtener energía, tales como adenosina, inosina, fructosa, manosa, galactosa y lactato. El empleo de estos sustratos es de especial interés en los procesos de almacenamiento de sangre y eritrocitos.

Los eritrocitos maduros tienen una capacidad de síntesis muy limitada. Pueden alargar las cadenas de los ácidos grasos, pero no pueden sintetizarlos. También pueden añadir grupos acilos a los lisofosfolípidos, con la participación de ATP y coenzima A, pero no pueden sintetizar lípidos de novo (van Deenen y de Gier, 1964). Sin embargo, la composición lipídica de la membrana eritrocitaria (ácidos grasos, fosfolípidos en general, fosfatidilcolina y colesterol, en particular) puede verse alterada por intercambios constantes con los lípidos plasmáticos (Murray, 1993). De hecho, se ha demostrado que la composición en ácidos grasos de los fosfolípidos eritrocitarios puede modificarse con la dieta 
(Farquhar y Ahrens, 1963, Cazzola et al, 2004) y durante el envejecimiento (Ogiso et al, 1985).

La hemoglobina, proteína mayoritaria del eritrocito, mantiene su estado funcional gracias a la presencia de NADH y a la participación de la metahemoglobina reductasa, que se encarga de reducir el hierro de la metahemoglobina, que se genera en pequeñas proporciones en situaciones normales, desde la forma trivalente a la divalente, revirtiendo así la hemoglobina a su forma funcional (Murray, 1993). Esta proteína juega también un papel importante como regulador del $\mathrm{pH}$ sanguíneo, aportando aproximadamente el $70 \%$ del poder amortiguador. El tampón de hemoglobina reducida/oxihemoglobina debe sus propiedades principalmente a la capacidad de disociación del grupo imidazólico de la histidina unida al $\mathrm{Fe}^{2+}$ (Culebras, 1991). 


\section{ORGANIZACIÓN ESTRUCTURAL Y FUNCIONAL DE LA MEMBRANA ERITROCITARIA}

\subsection{COMPOSICIÓN QUÍMICA. ORGANIZACIÓN ESTRUCTURAL DE LA BICAPA LIPÍDICA}

Las membranas biológicas están constituidas por lípidos, glúcidos y proteínas. Los lípidos se organizan formando una matriz lipídica con doble capa molecular.

La membrana eritrocitaria constituye una barrera física entre el plasma sanguíneo y los componentes del interior del eritrocito. Esta membrana es impermeable a las proteínas e intermediarios metabólicos fosforilados y relativamente permeable a los cationes. En cambio, el agua y los aniones atraviesan fácilmente la misma. Las moléculas pequeñas como la glucosa, la manosa, la fructosa y la galactosa, utilizan una serie de transportadores que se encargan del paso de estos componentes de forma bidireccional (Moraleda y Corral, 1996).

Los primeros datos completos acerca de la composición lipídica de la membrana eritrocitaria proceden de los eritrocitos humanos, donde se observa que la esfingomielina (SM, 25\%) y la lecitina (PC, 29\%) representan aproximadamente el $50 \%$ de los fosfolípidos totales. La fosfatidilserina (PS, $15 \%)$ y la fosfatidiletanolamina ( $P E, 27,5 \%)$ constituyen el resto de los fosfolípidos mayoritarios. En cambio, en los eritrocitos ovinos la SM (50\%), la PE (31\%) y la PS (13\%) representan los fosfolípidos mayoritarios, mientras que a la PC sólo le corresponde el $1 \%$ de los fosfolípidos totales (Billington et al, 1977; Marín et al, 1990). Un análisis pormenorizado de la composición en ácidos grasos de los lípidos totales de eritrocitos humanos indica que los ácidos palmítico $(16: 0,41 \%)$, esteárico $(18: 0,7,9 \%)$, oleico $(18: 1,18,9 \%)$, linoleico $(18: 2,15,3 \%)$ y araquidónico (20:4, 7,9\%) son los más abundantes, con una razón saturación/insaturación de 0,9 (Williams et al, 1975; Rogiers et al, 1980). El porcentaje mayoritario de los ácidos y aldehídos grasos que forman parte de los fosfolípidos corresponden a los ácidos grasos saturados, representando el $50,45,48$ y $67 \%$ de los ácidos grasos totales en la PE, PS, PC y SM, respectivamente. La SM presenta una composición en ácidos grasos con altos contenidos en $22: 0(9 \%), 24: 0(19 \%)$ y $24: 1(20 \%)$, mientras que no se 
detectan los ácidos grasos 18:2 y 20:4 (Rogiers et al, 1980; Laryea et al, 1988; de Castro et al, 2008).

La membrana eritrocitaria está compuesta en un $50 \%$ por proteínas, habiéndose identificado unas diez proteínas mayoritarias, varias de ellas de naturaleza glicoproteíca (Beck y Tepper, 1991). Estas proteínas pueden clasificarse en dos grandes grupos. Las de naturaleza intrínseca o integrales, que atraviesan completamente la bicapa lipídica de la membrana, interaccionando con sus componentes y se extraen con detergentes no iónicos. Las periféricas se sitúan en la cara externa o en la parte citosólica de la membrana, interaccionando electrostaticamente con las cabezas polares de los lípidos de ambas monocapas, y se extraen con disoluciones salinas de alta fuerza iónica.

Las proteínas integrales principales son la proteína de intercambio aniónico (banda 3) y las glicoforinas. La banda 3 es una glicoproteína transmembranal, con su extremo carboxilo en la superficie exterior y su extremo amino en la superficie citoplasmática. Es una proteína transmembranal, con diez pasos, conformando un túnel que permite el intercambio de cloruros por bicarbonato. El extremo amino se une a numerosas proteínas, tales como la hemoglobina, las proteínas 4.1 y 4.2 , la anquirina y varias enzimas glicolíticas (Murray, 1993) (véase Fig. I. 1).

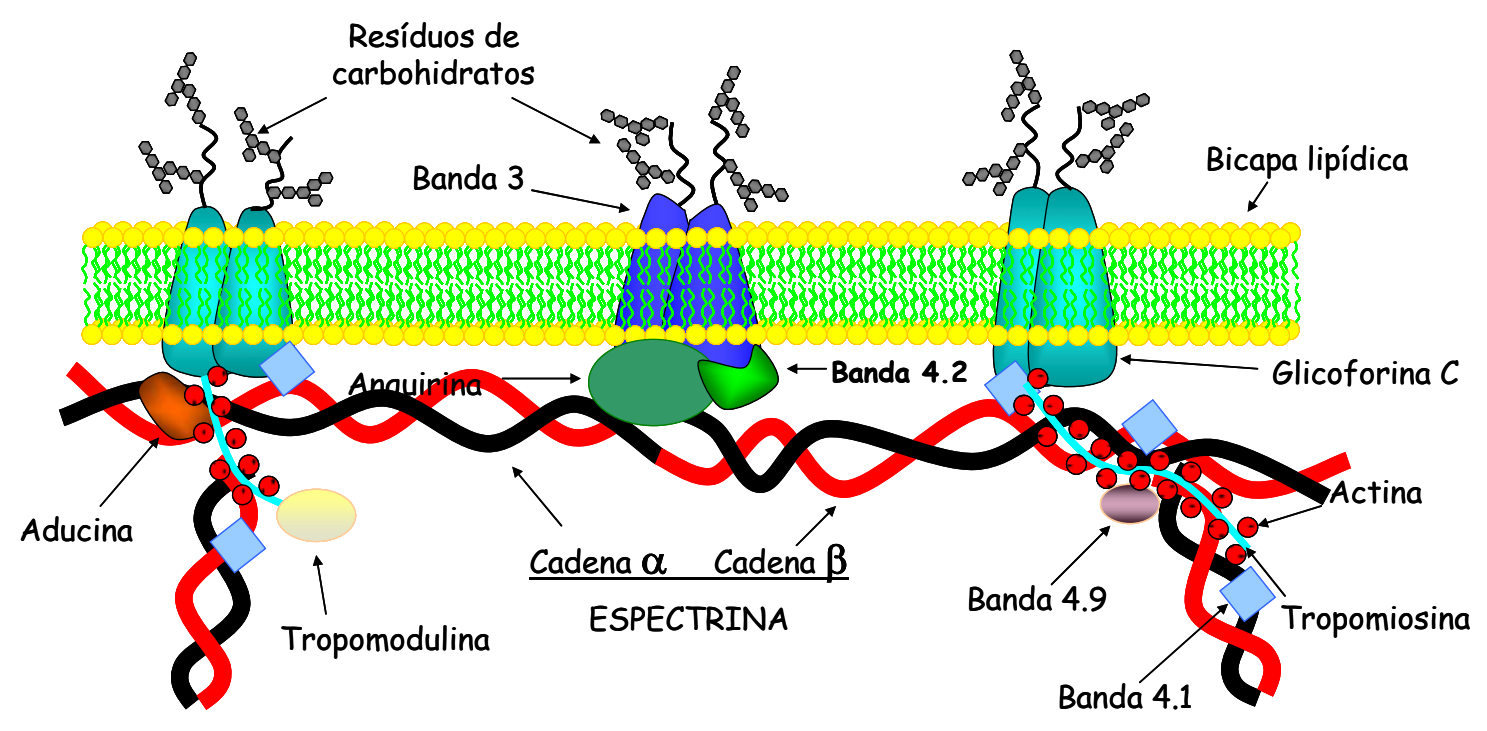

Fig. I. 1. Interacciones de las proteínas citoesqueléticas entre sí y con ciertas proteínas integrales en la cara citoplasmática de la membrana del eritrocito (Adaptación de Alberts et al, 2002). 
Las glicoforinas A, B, y C son también glicoproteínas trasmembranales, pero de un solo paso. La glicoforina $A$, que es muy abundante, está constituida por 131 aminoácidos y su molécula está glicosilada en un 60\%, localizándose en ella aproximadamente el $90 \%$ de los ácidos siálicos existentes en la membrana eritrocitaria. Su extremo amino, que contiene 16 cadenas de oligosacáridos, se proyecta hacia la superficie externa del eritrocito. El extremo carboxilo se extiende en el citosol y se une a la proteína 4.1, que a su vez se une a la espectrina. La glicoforina $A$ también es capaz de unirse al virus de la influenza y al Plasmodium falciparum. En el gran polimorfismo de esta proteína reside la diferenciación de los grupos sanguíneos MN.

Un cierto número de proteínas del citoesqueleto de naturaleza periférica se adhieren a la superficie interna de la membrana del eritrocito, y tienen funciones importantes en la preservación de la forma y en la flexibilidad celular. La espectrina es la principal proteína del citoesqueleto. Está formada por dos polipéptidos entrelazados, y establece uniones con otras proteínas de la membrana (Alberts et al, 2002). La anquirina es una proteína de forma piramidal, que se une a la espectrina. A su vez, la anquirina se enlaza a la banda 3 con lo que se asegura la adherencia de la espectrina a la membrana (Murray, 1993). La proteína 4.1, de carácter globular, se une a la cola de la espectrina y también a las glicoforinas A y C. Además puede interactuar con ciertos fosfolípidos membranales, lo cual hace que conecte la bicapa lipídica con el citoesqueleto.

Recientemente se ha descubierto un nuevo grupo de proteínas en la membrana eritrocitaria, que se denominan proteínas "rafts". Son de tipo integral y se denominan estomatina (banda 7.2b) y flotilinas 1 y 2 . Se asocian a zonas de la bicapa enriquecidas en colesterol, esfingomielina, glicolípidos y fosfolípidos con ácidos grasos mayoritariamente saturados, y no pueden ser extraídas con detergentes no iónicos a bajas temperaturas (Salzer y Prohaska, 2001).

Los lípidos y las proteínas constituyen la casi totalidad de la masa de las membranas biológicas. La pequeña cantidad de glúcidos presentes, generalmente forma parte de las glicoproteínas y de los glicolípidos. Las distintas membranas se diferencian entre sí en las proporciones relativas de proteínas y lípidos, lo que refleja la diversidad de papeles biológicos que desempeñan. Los fosfolípidos y los esteroles forman una bicapa lipídica con las 
regiones apolares de los lípidos enfrentadas en el centro de la bicapa y las cabezas polares situadas hacia el exterior, asociándose los lípidos de cada monocapa mediante interacciones hidrofóbicas, electrostáticas y/o puentes de hidrógeno (Boggs, 1987). Las proteínas se incorporan a la bicapa lipídica mediante interacciones electrostáticas con las cabezas polares de los fosfolípidos (proteínas periféricas o extrínsecas) o por interacciones de tipo hidrofóbico con las cadenas hidrocarbonadas de la bicapa (proteínas integrales o intrínsecas) (Singer, 1974).
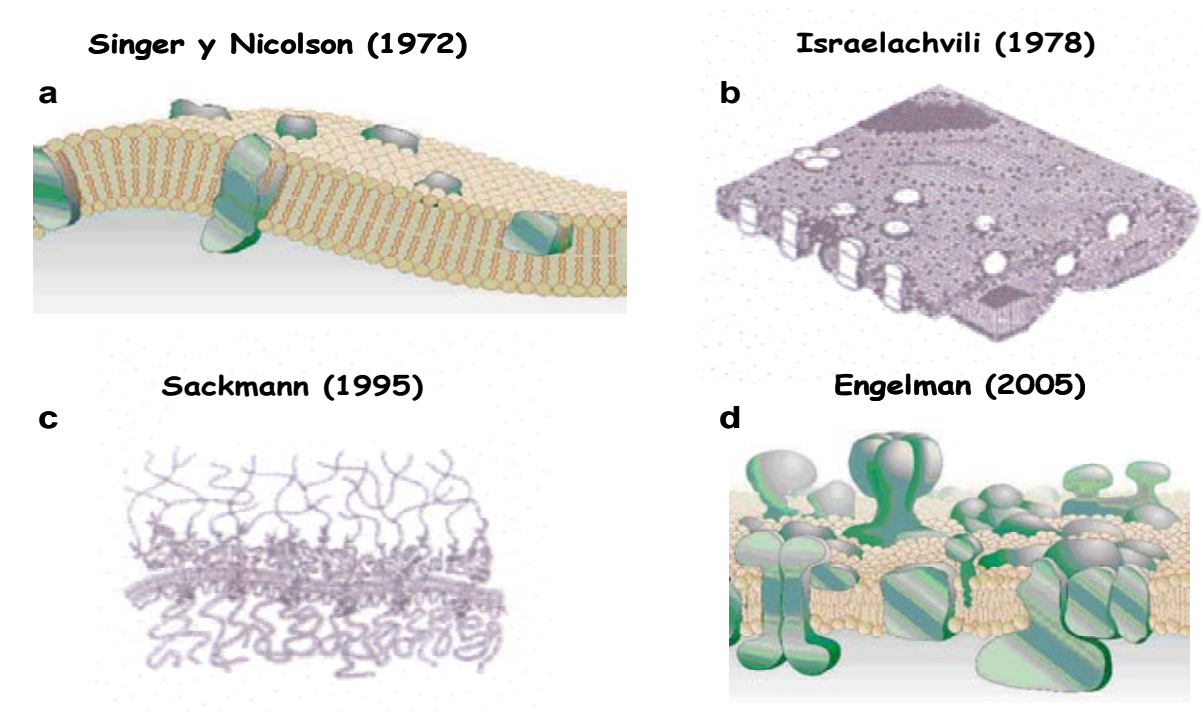

Fig. I. 2. Modelos de membrana (Mouritsen, 2005).

Singer y Nicolson en 1972 unifican las diferentes ideas que existían acerca del modelo de membranas en décadas precedentes, y proponen un modelo denominado "mosaico fluido", en el cuál los lípidos se organizan en un mar lipídico en forma de bicapa, dónde los diversos monómeros proteicos flotan libremente, y la superficie de la bicapa lipídica está en contacto directo con el entorno acuoso (Fig. I. 2a). Este modelo ha evolucionado en la última década, sobre todo por lo que a la disposición de las moléculas proteicas se refiere, a la vista de las asociaciones que se establecen entre proteínas en el mismo plano de la membrana, habiéndose propuesto otros modelos basados en el modelo del "mosaico fluido" (Fig. I. 2b, c y d), en los que se considera la estructura en bicapa con microdominios de diferente composición lípido-proteíca, distribuidos irregularmente dentro de dicha bicapa (Dowhan y Bogdanov, 2002; Simons y Vaz, 2004). La membrana es una estructura con gran dinamismo en la que todos sus componentes están sujetos a movimientos de rotación y difusión 
lateral. Además, los lípidos pueden desplazarse desde una cara a otra de la bicapa por un movimiento trasmembranal, también conocido como "flip-flop" (Kohlwein, 1992).

En 1972 se describió por primera vez la organización asimétrica de los fosfolípidos de la membrana de los eritrocitos humanos (Bretscher, 1972). Dicho autor concluyó que entre un $70-80 \%$ de la PC y de la SM se localizaban en el exterior de la bicapa, mientras que toda la PS y el $80 \%$ de PE se situaban en el interior de la bicapa (véase Fig. I. 3). Este tipo de distribución se asemeja a la que presentan los eritrocitos de diversas especies de mamíferos, donde se observa una localización preferente de los aminofosfolípidos en la monocapa interna de la membrana, mientras que la monocapa externa contiene la mayor parte de los fosfolípidos de colina (Zwaal et al, 1973; Zwaal et al, 1975; Marín et al, 1990; López-Revuelta et al, 2007).

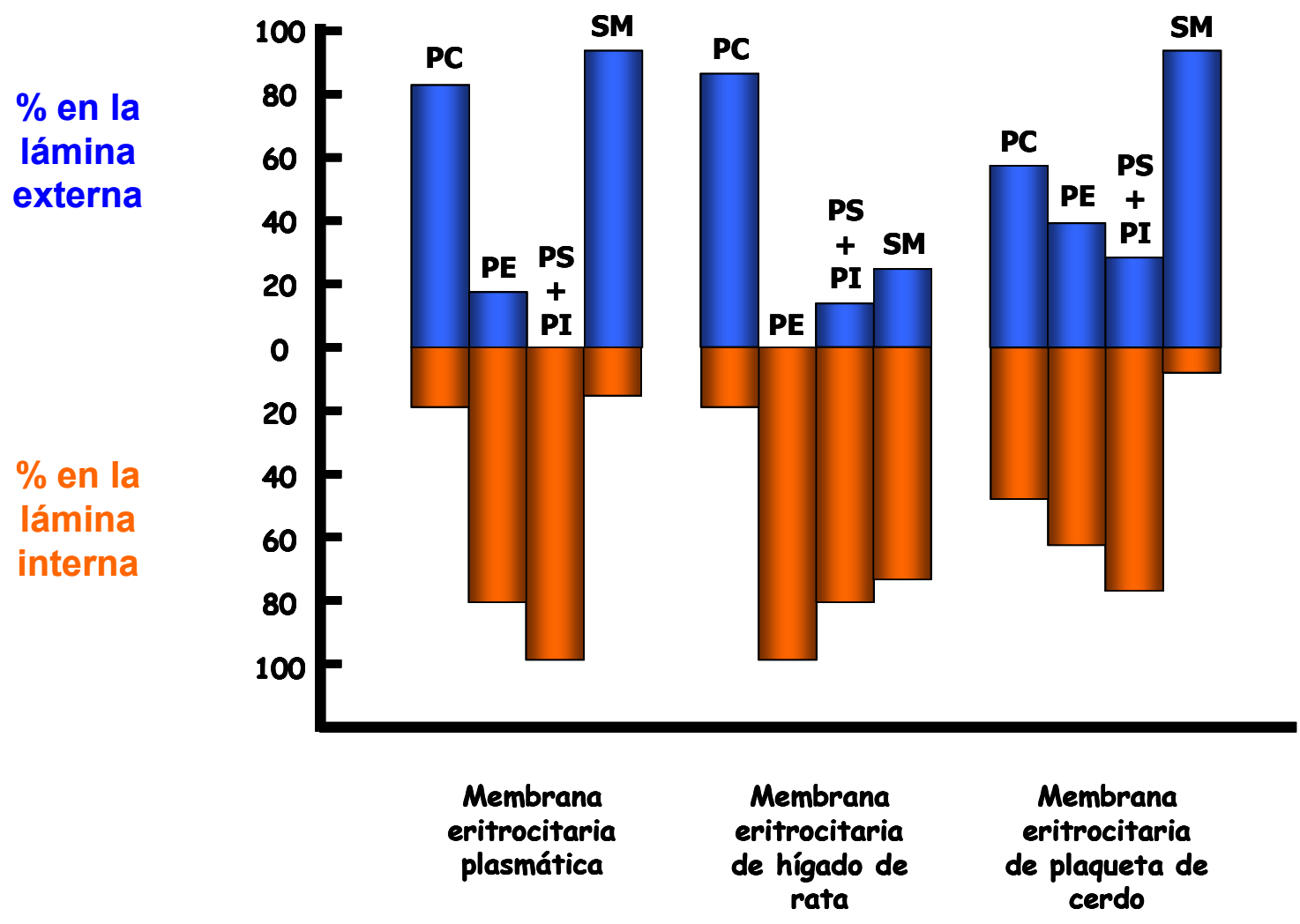

Fig. I. 3. Disposición de los fosfolípidos en membranas plasmáticas de diversa procedencia. Se representa la distribución porcentual de los diferentes fosfolípidos entre las láminas externa (columnas azules) e interna (columnas naranjas) (Mathews et al, 2002). PC: fosfatidilcolina; PE: fosfatidiletanolamina; PS+PI: fosfatidilserina + fosfaditilionositol; $\quad$ SM: esfingomielina. 
Estudios realizados en células eucarióticas, bacterias y virus también ponen de manifiesto la existencia de una asimetría en la distribución de los lípidos y de las proteínas de sus membranas (Op den Kamp, 1979; Schroit y Zwaal, 1991; Zachowski, 1993).

La hidrólisis enzimática con fosfolipasas es una de las técnicas habituales que permiten conocer la disposición que adoptan los fosfolípidos en las membranas. La fosfolipasa $A_{2}$, procedente del páncreas o de veneno de abeja, degrada los glicerofosfolípidos, liberando el ácido graso esterificado en la posición 2 del glicerol y el correspondiente lisofosfolípido (Roeleofsen y Op den Kamp, 1988; Dumaswala et al, 1996). Tras el tratamiento de hidrólisis en condiciones de impermeabilidad celular, se cuantifican porcentualmente las distintas clases de fosfolípidos y lisofosfolípidos existentes, de forma que los porcentajes de lisofosfolípidos detectados corresponderán a aquellos fosfolípidos situados en la monocapa externa de la bicapa lipídica.

La generación y el mantenimiento de la disposición asimétrica de los lípidos en las membranas biológicas se lleva a cabo fundamentalmente a través de mecanismos específicos que controlan el paso de los fosfolípidos de una cara a otra de la bicapa lipídica, en los que participan los siguientes grupos de enzimas:

1. Flipasas. Dentro de este grupo se engloba la aminofosfolípido translocasa (APLT), que es una enzima dependiente de ATP que transporta específicamente fosfatidilserina (PS), y con menor eficacia fosfatidiletanolamina $(\mathrm{PE})$, desde la monocapa externa de la bicapa lipídica de la membrana hacia la monocapa interna de dicha bicapa, en contra del gradiente de concentración de ambos fosfolípidos, con el gasto de una molécula de ATP por molécula de aminofosfolípido interiorizado (Seigneuret y Devaux, 1984; Connor y Schroit, 1987; Beleznay et al, 1993; Daleke, 2003; Devaux et al, 2008). La actividad aminofosfolípido translocásica puede ser inhibida por N-etilmaleimida (NEM), vanadato, fluoruro, oxidación de sus grupos sulfhidrilo y concentraciones micromolares de $\mathrm{Ca}^{2+}$ citoplásmico (Beleznay et al, 1997), asociándola con una ATPasa de tipo P. Diversos estudios han revelado también que esta actividad requiere la participación coordinada y complementaria de una $\mathrm{Mg}^{2+}$-ATPasa y una proteína de 32 kDa (Schroit y Zwaall, 1991). 


\section{Flopasas 0 transportadores ABC (ATP binding cassette),} representan los transportadores más numerosos asociados al gasto de ATP. Están ampliamente representados desde bacterias hasta organismos superiores. En humanos se han descrito 50 transportadores ABC diferentes. En su mayor parte están constituidos por una única cadena polipeptídica con dos dominios, uno altamente hidrofóbico a través del que se inserta en la membrana, y forma el poro de transporte y sitio de unión al sustrato, y el dominio de unión a nucleótidos, donde se ancla el ATP en presencia de $\mathrm{Mg}^{+2}$ para su posterior hidrólisis previa al proceso de transporte. Su forma activa requiere un estado oligomerizado de la proteína. Este grupo de proteínas efectúan el transporte unidireccional hacia el exterior de la célula de un amplio grupo de moléculas inespecíficas de carácter hidrofóbico, que engloba esteroides, fosfolípidos, múltiples fármacos y compuestos xenobióticos (Balasubramanian y Scroit, 2003; Devaux et al, 2008). Los transportadores ABC de tipo $G$, en su mayor parte, son responsables del mantenimiento de la asimetría lipídica de la membrana (Velamakanni et al, 2007). Otros transportadores, cuyos grupos más representativos son los tipos B1 (MDR1 o glicoproteína P), C1 (MRP1) y G2 (BCRP) confieren a las células resistencia a múltiples fármacos, debido a su capacidad para transportarlos fuera de la célula, además de llevar también a cabo la exteriorización de diferentes clases de lípidos (Sarkadi et al, 2004). Los transportadores $A B C$, inicialmente denominados flopasas, fueron descubiertos en eritrocitos, donde se demostró su capacidad de transportar fosfolípidos de colina y aminados desde el interior de la célula a la superficie celular (Bitbol y Devaux, 1988; Connor et al, 1992; Devaux et al, 2008). El proceso de transporte se inhibe por agotamiento del ATP o por oxidación de los grupos sulfhidrilo de la proteína (Connor et al, 1992).

3. Escramblasas. Estas enzimas necesitan concentraciones micromolares de $\mathrm{Ca}^{2+}$ citoplasmático para su actividad, pero no requieren la hidrólisis del ATP. Su forma activa se comporta como un canal a través del cuál difunden los lípidos de forma inespecífica en sentido bidireccional en función de su concentración, lo que provoca una pérdida de la asimetría en pocos minutos, ocasionando una exteriorización elevada de la fosfatidilserina (Smeets et al, 1994; Daleke, 2003; Devaux et al, 2008).

En resumen, la acción sincronizada y cooperativa de la APLT con las flopasas contribuye a generar y mantener la asimetría de los fosfolípidos de la membrana, con un desplazamiento lento de todas las clases de fosfolípidos 
hacia la cara externa de la membrana, y una interiorización más rápida de los aminofosfolípidos. La actividad escramblásica provoca la pérdida de esta asimetría creada. Las concentraciones fisiológicas de $\mathrm{Ca}^{2+}$ citoplasmático mantienen la asimetría de los fosfolípidos, a través de los estados activos de la APLT y las flopasas. Por el contrario, concentraciones de $\mathrm{Ca}^{2+}$ citoplasmático elevadas activan a las escramblasas, y bloquean la acción cooperativa de las dos enzimas anteriores, produciendo la pérdida de la asimetría fosfolipídica (Zwaal y Schroit, 1997) (véase Fig. I. 4).

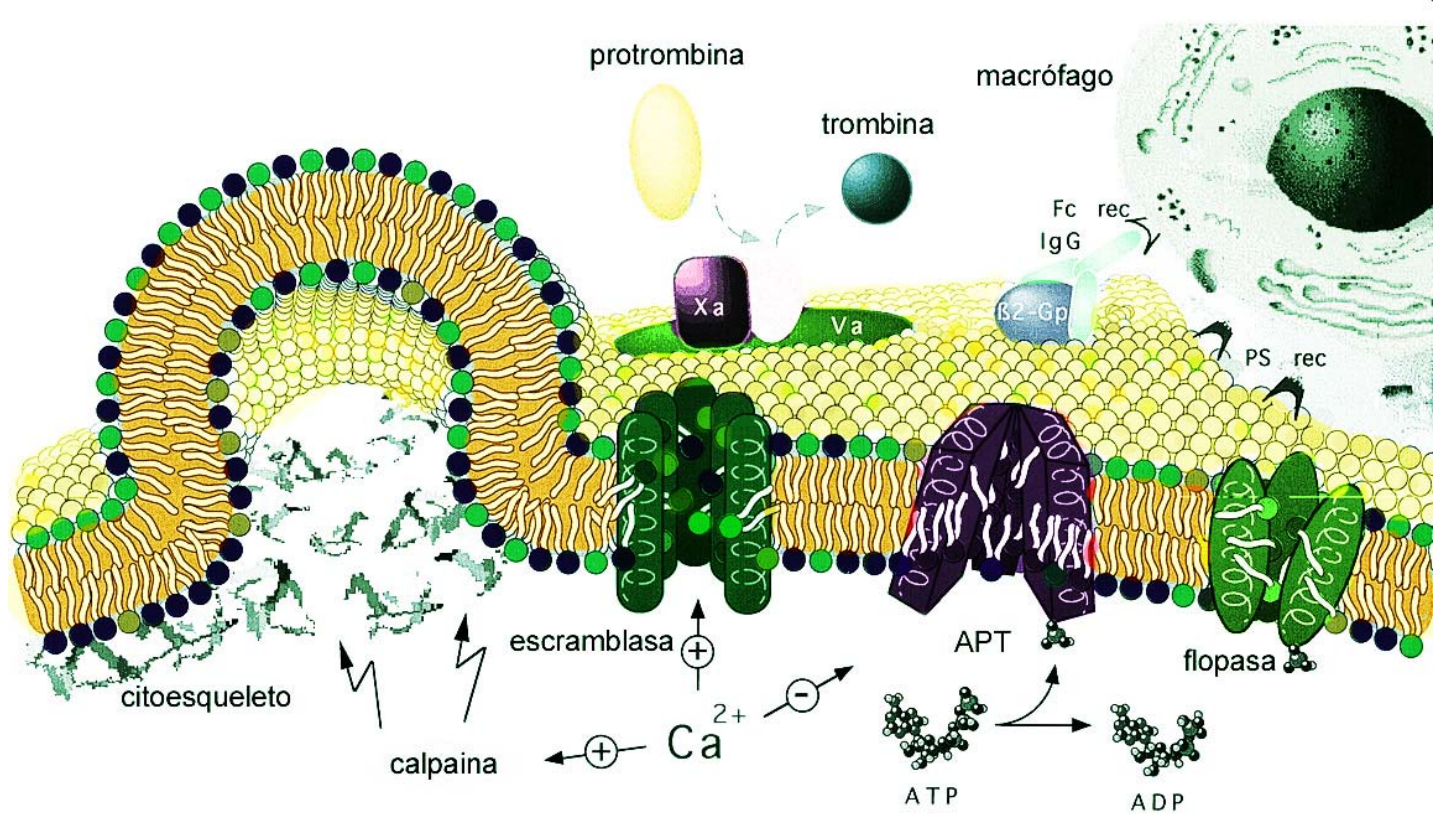

Fig. I. 4. Mecanismos de generación y mantenimiento de la asimetría lipídica en las biomembranas (Zwaal y Schroit, 1997).

Muchos estudios sugieren también que las proteínas del citoesqueleto, como la espectrina en el caso de los eritrocitos, y la actina y la miosina en las plaquetas, al interaccionar con los aminofosfolípidos pueden participar en el mantenimiento de la asimetría lipídica (Devaux, 1991; Devaux, 1993; Zachowski, 1993). Sin embargo, este tipo de interacciones son termodinámicamente débiles y existen datos que demuestran que la asimetría lipídica puede generarse y mantenerse en las membranas artificiales carentes de proteínas del citoesqueleto (Beleznay et al, 1993; Bruckheimer et al, 1995). Estos datos indican que el papel que juega el citoesqueleto en el mantenimiento de la asimetría lipídica es menos importante que la actuación coordinada de APLT y flopasas (Zwaal y Schroit, 1997). 


\subsection{ESTADO FÍSICO DE LA BICAPA LIPÍDICA}

El término fluidez, aplicado a las membranas biológicas, se define con frecuencia como una propiedad biofísica que expresa cuantitativamente la movilidad de las moléculas lipídicas en la membrana. Las moléculas de fosfolípidos pueden desplazarse en la bicapa lipídica de diferente forma: i) por difusión lateral en el plano de la bicapa; ii) por rotación alrededor de un eje perpendicular al plano de la bicapa; iii) por desplazamiento de una cara a otra de la bicapa (movimiento transmembranal o flip-flop) (Schachter, 1984; Richter, 1987). Esta movilidad depende del tipo de cabeza polar, de la naturaleza de la cadena hidrocarbonada de los fosfolípidos y del contenido en colesterol y proteínas de la membrana (Muller y Krueger, 1986).

El cambio más importante en la fluidez de las bicapas tiene lugar como resultado de la transición de la fase gel (mínima fluidez) a la fase líquidocristalina (máxima fluidez). En la fase de gel los fosfolípidos se disponen de manera que las cadenas hidrocarbonadas quedan en posición todo "anti". En estas circunstancias, la movilidad rotacional y translacional está muy limitada. En cambio, en el estado líquido-cristalino las cadenas hidrocarbonadas pierden la conformación todo "anti", pasando a estados más desordenados (conformación "anti-gauche"), lo que aumenta la fluidez.

La temperatura a la cual la estructura sufre el paso de un estado ordenado a un estado desordenado se conoce como temperatura de transición. Los fosfolípidos con altos contenidos de ácidos grasos saturados y cadenas carbonadas largas muestran temperaturas de transición altas con respecto a sus homólogos insaturados. La introducción de dobles enlaces en la configuración "cis" en las cadenas carbonadas de los ácidos grasos provoca una considerable disminución de la temperatura de transición, con el consiguiente incremento en la fluidez de la bicapa, como consecuencia de la distorsión producida por la presencia de los dobles enlaces en la bicapa lipídica, lo que provoca un descenso en la densidad del empaquetamiento de la cadena hidrocarbonada (Chapman y Hayward, 1985).

La cabeza polar del fosfolípido es también un factor determinante de la fluidez de membrana. La PC es un fosfolípido "fluidificador", mientras que la SM es un fosfolípido que "rigidifica" la membrana. Así un aumento de la razón 
SM/PC provoca un descenso en la fluidez de membrana (Borochov et al, 1977; Petkova et al, 1987).

Otro factor importante que afecta a la fluidez de las membranas es su contenido en esteroles. El colesterol es un modulador de las propiedades físicas de la membrana (Demel y de Kruiff, 1976; Gómez-Fernández y Goñi, 1983). En las membranas eritrocitarias se ha observado que el colesterol tiene un efecto ordenante, disminuyendo la fluidez de la membrana. Este efecto se ve aumentado cuando los ácidos grasos tienen un elevado grado de insaturación (Colin et al, 1992).

Las proteínas también modifican la fluidez de las membranas, ejerciendo un efecto similar al colesterol en la "fluidificación" de las bicapas lipídicas (Shinitzky y Barenholz, 1978).

La fluidez de la membrana tiene efectos significativos sobre sus funciones. Cuando su fluidez aumenta también lo hace su permeabilidad al agua y a otras moléculas hidrófobas pequeñas. Los cambios en la fluidez de las membranas están íntimamente relacionados con los procesos celulares que tienen lugar a nivel de membrana, tales como el transporte mediado por proteínas transportadoras, la actividad de las enzimas ligadas a la membrana, la unión de ligandos a receptores, la fagocitosis, la endocitosis, la exocitosis y los fenómenos relacionados con la citotoxicidad, el crecimiento y la diferenciación celular (Spector y Yorek, 1985). Las alteraciones en la fluidez de la membrana pueden influir en la actividad de ciertas enzimas, generalmente activándolas en entornos fluidos (Petkova et al, 1987; Abel et al, 2001). Los procesos de envejecimiento, la aterosclerosis o el cáncer pueden producir cambios en la fluidez de las membranas celulares, de modo que la alteración de dicha fluidez puede servir como parámetro para evaluar la malignidad de determinados tumores (Shinitzky, 1984).

La fluidez aparente de las bicapas lipídicas puede ser estimada mediante medidas de anisotropía de fluorescencia $\left(\mathbf{r}_{\mathbf{s}}\right)$ en presencia de sondas fluorescentes. Estas medidas indican el desplazamiento angular del fluoróforo en el medio durante su estado de excitación. Dicho desplazamiento depende de la viscosidad del medio y del tamaño y forma del fluoróforo. Un cambio en la viscosidad del medio produce variaciones en la magnitud de los valores de $r_{\mathrm{s}}$ de forma tal que un incremento en la fluidez (inverso de la viscosidad) del 
medio llevará consigo un aumento en la movilidad de la sonda, y por tanto, un descenso en sus valores de $r_{s}$ (Shinitzky y Barenholz, 1978; Lakowicz, 1983). Dos sondas fluorescentes que habitualmente se utilizan en este tipo de estudios son el 1,6-difenil-1,3,5,-hexatrieno (DPH) y su análogo catiónico, el 1-[4(trimetilamonio)-fenil]-6-fenil-1,3,5-hexatrieno (TMA-DPH), de localización en el núcleo hidrofóbico y en la región polar negativa-apolar de la bicapa lipídica, respectivamente (Prendergast et al, 1981; Lentz, 1989; van Ginkel et al, 1989; López-Revuelta, 2005).

\subsection{INFLUENCIA DE LA ASIMETRÍA LIPÍDICA EN EL FUNCIONAMIENTO DE LA MEMBRANA}

La composición y la distribución de los lípidos en las membranas biológicas influyen de forma determinante en el grado de funcionamiento de estas estructuras celulares.

\section{I- Influencia sobre la actividad de proteínas de membrana}

La configuración, actividad y propiedades de muchos de los componentes de la membrana, como las glicoproteínas, los receptores y los sistemas enzimáticos, están modulados por el entorno lipídico en el que se encuentran, ya sea a través de la cabeza polar del fosfolípido y/o por el grado de fluidez de la bicapa, entre otras causas (Muller y Krueger, 1986). Así se ha demostrado que enzimas como proteín-quinasas C (Marsh, 1992), ATPasa- $-\mathrm{Na}^{+}-\mathrm{K}^{+}$ (Roelofsen y van Deenen, 1973) y ATPasa-Mg ${ }^{+2}$ (Ronner et al, 1977) requieren para su actividad de entornos ricos en fosfatidilserina (PS) y fosfatidiletanolamina $(\mathrm{PE})$, mientras que en otros casos son entornos hidrofóbicos inespecíficos los que preservan la actividad enzimática.

\section{II- Intervención en los procesos de coagulación}

La asimetría lipídica en la membrana de los eritrocitos y de las plaquetas, y más concretamente, la localización prácticamente exclusiva de la fosfatidilserina (PS) en la cara interna de la membrana plasmática de estas células en estado no activado, impide que se desencadenen los procesos de coagulación (Schroit y Zwaal, 1991). Cuando los eritrocitos pierden la asimetría lipídica en sistemas in vitro en presencia de ionóforos de $\mathrm{Ca}^{2+}$, la actividad 
protrombinásica se estimula, induciéndose el proceso de la coagulación (Martin y Jesty, 1995). En enfermos diabéticos o con anemia falciforme, la salida de PS hacia la superficie de la membrana eritrocitaria también induce la aparición de fenómenos de trombosis. Sin embargo, esta vía de inducción de la coagulación no parece que desempeñe un papel decisivo en el mantenimiento de la hemostasis normal y en el desarrollo de la trombosis (Zwaal y Schroit, 1997).

La exteriorización de la PS en la membrana plaquetaria provoca una propagación eficiente del proceso hemostático. Existen datos que demuestran que la salida de PS es crítica en la coagulación, ya que la actividad protrombinásica de las plaquetas se inhibe en presencia de fosfolipasas (Bevers et al, 1982) o Anexina V (Thiagarajan y Tait, 1990), como consecuencia de la hidrólisis o el bloqueo de la cabeza polar del fosfolípido.

\section{III- Reconocimiento celular}

La organización lipídica de la membrana eritrocitaria afecta también al reconocimiento de los eritrocitos por parte de los macrófagos y a su interacción con otras células. La pérdida de la asimetría lipídica en los eritrocitos senescentes, que lleva consigo un aumento de PS en la cara externa de su membrana, es una señal de reconocimiento por parte de los macrófagos, que los fagocitan y eliminan de la circulación (Schroit y Zwall, 1991; Devaux, 1993; Connor et al, 1994; Kuypers y de Jong, 2004). Los macrófagos pueden reconocer y fagocitar estructuras que exponen la PS en su superficie, como los fantasmas de eritrocitos simétricos, los eritrocitos procedentes de pacientes con talasemia o anemia falciforme, inhibiéndose esta unión en presencia de vesículas que contienen PS. Este reconocimiento es debido a la expresión de receptores para PS en la superficie celular del macrófago (Schwartz et al, 1985; Pradhan et al, 1994; Kuypers y de Jong, 2004). Sin embargo, los macrófagos parece que disponen de un umbral para el reconocimiento de la PS expuesta en las superficie celular que les permite discernir entre células normales y células apoptóticas (Borisenko et al, 2003).

El empleo de anexina $V$, una proteína que se une a la PS en presencia de $\mathrm{Ca}^{+2}$ (Raynal y Pollard, 1994), enmascara la PS presente en la cara externa de la membrana y bloquea la fagocitosis de las células por parte de los macrófagos (Krahling et al, 1999; López-Revuelta, 2005). Esta propiedad ha sido utilizada para cuantificar la exteriorización de PS en la superficie celular en diversos 
sistemas, utilizando anexina $\mathrm{V}$ marcada con un fluoróforo (Koopman et al, 1994; Bennett et al, 1995; Martin et al, 1995; Arroyo et al, 2002).

Existen también otros tipos de receptores en los fagocitos que están implicados en la eliminación de las células apoptóticas (Savill, 1997). Así, el CD14 (Schlegel et al, 1999) y el receptor de LDL oxidadas (Sambrano y Steinberg, 1995) han sido implicados en los procesos de reconocimiento de las células apoptóticas y de los eritrocitos dañados, pudiendo jugar, en parte, un papel importante en el reconocimiento de los eritrocitos senescentes.

La capacidad de los eritrocitos para ser destruidos en respuesta a distintas señales, entre ellas la exteriorización de la PS, puede ser interpretada como una forma de apoptosis, en la que no existe la implicación mitocondrial (Bratosin et al, 2001). En eritrocitos se conoce como "eriptosis", y cursa con contracción celular, vesiculación de la membrana y exposición de PS hacia la superficie celular (Lang et al, 2006). Las células apoptóticas muestran una fragmentación del DNA y una serie de alteraciones morfológicas en las etapas tempranas de la apoptosis, dónde se observa también un incremento de la exteriorización de PS, lo que permite su reconocimiento por parte de los macrófagos (FadoK et al, 1992), y lo que demuestra la existencia de mecanismos de reconocimiento comunes en eritrocitos no viables y células apoptóticas por parte de los macrófagos (Kuypers y de Jong, 2004). 


\section{PROCESOS OXIDATIVOS EN LAS MEMBRANAS CELULARES}

Los fenómenos de oxidación biológica constituyen un problema de creciente interés en las Ciencias Biomédicas, a causa de su posible implicación en distintos procesos patológicos, derivados todos ellos de alteraciones en el funcionamiento celular (Comporti, 1993).

\subsection{RADICALES LIBRES Y ESTRÉS OXIDATIVO}

La oxidación es un proceso que tiene lugar tanto en las plantas como en los animales, y está producido, entre otras causas, por la presencia de radicales libres. En los organismos aerobios, el oxígeno, habitualmente utilizado en los procesos de respiración celular, se reduce en las mitocondrias por captación de cuatro electrones y forma la molécula de agua. Sin embargo, existen otras oxidaciones biológicas que transfieren un menor número de electrones al oxígeno, lo que provoca una reducción parcial de esta molécula, generando productos altamente reactivos que se conocen con el nombre de especies reactivas del oxígeno (ROS), tales como anión superóxido $\left(\mathrm{O}_{2}^{-{ }^{-}}\right)$, radical perhidroxilo $\left(\mathrm{HOO}^{\circ}\right)$ y radical hidroxilo $\left(\mathrm{OH}^{\circ}\right)$. Los ROS se han vinculado con más de cien enfermedades, entre las que destacan el cáncer y la aterosclerosis (Halliwell, 1992).

El radical hidroxilo es la especie más reactiva de las derivadas del oxígeno. Reacciona con los ácidos grasos poliinsaturados (PUFA) eliminando un átomo de hidrógeno de dicha molécula de ácido graso $(\mathrm{RH})$ para formar un derivado que tiene un electrón desapareado $\left(R^{*}\right)$ (Halliwell, 1992). El radical superóxido $\left(\mathrm{O}_{2}^{-*}\right)$ se genera por la transferencia de un solo electrón al oxígeno en situaciones de disfunción de la cadena transportadora de electrones mitocondrial, durante el transporte de oxígeno por la hemoglobina, por efecto de las actividades xantina oxidásica u óxido nítrico sintásica en condiciones subóptimas de sustrato, o durante la metabolización del ácido araquidónico (Halliwell, 1992).

Los ROS pueden interaccionar con moléculas de su entorno, como DNA, proteínas o lípidos, alterando su estructura-función. Cuando los radicales libres reaccionan con los lípidos, el proceso recibe el nombre de peroxidación lipídica 
(Slater, 1984; Halliwell, 1992). Dicho proceso ( $\mathrm{RH}$, ácido graso; Rं, radical lipídico) transcurre en tres etapas (Llanillo et al, 1994; Porter et al, 1995; Halliwell y Gutteridge, 1999):
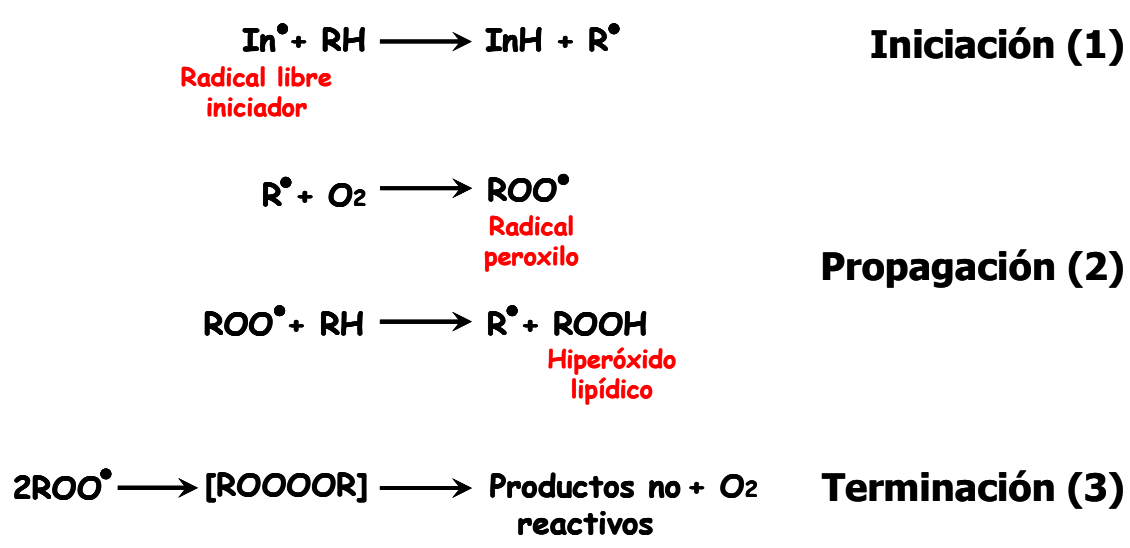

Los radicales $\mathrm{OH}^{*}, \mathrm{HOO}^{*}, \mathrm{RO}^{\bullet}$ y $\mathrm{RO}_{2}{ }^{\bullet}$ y varios complejos oxígeno-hierro son capaces de iniciar el proceso peroxidativo, formando un radical lipídico $\left(R^{\circ}\right)$ que reaccionan con el oxígeno molecular en el interior de las membranas, para formar los radicales peroxilo correspondientes (ROO*). Si la concentración de $\mathrm{O}_{2}$ es baja, los radicales lipídicos pueden reaccionar con otros componentes de la membrana como los grupos -SH de las proteínas. Los radicales peroxilo pueden atacar los dobles enlaces de los PUFA cercanos para formar hidroperóxidos lipídicos $(\mathrm{ROOH})$ y nuevos radicales libres de ácidos grasos $\left(\mathrm{R}^{\circ}\right)$, siendo éste el paso limitante de la reacción de peroxidación. Durante las reacciones de peroxidación, los radicales lipídicos también pueden interaccionar con las proteínas de la membrana y con otros tipos de biomoléculas, formando nuevos compuestos por los entrecruzamientos que se establecen entre ellos. Además, los radicales lipídicos pueden sufrir procesos de fragmentación, ciclación y reordenamientos moleculares, dando lugar a una gran variedad de productos finales de la peroxidación (epóxidos, malonidialdehído (MDA), 4-hidroxinonenal, hidrocarburos gaseosos como etano y pentano, etc.)(Wills, 1987; Halliwell y Gutteridge, 1999).

$\mathrm{El} \mathrm{Fe}{ }^{2+}$ puede participar en las reacciones de transferencia de electrones con el oxígeno, originando el anion superóxido, que a su vez puede dismutar a $\mathrm{H}_{2} \mathrm{O}_{2}$, dando lugar a la formación de radicales $\mathrm{OH}^{\bullet}$, a través de una reacción catalizada por metales pesados (reacción de Fenton):

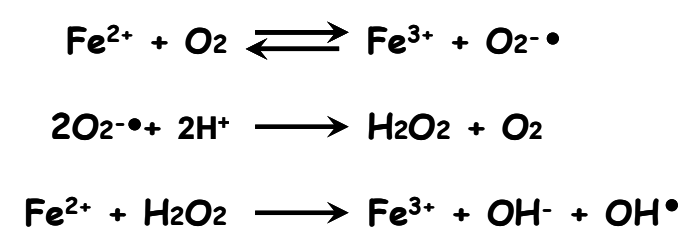


Por tanto, la presencia de $\mathrm{Fe}^{2+}$ en un medio rico en lípidos insaturados con alto contenido en $\mathrm{O}_{2}$, como sucede en el eritrocito, es un sistema inductor de la peroxidación lipídica (Halliwell y Gutteridge, 1999).

Los hidroperóxidos lipídicos formados durante la etapa de propagación son moléculas relativamente estables a temperaturas fisiológicas, que se descomponen de manera espontánea por el calor o mediante reacciones catalizadas por metales de transición, formando radicales alcoxilo ( $\left.\mathrm{RO}^{\bullet}\right)$ y peroxilo $\left(\mathrm{ROO}^{\bullet}\right)$. El Fe ${ }^{2+}$ y ciertos quelatos de $\mathrm{Fe}^{2+}$ catalizan estos procesos de descomposición, formando nuevos radicales lipídicos y peroxilos que propagan la reacción en cadena de la peroxidación:

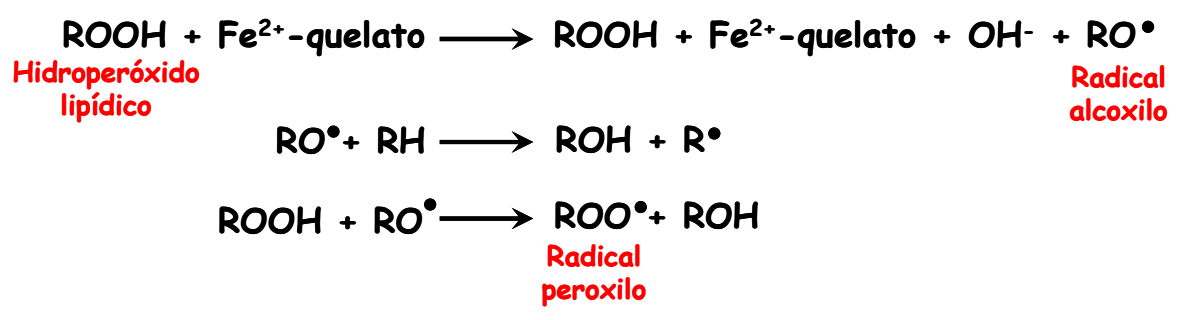

El $\mathrm{Fe}^{3+}$ y ciertos quelatos de $\mathrm{Fe}^{3+}$ pueden descomponer también los peróxidos en radicales peroxilo:

$$
\mathrm{ROOH}+\mathrm{Fe}^{3+} \text {-quelato } \longrightarrow \mathrm{Fe}^{2+} \text {-quelato }+\mathrm{H}^{+}+\mathrm{ROO}^{\bullet}
$$

La adición de iones de hierro no inicia la peroxidación lipídica en un sistema libre de peróxidos lipídicos, pero estimula el proceso cuando existen peróxidos preformados, ya que facilita su descomposición, generando radicales peroxilo. Muchos otros iones metálicos tampoco pueden estimular la peroxidación por sí mismos, pero asociados a las membranas pueden facilitar la peroxidación lipídica bajo ciertas condiciones (Halliwell y Gutteridge, 1999).

\subsection{IMPLICACIONES DEL ESTRÉS OXIDATIVO SOBRE LA ESTRUCTURA-FUNCIÓN DE LA MEMBRANA}

El estrés oxidativo es un proceso que produce alteraciones en la célula a nivel estructural, debido a las variaciones que experimenta su composición química, lo que conlleva una desorganización de la membrana y cambios importantes en sus propiedades físicas y funcionales (Slater, 1984). 


\subsubsection{Efecto sobre la composición lipídica}

El grado de susceptibilidad de las membranas celulares al daño oxidativo viene marcado por la proporción de ácidos grasos poliinsaturados (PUFA) presentes en las mismas (Slater, 1984), por el número de dobles enlaces en el ácido graso (Wills, 1987) y por la concentración de vitamina $E$ endógena presente (Dinis et al, 1993). Los eritrocitos son muy susceptibles al daño oxidativo debido a la presencia de altas concentraciones de ácidos grasos poliinsaturados en sus membranas, al alto contenido en iones ferrosos acomplejados y al oxígeno transportado por la hemoglobina (Sadrzadeh et al, 1984). La peroxidación produce una disminución del contenido en ácidos grasos poliinsaturados de las membranas, y un incremento paralelo de los productos derivados de la peroxidación, alterando las características estructurales y físicas de la bicapa lipídica de dichas membranas (Gutteridge y Halliwell, 1990; Dinis et al, 1993; Martín-Valmaseda et al, 1999; López-Revuelta et al, 2005). El proceso oxidativo provoca pérdidas de material lipídico, con descensos preferentes de los contenidos de PE y PC en los eritrocitos de conejo oxidados, potenciadas dichas pérdidas en los eritrocitos con bajos contenidos de colesterol (LópezRevuelta et al, 2005). En los eritrocitos humanos, el proceso oxidativo también provoca descensos en los contenidos de los diferentes fosfolípidos (Deuticke et al, 1986; Mawarati y Murakami, 2001).

En las membranas eritrocitarias se ha demostrado la existencia de una correlación positiva entre las concentraciones de ácidos grasos poliinsaturados y el grado de peroxidación de la membrana, siendo los ácido araquidónico (20:4n6) y docosahexaenoico (22:6n-6) los más susceptibles a la oxidación, mientras que los ácidos grasos con dos o menos dobles enlaces apenas sufren transformaciones (Clemens y Waller, 1987).

La oxidación de las distintas clases de fosfolípidos depende de su estructura, así como de las condiciones de peroxidación, produciéndose en el proceso distintos tipos de productos oxidados, como los hidroperóxidos $(\mathrm{ROOH})$, los radicales peroxilo (ROO*) y los aldehídos de cadena corta (Kawai et al, 1999). Los hidroperóxidos de los ácidos oleico, linoleico y araquidónico estimulan la actividad de la proteína quinasa $\mathrm{C}$, lo que constituye una respuesta temprana al daño oxidativo (O'Brian et al, 1988). La PC suele generar hidroperóxidos más estables que la PE. (Spiteller, 1996). La PE, con altos contenidos en ácido araquidónico, forma hidroperóxidos inestables, que por 
fragmentación dan lugar a la generación de productos aldehídicos de cadena corta (Guo et al, 1995; Uchida, 2003). Estos productos son responsables de los efectos fisiopatológicos observados en células y tejidos en el estrés oxidativo (Uchida, 2003).

Los productos de oxidación en la región hidrofóbica de la membrana producen una desestabilización del empaquetamiento de la bicapa lipídica, con interacciones diversas entre los componentes de las monocapas. Así, la formación de hidroperóxidos lipídicos disminuye la interacción entre cadenas adyacentes de fosfolípidos, incrementándose así el área ocupada por éstos (van den Berg et al, 1993; van Ginkel y Sevanian, 1994). Las disminución del empaquetamiento de las cadenas acílicas de los fosfolípidos en la parte superior de la bicapa provoca un incremento en la penetración de las moléculas de agua (Parasassi et al, 1995), aumentando el carácter hidrofílico de esta región de la membrana, lo que ocasiona un aumento de la permeabilidad de la bicapa lipídica a los protones, los aniones y ciertos cationes (Vladimirov et al, 1980; Comporti, 1993).

El colesterol, al igual que los fosfolípidos, también sufre el ataque de los ROS, generando una gran variedad de productos de oxidación. Los radicales peroxilo producen oxisteroles del tipo 3B, 7-dioles ( $\alpha$ y $\beta$ ), 7-cetocolesterol y 5 6- epóxidos de colesterol (Smith, 1996). Este último producto también puede generarse mediante acción enzimática de las lipooxigenasas y las epoxidasas que se activan con el daño tisular (Spiteller, 1996). Los oxisteroles generados tras la oxidación del colesterol presentan diferentes niveles de toxicidad, y están relacionados con diversos procesos crónicos como la aterosclerosis, el cáncer y el envejecimiento.

\subsubsection{Influencia sobre el estado físico y la asimetría lipídica de la membrana}

Un factor determinante del estado físico de la membrana, su grado de fluidez, se ve afectado por el estado de peroxidación de la bicapa lipídica. Cuando los radicales libres interaccionan con los lípidos de la membrana, los ácidos grasos poliinsaturados se oxidan, lo que en general ocasiona un aumento en el orden y en la viscosidad de la bicapa lipídica y un incremento del intercambio de fosfolípidos entre las dos monocapas, como consecuencia de la desestabilización de la estructura en bicapa (Slater, 1984; Richter, 1987; Dinis 
et al, 1993). Los lípidos oxidados pueden interaccionar con las cadenas acílicas adyacentes, con las cabezas polares de los fosfolípidos, o con las proteínas, estableciendo uniones covalentes que forman entrecruzamientos muy estables, incrementando la rigidez de la membrana, y en consecuencia, disminuyendo tanto la movilidad de sus componentes, como el volumen de la bicapa (Tirosh et al, 1997).

Los estudios de polarización de fluorescencia llevados a cabo con DPH en eritrocitos (Han et al, 1992; López-Revuelta et al, 2005), plaquetas (MartínValmaseda et al, 1999), microsomas de retículo sarcoplásmico y liposomas (Dinis et al, 1993), muestran un descenso de la fluidez de la región hidrofóbica de la bicapa lipídica por efecto de la peroxidación. La peroxidación lipídica inducida por fenilhidrazina en la membrana eritrocitaria también produce un incremento de su microviscosidad, a través del aumento de las interacciones lípido-lípido, lo que ocasiona un incremento en su empaquetamiento, aunque disminuyen las interacciones lípido-proteína (Rice-Evans y Hoschtein, 1981). En cambio, la estimulación de la peroxidación con un agente generador de radicales libres en sistemas acuosos (AAPH) no produce cambios en la fluidez de la membrana eritrocitaria (Sato et al, 1995).

Durante el envejecimiento celular se produce un aumento de la peroxidación en las membranas, que junto con el incremento de colesterol, provocan disminuciones en la fluidez de las membranas de las células envejecidas (Choi y Yu, 1995). Sin embargo en los eritrocitos envejecidos se han aportado datos contradictorios acerca del efecto de la peroxidación sobre la fluidez en las diferentes regiones de la membrana eritrocitaria. Tozzi-Ciancarelli et al (1989) indican que la peroxidación induce perturbaciones en la membrana, que provocan aumentos en la fluidez del centro de la bicapa, en cambio, la superficie se hace más rígida. En otros casos, el envejecimiento eritrocitario se asocia con aumentos significativos de los hidroperóxidos lipídicos, acompañado de un descenso en la fluidez de la membrana (Yanagawa et al, 1999).

Durante el envejecimiento celular se han descrito cambios en la disposición asimétrica de los fosfolípidos de las membranas, a consecuencia de los procesos peroxidativos que tienen lugar (Schroeder, 1984). El daño oxidativo produce en el eritrocito la pérdida de asimetría, que va acompañada de cambios morfológicos, alteraciones en las propiedades biofísicas y en la carga superficial de la membrana, junto con un aumento de los contenidos de 
MDA (Jain y Shohet, 1984; Han et al, 1992; Dumaswala et al, 1997; Shiono, 2003; López-Revuelta et al, 2005; López-Revuelta et al, 2007). Esta pérdida de asimetría puede ser debida fundamentalmente a un aumento de la translocación de los fosfolípidos tras el proceso de peroxidación (Richter, 1987). Otra explicación para esta pérdida de asimetría puede estar fundada en la pérdida de fosfolípidos de la cara interna de la membrana hacia el citosol, como consecuencia de la interacción de éstos con los productos de oxidación de la hemoglobina generados tras el daño oxidativo (Moxness et al, 1996).

Estudios recientes han demostrado que existe una relación entre el aumento de los ROS y la exteriorización de la PS hacia la superficie de la membrana en los eritrocitos (Banerjee y Kuypers, 2004; López-Revuelta et al, 2007). El daño oxidativo inducido in vitro a través del sistema $\mathrm{Cu}(\mathrm{II}) /$ ascorbato también provoca una salida de los aminofosfolípidos hacia la cara superficial externa del eritrocito. La presencia de eritropoyetina en este sistema reduce parcialmente la generación de radicales $\mathrm{OH}^{\circ}$, previniendo parcialmente la pérdida de asimetría lipídica observada (Chattopadhyay et al, 2000). La PE cuenta con una alto contenido en ácidos grasos poliinsaturados en comparación con otros fosfolípidos, por lo que es más susceptible al daño oxidativo, lo que puede inducir la salida de la PE oxidada hacia la monocapa externa de forma espontánea o a través del transporte selectivo conducido por la escramblasa (Dumaswala et al, 1997).

Debido a que el proceso de peroxidación lipídica en membranas es complejo y se forman gran variedad de productos, la estructura, el ordenamiento y la orientación de los componentes de la membrana se encuentran profundamente alterados, modificándose la fluidez de la bicapa lipídica. Todo ello lleva asociado cambios en las propiedades antigénicas, aumento en la permeabilidad a ciertos iones como el $\mathrm{Ca}^{2+}$ y descensos en la resistencia eléctrica de la membrana (Richter, 1987).

\subsubsection{Implicaciones fisiológicas del daño oxidativo. Repercusiones en el eritrocito}

Algunos procesos fisiológicos que tienen lugar en los organismos, tales como la síntesis de prostaglandinas, la fagocitosis y el envejecimiento celular, van asociados a procesos oxidativos (Choi y Yu, 1995), así como distintos tipos de diferenciación celular (Tsatmali et al, 2006; Buggisch et al, 2007). 
Las alteraciones estructurales producidas en la célula como consecuencia del estrés oxidativo, que han sido descritas en los apartados anteriores, conllevan la pérdida de funcionamiento celular, y en muchos casos, una pérdida también de la integridad celular, que desencadena la muerte celular (Slater, 1984; Gutteridge y Halliwell, 1990; Dinis et al, 1993; Porter et al, 1995).

Los radicales libres y la peroxidación lipídica están involucrados en el daño celular y tisular que se observa en un amplio número de enfermedades, estimándose que están vinculados a más de 100 situaciones patológicas, tales como las anemias hemolíticas, las disfunciones reproductoras, las atrofias musculares, la aterosclerosis, la artritis reumatoide, el cáncer, los daños pulmonares (Halliwell y Gutteridge, 1984; Halliwell, 1992) y la diabetes (Domínguez et al, 1998; Martín-Gallan et al, 2003), entre otros.

Los cambios en la permeabilidad de la membrana producen alteraciones celulares tales como la pérdida de la función respiratoria, con posterior lisis de la mitocondria, así como la vesiculación del retículo endoplásmico y la degradación de los lisosomas (Vladimirov et al, 1980).

La exteriorización de la PS producida durante la oxidación de los eritrocitos con hidroperóxido de ter-butilo provoca un incremento de su fagocitosis, acompañado también de un aumento de PE en la superficie eritrocitaria (López-Revuelta et al, 2007). La acumulación de PS en la cara externa de la membrana es responsable del reconocimiento de la célula apoptótica por parte de los macrófagos (Kagan et al, 2000; Tyurina et al, 2004a; Tyurina et al, 2004b). La exteriorización de los aminofosfolípidos, especialmente por lo que se refiere a la PS, debe ir asociada a una inactivación de la aminofosfolípido translocasa (APLT) acompañada de la activación de las escramblasas, como paso previo a la pérdida de la asimetría. Este aumento en la superficie eritrocitaria de los aminofosfolípidos también podría producirse como consecuencia de los incrementos micromolares de $\mathrm{Ca}^{2+}$ citoplasmático que tienen lugar en las fases preliminares de la eriptosis (apoptosis eritrocitaria) mediada a través de ROS (Kagan et al, 2000). Otros estudios experimentales también han puesto de manifiesto que el estrés oxidativo inhibe la actividad APLTásica de los eritrocitos (Mandal et al, 2002; Banerjee y Kuypers, 2004; López-Revuelta et al, 2007), a través de la oxidación de sus cisteínas que son esenciales para la actividad de la enzima (Devaux, 1988; Fabisiak et al, 2000), 
lo cuál podría también ser causa de la exteriorización de PS observada en el eritrocito oxidado.

La apoptosis produce la oxidación selectiva de la PS, como proceso previo a su exteriorización (Kagan et al, 2000). Esta forma oxidada podría actuar como "escramblasa no enzimática", estimulando la salida de las diferentes clases de aminofosfolípidos hacia la superficie celular (Tyurina et al, 2004a), con una salida minoritaria de PE (Fadok et al, 1992; Fabisiak et al, 2000).

La toxicidad biológica de los ROS en el eritrocito se manifiesta también por un incremento en su fragilidad osmótica (López-Revuelta et al, 2007), junto a cambios en su morfología, que se traducen en la aparición de esferocitosis (El-Missiry y Abou-Seif, 2000; López-Revuelta et al, 2007). Este daño oxidativo es producido generalmente a través de la oxidación de la hemoglobina a metahemoglobina, con posterior transformación irreversible de ésta en hemicromos, que actúan como radicales libres atacando a los componentes de la membrana (Rice-Evans, 1990).

Los eritrocitos son estructuras celulares sumamente sensibles al daño por radicales libres, y por ello manifiestan cambios estructurales y funcionales en diferentes patologías asociadas al estrés oxidativo, como en la aterosclerosis coronaria (Dincer et al, 1999) y en el cáncer de pulmón (de Castro et al, 2008), observándose en muchos casos un descenso en la defensa antioxidante, lo que ocasionará una propagación del daño oxidativo en el organismo (Guven et al, 1999). 


\section{SISTEMAS INTRACELULARES DE DEFENSA FRENTE AL DAÑO OXIDATIVO}

Las células aeróbicas han desarrollado mecanismos de desintoxicación o sistemas antioxidantes que las protegen de los efectos perjudiciales de los radicales libres. El daño celular se produce cuando existe un desequilibrio entre la formación de radicales libres y los sistemas encargados de su eliminación, con un predominio de los primeros que conduce al desarrollo del estrés oxidativo (Halliwell, 1992).

La célula dispone de diferentes mecanismos de protección frente al daño oxidativo:

1) Mecanismos de prevención. El plasma sanguíneo contiene moléculas como la transferrina, la ferritina o la ceruloplasmina, que secuestran los iones metálicos capaces de catalizar las reacciones desencadenantes de los procesos peroxidativos (reacción de Fenton). La melanina y los carotenoides son pigmentos que protegen a las células de las radiaciones, evitando los procesos peroxidativos (Halliwell y Gutteridge, 1999).

2) Mecanismos de interrupción. Las células están dotadas de sistemas enzimáticos y no enzimáticos que bloquean las reacciones de oxidación. Diversas sustancias reductoras intracelulares de naturaleza hidrofílica - lipofílica tienen efectos antioxidantes, ya que se encargan de captar los radicales libres que aparecen en su entorno, protegiendo así a los diversos compartimentos intracelulares de los procesos oxidativos. Entre los compuestos de carácter hidrofílico se encuentran el ADP, el ácido ascórbico, el ácido úrico, la taurina y las moléculas con grupos tioles como el glutation.

Los eritrocitos poseen una amplia defensa antioxidante frente a los radicales libres que inducen el estrés oxidativo, siendo el sistema glutation reducido/glutation oxidado (GSH/GSSG), en el que predomina la forma reducida $(99 \%)$, el sistema de defensa antioxidante más importante para este tipo de células. El glutation reducido cumple una doble misión en el interior del eritrocito: i) evita la oxidación de los grupos sulfhidrilo presentes en los residuos de cisteína de diversas proteínas (enzimas, hemoglobina o proteínas de membrana); ii) interviene en los procesos de descomposición de peróxidos $\left(\mathrm{H}_{2} \mathrm{O}_{2}\right.$, peróxidos lipídicos) que se forman en el eritrocito. El GSH se oxida a 
través de la reacción catalizada por la glutation peroxidasa, en la que se utilizan como sustratos los peróxidos ( $\mathrm{ROOH}$ y $\mathrm{H}_{2} \mathrm{O}_{2}$ ), constituyendo un importante mecanismo de destoxificación. La disminución de los niveles de glutation reducido en tales circunstancias supone un elevado riesgo de oxidación y, por tanto, de alteración en la estructura-función del eritrocito (Clemens y Waller, 1987; Rice-Evans, 1990; Banerjee y Kuypers, 2004).

Los carotenos y los tocoferoles (vitamina E) son los principales antioxidantes lipofílicos (Mahfouz y Kummerow, 2000), ejerciendo su acción tras incorporarse a la membrana. La membrana eritrocitaria contiene unos niveles de $\alpha$-tocoferol prácticamente constantes durante toda la vida del eritrocito. Este compuesto impide la propagación de las reacciones de peroxidación mediante la cesión de un átomo de hidrógeno al radical peroxilo (ROO*). Los hidroperóxidos formados $(\mathrm{ROOH})$ se descomponen es sustancias no tóxicas por acción de la glutation peroxidasa. Los radicales $\alpha$-tocoferoxilo ( $\alpha$ Toc $^{\circ}$ ) son muy estables, pero pueden ser reducidos nuevamente a $\alpha$-tocoferol en la membrana por acción del ascorbato citoplásmico o extracelular a bajas concentraciones, o por el glutation reducido (Sies, 1993; Halliwell y Gutteridge, 1999; Chung y Benzie, 2000). El ascorbato oxidado puede ser regenerado en el citoplasma del eritrocito por acción de la dehidroascorbato reductasa dependiente de GSH (May et al, 1996). Por tanto, la acción combinada del $\alpha$ tocoferol y el ascorbato tendrá un carácter protector destacado frente a la peroxidación eritrocitaria.

Los plasmalógenos también desempeñan un papel protector frente al estrés oxidativo, ya que en los procesos peroxidativos inducidos por hierro protegen a los PUFA a través de su función vinil-éter, captando el radical libre (Sindelar et al, 1999).

Las células también disponen de mecanismos enzimáticos que eliminan los radicales libres generados, lo que evita la propagación del daño oxidativo. El eritrocito está sometido a un intenso estrés oxidativo debido a su función, habiéndose puesto de manifiesto en dicha célula la presencia de estos mecanismos (Fig. I. 5). 


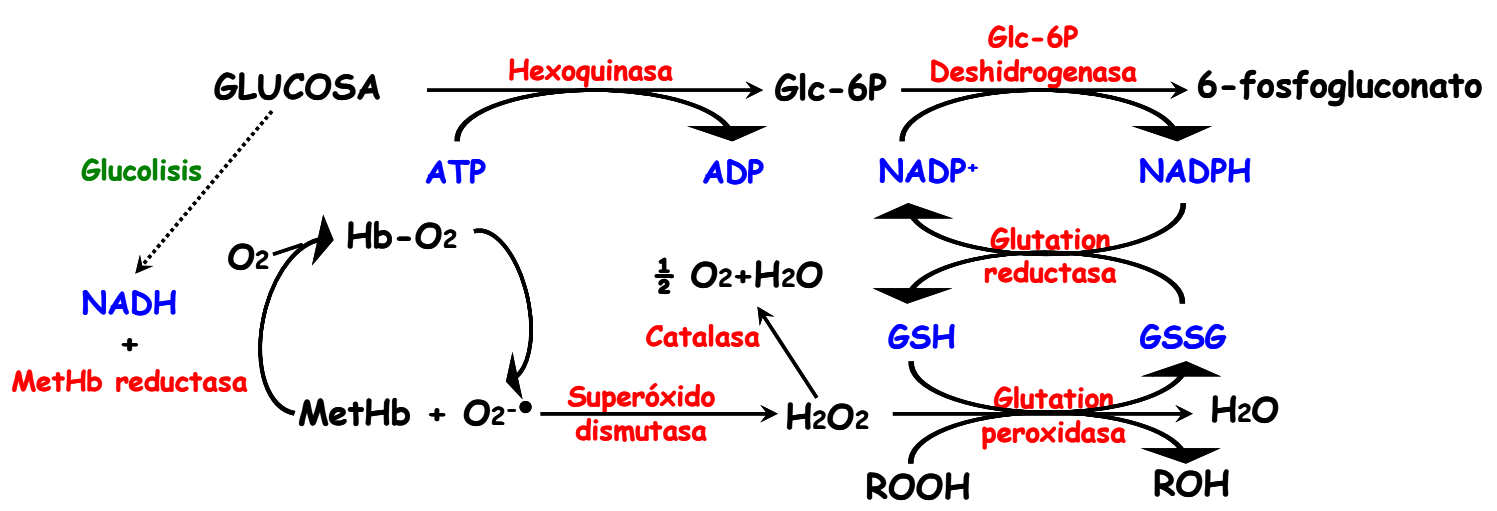

Fig. I. 5. Mecanismos enzimáticos de defensa antioxidante en el eritrocito (Rice-Evans, 1990).

Bajo la denominación de superóxido dismutasa (SOD) se engloba un grupo de metaloproteínas que se encargan de la eliminación del anión superóxido. El eritrocito cuenta con altas concentraciones de esta enzima en el citosol (isoforma dependiente de $\mathrm{Cu}$ y $\mathrm{Zn}$ ). Esta enzima cataliza la dismutación del anión superóxido en peróxido de hidrógeno. A su vez el $\mathrm{H}_{2} \mathrm{O}_{2}$ es descompuesto por la catalasa y/o la glutation peroxidasa en $\mathrm{H}_{2} \mathrm{O}$ y $\mathrm{O}_{2}$. En general, la catalasa presenta baja afinidad por este sustrato, y por tanto actúa solamente cuando las concentraciones de $\mathrm{H}_{2} \mathrm{O}_{2}$ son elevadas en el medio. $\mathrm{A}$ concentraciones fisiológicas, la descomposición del peróxido de hidrógeno se lleva a cabo por la glutation peroxidasa (Dumaswala et al, 1999; Halliwell y Gutteridge, 1999), enzima que se encarga también de degradar los peróxidos lipídicos en alcoholes, productos ya carentes de poder oxidante. Las reacciones catalizadas por la glutation peroxidasa son dependientes de GSH, que se transforma en glutation oxidado, regenerándose de nuevo a la forma reducida mediante la participación de la glutation reductasa y el NADPH procedente del ciclo de las pentosas fosfato (Rice-Evans, 1990; Kurata et al, 1993; Halliwell y Gutteridge, 1999; Mahfouz y Kummerow, 2000; Banerjee y Kuypers, 2004).

3) Mecanismos de reparación. La célula está dotada de equipos enzimáticos (proteasas, fosfolipasas y enzimas reparadoras de DNA) encargados de reparar los daños producidos por los procesos oxidativos. La fosfolipasa $A_{2}$ participa en la reparación, hidrolizando preferentemente los ácidos grasos de los fosfolípidos de la membrana que han sufrido peroxidación, proceso que es extraordinariamente rápido (van den Berg et al, 1993). Los ácidos grasos peroxidados en estado libre son susceptibles de ser degradados por la glutation peroxidasa (van Kuijk et al, 1987). Posteriormente, el lisofosfolípido presente en la membrana incorpora un nuevo ácido graso mediante un proceso de reacilación (van den Boom et al, 1996). 


\section{FLAVONOIDES. GENERALIDADES}

Los compuestos fenólicos constituyen un amplio grupo de sustancias (más de 8.000) presentes en el reino vegetal, aunque también existen compuestos de carácter sintético, que en su mayoría son potentes antioxidantes. Todos ellos comparten una estructura común, un grupo fenol, al que pueden asociarse núcleos aromáticos con diversos tipos de sustituyentes, predominando los grupos hidroxilos (Visioli et al, 2000). Sus estructuras químicas les permiten donar hidrógeno/electrones a los radicales libres, lo que les confiere el carácter antioxidante. En estudios in vitro se ha demostrado que muchos polifenoles son mejores antioxidantes que las vitaminas $\mathrm{C}$ y $\mathrm{E}$. La eficacia de estos antioxidantes depende en gran medida de la especie del radical libre generado, y de la naturaleza del oxidante (Halliwell y Gutteridge, 1999).

Los flavonoides (del latín flavus, "amarillo") constituyen el grupo más abundante dentro de los compuestos fenólicos, con más de 6.500 compuestos identificados (Hendrich, 2006). Están presentes en organismos fotosintéticos, especialmente en plantas superiores, pero son poco abundantes en algas y hongos. Son considerados metabolitos secundarios de las plantas. La concentración de flavonoides varía con la especie vegetal, y también en respuesta al medio ambiente de la planta. Se localizan fundamentalmente en frutos, semillas, hojas y otros órganos vegetales. Intervienen en las características organolépticas de las frutas y verduras, contribuyendo al color, sabor amargo y astringente, así como al pardeamiento enzimático de los vegetales (Martínez-Valverde et al, 2000). Se consideran los pigmentos responsables del color de las hojas y de los tonos amarillo, naranja y rojo en flores y frutos (Brouillard y Cheminant, 1988). Su presencia en tejidos animales está en relación directa con el consumo de alimentos vegetales (Scalbert y Williamson, 2000).

Los flavonoides poseen multitud de funciones fisiológicas dentro de las células vegetales, funcionando como metabolitos esenciales para el crecimiento y reproducción de las plantas, además de otorgar a la planta protección frente a la acción de los patógenos y de los animales herbívoros, aunque pueden atraer a los animales polinizadores (Butler, 1992). 
Los flavonoides han adquirido notoriedad pública a raíz de su actividad biológica en el hombre, ya que presentan actividades antimicrobianas y anticancerígenas. También son conocidos por los cultivadores de plantas ornamentales, que manipulan el ambiente de las plantas para aumentar la concentración de flavonoides que dan color a las hojas y a las flores. Debido a las importantes funciones metabólicas que los flavonoides tienen en las plantas y en los animales, sus rutas biosintéticas y sus mecanismos de regulación están siendo cuidadosamente estudiados.

\subsection{ESTRUCTURA QUÍMICA Y CLASIFICACIÓN}

Los flavonoides son derivados de la estructura química 2-fenilcromen-4ona (2-fenil-1,4-benzo pirona) (Fig. I. 6), y contienen un número variable de grupos hidroxilo insertados en dicha estructura lo que les confiere actividad antioxidante (Rice-Evans et al, 1996).

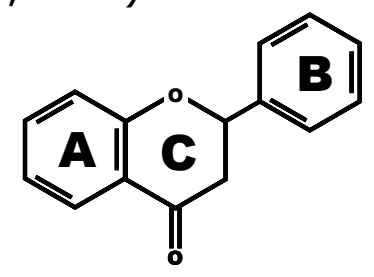

Fig. I. 6. Estructura básica de los flavonoides (Rice-Evans et al, 1996).

Por lo que respecta a los flavonoides propiamente dichos, tomando en cuenta el tipo y posición de los sustituyentes en los anillos A, B y C, estos se dividen en 14 grupos diferentes. Cinco de ellos están particularmente bien caracterizados y son muy conocidos: flavonoles, flavonas, flavanonas, flavanoles y antocianinas (Tabla I. 1) (Lien et al, 1999; Hendrich, 2006).

- Flavonoles: Poseen un doble enlace entre los carbonos $C_{2}-C_{3}$, con una grupo hidroxilo en la posición $\mathrm{C}_{3}$. Suelen ser incoloros o amarillos y se encuentran en las hojas de las plantas y en muchas flores. Entre los flavonoles más representativos se encuentra la quercetina (3,3'4',5,7-pentahidroxiflavona), presente en el polen de muchas fagáceas (Quercus $s p$.). Una de sus formas glicosiladas es la rutina (quercetina-3-rutinósido) (Hendrich, 2006). 
Tabla I. 1. Componentes estructurales de los distintos tipos de flavonoides

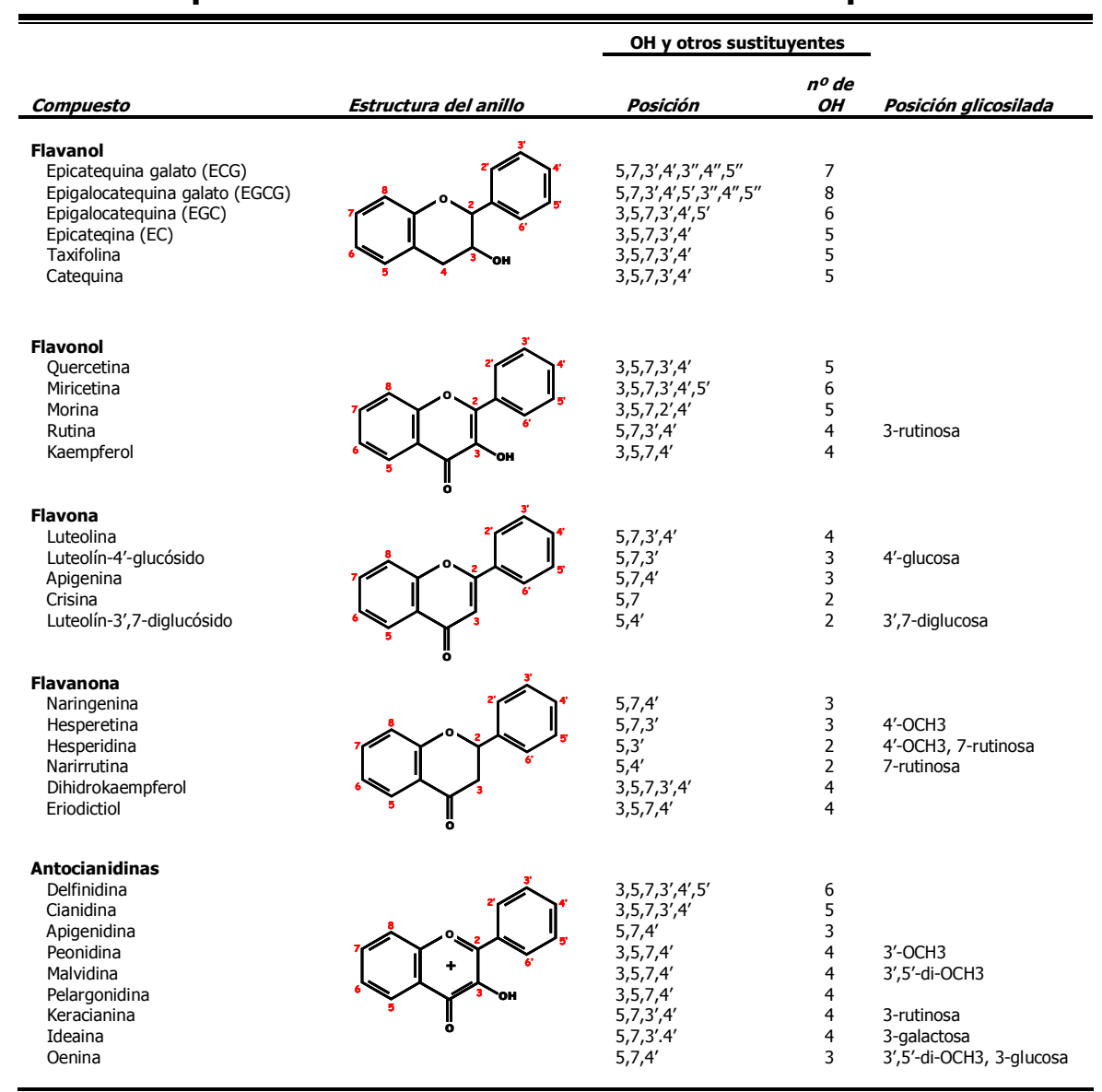

Procedente de Lien et al, 1999.

Flavonas: Tienen un doble enlace entre los carbonos $C_{2}-C_{3}$. Son metabolitos de color amarillo, presentes en algunas flores, como en la prímula, o en frutos, como en la piel de las uvas en forma de flavonas polihidroximetiladas, responsables del color amarillento de los vinos blancos (Hendrich, 2006).

Flavanonas: Se caracterizan por la ausencia del doble enlace en la posición 2-3 del anillo $\mathrm{C}$ y la presencia de un átomo de oxígeno en $\mathrm{C}_{4}$. Están presentes en cítricos, en altas concentraciones, en el tomate y en ciertas plantas aromáticas, como la menta (Hendrich, 2006).

Flavanoles: Se caracterizan por la ausencia también del doble enlace en la posición 2-3 del anillo $\mathrm{C}$ y la presencia de un grupo hidroxilo en $\mathrm{C}_{3}$. Existen en forma de monómero y en estado polimerizado, entre las que cabe citar catequinas y proantocianidinas, respectivamente. A diferencia de otras clases de flavonoides existentes en los alimentos, los flavanoles no están glicosilados (Hendrich, 2006). 
Antocianinas: Muestran dobles enlaces conjugados en el anillo $\mathrm{C}$, que a su vez porta un grupo hidroxilo en posición 3 y un grupo cetónico en posición 4. Normalmente se encuentran en forma glicosilada, denominándose antocianidinas, solubles en agua (Hendrich, 2006). La cadena oligosacarídica se une principalmente a la posición 3 del anillo $C_{\text {, }}$ aunque en ocasiones puede situarse en las posiciones 5 y 7 del anillo $A$, y de forma menos frecuente en las posiciones $3^{\prime}, 4^{\prime}$ y $5^{\prime}$ del anillo $B$. Son las responsables de los colores rojo, azul y púrpura de frutas, verduras, flores y tejidos vegetales (McGhie y Walton, 2007).

\subsection{PROPIEDADES}

Las propiedades fisicoquímicas dependen de la clase de flavonoide, y de su estado libre o conjugado. Las flavonas y flavonoles aportan colores desde el amarillo muy tenue hasta el rojo. Las antocianidinas son de colores rojo intenso, morado, violeta y azul.

Las flavanonas y flavanonoles debido al carbono quiral en $C_{2}$ presentan rotación óptica.

Los flavonoides conjugados, en general, son sólidos amorfos, mientras que sus aglucones y las formas altamente metoxiladas son cristalinos. Su solubilidad depende del estado de conjugación del aglucón y del número y clase de sustituyentes presentes en el aglucón. Los glucósidos (heterósidos), las antocianidinas y las formas sulfatadas del aglucón son solubles en agua y alcohol. Las formas aglucónicas altamente hidroxiladas son solubles en alcoholes (etanol, metanol y n-butanol), mientras que las poco hidroxiladas lo son en solventes como el éter etílico, el acetato de etilo o la acetona. Los aglucones con un número elevado de restos metoxilo son solubles en solventes poco polares como el éter de petróleo y el cloroformo, mientras que los flavonoides con sustituyentes fenólicos son solubles en soluciones alcalinas.

En cuanto a sus propiedades ácido-base, se han asignado sus valores de pK en la mayoría de los casos, a partir de los valores de pK determinados experimentalmente en compuestos no-flavonoides relacionados estructuralmente con ellos. Estos valores, que son muy sensibles a la naturaleza y posición de grupos vecinales, normalmente recaen en el rango de $\mathrm{pH}$ de 8- 
10.5 (Havsteen, 2002). Los radicales flavonoides son neutros en un medio ácido, por debajo de $\mathrm{pH} 3$, y poseen una carga negativa a pH 7 (MartínezFlorez et al, 2002).

La mayor parte de las flavonas y flavonoles muestran dos bandas de máxima absorción en la zona ultravioleta/visible, la banda I en la región 320$385 \mathrm{~nm}$, que representa la absorción correspondiente al anillo B, y la banda II en el rango de los 250-285 nm correspondiente a la absorción producida por el anillo $\mathrm{A}$. El número de grupos hidroxilo que portan estos compuestos modifica el máximo de absorción de la banda I. Las flavanonas muestran un máximo de absorción muy acentuado en la banda I (270-295 nm), y un pequeño hombro en la banda II, debido a la presencia en su molécula del anillo $\mathrm{C}$, de carácter heterocíclico saturado. En el caso de las antocianinas, el color que aportan estos compuestos varía en función del número y posición de los grupos hidroxilo (Rice-Evans et al, 1996). El estado de ionización de los grupos fenólicos de los flavonoides modifica las características espectrales de absorción de luz y de fluorescencia de estos compuestos. Esto se debe a una propiedad tautomérica prototrópica, fenómeno que es probablemente responsable del grado de pigmentación de flores y frutos (Havsteen, 2002).

\subsection{LOS FLAVONOIDES EN LAS PLANTAS}

Los flavonoides aparecieron por primera vez en los ancestros de las embriofitas, que comprende el grupo monofilético de todas las plantas terrestres (musgos, helechos, gimnospermas y angiospermas). Se cree que fueron una de las adaptaciones clave para la transición a la vida terrestre desde el alga verde ancestral, debido a su capacidad de absorber la radiación ultravioleta, mucho más intensa en la atmósfera que en el agua (Judd et al, 2002).

Las enzimas de la biosíntesis de los flavonoides aparentemente derivaron de enzimas del metabolismo primario de las plantas, que tenían genes duplicados, lo que debió permitir adaptar algunas de esas enzimas a otras funciones específicas (Rausher et al, 1999; Durbin et al, 2000).

Las rutas biosintéticas de los flavonoides se han conservado en su mayor parte en el transcurso de la evolución de las plantas, pero han divergido 
considerablemente tanto en las funciones para las que han sido destinados, como en los mecanismos que regulan su expresión (Winkey-Shirley, 2001).

\subsubsection{Biosíntesis y regulación}

Todas las células de las plantas verdes son capaces de sintetizar flavonoides. Su biosíntesis comienza invariablemente a partir de fenilalanina, aminoácido que sufre una serie de transformaciones por rutas distintas, aunque relacionadas, dependiendo del tipo de flavonoide generado. En general, la ruta de síntesis transcurre con la eliminación del grupo amino de la fenilalanina por una transaminación o una desaminación oxidativa. El grupo amino es transferido a un cetoácido del ciclo del ácido cítrico, o bien es liberado como ión amonio. Como resultado de este proceso obtenemos el fenilpiruvato. Dos moléculas de ácido fenilpirúvico sufren una descarboxilación oxidativa catalizada por el complejo piruvato-deshidrogenasa para producir dos moléculas de aldehído activo, que junto con un fragmento- $\mathrm{C}_{1}(-\mathrm{CHO})$ forman el núcleo de la flavona, la fenil- $\gamma$-cromona tras una etapa oxidativa (Fig. I. 7).

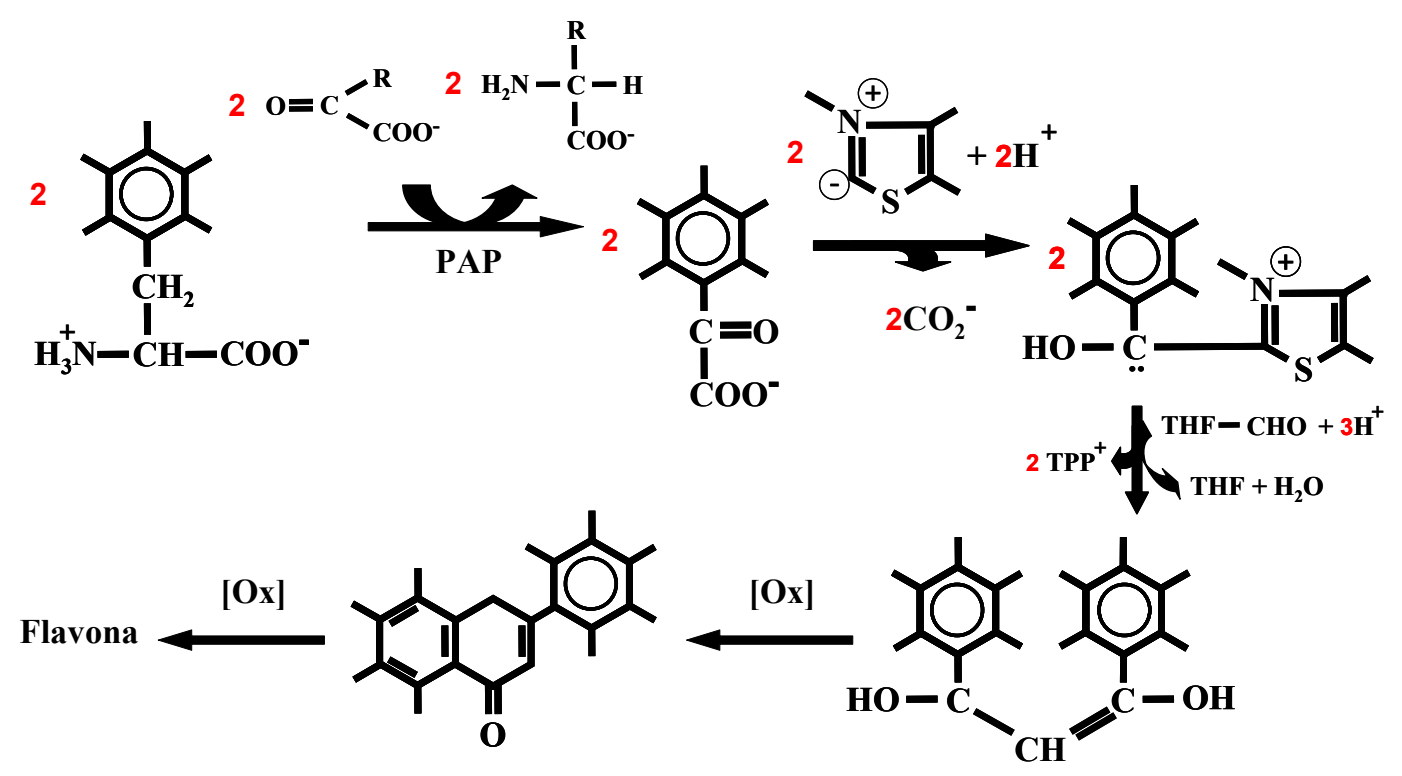

Fig. I. 7. Biosíntesis de una flavona. Ejemplo representativo de la síntesis de flavonoides. PAP: piridoxal-P, $\mathrm{TPP}^{+}$: tiamina pirofosfato, THF: tetrahidrofolato, Ox: oxigenasa (Havsteen, 2002)

Este núcleo precursor, es seguidamente hidroxilado múltiples veces por un número de oxigenasas específicas para la síntesis de los distintos flavonoides. 
La metilación de los grupos hidroxilo se produce a partir de metanol, en reacciones catalizadas por metil-transferasas específicas, tal y como se conoce en células animales (Havsteen, 2002).

Los glucósidos (heterósidos) se forman por unión del flavonoide (aglucón) a través del grupo hidroxilo, que ocupa preferentemente la posición 3, y en ciertos casos la posición7, con monosacáridos (L-ramnosa, D-glucosa, galactosa $o$ arabinosa) activados en forma de UDP en su carbono anomérico $\left(C_{1}\right)$ mediante enlaces $O$-glicosídicos. Estos compuestos se suelen localizar en las vacuolas celulares vegetales, habiéndose sugerido que sus aglucones serían productos terminales de procesos metabólicos, sirviendo la formación de los heterósidos como proceso destoxificante similar al que presentan los animales. Otra posibilidad es que sirvan para regular la presión osmótica o para estabilizar y solubilizar a los aglucones lábiles o de carácter lipofílico (Montaña del Olmo, 1977).

Los flavonoides isoprenilados se sintetizan por incorporaciones sucesivas de unidades de isopreno activo, isopentenil-pirofosfato, generalmente, a la posición $C_{3}$ de la $\gamma$-cromona (Havsteen, 2002).

\subsubsection{Funciones en las plantas}

Los flavonoides se asemejan en sus propiedades reguladoras a las vitaminas liposolubles, pero además debido a su color y olor, sirven como intercomunicadores con el medio ambiente. Son reconocidos por los diversos agentes polinizadores, insectos, pájaros y otros animales.

Los flavonoides constituyen los pigmentos vegetales capaces de absorber la luz en las regiones visible y ultravioleta (UV), en un amplio espectro, teniendo como misión la captura de energía y su transferencia, además de cumplir también una función de selección biológica. La acción de selección biológica que desempeñan los flavonoides, también se relaciona con la activación selectiva de algunos genes sensibles a la luz (Harborne y Williams, 2000)

La resistencia de las plantas a los rayos ultravioleta-B (UV-B) recae, entre otros factores, en los flavonoides. Estas moléculas, debido a su poder de absorción lumínica en la región de 280-315 nm, son capaces de actuar como 
filtro de los rayos UV, protegiendo a los tejidos fotosintéticos del posible daño inducido por la luz UV. Aunque se observa una gran absorción de luz por parte de los flavonoides, que están presentes en todas las células de la planta que contienen plastidios, no se conoce evidencia de su participación en los procesos fotosintéticos primarios (Harborne y Williams, 2000).

La emisión de fluorescencia que muestran los flavonoides, podría ser aprovechado por la planta, a través de las pequeñas cantidades de energía transferidas, para activar pigmentos asociados con genes sensibles a la luz, lo que constituiría un aspecto fisiológico relevante para la planta, que aún no ha sido demostrado.

Una función indiscutible de los flavonoides, y de los polifenoles en general en las plantas, es su papel protector contra la invasión microbiana. Esto no sólo se debe a su presencia como agentes constitutivos, sino también a la inducción de su síntesis en respuesta al ataque microbiano, como sucede con la acumulación de fitoalexinas. La mayoría de los flavonoides catalogados como antifúngicos constitutivos en plantas pertenecen a los grupos de los isoflavonoides, flavanos y flavanonas. El isoflavonoide maackiaina (3-hidroxi8,9-metilendioxipterocarpano) es un agente antifúngico constitutivo muy conocido, que se encuentra en la corteza de árboles leguminosos, siendo también inducido en leguminosas herbáceas. Diversos factores contribuyen a un aumento de la concentración de flavonoides libres después de una infección, incluido un incremento del flujo de fenilalanina, la inhibición de la glicosilación y la acción de las glicosidasas (Harborne y Williams, 2000).

Se acepta, en general, que los flavonoides del tipo flavanoles y proantocianidinas, junto con otros polifenoles, llevan a cabo una acción protectora en las plantas frente al ataque de insectos y animales herbívoros (Harborne y Williams, 2000).

Los flavonoides también interaccionan con cierto tipo de genes en las plantas. Estos genes están asociados con el crecimiento longitudinal de la planta, la respuesta al estrés y la coloración de los pétalos florales. El efecto sobre el crecimiento de la planta es parcialmente indirecto, y está asociado con la acción de las auxinas. Los flavonoides aumentan la concentración de un tipo de auxina, el ácido indolacético (IAA), al bloquear su salida de la célula. El IAA 
induce un incremento en la expresión génica, que estimula el crecimiento longitudinal de las células de la planta.

Los flavonoides también juegan un papel importante en el metabolismo del nitrógeno en las plantas fijadoras de este elemento, ya que inducen la nodulación de sus raíces. Estos nódulos contienen bacterias fijadoras de dinitrógeno, como la variedad Rhizobium, que vive en simbiosis con las plantas leguminosas. Estos compuestos también pueden estar implicados en la expresión de proteínas necesarias para la fijación del nitrógeno en las células nodulares, incrementando el complejo nitrogenasa, y participando en la eliminación del oxígeno molecular debido a su actividad antioxidante (Rolfe, 1988).

\subsection{FLAVONOIDES EN LA DIETA}

\subsubsection{Distribución}

Un amplio porcentaje de flavonoides son consumidos en la dieta, aunque la cantidad y el tipo vienen dictados por los hábitos alimenticios y culturales. En países del noreste de Asia, como China y Japón, se consumen principalmente isoflavonas junto con otros flavonoides derivados del té, frutas y verduras. En el sureste de Asia, en países como India, abunda el consumo de grandes cantidades de curcumina, como resultado de la presencia en la dieta de especias de cúrcuma.

Las mejores fuentes de polifenoles en la dieta humana son las frutas y sus zumos, ya que contienen una gran cantidad de este tipo de metabolitos, y su ingesta es bastante abundante (100-200 g de fruta/ración). Una ración de manzanas contiene unos $400 \mathrm{mg}$ de fenoles totales, expresados como equivalentes de ácido gálico. Las peras y las uvas pueden contener hasta 300 mg de fenoles totales por ración, mientras que la concentración en arándanos y cerezas es de 200-400 mg/ración. Existe una fuerte correlación entre el contenido total de fenoles en las frutas y verduras, y la capacidad antioxidante total de estos alimentos medida in vitro. El aporte antioxidante a través de la ingesta de flavonoides y polifenoles en la dieta humana, mediante toma de alimentos de origen vegetal, en particular de verduras, frutas, té y vino, es en 
general mucho mayor que el que aportan otros tipos de antioxidantes como las vitaminas $\mathrm{C}$ y $\mathrm{E}$ o los carotenoides.

Las verduras como las espinacas, el brócoli y las cebollas, también aportan cantidades significativas de polifenoles a la dieta humana.

Otros alimentos y bebidas de origen vegetal, también pueden contribuir enormemente al total de la ingesta diaria de polifenoles en el hombre. Por ejemplo, el té, el café, el chocolate, el vino y la cerveza poseen una gran capacidad antioxidante in vitro, lo que se debe casi exclusivamente a la presencia de polifenoles. En el té negro los niveles de polifenoles, que varían dependiendo de la cantidad de hojas, del tiempo y temperatura de elaboración, suelen mantenerse alrededor de $150-250 \mathrm{mg} / 200 \mathrm{ml}$ de té consumido. El café contiene unos $150-180 \mathrm{mg}$ de polifenoles/200 ml, y el vino tinto aporta 200-500 $\mathrm{mg} / 200 \mathrm{ml}$, en función del tipo de uva y de las condiciones de vinificación, entre otras causas. Sin embargo, el contenido de polifenoles en el vino blanco es considerablemente menor, entre $40-60 \mathrm{mg} / 200 \mathrm{ml}$. El chocolate negro aporta unos $340 \mathrm{mg}$ de polifenoles/40 $\mathrm{g}$ consumidos. Teniendo en cuenta las cantidades de fenoles totales que aporta cada ración de los alimentos anteriormente citados, una dieta equilibrada, compuesta por 9 raciones diarias de frutas y verduras, y una ingesta moderada de té, café, vino, cerveza o chocolate, puede aportar unos $1.000 \mathrm{mg}$ de fenoles totales por día (Lotito y Frei, 2006). Sin embargo, la ingesta diaria puede variar entre $20 \mathrm{mg}$ y $1 \mathrm{~g}$ (Rice-Evans et al, 1996).

La mayor parte de los flavonoides de la dieta derivan del té (48\%), las cebollas $(29 \%)$, las manzanas $(7 \%)$ y el vino tinto $(1 \%)$. Los flavanoles, en especial la catequina, el galeato de catequina, y los flavonoles quercetina, kaemferol y sus glucósidos correspondientes son constituyentes del té verde y negro, así como del vino tinto. La quercetina también es un flavonoide mayoritario en cebollas y manzanas, mientras que en las bayas de los frutos predominan la miricetina y la quercetina. Los cítricos contienen fundamentalmente flavanonas.

Los flavonoides ingeridos a través de la dieta se encuentran abundantemente en forma 3-O-glicosilada y en estado polimerizado. La glicosilación aumenta su hidrosolubilidad, pero les dota de una menor 
reactividad frente a los radicales libres en comparación con su aglucón correspondiente (Heim et al, 2002).

Una relación pormenorizada de las fuentes de procedencia de los flavonoides de la dieta se recoge en la Tabla I. 2.

Tabla I. 2 Algunas fuentes de flavonoides en la dieta

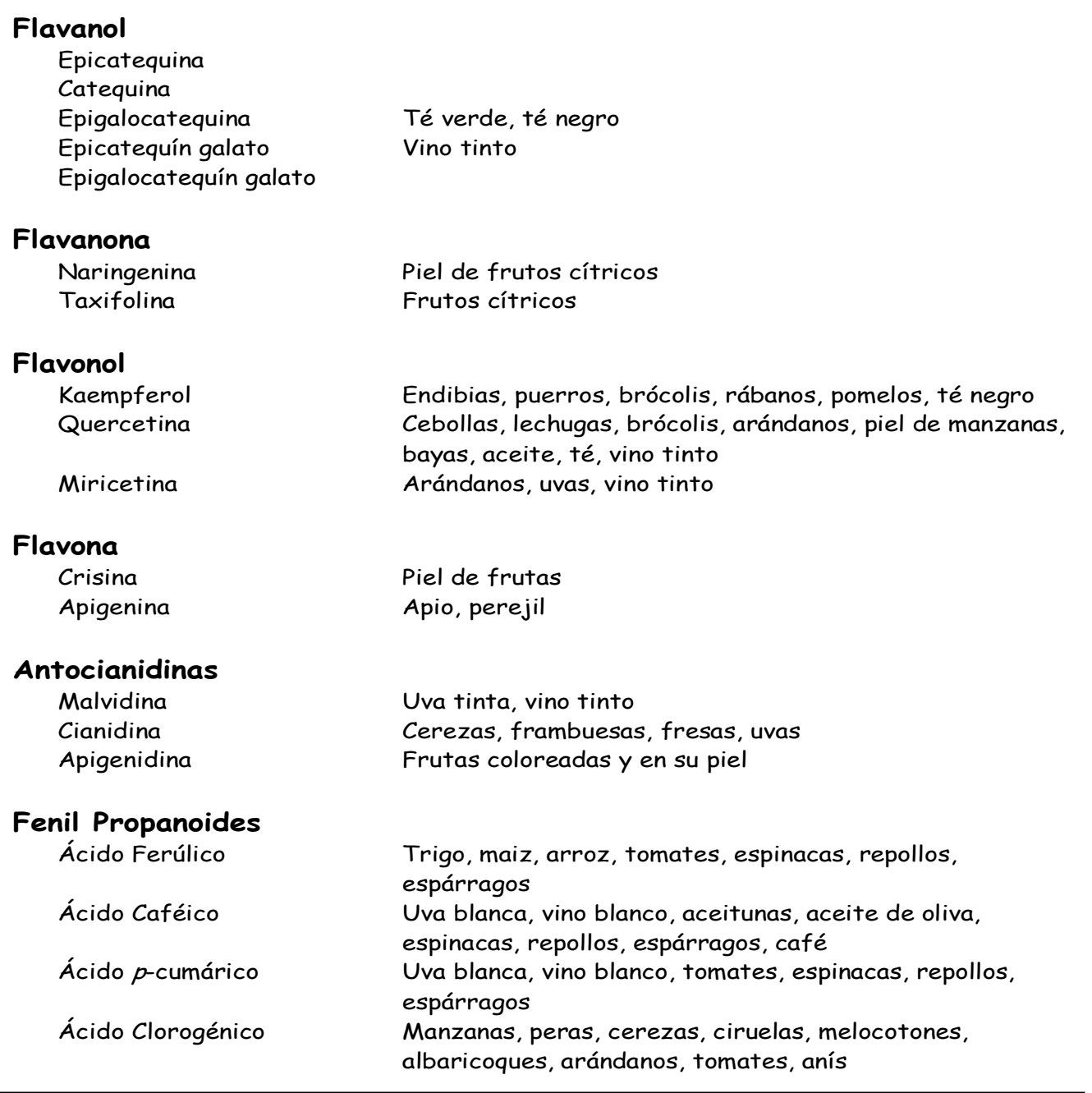

Procedente de Rice-Evans et al, 1996

\subsubsection{Bioasimilación y metabolismo de los flavonoides}

A pesar de la gran capacidad antioxidante de los flavonoides in vitro, su eficacia in vivo está limitada por varios factores. Uno de ellos, y tal vez el más importante, es la baja absorción de los flavonoides en humanos, en contraste con otros antioxidantes de la dieta como las vitaminas C y E. La máxima concentración de flavonoides en el plasma humano, que se alcanza normalmente entre 1 y 3 horas después del consumo de los alimentos ricos en 
estos polifenoles, está entre 0,06 y 7,6 $\mu \mathrm{M}$ para flavonoles, flavanoles y flavanonas, y menos de $0,15 \mu \mathrm{M}$ para antocianidinas. Además la vida media de los flavonoides en el plasma humano es corta, normalmente de unas pocas horas. Estos factores limitan mucho la capacidad de los flavonoides de la dieta para actuar como antioxidantes in vivo en el plasma, especialmente cuando se les comparan con otros antioxidantes también presentes que están a concentraciones más elevadas, como el ascorbato (30-150 $\mu \mathrm{M})$, el urato (160$450 \mu \mathrm{M})$, el $\alpha$-tocoferol $(15-40 \mu \mathrm{M})$. El consumo habitual o durante largos períodos de tiempo de alimentos ricos en flavonoides no produce un aumento considerable de éstos en el plasma sanguíneo (Lotito y Frei, 2006).

El grado de eficacia de un flavonoide in vivo reside, entre otras causas, en su bioasimilación (Holst y Williamson, 2008). Por lo tanto, es más importante conocer la capacidad de bioasimilación por parte del organismo de un nutriente o suplemento dietético procedente de un alimento específico, que saber la cantidad del mismo que está presente en el alimento (D'Archivio et al, 2007). Para ser bioasimilados, los flavonoides deben de superar ciertas barreras como la solubilidad, la permeabilidad, el metabolismo, la excreción y la captación por parte de los tejidos diana ( $\mathrm{Hu}, 2007)$. Los flavonoides sufren tres tipos de transformaciones intracelulares: i) conjugación con grupos tioles, particularmente con GSH; ii) metabolismo oxidativo; iii) transformaciones relacionadas con el citocromo P-450 (Williams et al, 2004).

Generalmente, los flavonoides libres (aglucones) procedentes de la dieta suelen ser absorbidos en el intestino delgado, pero en su mayoría se presentan en forma glicosilada (heterósidos o glucósidos) o en estructuras polimerizadas, lo que dificulta su absorción. La mayoría de los glucósidos resisten la hidrólisis ácida del estómago y llegan intactos al intestino. Las enzimas intestinales (glicosidasa y otras hidrolasas) o las procedentes de su microflora hidrolizan estos compuestos hasta las formas aglucón (Heim et al, 2002), convirtiéndolos en metabolitos más asimilables. Posteriormente sufrirán conjugaciones en las células del intestino delgado, con posteriores modificaciones (metilaciones, sulfataciones y/o transformaciones con ácido glucurónico) en el hígado. Como consecuencia de estas modificaciones, las formas procedentes de la dieta son totalmente diferentes de aquellas que ejercen su acción en los tejidos diana. Los flavonoides que no han sido absorbidos en el intestino delgado alcanzan el colon, donde la microflora hidroliza los glucósidos hasta su correspondiente aglucón, los cuáles sufren posteriores transformaciones que dan lugar a una 
amplia gamma de metabolitos aromáticos (Aura et al, 2005; D'Archivio et al, 2007).

Una vez en el torrente sanguíneo, los flavonoides circulan unidos a proteínas, en particular a albúmina. La afinidad que muestran por esta proteína varía en función de su estructura química. Su grado de unión con la albúmina puede afectar tanto a su tasa de eliminación, como a su grado de incorporación en células y tejidos, de forma que la captación celular de estos metabolitos parece ser solamente proporcional a su concentración en la forma flavonoide libre. La actividad biológica que muestra la forma libre de la quercetina se mantiene en su forma conjugada con albúmina, fenómeno que aún no se ha demostrado en el resto de los flavonoides (Dufour et al, 2007).

La mayoría de los flavonoides, y polifenoles en general, no están sometidos a transformaciones metabólicas en fase I, ya que son inductores y buenos sustratos de las enzimas que participan en las transformaciones en fase II, lo que indica que son reconocidos por el cuerpo como xenobióticos, y por lo tanto, como compuestos potencialmente tóxicos, probablemente debido a su estructura polihidroxilada y a su potente actividad redox (Yang et al, 2008).

La biotransformación que sufren por parte del intestino y del hígado, afecta enormemente a sus propiedades físicas, haciéndolos más solubles en agua, lo que facilita su eliminación vía biliar o a través de la orina, afectando incluso a su capacidad antioxidante. Algunos flavonoides transformados mantienen la actividad antioxidante de sus formas nativas, pero en general suelen perder poder antioxidante debido a las modificaciones en sus grupos catecol y fenol. Los flavonoides suelen sufrir metilaciones en las posiciones $C_{3}, y$ con menos frecuencia en $\mathrm{C}_{4}$, con la participación de la S-adenosil-L-metionina y de la enzima catecol-O-metil transferasa, abundante en hígado y riñones. También se llevan a cabo procesos de sulfatación en los flavonoides polihidroxilados, principalmente en el hígado, así como conjugaciones con el ácido glucurónico en la posición $C_{3}$ de su molécula (D'Archivio et al, 2007).

La quercetina es un flavonol abundante en la dieta humana, que tiene alto poder antioxidante in vitro. En los alimentos la quercetina se presenta habitualmente en forma conjugada, como glucósido de quercetina. Algunos autores indican que estos glucósidos son directamente transportados hacia el interior de los enterocitos por el transportador I de glucosa dependiente de $\mathrm{Na}$ 
(Hollman et al, 1995), mientras que otros señalan que es necesaria una desglicosilación previa intestinal para que estos metabolitos sean absorbidos (Nemeth et al, 2003). Cuando los metabolitos de quercetina se encuentran en el torrente sanguíneo, éstos pueden mantenerse en circulación más de 10 horas como consecuencia del reciclaje enterohepático, lo que representa un tiempo de permanencia en circulación muy superior al mostrado por otros flavonoides, como sucede con antocianidinas y catequinas (Arts et al, 2004). Las concentraciones de quercetina en el plasma humano tras el consumo de alimentos ricos en este tipo de flavonol varían desde 0,7 a 7,6 $\mu \mathrm{M}$. La quercetina circula en el plasma sanguíneo humano en forma sulfatada (35\%), asociada a glucuronato (46\%) y en forma glucurono-metilada (19\%), mostrando en la rata un patrón de conjugación bastante diferente (van der Woude et al, 2006).

Hasta el momento se han realizado escasos estudios sobre la captación de flavonoides por los tejidos, sin embargo en los pocos estudios existentes se ha puesto de manifiesto que no existe correlación entre las concentraciones de estos metabolitos en plasma y la captación de flavonoides por parte de los tejidos diana.

\subsection{ACTIVIDADES BIOLÓGICAS DE LOS FLAVONOIDES}

\subsubsection{Propiedades antioxidantes en relación con su estructura}

Para que una sustancia sea considerada antioxidante debe actuar a bajas concentraciones en relación al sustrato oxidable, retrasando o impidiendo significativamente la oxidación del mismo. Además el radical antioxidante formado debe ser relativamente estable (Rice-Evans et al, 1996). Las siguientes características en una molécula marcan su grado de capacidad antioxidante:

1. La presencia en su molécula de sustituyentes con capacidad donadora de hidrógeno/electrones, asociado con apropiados potenciales de reducción (Bors et al, 1990; Jovanovic et al, 1994; Bors et al, 1995).

2. La capacidad de la molécula para deslocalizar el radical resultante (Bors et al, 1990). 
3. El potencial de quelación de metales de transición, que depende de la naturaleza y disposición de los grupos funcionales en la molécula (Thompson y Wiliams, 1976; Afanas'ev, 1989; Frankel, 1993; Morel et al, 1993; Paganga et al, 1996).

4. La accesibilidad del antioxidante al lugar de acción, en relación directa con su coeficiente de reparto (Niki, 1996).

5. El potencial de interacción entre los radicales del antioxidante y otras moléculas antioxidantes (Halliwell et al, 1995).

En el caso de los flavonoides se cumplen la mayor parte de los cinco requisitos formulados para portar actividad antioxidante. Son moléculas donadoras de hidrógeno, en virtud de las propiedades reductoras de los grupos polihidroxilo presentes en sus anillos aromáticos, tienen la capacidad de deslocalizar el radical resultante dentro de sus estructuras, acomplejan metales de transición a través de su estructura catecol, y tienen el poder de regenerar los $\alpha$-tocoferoles a través de la reducción de los radicales $\alpha$-tocoferilo (RiceEvans et al, 1996; Rice-Evans et al ,1998; Moridani et al, 2003).

La disposición espacial de los sustituyentes en la molécula del flavonoide determina su actividad antioxidante de un modo esencial, a través de la disposición y número de sus grupos hidroxilo, que debido a su gran reactividad (flavonoide, $\mathrm{F}-\mathrm{OH}$ ) participan del siguiente modo en la eliminación de radicales libres $(\mathrm{R} \bullet$ ) procedentes de oxígeno (ROS) o de nitrógeno (RNS):

\section{$\mathrm{F}-\mathrm{OH}+\mathrm{R} \bullet \longrightarrow \mathrm{F}-\mathrm{O} \bullet+\mathrm{RH}$}

Los grupos hidroxilo del flavonoide donan un hidrógeno y un electrón a diversos radicales, hidroxilo, peroxilo y peroxinitrito, que pierden su reactividad como consecuencia de su estabilización, formándose también un radical flavonoide relativamente estable (Heim et al, 2002). Esta donación está basada en el potencial de reducción del flavonoide, que es dependiente de su estructura molecular. En general, estos compuestos son capaces de reducir los radicales anteriormente citados, junto con los superóxido, ya que los flavonoides presentan potenciales de reducción con valores inferiores a los mostrados por los radicales (Rice-Evans et al, 1996). 
Una estructura catecol en $3^{\prime}, 4^{\prime}$ del anillo B favorece enormemente la inhibición de la peroxidación lipídica, como se observa en la luteolina, con una capacidad para eliminar radicales peroxilo muy superior al kaempferol. Ambas difieren estructuralmente en el grupo catecol del anillo B, presente en la luteolina y ausente en el kaempferol. Cuando el grupo catecol está presente, la oxidación de los flavonoides se produce en el anillo $B$, obteniéndose un radical orto-semiquinona bastante estable, que facilita la deslocalización electrónica. La influencia de la disposición de otros grupos hidroxilo en la actividad antioxidante del flavonoide es menos destacada, sobre todo por lo que respecta al anillo A (Heim et al, 2002).

La eliminación de radicales libres por los flavonoides depende también en gran parte de la presencia de un $\mathrm{OH}$ libre en el carbono 3. Los flavonoides que poseen un $\mathrm{OH}$ en $\mathrm{C}_{3}$ y un grupo catecol en $3^{\prime}, 4^{\prime}$ son 10 veces más potentes contra el peroxinitrito, que el ebseleno, un potente compuesto eliminador de RNS. La gran capacidad de la quercetina $\left(3,3^{\prime}, 4^{\prime}, 5,7\right.$-pentahidroxiflavona) para inhibir el daño oxidativo inducido tanto por metales como no metales, se adscribe parcialmente a la presencia de su grupo $3-\mathrm{OH}$ libre, el cual aumenta la estabilidad del radical flavonoide. El ángulo de torsión del anillo $B$ con respecto al resto de la molécula, ejerce un papel preponderante para eliminar radicales libres. Los flavonoles y los flavanoles con un grupo $3-\mathrm{OH}$, adoptan estructuras planas, mientras que las flavonas y las flavanonas, que carecen del $3-\mathrm{OH}$, adoptan estructuras ligeramente curvadas. Las formas planares de algunos flavonoides permiten la conjugación, una mejor deslocalización electrónica y un aumento en la estabilización del radical fenoxilo. Se ha postulado que los grupos $\mathrm{OH}$ del anillo $\mathrm{B}$ forman puentes de hidrógeno con el $\mathrm{OH}$ en posición 3, alineando el anillo $\mathrm{B}$ con los anillos $\mathrm{A}$ y $\mathrm{C}$ del núcleo flavonoide. La eliminación del hidroxilo en posición 3 provoca una ligera curvatura del anillo $B$, y la pérdida de coplanaridad de los anillos que conforman la molécula flavonoide, lo que disminuye la capacidad de deslocalización electrónica del compuesto (Heim et al, 2002).

Los grupos metoxilo proporcionan a los flavonoides lipofilicidad y capacidad de incorporación a las membranas, aunque cuando se produce la metilación en posición 4' (4'-O-metilación), se genera una obstrucción estérica en la estructura $3^{\prime}, 4^{\prime}$-catecol que disminuye la capacidad antioxidante de la molécula. Así la 4'-O-metilación de la quercetina para formar tamarixetina, disminuye el porcentaje de inhibición de la peroxidación lipídica inducida por 
sulfato de hierro desde un $98 \%$ a un 2,6\%. La presencia de múltiples grupos metoxi en el anillo $A$ también revierte el efecto positivo del grupo catecol en el anillo B. Así la isorhamnetina, el metabolito 3'-metoxi de la quercetina que se detecta en humanos, es un antioxidante menos efectivo que su aglucón (Heim et al, 2002).

Además del grupo catecol en $3^{\prime}, 4^{\prime}$, del $3-\mathrm{OH}$ libre y del patrón de hidroxilación, muchos estudios han puesto de manifiesto también la importancia en el anillo $C$ de la instauración en 2-3 y del grupo carbonilo en posición 4. En sistemas microsómicos se ha demostrado que los flavonoides que poseen un doble enlace en $\mathrm{C}_{2}-\mathrm{C}_{3}$ en conjugación con un grupo carbonilo en 4 , presentan valores de $\mathrm{IC}_{50}$ más bajos (una actividad antioxidante mayor) que los flavonoides que contienen un anillo $\mathrm{C}$ carente del doble enlace en 2-3 (Heim et al, 2002).

La conjugación entre los anillos A y $\mathrm{B}$ permite un efecto de resonancia del núcleo aromático que confiere estabilidad al radical flavonoide, lo que resulta ser un punto clave para favorecer la estabilización del radical fenoxil por parte del grupo catecol en $3^{\prime}, 4^{\prime}$ (Heim et al, 2002).

Como he comentado anteriormente, los aglucones son antioxidantes más potentes que sus correspondientes formas glicosiladas (glucósidos 0 heterósidos). Plumb et al (1999) demostraron que las propiedades antioxidantes de los flavonoles glicosilados del té disminuían cuando aumentaba el número de grupos glicosídicos. Además del número total de grupos, también son importantes la posición y la estructura de la cadena glicánica.

Estudios cinéticos que miden las constantes de velocidad de las reacciones de flavonoides con radicales de nitrógeno generados por radiólisis, indican también que las dos características principales para el control del potencial redox son la presencia del grupo catecol en el anillo $B$ y el doble enlace en el anillo $C$. El carbonilo en posición 4 del anillo $C$, junto con los grupos hidroxilo libres en posición 3 y/o 5 en los anillos $\mathrm{C}$ y $\mathrm{A}$ respectivamente, parecen ser fundamentales para la actividad antioxidante de la molécula. Así mismo, el grupo $o$-dihidroxi en un anillo y el $p$-dihidroxi en otro producen gran potencial antioxidante, mientras que la hidroxilación en 5 y 7 tiene menor influencia (Rivas-Gonzalo y García-Alonso, 2002). 
De todo lo anterior se deduce, que existe una serie de características estructurales en la molécula del flavonoide que son determinantes de su poder antioxidante:

1. La presencia de la estructura 3', 4'-o-dihidroxi en el anillo aromático B (catecol), lo cual confiere mayor estabilidad al radical formado, y participa en la deslocalización de los electrones.

2. La existencia de grupos hidroxilo en los carbonos 5 y 7 del anillo $A$.

3. El doble enlace localizado en posición 2,3 en conjunción con el grupo 4-oxo y la presencia del $3-\mathrm{OH}$ en el anillo $\mathrm{C}$, responsables de la deslocalización desde el anillo $\mathrm{B}$.

La máxima efectividad del antioxidante requiere la presencia de todas las funciones antes citadas, produciéndose cambios en su actividad por ausencia de alguna de ellas (Rice-Evans et al, 1996; Lien et al, 1999).

La quercetina $\left(3,3^{\prime}, 4^{\prime}, 5,7\right.$-pentahidroxiflavona) satisface los requisitos estructurales que debe cumplir un flavonoide para presentar máximo potencial antioxidante. Su glucósido, la rutina, quercetina unida a través del 3-OH por un enlace O-glicosídico al $\mathrm{C}_{1}$ del disacárido glucosa-ramnosa (quercetina-3-rutinósido), presenta un poder antioxidante menor (RiceEvans et al, 1996; Lien et al, 1999). La capacidad antioxidante total de la quercetina medida como actividad antioxidante equivalente en Trolox (TEAC) es de 4,7 mM, lo que representa un valor 5 veces superior a los cuantificados para las vitaminas E y C (Rice-Evans y Miller, 1998; Martínez-Florez et al, 2002). Diversos polifenoles, entre los que se incluye la quercetina y sus derivados glicosilados, son capaces de inhibir in vitro la peroxidación lipídica en diversos sistemas biológicos: lipoproteínas (Nigdikar et al, 1998), liposomas (Ioku et al, 1995), hepatocitos en cultivos celulares (Sugihara et al, 1999) y membranas de eritrocitos (Tedesco et al, 2000; Araya et al, 2001).

\subsubsection{Propiedades de quelación}

Una propiedad que contribuye a incrementar la actividad antioxidante de los flavonoides es la quelación, proceso por el cuál los iones metálicos son captados por la molécula de flavonoide, lo que provoca su eliminación y/o 
neutralización del medio de reacción. Además, la quelación no produce necesariamente una inactivación del flavonoide, sino que el complejo final sigue poseyendo la capacidad de eliminar ROS, lo que en conjunto provoca una potenciación del efecto antioxidante del flavonoide frente al daño oxidativo (Afanas'ev et al, 1995).

Esta actividad quelante puede potenciar la capacidad antioxidante de los compuestos en situaciones patológicas asociadas al estrés oxidativo que conllevan sobrecargas de hierro. En ratas con elevadas tasas de este metal, se observa que la administración de rutina provoca una reducción significativa de la peroxidación de sus microsomas hepáticos, y una reducción de la producción de ROS por parte de sus fagocitos (Afanas'ev et al, 1995).

La reacción del ion ferroso con peróxido de hidrógeno genera el radical hidroxilo, el cual a su vez puede oxidar las biomoléculas vecinas. Este proceso se conoce como reacción de Fenton, y el radical hidroxilo producido está directamente relacionado con la concentración de hierro o cobre presente en el medio. La reacción de Fenton constituye una importante fuente generadora de ROS in vivo en estados patológicos, entre los que se incluyen sobrecargas de hierro o falta de captación del mismo por las proteínas transportadoras o de almacenaje. Tanto la quercetina como la rutina son agentes quelantes muy potentes de los metales de transición. Los flavonoides que portan estructuras con funciones 3', 4'-catecol y/o 4-oxo junto con 5-OH inhiben fuertemente la oxidación inducida por la reacción de Fenton. Los complejos de quelación con los cationes divalentes pueden formarse entre los grupos $5-\mathrm{OH}$ y 4-oxo, o bien entre los grupos hidroxilo de las posiciones 3' y 4' (Afanas'ev et al, 1995).

\subsubsection{Interacciones de los flavonoides con biomembranas}

La protección que otorgan los compuestos polifenólicos (los flavonoides en particular) frente al daño oxidativo celular, reside en su poder antioxidante, así como en su capacidad de incorporación, modo de distribución y forma de orientación en las membranas biológicas (Saija et al, 1995b; Arora et al, 2000; Areias et al, 2001; Hendrich, 2006). Tanto en sistemas liposómicos como en membranas biológicas, las características estructurales de los polifenoles determinan el grado de incorporación de éstos a las bicapas lipídicas (Scheidt et al, 2004). Los efectos que tiene su inserción dependerán en último término de su mayor o menor capacidad para introducirse en la célula, permaneciendo en 
la membrana o incorporándose al citosol (Oteiza et al, 2005). El grado de incorporación y la distribución del flavonoide en la membrana viene marcado por su coeficiente de reparto (hidrofobicidad/hidrofilicidad), que determinará el tipo de interacciones que éste establece con los componentes de la membrana, uniones de tipo electrostático, formación de puentes de hidrógeno con los grupos polares de los fosfolípidos, interacciones hidrofóbicas con las cadenas hidrocarbonadas de los ácidos grasos, influyendo también en el anclaje del flavonoide la geometría molecular de los fosfolípidos (Afanas'ev et al, 1989). A medida que se incrementa la formación de puentes de hidrógeno en el binomio flavonoide-membrana, el poder antioxidante del primero disminuye, mientras que el aumento de la flexibilidad conformacional del flavonoide incrementa su potencial antioxidante (Arora et al, 1998; Areias et al, 2001).

El anclaje de los flavonoides en las membranas conlleva cambios físicos en las mismas. Los flavonoides que se localizan en la región más profunda de la membrana ejercen un efecto de ordenamiento de la región hidrocarbonada de la bicapa lipídica, como consecuencia de las interacciones hidrofóbicas que se establecen entre la molécula del flavonoide y las cadenas hidrocarbonadas de los ácidos grasos, disminuyendo la fluidez de la bicapa (Arora et al, 2000; Oteiza et al, 2005). Este efecto se asemeja al que produce el aumento de colesterol en las bicapas lipídicas, lo que dificultará la difusión de los radicales libres a través de la membrana (Kagan et al, 1990; Arora et al, 2000; Barros et al, 2001; Hendrich, 2006), previniendo así el daño oxidativo celular que se observa in vivo en presencia de antioxidantes lipofílicos (Zhang et al, 2006). Los flavonoides de naturaleza hidrofílica se sitúan en la superficie de la membrana (interfase lípido-agua) mediante el establecimiento de puentes de hidrógeno principalmente, estableciéndose también interacciones de tipo iónico con las cabezas polares de los fosfolípidos (Saija et al, 1995b; Scheidt et al, 2004; Oteiza et al, 2005).

La incorporación de los polifenoles a las membranas también puede modificar su permeabilidad, y por tanto, alterar sus funciones como barrera biológica (Saija et al, 1995a; Saija et al, 1995b). El aumento de la hidrofobicidad del antioxidante produce un incremento en la permeabilidad de la membrana, como se ha puesto de manifiesto en estudios efectuados con ácidos cinámico y $p$-cumárico con técnicas de calorimetría diferencial de barrido (Castelli et al, 1999). En otros casos se ha observado que la presencia del antioxidante, floretina, que se localiza en la región polar de la bicapa lipídica 
también incrementa la permeabilidad de la membrana (Tarahovsky et al, 2008). Otros estudios indican que la incorporación del flavonoide a la membrana modifica su potencial redox (Ollila, 2002).

La quercetina se incorpora de forma eficiente en la membrana, anclándose en la región hidrofóbica de la misma cuando dicho flavonoide presenta un carácter apolar predominante (Nakayama et al, 1998). Su anclaje en la membrana eritrocitaria provoca un aumento en la deformación del eritrocito (Begum y Terao, 2002). La localización de este flavonoide en las bicapas lipídicas viene determinada por el $\mathrm{pH}$ del medio, como se ha demostrado en estudios llevados a cabo en bicapas lipídicas planares. A pH ácido, la quercetina se encuentra en estado protonado, mostrando un carácter lipofílico que le permite insertarse profundamente en la membrana, mientras que en medios básicos, la quercetina desprotonada se localiza preferentemente en dominios hidrofílicos de la membrana. A pH fisiológico, en general, la quercetina se sitúa mayoritariamente en un entorno lípido-agua, que corresponde a la zona polar de la bicapa lipídica (Movileanu et al, 2000). Estudios llevados a cabo en eritrocitos con técnicas de resonancia de espín electrónico demuestran que la quercetina en las condiciones experimentales de dicho estudio se localiza en la interfase polar-apolar de la membrana eritrocitaria, protegiéndola del daño oxidativo (Pawlikowska-Pawlega et al, 2003; Pawlikowska-Pawlega et al, 2007). Sin embargo, estudios de microscopia de fluorescencia en líneas celulares de fibroblastos de piel humana demuestran múltiples localizaciones de este flavonol, con presencia en la membrana, el citosol y el interior del núcleo, con alteraciones destacadas en estas estructuras como consecuencia de la incorporación del antioxidante (Pawlikowska-Pawlega et al, 2007).

La rutina, debido a su estado glicosilado, es más hidrofílica que la quercetina, y por tanto, menos accesible a la membrana, otro motivo al que se deberá su menor efectividad en la prevención del daño oxidativo (Kaneko et al, 1994). Otros autores consideran que ni siquiera interacciona superficialmente con la bicapa lipídica (Ratty et al, 1988), mientras que en estudios efectuados con liposomas se considera que la rutina se sitúa en la región hidrofóbica de la bicapa lipídica, provocando la pérdida de fluidez (Arora et al, 2000). 


\subsubsection{Propiedades pro-oxidantes de los flavonoides}

Recientemente se ha observado que los polifenoles en general, y los flavonoides en particular, además de ser capaces de captar radicales libres, y por tanto actuar como antioxidantes, también pueden llevar a cabo reacciones pro-oxidantes, ejerciendo efectos citotóxicos sobre células y tejidos (Kondo et al, 1999).

La actividad pro-oxidante puede estar relacionada directamente con el número total de grupos hidroxilo presentes en la molécula. Así, mientras mono y di-hidroxiflavonoides no muestran actividad pro-oxidante detectable, la presencia de múltiples grupos hidroxilo en estas clases de moléculas, especialmente en el anillo $B$, aumenta significativamente la producción de radicales hidroxilo en sistemas Fenton. Compuestos con variedad de grupos hidroxilo, como la miricetina y la baiceleína, ambos con una estructura pirogalol en su anillo $A$, han sido descritos como promotores de la producción de peróxido de hidrógeno, el cuál puede participar en la reacción de Fenton generando radicales hidroxilo altamente reactivos (Hanasaki et al, 1994).

Este efecto pro-oxidante es el responsable de la citotoxicidad y del efecto proapoptótico que presentan los flavonoides aislados de algunas hierbas medicinales. En presencia de RNS, los flavonoides con un pirogalol en el anillo $\mathrm{A}$ o $B$ inducen la rotura del DNA de cadena simple. Los que poseen un catecol en el anillo $B$ pueden auto-oxidarse en presencia de metales de transición, produciendo ROS que aceleran la oxidación de las lipoproteínas de baja densidad (LDL) (Ahmad et al, 1992). También hay evidencias de que la instauración en 2-3 y la función 4-oxo de las flavonas pueden promover la formación de ROS inducida por $\mathrm{Cu}^{2+}$ en presencia de oxígeno. Todos estos datos indican que algunos de los motivos estructurales que optimizan la capacidad antioxidante, pueden también exacerbar el estrés y el daño oxidativo hacia las biomoléculas y la estructura-función celular. Aunque el radical flavonoide puede tener carácter pro-oxidante, sin embargo, dada la estabilidad y la capacidad de deslocalización electrónica que presenta su molécula, sus efectos oxidativos adversos serán de carácter menos nocivo que el que muestran los radicales libres.

En el caso concreto de la quercetina, ésta se transforma en un producto de oxidación relativamente estable después de la eliminación de especies 
altamente reactivas, dando lugar a la formación de una orto-quinona/metilquinona, que es muy reactiva con grupos tioles, y por lo tanto tóxica. La forma oxidada de la quercetina reacciona con el GSH formando productos glutationquercetina no tóxicos (Boots et al, 2005). La actividad pro-oxidante de la quercetina parece atenuarse por la formación de metabolitos metilados. Los metabolitos catecol- $O$-metilados de quercetina pueden unirse covalentemente al DNA (Galati y O'brien, 2004; van der Woude et al, 2006). La oxidación de la quercetina no siempre conduce a la formación de un intermediario orto-quinona de carácter potencialmente pro-oxidante. Otros metabolitos generados durante su oxidación podrían aportar dicho carácter pro-oxidante (van der Woude et al, 2006).

Además de la metilación, la glicosilación de los grupos $\mathrm{OH}$ también atenúa el comportamiento pro-oxidante de los flavonoides (Heim et al, 2002). Los efectos adversos de los flavonoides pueden ser mitigados in vivo por la catecol- $O$-metiltransferasa (COMT) y por otras metiltransferasas hepáticas (van der Woude et al, 2006).

Se sabe que ciertos flavonoides pueden transformar su acción antioxidante por otra pro-oxidante bajo ciertas condiciones, como por ejemplo un cambio en la razón molar de iones metálicos y un descenso del potencial redox de los complejos flavonoide-metal. La presencia del catión divalente de hierro puede acelerar el efecto pro-oxidante in vivo (Galati y O'brien, 2004; Teixeira et al, 2005)

La acción pro-oxidante de los flavonoides parece que es dependiente de su concentración. Elevadas dosis de estos compuestos podrían ser tóxicas y mutagénicas, de forma que un exceso en su consumo por parte de los mamíferos podría causar reacciones metabólicas adversas (Brusick, 1993; Alía et al, 2006a). En cambio, el resveratrol a bajas concentraciones puede potenciar la apoptosis en células leucémicas humanas mediante su acción prooxidante (Ahmad et al, 2003; Ahmad et al, 2004). De hecho, algunos autores postulan que los antioxidantes a bajas concentraciones pueden reducir los metales de transición, lo que les permite inducir el estrés oxidativo (Teixeira et al, 2005) 


\subsubsection{Otras actividades biológicas}

El interés de los flavonoides en la medicina ha ido creciendo con el paso de los años debido a sus múltiples y variadas propiedades. En un principio se estableció que sus cualidades beneficiosas eran debidas a su gran poder como agentes antioxidantes, capaces de eliminar radicales libres e incluso capaces de evitar su formación mediante la quelación de metales de transición. Posteriormente se descubrió su lado oscuro como agentes pro-oxidantes, capaces de provocar daño oxidativo, pero se comprobó que incluso esta actividad pro-oxidante podría ser de gran ayuda en algunos casos, como en la eliminación de células cancerosas, por promoción de la apoptosis o muerte celular de dichas células. Hoy en día se sabe también que los flavonoides no sólo actúan como antioxidantes o quelantes de metales de transición, sino que también son capaces de actuar como moduladores de diversa rutas de señalización celular, activándolas o inhibiéndolas (Havsteen, 2002). De hecho, algunos autores proponen que el efecto beneficioso de los flavonoides para la salud reside en la capacidad de sus metabolitos generados para modular ciertas rutas de señalización celular, más que en su poder supresor de radicales libres (Formica y Regelson, 1995).

1) Moduladores de la actividad enzimática. Implicaciones en los sistemas de señalización celular

Los flavonoides son capaces de inhibir gran cantidad de enzimas entre las que se incluyen hidrolasas, oxidorreductasas, DNA-sintetasas, RNApolimerasas, fosfatasas, proteín-fosfoquinasas, oxigenasas y aminoácido oxidasas. En algunos casos ejercen inhibiciones de tipo competitivo, aunque más frecuentemente suelen ser de tipo alostérico (Havsteen, 2002).

Se ha observado que son inhibidores de NADH oxidasa, de un modo preferente las estructuras flavonoides que poseen doble enlace en posición 2,3 y que portan además la función 4-oxo e hidroxilos en $3^{\prime}, 4^{\prime}$, y 5' en el anillo B. Algunos flavonoides también inhiben la enzima xantin-oxidasa, que cataliza la oxidación de xantina e hipoxantina en ácido úrico, generándose en el proceso tanto radicales superóxido como peróxido de hidrógeno. Las flavonas muestran más actividad inhibidora de xantin-oxidasa que los flavonoles, y gracias a los hidroxilos tanto en posición 3 como en $3^{\prime}$ también poseen una gran actividad eliminadora de radicales superóxido (Harborne y Williams, 2000). 
La inhibición que ejercen los flavonoides sobre las oxidorreductasas se debe a la similitud estructural existente entre los flavonoides y las coenzimas del tipo nucleotídico requeridas por las oxidorreductasas para su funcionamiento. En algunos casos, los flavonoides compiten con las coenzimas nucleotídicas por la unión al sitio activo de la enzima, y en otros interfieren directamente con el estado de transición enzima-coenzima-sustrato (Havsteen, 2002).

Dentro del grupo de las hidrolasas, los flavonoides inhiben la fosfolipasa $A_{2}$, lo que conlleva una inhibición de las rutas de síntesis de compuestos eicosanoides, estando por tanto implicados en la regulación de los procesos inflamatorios (Havsteen, 2002). Las fosfatasas ácidas o alcalinas, así como las pirofosfatasas pueden ser inhibidas o activadas según la naturaleza del flavonoide y su tipo de entorno (Ait-Si-Ali et al, 1998).

La acción de los flavonoides sobre las quinasas es de especial relevancia, ya que dichas enzimas están involucradas en diversos procesos metabólicos y en rutas de señalización celular (Havsteen, 2002).

Los flavonoides compiten por los sitios de unión del ATP a ciertas proteínas, incluidas la ATPasa mitocondrial, la ATPasa dependiente de calcio de la membrana plasmática, las proteín-quinasas A y C y la topoisomerasa. Este tipo de inhibición mediante la adhesión a sitios de unión del ATP, provoca un cambio estructural en la conformación tridimensional de la proteína, que la convierte en una forma inactiva. Además se han descrito interacciones de estos compuestos con los sitios de unión de benzodiacepinas en los receptores GABAA y en los receptores de adenosina. Los flavonoides también pueden interaccionar con la mitocondria, interfiriendo en las rutas del metabolismo intermediario (Williams et al, 2004).

Muchos de los efectos biológicos de los flavonoides están relacionados con su capacidad para modular rutas que regulan numerosos procesos en la célula, como el crecimiento, la proliferación y la muerte celular. Sin embargo, estos efectores suelen ser formas metabólicamente modificadas del flavonoide nativo, que en estado circulante son captados, y a veces de nuevo modificados in situ por las propias células diana. Dichos compuestos actúan sobre proteínquinasas y lípido-quinasas, sobre la 3-fosfoinositido-quinasa, la Akt/PKB, la tirosin-quinasa, la proteín-quinasa $C$ y las MAP quinasas, enzimas implicadas en 
diversas rutas de señalización celular. Su acción inhibidora o estimuladora de estas rutas se ejerce a concentraciones considerablemente mas bajas que las que se requieren para ejercer su acción antioxidante, afectando profundamente la función celular al alterar el estado de fosforilación de las moléculas diana y al modular la expresión génica (Havsteen, 2002).

Los flavonoides que inhiben la apoptosis inducida por el estrés oxidativo, pueden ejercer su acción previniendo la activación de las quinasas jun $\mathrm{N}$ terminal (JNK), posiblemente a través de la influencia sobre alguna de las numerosas proteínas que activan las MAP quinasa quinasa quinasa (MAPKKK), que transducen a su vez señales a las JNK. Alternativamente también pueden actuar manteniendo la homeostasis del calcio, ión implicado en la activación de las MAP-quinasas. También pueden interaccionar directamente con la mitocondria, modulando el poro de transición mitocondrial, que controla la liberación del citocromo $\mathrm{C}$ durante la apoptosis, o modulando otros factores proapoptóticos asociados a la mitocondria, como el DIABLO/smac (Schroeter et al, 2002).

\section{2) Acciones mutagénica y cancerígena}

Cierto tipo de flavonoles como la quercetina, la miricetina, y el kaempferol, han mostrado resultados positivos de mutagenicidad con el test de Ames. La mutagenicidad parece estar asociada con la presencia de un doble enlace en posición 2-3 y de un grupo 3-OH en la molécula del flavonoide.

Sin embargo, la actividad cancerígena reside en los intermediarios quinónicos generados durante la oxidación del flavonoide, los cuáles interaccionan con las moléculas de DNA. Estas quinonas, por su carácter electrófilo, son muy reactivas y pueden participar en la producción de radicales superóxidos y peróxidos, lo que explicaría sus propiedades mutagénicas y cancerígenas (Havsteen, 2002).

\section{3) Acción anticancerígena}

Las propiedades quimiopreventivas de los flavonoides pueden residir en su actividad eliminadora de ROS endógenos, ejerciendo así un efecto anticancerígeno. La acción pro-oxidante de los flavonoides también puede constituir un importante mecanismo para ejercer sus propiedades 
anticancerígenas, a través de la fragmentación apoptótica del DNA inducida por los ROS generados durante la oxidación, lo que conlleva a la apoptosis celular (Galati y O'brien, 2004). En células de melanoma se ha puesto de manifiesto que la quercetina aporta actividad pro-oxidante, debido a su transformación en especies reactivas de quinona por la acción de la tirosinasa, lo que ocasiona aumentos significativos de los niveles basales de ROS, incrementándose la apoptosis celular (Thangasamy et al, 2007)

Los flavonoides pueden interferir en varios de los pasos que conducen al desarrollo de tumores malignos, favoreciendo la protección del DNA contra el daño oxidativo, desactivando las sustancias carcinogénicas y activando los sistemas de destoxificación de estas sustancias (Galati y O'brien, 2004).

El poder anticancerígeno del flavonoide puede residir en su intervención en alguno de los siguientes puntos:

1. Estimulando el proceso enzimático (fase II) responsable de la desintoxicación. Los flavonoides serían agonistas de las enzimas que catalizan las reacciones que promueven la excreción de productos químicos potencialmente tóxicos o carcinogénicos.

2. Preservando el ciclo celular, y activando las rutas de apoptosis si el daño producido durante la replicación del DNA es irreparable.

3. Inhibiendo la proliferación celular y activando la apoptosis. En células humanas de cáncer mamario se observa que la apigenina inhibe el proteosoma e induce la apoptosis celular (Chen et al, 2007).

4. Suprimiendo la angiogénesis, lo que conduce a un bloqueo de la invasión tumoral, potenciado por la inhibición de las metaloproteasas a través de los flavonoides.

5. Disminuyendo la inflamación mediante un descenso en la producción de prostaglandinas, a través de la inhibición de la fosfolipasa $A_{2}$ y las ciclooxigenasas. La inflamación puede ocasionar un incremento local de radicales libres, así como la producción de mediadores que promueven la proliferación celular y la angiogénesis en el tumor, con inhibición simultánea de la apoptosis (Havsteen, 2002). 


\section{4) Acciones antihipertensiva y antiaterogénica}

Los flavonoides pueden influir en el proceso de mantenimiento de la presión arterial, inhibiendo la fosfodiesterasa (PDE), enzima responsable de la hidrólisis del AMPc. El descenso en los niveles de AMPc ocasiona una disminución del volumen plasmático, y por lo tanto de la presión arterial, como consecuencia de la pérdida de agua a través de la orina. Los agentes antihipertensivos más potentes de origen flavónico son los compuestos sintéticos hidrosolubles hidroxietil-rutósidos.

Los flavonoides pueden actuar también estimulando la hidroxilación de hormonas esteroideas, como la aldosterona, a través de oxigenasas, inhibiendo la hormona, lo que ocasiona pérdidas de $\mathrm{Na}^{+}$(hiponatremia) y agua a través de la orina, con descenso del volumen plasmático y disminución de la presión sanguínea (Havsteen et al, 2002).

Se ha demostrado que los flavonoides inhiben la oxidación de las proteínas de baja densidad (LDL) in vitro. En presencia de vino, como fuente de antioxidantes, se observa una inhibición de la oxidación de las LDL catalizada por cobre. Los flavonoides procedentes del té negro y del té verde añadidos directamente al medio de reacción también son capaces de inhibir la peroxidación lipídica inducida por radicales libres en LDL purificadas (Riemersma et al, 2001). Compuestos con alto poder antioxidante, como el $\alpha$ tocoferol, muestran una capacidad de protección frente al estrés oxidativo inferior (alrededor del $60 \%$ menor) al aportado por dietas ricas en polifenoles, a través de la ingesta de vino. De hecho, diversos estudios epidemiológicos han puesto de manifiesto que existe una correlación positiva entre la ingesta de grasas y la mortalidad asociada a procesos cardiovasculares en las poblaciones occidentales. Sin embargo, esta aseveración no se corresponde con lo detectado en las poblaciones de algunas regiones de Francia, que muestran alta ingesta de grasas y baja mortalidad asociada a enfermedades cardiovasculares, lo que se conoce como "paradoja francesa". Este fenómeno se explica por la toma regular de vino tinto en la dieta de estas poblaciones, lo que debe preservar a las LDL plasmáticas de los procesos oxidativos habituales ante la presencia de polifenoles procedentes del vino, debido a sus propiedades antiaterogénicas. Es sabido que las LDL plasmáticas oxidadas son las inductoras de la formación de la placa fibroadiposa (ateroma), dando así lugar a la aparición de enfermedades cardiovasculares y cerebrales (Harborne y Williams, 
2000). Estudios llevados a cabo por Jiménez et al (2007), corroboran que el tratamiento crónico de ratas con polifenoles procedentes del vino tinto, previene la hipertensión y la disfunción vascular.

\section{5) Efectos protectores sobre el sistema nervioso central y células relacionadas}

Estudios epidemiológicos y dietéticos llevados a cabo en humanos y en animales de experimentación muestran que los flavonoides pueden jugar un papel preventivo en los procesos neurodegenerativos, especialmente los asociados al área cognitiva. También pueden ejercer una protección frente al estrés oxidativo y el daño cerebral producido por situaciones de isquemia/reperfusión. Ensayos en humanos usando flavonoides procedentes de extractos de plantas del tipo Gingo biloba, o preparaciones puras de flavonoides, muestran efectos positivos en los desarrollos de las funciones cognitivas y de la memoria en grupos de voluntarios sanos de todas las edades, al igual que en pacientes con Alzheimer. También se ha propuesto que la acción antioxidante de los flavonoides puede ser beneficiosa en enfermedades como el Parkinson, en situaciones de hipoxia/isquemia y en apoplejías, incluso pueden aumentar la supervivencia en cánceres de cerebro, y en general, pueden frenar los procesos neurodegenerativos relacionadas con la edad (Havsteen, 2002). Estudios in vivo llevados a cabo en animales de experimentación han mostrado que la epicatequina y la quercetina ejercen un efecto protector contra el daño neuronal inducido por procesos de isquemia/reperfusión. Estos flavonoides también aportan protección contra la peroxidación lipídica producida en el cerebro en ausencia de vitamina $\mathrm{E}$, y atenúan la neurotoxicidad inducida por la administración de etanol (Schroeter et al, 2002).

Recientemente se ha demostrado que la aplicación a neuronas del estrato primario de concentraciones micromolares de epicatequina 0 kaempferol, previa al tratamiento con las LDL oxidadas, protege dichas células de la muerte neuronal, inhibiendo la unión de anexina- $V$, la activación de la caspasa 3 y la fragmentación del DNA. Este pre-tratamiento no impide el incremento de estrés oxidativo inducido en la neurona por las LDL oxidadas, pero sí inhibe potentemente la activación de JNK, c-Jun (proteína que en combinación con otra, c-Fos, forma el factor de transcripción AP-1) y la caspasa 3 (Schroeter et al, 2002). 


\section{6) Otras actividades}

A los polifenoles se les atribuyen también propiedades termogénicas (Dulloo et al, 1999), antiulcerogénicas (Harborne y Williams, 2000), antiinflamatorias, antitrombóticas, vasodilatadoras, antimicrobianas, antialérgicas y antivirales (Havsteen et al, 2002). 
CAPÍTULO II: Objetivos 

Las células están sometidas a una agresión permanente por las especies reactivas de oxígeno (ROS) que se generan en el medio celular como consecuencia del metabolismo aerobio, o por las actuaciones de ciertas enzimas como oxidasas, deshidrogenasas y peroxidasas. Agentes externos como las radiaciones, el humo de diversas procedencias, los disolventes, los pesticidas, el ozono, así como determinados contaminantes, pueden contribuir en el organismo a la generación de ROS y otros tipos de radicales. Estos radicales pueden dañar las estructuras celulares a través de la oxidación de las proteínas, los lípidos y los ácidos nucleicos, siendo la membrana plasmática una estructura celular sumamente susceptible al estrés oxidativo generado. Las alteraciones de los lípidos y las proteínas conllevan una desorganización estructural de la membrana y cambios importantes en sus propiedades físicas y funcionales (Slater, 1984; Halliwell y Gutteridge, 1999). Dichas alteraciones son responsables de diversos procesos patológicos, como algunas enfermedades neurodegenerativas, el cáncer y las patologías cardiovasculares (Halliwell y Gutteridge, 1999). Sin embargo, la generación controlada de ROS también se vincula con determinados procesos que tienen lugar en la célula, como la fagocitosis y el envejecimiento celular (Choi y Yu, 1995), la apoptosis (Matsura et al, 2002), o la participación en rutas de señalización implicadas en procesos de diferenciación celular (Tsatmali et al, 2006; Buggisch et al, 2007).

Las células, y el eritrocito de forma particular, disponen de mecanismos de protección para evitar la acción de los radicales libres mediante sistemas enzimáticos y compuestos que secuestran dichos radicales, como el GSH, los tocoferoles o el ascorbato (Rice-Evans, 1990). Diversos compuestos naturales y de carácter sintético pueden cumplir esta misma misión, en especial aquellas moléculas que portan un anillo aromático con al menos un grupo hidroxilo en su molécula, los compuestos fenólicos. Estos compuestos tienen amplia distribución en la naturaleza, en especial los compuestos polifenólicos, que son actualmente objeto de múltiples estudios, dada la importancia que tienen en la prevención del daño oxidativo desencadenado por radicales libres. Los flavonoides forman parte del grupo de los polifenoles, y están ampliamente representados en los organismos fotosintéticos, formando parte de los componentes de la dieta. Estos compuestos están dotados de un alto poder antioxidante, atribuyéndoseles además un amplio número de actividades biológicas adicionales (Rice-Evans et al, 1996; Afanas'ev et al, 1989; Lien et al, 1999). Su poder antioxidante, así como otras propiedades inherentes a estos compuestos son estrictamente dependientes de su grado de incorporación, 
distribución y orientación en las membranas biológicas, lo que viene marcado por la composición y estructura de la propia membrana, dadas las interacciones que se establecen entre el flavonoide y los componentes de la membrana (Arora et al, 2000; Saija et al, 1995b; Scheidt et al, 2004; Oteiza et al, 2005; Hendrich, 2006). Estudios previos llevados a cabo en nuestro grupo han puesto de manifiesto que la modificación de los contenidos de colesterol en el eritrocito producen modificaciones en el estado físico de la membrana e incrementan la exteriorización de los aminofosfolípidos, alterando la morfología y la integridad celular, lo que hace al eritrocito más susceptible al daño oxidativo (LópezRevuelta et al, 2005; López-Revuelta et al, 2007). Nuestra hipótesis de trabajo en este estudio se sustenta en la alteración estructural y física que sufre la célula ante la modificación de los contenidos de colesterol de su membrana plasmática, lo que debe repercutir en la incorporación del flavonoide, y por tanto, en el grado de protección que otorgan éste y otros antioxidantes a la célula frente al daño oxidativo inducido por radicales libres, estudios sobre los que desconocemos que existan datos previos. Con el fin de verificar la citada hipótesis de trabajo se ha utilizado un modelo experimental bien conocido en nuestro grupo de investigación, el eritrocito. Se trata de una célula fácilmente modificable en sus contenidos de colesterol, y sumamente sensible al ataque por ROS, induciendo el proceso oxidativo mediante tratamiento del eritrocito con hidroperóxido de ter-butilo (tBHP). Como antioxidante se ha elegido la quercetina, compuesto con alta representación en la dieta, que aporta gran protección frente al daño oxidativo en nuestro modelo experimental, como demostraron nuestros estudios preliminares. En paralelo se han efectuado análisis con su glucósido rutina, cuyo estudio ha aportado información adicional.

Por tanto, la investigación propuesta se concreta en el siguiente OBJETIVO GENERAL: "Analizar la influencia que ejerce la modificación de los contenidos de colesterol en la membrana sobre la protección otorgada por la quercetina y la rutina frente a las alteraciones estructurales y funcionales que sufre el eritrocito sometido a estrés oxidativo", circunscribiéndose el estudio a los siguientes 


\section{OBJETIVOS ESPECÍFICOS:}

1. Estudiar las alteraciones estructurales y funcionales que provocan la incorporación de quercetina y rutina en ausencia de oxidación en los eritrocitos controles y modificados.

2. Determinar el grado de protección que otorgan ambos antioxidantes frente a la generación de ROS y a la peroxidación, con un análisis complementario de la composición lipídica en los diferentes tipos de eritrocitos oxidados.

3. Analizar la protección que aportan ambos antioxidantes frente a los cambios estructurales (distribución de aminofosfolípidos y estado de fluidez de la membrana) mostrados por los distintos tipos de eritrocitos oxidados.

4. Explorar algunos aspectos relacionados con la viabilidad e integridad celular (grado de hemólisis, estabilidad isotónica, contenidos en GSH y hemoglobina, eritrofagocitosis y morfología) en los eritrocitos controles y modificados oxidados en presencia de ambos antioxidantes. 


\section{CAPÍTULO III: Materiales y Métodos}





\section{APARATOS Y MATERIALES}

Agitador de bolsas SBS ABT-5.

Agitador orbital SBS modelo AN-1.

Agitador de plataforma para placas Grant Boekel "BFR25".

Autoclave Selecta "Autotester-G".

Baños termorregulables SBS TFB serie B y Memmert con sistema de agitación incorporado.

Balanzas analítica Precisa "40SM-200a y granataria Cobos "modelo 201".

Bomba peristáltica Ismatec "MS-REGLO".

- Campana de flujo laminar Gelaire "TC48".

+ Cámara de video digital Olympus "DP170" adaptada a un microscopio invertido de fluorescencia.

Cámara digital Nikon "Coolpix 4300".

+ Centrífugas: Beckman "Allegra 21R" y "J2-21M"; Heraeus Sepatech "Omnifuge 2.0 RS"; Kubota "KR-1500".

Citómetro FACScalibur (Becton Dickinson, San Jose, CA, USA) del

Servicio de Citometría de Flujo de la Universidad de Salamanca.

+ Congeladores de $-20^{\circ} \mathrm{C}$ y $-80^{\circ} \mathrm{C}$.

+ Contenedor de nitrógeno líquido ThermoForma "CryoPlus 3".

+ Cromatógrafo de gases Shimadzu "GC 17A" acoplado a un espectrómetro de masas Shimadzu "MS QP 5000" del Servicio General de Espectrometría de Masas de la Universidad de Salamanca.

Equipo para cromatografía en capa fina.

Espectrofluorímetro Hitachi F-4010.

Espectrofotómetros Novaspec II LKB 4040 e Hitachi U-2000.

+ Fluorímetro Flouoroskan ascent FL equipado para lectura de placas.

Frigoríficos y cámaras frías.

Incubadores para cultivos celulares Heraeus "CO - -AUTO-ZERO" y

Shellab.

Microscopio invertido Nikon "TMS".

Ordenadores PC compatibles.

Rotavapor Büchi "R-200".

+ Termobloc Liebisch.

Ultracentrífuga Beckman Optima XL-100K.

Materiales para cultivos celulares. Otros aparatos de uso frecuente en el laboratorio: agitadores, pipetas automáticas, estufas, pH-metro, etc. Materiales de vidrio y plástico. 


\section{REACTIVOS}

Los siguientes productos fueron suministrados por Sigma Chemical Co (Sigma-Aldrich-Química, Madrid, España): ácido tiobarbitúrico (TBA), ácido N[2-hidroxietil]piperacina- $\mathrm{N}$ '-[2-etanosulfónico] (HEPES), adenina, anexina $\mathrm{V}$ procedente de placenta humana, anexina $\mathrm{V}$ conjugada con isotiocianato de fluoresceína (anexina V-FITC), azida sódica, 3-t-butil-4-hidroxianisolona (BHA), ciclodextrinas $[\beta$-ciclodextrina (BCD) y metil- $\beta$-ciclodextrina (MBCD)], colesterol, diacetato de diclorofluoresceína (DCFDA), dimetil sulfóxido (DMSO), 5-5'dithio-bis(2-ácido nitrobenzoico) (DTNB), 3-3'dimetoxibencidina, fluoruro de fenil-metil-sulfonilo (PMSF), formaldehído, fosfolipasa $A_{2}$ procedente de veneno de abeja, glutation reducido (GSH), hemoglobina, hidroperóxido de ter-butilo (tBHP), hidroxitolueno butilado (BHT), lauril sulfato sódico (SDS), patrones de fosfolípidos y ácidos grasos, polivinilpirrolidona (PVP), polioxietileno-23-lauril éter (Brij 35), quercetina, rutina, seroalbúmina bovina (BSA), tris[hidroximetil] aminometano (TRIS) y 1-[4-(trimetilamonio)-fenil]-1,3,4-hexatrieno (TMA$\mathrm{DPH})$.

Productos suministrados por Merck (Merck Farma y Química, Barcelona, España): $\beta$-mercaptoetanol, isooctano, malonildialdehídobis (dietilacetal), placas para cromatografía en capa fina (TLC) (Silicagel G60 de 10×20 cm, 0,25 mm de espesor). Los reactivos $\mathrm{BF}_{3}$-metanol y "Phospray" procedían de Supelco Inc. (Sigma-Aldrich-Química, Madrid, España). El ditionito sódico y el glutaraldehído $25 \%$ fueron proporcionados por Fluka (Fluka Chemie $\mathrm{GmbH}$, Buchs, Switzerland). Reactivos para cultivos celulares procedentes de BioWhittaker (Walkersville, MD, USA): L-Glutamina (200 mM en $\mathrm{NaCl}$ 0,85\%), medio RPMI 1640 sin L-glutamina, penicilina-estreptomicina (penicilina $5000 \mathrm{U} / \mathrm{ml}$ estreptomicina $5000 \mu \mathrm{g} / \mathrm{ml}$ ), suero bovino fetal (BSF). Otros reactivos procedían de diversas casas comerciales: 1-palmitoil-2-[6-[(7-nitro-2-1,3-benzoxadiazol-4il)amino]hexanoil]-sn-glycero-3-phosphoserine (NBD-PS) de Avanti Polar Lipids, Inc. (Alabaster, AL, USA), 1,6-difenil-1,3,5-hexatrieno (DPH) de Aldrich (SigmaAldrich-Química, Madrid, España), solución de azur-eosina-azul de metileno según Giemsa de Panreac (Barcelona, España). El resto de los reactivos comunes utilizados fueron proporcionados por Panreac (Barcelona, España).

Los disolventes orgánicos cloroformo y metanol, de origen comercial, e isopropanol y éter de petróleo, procedentes de Panreac, fueron destilados antes de su utilización. 


\section{MUESTRAS}

La experimentación se ha llevado a cabo con conejos (Oryctolagus cuniculus) machos, adultos de más de 2 meses de edad, de raza albina neozelandesa. Los animales se han mantenido estabulados en el Servicio de Experimentación Animal de la Universidad de Salamanca en jaulas individuales a temperatura de $20-22^{\circ} \mathrm{C}$, con periodos de luz-oscuridad de $12 \mathrm{~h}$, con libre acceso tanto a la comida como al agua de bebida. La alimentación se ha realizado con una dieta estándar para conejos (Panlab S.L., Barcelona, España).

Los estudios se han llevado a cabo con la sangre de estos animales, que ha sido extraída mediante punción de la arteria mayor de la oreja, recogiéndose, generalmente, $25 \mathrm{ml}$ de la misma sobre $3,5 \mathrm{ml}$ de anticoagulante citrato/fosfato/glucosa/adenina (CPD- $\left.A_{1}\right)(15 \mathrm{mM}$ ácido cítrico, $88 \mathrm{mM}$ citrato sódico, $16 \mathrm{mM}$ fosfato monosódico, $140 \mathrm{mM}$ glucosa y $2 \mathrm{mM}$ adenina) (Scott y Slichter, 1980), en tubos "Falcon" de $50 \mathrm{ml}$ de capacidad.

\section{MÉTODOS}

\subsection{OBTENCIÓN DE LOS ERITROCITOS}

La sangre recogida en las condiciones especificadas en el apartado 3 de este capítulo, se centrifugó a $200 \times \mathrm{g}$ durante 15 min para sedimentar los eritrocitos y separarlos del plasma rico en plaquetas y leucocitos. Se obtuvo de este modo un plasma rico en plaquetas (PRP), situado en la parte superior, que fue desechado. Los eritrocitos, que ocupan la parte inferior del tubo, fueron lavados dos veces consecutivas con 3 volúmenes de una disolución de fosfato sódico $5 \mathrm{mM}, \mathrm{NaCl} 150 \mathrm{mM}$, pH 7.5 (disolución PBS) a 700 x g durante 6 min. Finalmente se realizó un último lavado de los eritrocitos con la disolución de PBS a $2.500 \times \mathrm{g}$ durante $5 \mathrm{~min}$ para lograr la compactación total de los eritrocitos. 


\subsection{MODIFICACIÓN DE LOS CONTENIDOS DE COLESTEROL EN LOS ERITROCITOS}

\subsubsection{Enriquecimiento en colesterol}

El procedimiento utilizado se basa en el empleo de polivinilpirrolidona (PVP), sustancia conocida por su capacidad para expandir la membrana e incorporar compuestos hidrofóbicos de diversa índole (Shinitzky et al, 1979; Sánchez-Yagüe et al, 1987).

El medio de enriquecimiento corresponde al sobrenadante obtenido al centrifugar a $3.000 \times \mathrm{g}$ durante $10 \mathrm{~min}$ una disolución de colesterol $(5 \mathrm{mg} / \mathrm{ml}$ de etanol) diluida 10 veces con la suspensión de PVP (disolución de fosfato sódico $10 \mathrm{mM}, \mathrm{NaCl} 140 \mathrm{mM}$, glucosa $0,2 \%$ y BSA 0,05\% que contiene 3,5\% de $\mathrm{PVP}, \mathrm{p} / \mathrm{v})$, previamente agitada.

El enriquecimiento fue llevado a cabo según indican López-Revuelta et al (2005). Los eritrocitos al $10 \%$ de hematocrito (4 ml de hematocrito al 100\%) fueron incubados con agitación (en un agitador de bolsas SBS ABT-5) en el medio de enriquecimiento $(36 \mathrm{ml}$ ) a temperatura ambiente durante $4 \mathrm{~h}$. Como control, se utilizaron eritrocitos dispersos en la suspensión de PVP (exenta de colesterol), en condiciones idénticas a las descritas para incorporar el colesterol. Los eritrocitos tratados fueron posteriormente sedimentados a $1.000 \times \mathrm{g}$ durante $5 \mathrm{~min}$, recogiéndose una alícuota del sobrenadante para determinar la hemólisis (véase apartado 4.7.1 de este capítulo) producida durante los tratamientos. Con el fin de eliminar las disoluciones de transferencia, los eritrocitos fueron lavados con una disolución de PBS a $1.000 \times \mathrm{g}$ durante $5 \mathrm{~min}$, y posteriormente a 2.500 x g $5 \mathrm{~min}$, obteniéndose así los eritrocitos controles y enriquecidos en colesterol al $100 \%$ de hematocrito.

\subsubsection{Empobrecimiento en colesterol}

El procedimiento utilizado es una modificación de las metodologías descritas por Ohtani et al (1989) y Niu et al (2002). Los eritrocitos (13\% hematocrito) fueron incubados con $5 \mathrm{mM}$ de ciclodextrinas [ $\beta$-ciclodextrina (BCD) o metil- $\beta$-ciclodextrina (MBCD)] a $37^{\circ} \mathrm{C}$ durante una hora, con agitación continua, y sedimentados a $1.000 \mathrm{x} g$ durante $5 \mathrm{~min}$, recogiéndose una alícuota de sobrenadante para determinar la hemólisis. Posteriormente, los eritrocitos 
fueron lavados y sedimentados de forma idéntica a lo descrito en el enriquecimiento de colesterol (López-Revuelta, 2005; López-Revuelta et al, 2005).

\subsection{OBTENCIÓN DE LAS MEMBRANAS DE LOS ERITROCITOS}

Los eritrocitos aislados y modificados según los procedimientos indicados en los apartados 4.2.1 y 4.2.2 fueron suspendidos en un medio hipotónico, como paso previo a la obtención de sus membranas. Esta obtención está basada en el método de Steck y Kant (1974). A $10 \mathrm{ml}$ de eritrocitos (100\% de hematocrito) se les añadieron $10 \mathrm{ml}$ de una disolución de fosfato sódico $5 \mathrm{mM}$, pH 8.0, que contenía $\beta$-mercaptoetanol (1\%), PMSF $2 \mathrm{mM}$ y leupeptina (2 $\mu \mathrm{g} / \mathrm{ml}$ ). La mezcla se mantuvo en un baño de hielo durante 10 min con agitación intermitente, diluyéndose posteriormente con $190 \mathrm{ml}$ de fosfato sódico $5 \mathrm{mM}$ con $1 \%$ de $\beta$-mercaptoetanol, pH 8.0, permaneciendo en agitación intermitente $10 \mathrm{~min}$. Posteriormente, la mezcla se centrifugó a $25.000 \times \mathrm{g}$ durante $25 \mathrm{~min}$ a $4^{\circ} \mathrm{C}$. El sedimento obtenido se sometió a varios lavados con una disolución de fosfato sódico $5 \mathrm{mM}, \mathrm{pH}$ 8.0, en las condiciones señaladas anteriormente, hasta que éste se encontraba exento de hemoglobina. El último lavado se llevó a cabo con una disolución de fosfato sódico 5 mM, pH 7.5, suspendiéndose las membranas eritrocitarias en esta última disolución con la ayuda de un homogeneizador manual de vidrio, para almacenarlas finalmente a $-20^{\circ} \mathrm{C}$ en atmósfera de nitrógeno, previa determinación de su contenido en proteínas

\subsection{DETERMINACIÓN DE HEMOGLOBINA Y METAHEMOGLOBINA}

\subsubsection{Determinación de la hemoglobina $(\mathrm{Hb})$}

La determinación de la hemoglobina se llevó a cabo mediante la detección por espectrofotometría del complejo cianometahemoglobina (Tentori y Salvati, 1981).

La hemoglobina se valoró a partir de $100 \mu \mathrm{l}$ de eritrocitos (100\% hematocrito) diluidos al $10 \%$ y $20 \%$, respectivamente, en el reactivo de hemoglobina [disolución de $\mathrm{K}_{3} \mathrm{Fe}(\mathrm{CN})_{6} \quad 0,6 \mathrm{mM}, \mathrm{KCN} \quad 0,75 \mathrm{mM}, 0,5 \mathrm{~g} / \mathrm{l}$ de 
detergente Brij 35 en tampón fosfato potásico 2,5 mM, pH 7.2, diluido 50 veces con $\mathrm{H}_{2} \mathrm{O}$ ]. Alícuotas de las mezclas anteriores $(50,100,150$ y $200 \mu \mathrm{l})$ fueron llevadas a un volumen final de $2,5 \mathrm{ml}$ con el reactivo de hemoglobina, y tras 5 min de reposo, sus absorbancias fueron leídas a $540 \mathrm{~nm}$.

A partir de una disolución de hemoglobina de $16,7 \mathrm{mg} / \mathrm{ml}$, se construyó una recta patrón de calibrado con concentraciones comprendidas entre 0,42 y $3,36 \mathrm{mg}$.

\subsubsection{Determinación de la metahemoglobina (MetHb)}

La metahemoglobina se determinó porcentualmente por el método de Salvati y Tentori (1981).

Los eritrocitos ( $50 \mu \mathrm{l}$ del $100 \%$ de hematocrito) fueron hemolizados con 40 volúmenes de agua destilada $(2 \mathrm{ml})$. El hemolizado $(1,5 \mathrm{ml})$ se mezcló con $1,5 \mathrm{ml}$ de una disolución amortiguadora de fosfato sódico 0,1 M, pH 6.8. A $1 \mathrm{ml}$ de esta mezcla se le añadieron $34 \mu \mathrm{lde} \mathrm{K}_{3} \mathrm{Fe}(\mathrm{CN})_{6}$ al $20 \%(\mathrm{p} / \mathrm{v})$, transcurridos 5 min, se determinó la absorbancia de la mezcla a $630 \mathrm{~nm}\left(\mathrm{~A}_{1 \mathrm{a}}\right)$. A continuación se añadieron $34 \mu \mathrm{l}$ de $\mathrm{KCN}$ al $5 \%(\mathrm{p} / \mathrm{v})$, y transcurridos 3 min más, se repitió la lectura a $630 \mathrm{~nm}\left(\mathrm{~A}_{1 \mathrm{~b}}\right)$.

Por otra parte, se tomó $1 \mathrm{ml}$ de la mezcla hemolizado-tampón, y se le añadieron $34 \mu \mathrm{l}$ de agua destilada, realizándose después de 5 min la medida de la absorbancia a $630 \mathrm{~nm}\left(\mathrm{~A}_{2 \mathrm{a}}\right)$. Seguidamente se añadieron $34 \mu \mathrm{l}$ de $\mathrm{KCN}$ al $5 \%$ $(p / v)$, y al cabo de 3 min se determinó de nuevo la absorbancia a $630 \mathrm{~nm}\left(\mathrm{~A}_{2 b}\right)$.

El porcentaje de metahemoglobina (MetHb) presente en la muestra se determinó utilizando la siguiente expresión matemática:

$$
\% \text { MetHb }=\frac{A_{2 a}-A_{2 b}}{A_{1 a}-A_{1 b}} \times 100
$$




\subsection{VALORACIÓN DE PROTEÍNAS}

El contenido en proteínas de las muestras de membranas eritrocitarias se determinó por el método de Markwell et al (1978). La valoración está basada en la absorción que presentan a $660 \mathrm{~nm}$ los complejos de color violeta que forman los grupos fenólicos e indólicos de la tirosina y el triptófano existentes en las proteínas cuando reaccionan con el reactivo de Folin-Ciocalteu (ácido fosfomolibdowolfrámico), junto con los complejos cúprico-alcalinos originados por la reacción de los enlaces peptídicos con el cobre del reactivo de Biuret.

Como patrón se utilizó seroalbúmina bovina $(0,5 \mathrm{mg} / \mathrm{ml})$. Distintos volúmenes de muestras, diluidas convenientemente en $\mathrm{NaOH} 0,1 \mathrm{~N}$, y de patrones, ajustados con $\mathrm{NaOH} 0,1 \mathrm{~N}$ a $300 \mu$, fueron incubados en cada caso con $1 \mathrm{ml}$ del reactivo de Biuret $\left[100\right.$ partes de reactivo $\mathrm{A}\left(2 \% \mathrm{Na}_{2} \mathrm{CO}_{3}, 0,4 \%\right.$ $\mathrm{NaOH}, 0,16 \%$ tartrato sódico, $1 \% \mathrm{SDS}, \mathrm{p} / \mathrm{v})$ y 1 parte de $\mathrm{CuSO}_{4}$ al $4 \%, \mathrm{p} / \mathrm{v}$ ] durante 10 min a temperatura ambiente. A continuación se añadieron $100 \mu \mathrm{l}$ de reactivo Folin-Ciocalteu diluido $(1: 1, v / v)$, efectuándose la lectura de las muestras a $660 \mathrm{~nm}$ después de 45 min en oscuridad.

Este procedimiento experimental permite cuantificar cantidades de proteínas comprendidas entre 10 y $100 \mu \mathrm{g}$.

\subsection{DETERMINACIÓN DEL GLUTATION REDUCIDO (GSH)}

El contenido en glutation reducido (GSH) de los eritrocitos fue determinado por medida de los grupos sulfhidrilo en disoluciones ácidas, que proceden de los sobrenadantes de las mezclas de oxidación que contienen ácido tricloroacético (TCA) (véase el apartado 4.8.1). Los grupos $\mathrm{SH}$ al reaccionar con el ácido 5,5'-ditiobis (2-nitrobenzoico) (DTNB) forman complejos de color amarillo que presentan máxima absorción a $412 \mathrm{~nm}$ (Dise y Goodman, 1986).

La valoración de GSH se realizó en una mezcla que contenía $6 \mu$ moles de DTNB, compuesta por $200 \mu$ de sobrenadante, $100 \mu$ de una disolución de TCA al $14 \%$ en PBS $(\mathrm{p} / \mathrm{v}), 600 \mu \mathrm{l}$ de Tris $1 \mathrm{M}, \mathrm{pH} 8.0$ y $60 \mu \mathrm{l}$ de DTNB $100 \mathrm{mM}$ en Tris $1 \mathrm{M}, \mathrm{pH}$ 7.0. La mezcla se agitó y se midió su absorbancia a $412 \mathrm{~nm}$. La cuantificación del GSH se realizó con una recta de calibrado construida con una 
disolución de GSH 10 mM, con concentraciones comprendidas entre 2,5 y 100 nmoles.

\subsection{MEDIDAS DE LA HEMÓLISIS Y DE LA ESTABILIDAD EN MEDIOS ISOTÓNICOS}

\subsubsection{Determinación de la hemólisis durante la modificación de los contenidos de colesterol}

Las medidas de absorbancia a $418 \mathrm{~nm}$ de los sobrenadantes procedentes de los medios de enriquecimiento y empobrecimiento de colesterol, permiten valorar el grado de hemólisis producido por los tratamientos. Los eritrocitos no tratados (100\% de hematocrito) fueron suspendidos en volúmenes de agua destilada idénticos a los volúmenes de las mezclas de tratamiento utilizadas durante la modificación (enriquecimiento y empobrecimiento) de los contenidos de colesterol, considerándose el $100 \%$ de hemólisis al valor de la absorbancia de dicha mezcla a $418 \mathrm{~nm}$. A partir de dicho valor se estableció el correspondiente porcentaje de hemólisis en los sobrenadantes de cada tratamiento medidos a $418 \mathrm{~nm}$. Esta forma de medida aporta porcentajes de hemólisis prácticamente idénticos a los que se obtienen por valoración del complejo cianometahemoglobina a $540 \mathrm{~nm}$, tal como se describe a continuación.

La determinación de la hemólisis en los sobrenadantes por valoración del contenido de hemoglobina se llevó a cabo en condiciones similares a las descritas en el apartado 4.4.1. A $200 \mu \mathrm{l}$ del sobrenadante procedente de los medios de modificación se añadieron $1,05 \mathrm{ml}$ del reactivo de hemoglobina, transcurridos $5 \mathrm{~min}$, se realizó la lectura de las absorbancias a $540 \mathrm{~nm}$, estableciéndose el porcentaje de hemólisis en cada muestra a partir del valor del control (eritrocitos suspendidos en $\mathrm{H}_{2} \mathrm{O}$ ), al que le corresponde el valor de $100 \%$. 


\subsubsection{Determinación de la hemólisis durante el daño oxidativo}

Este método se basa en la medida de la dispersión de la luz "light scattering" a $700 \mathrm{~nm}$ que producen los eritrocitos intactos suspendidos en un determinado medio (Ivanov, 1999).

Se utilizaron como control los eritrocitos intactos $(100 \mu \mathrm{l}$ del $100 \%$ de hematocrito) suspendidos en 7,5 volúmenes de una disolución de PBS, asignándose el $100 \%$ de eritrocitos intactos al valor de la absorbancia a $700 \mathrm{~nm}$ que presenta dicha suspensión. La suspensión de eritrocitos oxidados (100 $\mu \mathrm{l})$, diluida convenientemente, fue medida a $700 \mathrm{~nm}$, estableciéndose el porcentaje de eritrocitos intactos en la misma a partir de los valores del control.

\subsubsection{Determinación de la estabilidad en medios isotónicos}

Esta determinación está basada en el procedimiento descrito por Pessina et al (1981). Los eritrocitos (50 $\mu \mathrm{l}$ al $100 \%$ de hematocrito) sometidos a los distintos tratamientos fueron incubados en $1,25 \mathrm{ml}$ de $\mathrm{NaCl} 154 \mathrm{mM}$ durante 16 $\mathrm{h}$ a temperatura ambiente, centrifugándose posteriormente a $3.500 \times \mathrm{g}$ durante $5 \mathrm{~min}$. En los sobrenadantes obtenidos (50 $\mu$ l) fueron valorados los contenidos de hemoglobina mediante la adición de 1,2 $\mathrm{ml}$ del reactivo de hemoglobina, tras la medida a $540 \mathrm{~nm}$ del complejo cianometahemoglobina formado (apartado 4.4.1). El 100\% de hemólisis correspondía en este caso, al valor de la absorbancia a $540 \mathrm{~nm}$ del complejo de cianometahemoglobina procedente del sobrenadante de los eritrocitos suspendidos en $\mathrm{NaCl} 10 \mathrm{mM}$, estableciéndose a partir de este valor el porcentaje de hemólisis en las distintas muestras.

\subsection{INDUCCIÓN DEL DAÑO OXIDATIVO}

\subsubsection{En ausencia de antioxidante}

El hidroperóxido de ter-butilo (tBHP) es un agente generador de radicales butoxilo $\left(\mathrm{t}-\mathrm{BuO}^{\circ}\right.$ ), que requiere la presencia de $\mathrm{Fe}^{+2}$ en el medio para la formación de estos radicales. Los radicales butoxilo atacan las moléculas orgánicas provocando su alteración, proceso en el que se liberan diferentes productos de la oxidación. En nuestro estudio experimental se ha empleado 
este agente como inductor del daño oxidativo, por ser el más efectivo de todos los ensayados, como se desprende de estudios previos realizados por nuestro grupo (López-Revuelta, 2001). Distintos autores han utilizado también este agente como inductor del daño oxidativo en diferentes sistemas biológicos (Rice-Evans et al, 1985; Borowitz y Montgomery, 1989; Chen et al 2000), incluidos los eritrocitos (López-Revuelta et al, 2005; López-Revuelta et al, 2007).

Los eritrocitos intactos fueron suspendidos en PBS al $13 \%$ de hematocrito y oxidados a $37^{\circ} \mathrm{C}$ durante $30 \mathrm{~min}$ en mezclas de reacción de 1,5 $\mathrm{ml}$ con tBHP, generalmente, $2 \mathrm{mM}$.

Las membranas eritrocitarias $(0,8 \mathrm{mg}$ de proteínas) suspendidas en $1 \mathrm{ml}$ de tampón fosfato sódico $5 \mathrm{mM}, \mathrm{pH} 7.5$, fueron oxidadas a $37^{\circ} \mathrm{C}$ durante 45

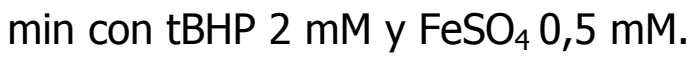

Como blancos se utilizaron muestras que no contenían agente oxidante (tBHP), y que fueron tratadas en idénticas condiciones a las muestras oxidadas.

Las reacciones en las que se determinó el grado de oxidación por medida de las sustancias reaccionantes con el ácido tiobarbitúrico (TBARS) (véase apartado 4.9.1) o en las que se valoró el contenido en GSH (véase apartado 4.6) se pararon, en todos los casos, por inmersión en un baño de hielo. A $1 \mathrm{ml}$ de la mezcla de oxidación se adicionaron $0,5 \mathrm{ml}$ de ácido tricloroacético (TCA) al $28 \%(\mathrm{p} / \mathrm{v})$ en $\mathrm{NaAsO}_{2}$ 0,1 M, centrifugándose posteriormente a $3.000 \times \mathrm{g}$ durante 5 min para recoger el sobrenadante (Rohn et al, 1993).

Cuando los eritrocitos oxidados fueron utilizados para otros estudios, inmediatamente después de la oxidación, las mezclas fueron centrifugadas a $2.500 \times \mathrm{g}$ durante $5 \mathrm{~min}$, y los eritrocitos sedimentados fueron lavados dos veces con una disolución de PBS a $2.500 \times \mathrm{g}, 5 \mathrm{~min}$.

Para las medidas de anisotropía de fluorescencia en las membranas eritrocitarias oxidadas, la reacción de oxidación llevada a cabo en las condiciones descritas anteriormente fue parada por adición al medio de reacción de $25 \mu \mathrm{l}$ de $\mathrm{BHT}$ al 0,02\% (p/v) y $100 \mu \mathrm{l}$ de EDTA-Na $\mathrm{Na}_{2}$,5. Las membranas oxidadas se obtuvieron a partir de la mezcla anterior por centrifugación a $100.000 \times \mathrm{g}, 30 \mathrm{~min}$, y posteriormente fueron lavadas con 
tampón fosfato sódico $5 \mathrm{mM}, \mathrm{pH}$ 7.5. El sedimento de membranas fue suspendido en este mismo tampón, determinándose su contenido en proteínas y almacenándose $\mathrm{a}-80^{\circ} \mathrm{C}$ hasta su posterior uso.

\subsubsection{En presencia de antioxidante}

Se ensayaron los compuestos flavonoides con propiedades antioxidantes, quercetina y rutina. Los eritrocitos diluidos al $13 \%$ de hematocrito con PBS, fueron preincubados a $37{ }^{\circ} \mathrm{C}$ durante $10 \mathrm{~min}$ en presencia de cada uno de estos compuestos para favorecer la incorporación de los mismos al eritrocito. Posteriormente se añadió tBHP y se incubaron las mezclas de reacción a $370 \mathrm{C}$ durante $30 \mathrm{~min}$. Las concentraciones finales de oxidante y antioxidante en las mezclas de reacción fueron diferentes en función del estudio a realizar, manteniéndose, en general, razones molares antioxidante:oxidante de 1:2. Las reacciones de oxidación finalizaron en cada caso con los tratamientos indicados en el apartado anterior.

Para establecer los correspondientes blancos y controles en este tipo de estudio, los eritrocitos fueron tratados del siguiente modo: i) el control, contenía en el medio de oxidación tBHP en ausencia de antioxidante; ii) el blanco, contenía el correspondiente antioxidante sin agente oxidante, llevándose a cabo las reacciones de oxidación en idénticas condiciones a las señaladas anteriormente. El daño oxidativo en presencia de cada compuesto antioxidante fue expresado en porcentaje a partir del valor del control, al que se asigna el $100 \%$ de oxidación en ausencia del antioxidante, previa sustracción de los valores de los blancos correspondientes. El valor porcentual obtenido corresponderá al porcentaje de capacidad antioxidante del compuesto.

\subsection{CUANTIFICACIÓN DEL DAÑO OXIDATIVO POR MEDIDA DE LAS SUSTANCIAS REACCIONANTES CON EL ÁCIDO TIOBARBITÚRICO (TBARS).}

Se siguió el método descrito por Rohn et al (1993). Este método se basa en la determinación por espectrofotometría del complejo coloreado que se forma entre los productos procedentes de la oxidación y el ácido tiobarbitúrico (TBA), cuya reacción es conocida como reacción de los TBARS (sustancias reaccionantes con el ácido tiobarbitúrico). 
La valoración de los TBARS se realizó en los sobrenadantes de las mezclas de oxidación que contenían TCA al 28\% (véase apartado 4.8.1), expresándose los resultados en equivalentes de malonildialdehído (pmoles $\mathrm{MDA} / \mathrm{mg} \mathrm{Hb}$ en el caso de los eritrocitos; nmoles MDA/mg proteína en el caso de las membranas eritrocitarias). A $600 \mu \mathrm{l}$ de sobrenadante del medio de oxidación que contiene TCA al $28 \%$ (ver apartado 4.8.1) se añadieron $150 \mu \mathrm{l}$ de TBA al $1 \%(\mathrm{p} / \mathrm{v})$ en $\mathrm{NaOH} 0,1 \mathrm{~N}$. La mezcla se incubó en un baño de agua en ebullición durante $15 \mathrm{~min}$, sumergiéndose en un baño de hielo y midiéndose posteriormente la coloración rosácea de la mezcla a $535 \mathrm{~nm}$. Como patrón se utilizó MDA a concentraciones de 0,2-7 nmoles, formado a partir de la hidrólisis del compuesto comercial malondialdehído-bis (dietilacetal) añadido al medio de oxidación.

\subsection{DETERMINACIÓN DEL CONTENIDO DE ESPECIES REACTIVAS DE OXÍGENO (ROS) EN AUSENCIA Y PRESENCIA DE ANTIOXIDANTE}

Para esta determinación se ha empleado la sonda diacetato de diclorodihidrofluoresceína (DCFDA), un compuesto no fluorescente que penetra por difusión pasiva en las células. Dicho compuesto es hidrolizado en el citosol a $2^{\prime}, 77^{\prime}$-diclorodihidrofluoresceína $\left(\mathrm{DCFH}_{2}\right)$, que es susceptible de ser oxidada por los ROS dando el compuesto fluorescente $2^{\prime}, 7^{\prime}$-diclorofluoresceína (DCF). La medida de la fluorescencia emitida por la DCF a $530 \mathrm{~nm}$ después de haber sido excitada a $495 \mathrm{~nm}$, permite determinar la cantidad de ROS formados tras el proceso oxidativo (Wang y Joseph, 1999), siendo especialmente sensible a la detección de $\mathrm{H}_{2} \mathrm{O}_{2}$ y radicales peroxilo (Gomes et al, 2005).

El método de determinación está basado en el procedimiento descrito por Tedesco et al (2000). Los eritrocitos intactos, al 10\% de hematocrito en una disolución de PBS, fueron incubados con DCFDA $10 \mu \mathrm{M}$ a $37^{\circ} \mathrm{C}$ durante 30 min en oscuridad. Posteriormente fueron centrifugados a $1.000 \times \mathrm{g}, 5 \mathrm{~min}$ y lavados dos veces con PBS. La primera vez a 1.000 x g, $5 \mathrm{~min}$, y la segunda vez a $2.500 \times$ g, 5 min, aislándose así los eritrocitos cargados con la sonda DCFDA.

La determinación de la producción de ROS por exposición al tBHP, en presencia o ausencia de los antioxidantes quercetina y rutina, se realizó en placas "multipocillo de 96" en un lector de fluorescencia para placas Fluoroskan 
ascent FL. Cada pocillo contenía eritrocitos al $0,25 \%$ de hematocrito cargados con DCFDA en un volumen final de $100 \mu$ l. Como controles se utilizaron eritrocitos oxidados con tBHP, cuyo valor de fluorescencia constituía el $100 \%$ de oxidación, y como blancos, eritrocitos preincubados con antioxidantes y no sometidos al proceso oxidativo. El resto de pocillos se prepararon formando un gradiente creciente de relaciones antioxidante:oxidante, manteniendo siempre constante la concentración del agente oxidante. La incorporación del antioxidante se llevó a cabo en condiciones idénticas a las indicadas en el apartado 4.8.2, por preincubación de los eritrocitos previa a la oxidación a $37^{\circ} \mathrm{C}$ durante $10 \mathrm{~min}$ en presencia del antioxidante correspondiente.

Se tomaron medidas puntuales de la fluorescencia emitida a $538 \mathrm{~nm}$ (Exc. $485 \mathrm{~nm}$ ) por la mezcla de reacción inmediatamente después de la adicción del oxidante durante $10 \mathrm{~min}$, a intervalos de $5 \mathrm{~s}$. Los resultados fueron expresados como la variación de las unidades de fluorescencia relativa (UFR) por minuto $(\triangle \mathrm{UFR} / \mathrm{min})$. Los contenidos de ROS en presencia de los antioxidantes fueron expresados porcentualmente, considerando que el $100 \%$ de la producción de ROS se asigna al valor de fluorescencia obtenido en las mezclas de los eritrocitos tratados con el tBHP en ausencia de antioxidante.

\subsection{ESTUDIO DE LA COMPOSICIÓN LIPÍDICA}

\subsubsection{Extracción de los lípidos}

Los lípidos procedentes de las diferentes muestras fueron extraídos por el método de Rose y Oklander (1965).

A un volumen de muestra (eritrocitos al $100 \%$ de hematocrito) se añadieron 0,5 volúmenes de $\mathrm{EDTA}-\mathrm{Na}_{2} \quad 0,5 \mathrm{M}, \mathrm{pH} 7.4$ y 7 volúmenes de isopropanol, manteniéndose la mezcla en agitación intermitente durante $1 \mathrm{~h}$ a temperatura ambiente, bajo atmósfera de $\mathrm{N}_{2}$. A continuación se añadieron 5 volúmenes de cloroformo, agitándose en idénticas condiciones a las indicadas anteriormente. Posteriormente la mezcla se centrifugó a 2.500 r.p.m. durante 5 min en una centrífuga de mesa, con el fin de eliminar el sedimento. El sobrenadante se filtró y se llevó a sequedad bajo corriente de $\mathrm{N}_{2}$ o bajo presión reducida en un rotavapor a $37^{\circ} \mathrm{C}$. El extracto obtenido se disolvió en 
cloroformo/metanol $2: 1(\mathrm{v} / \mathrm{v})$ y se almacenó a $-20^{\circ} \mathrm{C}$ bajo atmósfera de $\mathrm{N}_{2}$ hasta el momento de su utilización.

\subsubsection{Valoración de los contenidos en fosfolípidos}

La cuantificación de los fosfolípidos se llevó a cabo mediante la determinación del fósforo lipídico (Pi) contenido en cada muestra, y multiplicando este valor por el factor 25 ( $1 \mu \mathrm{g}$ de fósforo lipídico procede de 25 $\mu \mathrm{g}$ de fosfolípidos), tal como indican Barber y Jamieson (1970).

La valoración del Pi se realizó siguiendo el método descrito por Rouser et al (1970). Las muestras llevadas previamente a sequedad, fueron hidrolizadas con $150 \mu \mathrm{l}$ de $\mathrm{HClO}_{4}$ al $60 \%$ durante $45 \mathrm{~min}$ a $190^{\circ} \mathrm{C}$ en un "termobloc". El fósforo liberado en dicho proceso se cuantificó por espectrofotometría. A las muestras hidrolizadas se añadieron $700 \mu \mathrm{l}$ de agua destilada, $100 \mu \mathrm{l}$ de molibdato amónico al 2,5\% (p/v) y $100 \mu$ de ácido ascórbico al $10 \%(\mathrm{p} / \mathrm{v})$. La mezcla se agitó y se incubó en un baño de agua en ebullición durante 5 min, midiéndose a continuación la coloración azul de la mezcla fría a 797 nm.

La cuantificación de $\mathrm{Pi}$ se realizó utilizando una recta de calibrado construida con una disolución de $\mathrm{KH}_{2} \mathrm{PO}_{4}(4,3 \mathrm{~g} / \mathrm{l})$, que equivale a $1 \mathrm{~g} \mathrm{Pi} / \mathrm{l}$, diluida al $1 \%$ y $0,1 \%$, respectivamente, de forma que abarcara concentraciones comprendidas entre 0,1 y $2 \mu \mathrm{g}$ de fósforo en la mezcla de reacción.

\subsubsection{Valoración del contenido en colesterol}

El colesterol total se valoró como describe Kates (1972). Se llevaron a sequedad alícuotas de los diferentes extractos lipídicos, a las que se añadieron $750 \mu \mathrm{l}$ de ácido acético glacial y $500 \mu \mathrm{l}$ del "reactivo de color" (4 ml del reactivo de $\mathrm{FeCl}_{3} \cdot 6 \mathrm{H}_{2} \mathrm{O}$ al 2,5 \% (p/v) en ácido ortofosfórico al $85 \%$ fueron añadidos a $\mathrm{H}_{2} \mathrm{SO}_{4}$ concentrado c.s.p. $50 \mathrm{ml}$ ). La mezcla se agitó vigorosamente y se mantuvo en oscuridad durante $10 \mathrm{~min}$. El color púrpura desarrollado se midió a $550 \mathrm{~nm}$.

La recta patrón para la cuantificación del colesterol se realizó con mezclas de reacción que contenían cantidades colesterol libre comprendidas 0,01-0,07 mg, a partir de una disolución concentrada de colesterol $(0,1 \mathrm{mg} / \mathrm{ml}$ de ácido acético). 


\subsubsection{Separación y cuantificación de las diferentes clases de fosfolípidos}

La separación de las diferentes clases de fosfolípidos se realizó mediante cromatografía en capa fina (TLC), modalidad bidimensional, según el método de Broekhuyse (1969). Se utilizaron placas de Silicagel $60 \mathrm{G}$ de $10 \times 20 \mathrm{~cm}$ y $0,25 \mathrm{~mm}$ de espesor (Merck). Las cubetas de cromatografía se saturaron con los líquidos de desarrollo correspondientes antes del desarrollo de las placas, empleándose papel de filtro para conseguir una atmósfera saturada. Los líquidos de desarrollo utilizados fueron los siguientes:

I: cloroformo: metanol: amoniaco al 28\%: agua destilada $(60: 36: 3,7: 3,7, v / v)$.

II: cloroformo: metanol: ácido acético: agua destilada (90:40:12:2, v/v).

Cada placa, que contenía 5-15 $\mu \mathrm{g}$ de Pi, fue desarrollada en sentido ascendente con el líquido I en la primera dimensión. Posteriormente se secó al vacío durante 45 min para eliminar cualquier traza del líquido de desarrollo. A continuación se desarrolló en la segunda dimensión, también de forma ascendente, empleando el líquido II. El revelado de las placas se realizó con "Phospray", revelador específico de lípidos que contienen fósforo en su molécula, o mediante la exposición de la placa a vapores de yodo. La identificación de las diferentes clases de fosfolípidos se llevó a cabo por comparación de sus Rfs con patrones comerciales de fosfolípidos (PC, PE, PS, PI, DPG, SM y sus lisofosfatidilderivados correspondientes), que fueron desarrollados en idénticas condiciones a las muestras a identificar.

Para proceder a la cuantificación de los diferentes fosfolípidos, se rasparon cada una de las manchas detectadas en las placas y se valoró el contenido en fósforo de las mismas tal como se describe en el apartado 4.11.2 de este capítulo. El color desarrollado se midió mediante espectrofotometría a $797 \mathrm{~nm}$, previa eliminación de la silicagel presente en la muestra por centrifugación a 2.500 r.p.m. durante 5 min. Como blancos se emplearon zonas de las placas que contenían silicagel libre de material lipídico y que fueron tratadas de igual forma que el resto de las muestras. 


\subsubsection{Separación, identificación y cuantificación de los ácidos grasos mediante cromatografía en fase gaseosa (GC) acoplada a espectrometría de masas (MS)}

Esta determinación está basada en estudios precedentes llevados a cabo en eritrocitos y plaquetas (Llanillo et al, 1995; Martín-Valmaseda et al, 1998; López-Revuelta et al, 2005). En primer lugar se procedió a la formación de los ésteres metílicos de los ácidos grasos (FAME) según el método de Metcalfe et al (1966). Las alícuotas de los extractos lipídicos que contenían 10-15 $\mu \mathrm{g}$ de Pi se llevaron a sequedad bajo atmósfera de nitrógeno. A continuación se disolvieron en $1 \mathrm{ml}$ de éter de petróleo y se añadieron $750 \mu \mathrm{l}$ de $\mathrm{BF}_{3}$-metanol. La mezcla se agitó y se incubó a $100^{\circ} \mathrm{C}$ durante 45 min en un "termobloc", bajo atmósfera de nitrógeno, para conseguir la formación de los FAME. La reacción se paró por enfriamiento rápido y posterior adición de $500 \mu \mathrm{l}$ de agua destilada. La mezcla se agitó vigorosamente y se separaron dos fases por centrifugación a 2.500 r.p.m. Se recogió la fase superior que contenía los FAME, al resto se añadieron $500 \mu \mathrm{l}$ de éter de petróleo para lograr reextraer el resto de los FAME. Las fases superiores se llevaron a sequedad mediante una corriente de nitrógeno y se almacenaron a $-20^{\circ} \mathrm{C}$ disueltas en $150 \mu$ de éter de petróleo, bajo atmósfera de nitrógeno, hasta el momento de su utilización.

Las muestras almacenadas, fueron desecadas previamente, y disueltas a continuación en $20 \mu \mathrm{l}$ de isooctano inmediatamente antes de ser inyectadas en el cromatógrafo. La separación y cuantificación de los FAME se realizó a partir de la inyección de $0,15 \mu \mathrm{l}$ del extracto disuelto en isooctano en un cromatógrafo de gases del Servicio General de Espectrometría de Masas de la Universidad de Salamanca (Shimadzu GC 17A acoplado a un espectrómetro de masas Shimadzu MS QP 5000), equipado con un detector de ionización de llama (FID) y una columna capilar TR-Wax (30 m x 0,25 mm x 0,25 $\mu \mathrm{m})$. El programa de temperaturas utilizado fue el siguiente: temperaturas del inyector $y$ del detector $210^{\circ} \mathrm{C}$ y $240^{\circ} \mathrm{C}$, respectivamente, aplicándose a la columna un gradiente de temperaturas que iba desde $115^{\circ} \mathrm{C}$ durante $5 \mathrm{~min}$ (temperatura inicial) hasta alcanzar, mediante una rampa de $10^{\circ} \mathrm{C} / \mathrm{min}$, una temperatura de $190^{\circ} \mathrm{C}$, seguido de una segunda rampa de $2^{\circ} \mathrm{C} / \mathrm{min}$ hasta alcanzar la temperatura final de $230^{\circ} \mathrm{C}$, a la que se mantuvo la columna durante $20 \mathrm{~min}$. Se empleó helio como gas portador. 
Los ácidos grasos fueron identificados por comparación de sus perfiles cromatográficos y/o sus tiempos de retención con patrones de ésteres metílicos de ácidos grasos comerciales, confirmado mediante espectrometría de masas. Su cuantificación se llevó a cabo mediante la integración de las áreas correspondientes a cada uno de los picos del cromatograma, lo que permitió determinar el porcentaje en peso de cada ácido graso presente en la muestra, considerándose el $100 \%$ a la suma total de las áreas integradas.

\subsection{ESTUDIOS DE POLARIZACIÓN DE FLUORESCENCIA}

La polarización de fluorescencia es una técnica física simple y de gran sensibilidad que se aplica al estudio del estado físico de la membrana, permitiendo determinar su grado de fluidez. La magnitud de la polarización se puede expresar de acuerdo con Shinitzky y Barenholz (1974) como el grado de polarización de fluorescencia (P) o como el grado de anisotropía de fluorescencia $\left(r_{s}\right)$.

La metodología empleada en este estudio, basada en los trabajos de Barenholz et al (1976) y Shinitzky y Barenholz (1978), se apoya en estudios previos realizados por nuestro grupo (Martín-Valmaseda, 1996; MartínValmaseda et al, 1998), donde se han dado a conocer las condiciones óptimas para realizar las medidas de polarización y anisotropía de fluorescencia de las sondas 1,6-difenil-1,3,5-hexatrieno (DPH) y 1-[4-(trimetilamonio)-fenil]-6-fenil1,3,5-hexatrieno (TMA-DPH) incorporadas a las membranas: concentraciones de sonda, cantidad de membrana y cinéticas de incorporación de las sondas.

\subsubsection{Condiciones de medida}

Las medidas de anisotropía de fluorescencia $\left(r_{\mathrm{s}}\right)$ en estado estacionario se realizaron con un espectrofluorímetro Hitachi F-4010 equipado con una lámpara de Xenon de $150 \mathrm{~W}$ como fuente de excitación, y un accesorio formado por dos polarizadores dispuestos en $L$, uno para el haz de excitación y otro para el haz de emisión. El polarizador de excitación se situaba a $0^{\circ}$ ó $90^{\circ}$ manualmente, mientras que el de emisión cambiaba su posición de $0^{\circ}$ a $90^{\circ}$ con una frecuencia de $15 \mathrm{~s}$ mediante un dispositivo de rotación automática. Las longitudes de onda de excitación y de emisión fueron de 360 y 430 nm, respectivamente, para el DPH. En los estudios con TMA-DPH se empleó una 
longitud de onda de excitación de $365 \mathrm{~nm}$, siendo la de emisión de $428 \mathrm{~nm}$. Las rendijas de excitación y emisión fueron de 10 y 20 nm, respectivamente, para ambas sondas.

Las dos sondas fluorescentes utilizadas en este estudio se localizan en distintas regiones de la bicapa lipídica de la membrana. El DPH se sitúa en la región central de la bicapa, paralelo a las cadenas aćlicas de los lípidos, mientras que la sonda TMA-DPH se localiza en la superficie de la membrana, interaccionando con las cabezas polares de los fosfolípidos aniónicos (Prendergast et al, 1981; Lentz, 1989). Las condiciones de medida aplicadas son idénticas a las aplicadas en estudios recientes efectuados en eritrocitos (López-Revuelta et al, 2005). Se añadieron 0,5 nmoles de las sondas DPH (disuelta en tetrahidrofurano) o TMA-DPH (disuelta en dimetilsufóxido) a 100 $\mu \mathrm{g}$ de proteínas de membranas eritrocitarias (controles u oxidadas) suspendidas en $4 \mathrm{ml}$ de una disolución de PBS, manteniéndose una razón molar fosfolípido/sonda 50:1. El disolvente orgánico añadido a la mezcla fue siempre inferior al 0,03\% $(\mathrm{v} / \mathrm{v})$, con el fin de no interferir en la estructura de la bicapa lipídica. La mezcla se agitó vigorosamente durante $10 \mathrm{~s}$ y se incubó en oscuridad a $370 \mathrm{C}$ durante 30 min para lograr la incorporación total de las sondas a la membrana. Las medidas se realizaron a temperaturas puntuales de $10^{\circ} \mathrm{C}, 20^{\circ} \mathrm{C}, 30^{\circ} \mathrm{C}$ y $40^{\circ} \mathrm{C}$. La temperatura se mantuvo constante con un baño termostático acoplado al portacubetas del espectrofluorímetro y controlada convenientemente a lo largo del experimento.

El grado de anisotropía de fluorescencia $\left(r_{\mathrm{s}}\right)$ se calculó a partir de la siguiente ecuación (Shinitzky y Barenholz, 1974; Shinitzky y Barenholz, 1978),

$$
r_{s}=\left(I_{||}-I_{\perp} \times G\right) /\left(I_{||}+2 I_{\perp} \times G\right)
$$

donde $I_{\|}$e $I_{\perp}$ son las intensidades de luz emitidas con el plano de polarización paralelo $(||)$ y perpendicular $\left({ }_{\perp}\right)$ al plano de polarización de la luz de excitación cuando el polarizador de excitación se encuentra en posición de $0^{\circ}$. A estos valores obtenidos se restó la luz dispersada por la muestra (light scattering). $G$ es un factor corrector para la polarización del aparato y cuyo valor viene dado por la siguiente expresión: $G=i_{\| \mid} / i_{\perp}$, donde $i_{\|}$e $i_{\perp}$ son las intensidades de luz emitidas con el plano de polarización paralelo (II) y perpendicular $\left({ }_{\perp}\right)$ al plano de polarización de la luz de excitación cuando el polarizador de excitación se sitúa en posición de $90^{\circ}$. Los valores de $\mathrm{I}_{\|}$e $\mathrm{I}_{\perp}$ son 
la media aritmética de tres determinaciones independientes hechas para cada temperatura.

\subsection{ESTUDIOS SOBRE LA ORIENTACIÓN DE LOS FOSFOLÍPIDOS EN LA MEMBRANA ERITROCITARIA}

\subsubsection{Mediante tratamiento con fosfolipasa $A_{2}$}

Los cambios en la disposición asimétrica de los fosfolípidos de la membrana fueron investigados mediante el uso de fosfolipasa $A_{2}$ de veneno de abeja, enzima que hidroliza exclusivamente especies moleculares de los glicerofosfolípidos que se sitúan en la cara externa de la bicapa lipídica, en células intactas o no permeables.

El método empleado es una modificación del utilizado por Dumaswala et al (1996), y ha sido aplicado recientemente en eritrocitos (López-Revuelta, 2005; López-Revuelta et al, 2007). Los eritrocitos $(0,5 \mathrm{ml}$ al $100 \%$ de hematocrito) procedentes de los distintos tratamientos fueron resuspendidos en $2 \mathrm{ml}$ de una disolución de $\mathrm{HBS}_{1}$ (Hepes $10 \mathrm{mM}, \mathrm{KCl} 150 \mathrm{mM}, \mathrm{pH}$ 7.4) que contenía $\mathrm{CaCl}_{2} 13 \mathrm{mM}$ y $\mathrm{MgCl}_{2}$ 0,3 mM, ya que la presencia de $\mathrm{Ca}^{2+}$ es fundamental para la actividad de la fosfolipasa $A_{2}$. A esta mezcla se añadieron $100 \mu \mathrm{l}$ de una disolución de fosfolipasa $\mathrm{A}_{2}(1.000 \mathrm{IU} / \mathrm{ml}$ de disolución acuosa con glicerol al 50\%), incubándose a $37^{\circ} \mathrm{C}$ durante $20 \mathrm{~min}$. Posteriormente, los eritrocitos fueron sedimentados por centrifugación a $1.000 \times \mathrm{g}, 5 \mathrm{~min}$, recogiéndose una alícuota del sobrenadante para determinar el grado de hemólisis (véase apartado 4.7.1 de este capítulo) producido durante el tratamiento. Posteriormente se detuvo la reacción de forma completa por la adición de $250 \mu$ de una disolución de $\mathrm{HBS}_{1}$ que contenía 10 mM de EDTA $\mathrm{Na}_{2}$.

A continuación, se llevó a cabo la extracción de los lípidos procedentes de los eritrocitos tratados, la separación mediante TLC de los distintos fosfolípidos y lisofosfolípidos presentes en los extractos lipídicos y su cuantificación mediante los métodos descritos en el apartado 4.11 de este capítulo. El porcentaje de cada clase de fosfolípido presente en la cara externa de la membrana se corresponde con el porcentaje de lisofosfolípido presente en la muestra, que es calculado a partir del $100 \%$ asignado a la suma del Pi de cada fosfolípido junto con su lisofosfolípido correspondiente presentes en cada 
muestra. Seguidamente, se llevó a cabo una corrección de los porcentajes de hidrólisis obtenidos, ya que el tratamiento con la fosfolipasa $A_{2}$ en los eritrocitos de conejo produce una hidrólisis del $90 \%$ de la PC, del $89 \%$ de la PE y del 48 $\%$ de la PS presentes en el extracto lipídico.

\subsubsection{Por citometría de flujo}

Este método requiere un marcaje previo de los eritrocitos, basado en la unión de la PS exteriorizada con la proteína anticoagulante anexina $\mathrm{V}$ conjugada con el compuesto fluorescente isotiocianato de fluoresceína (FITC). La intensidad de fluorescencia emitida por la muestra, que puede ser cuantificada mediante citometría de flujo, será directamente proporcional al grado de exteriorización de la PS en la superficie del eritrocito.

El marcaje de los eritrocitos está basado en el procedimiento descrito por de Jong et al (1997). Los eritrocitos (100\% de hematocrito) fueron suspendidos al 0,04\% hematocrito en una disolución $\mathrm{HBS}_{2}$ (Hepes $10 \mathrm{mM}, \mathrm{NaCl} 145 \mathrm{mM}, \mathrm{pH}$ 7.4) que contenía $\mathrm{CaCl}_{2} 2,5 \mathrm{mM}$, añadiéndose anexina V-FITC $(60 \mathrm{ng} / \mathrm{ml}$ de disolución Tris- $\mathrm{HCl} 50 \mathrm{mM}, \mathrm{NaCl} 100 \mathrm{mM}, \mathrm{pH}$ 7.5) e incubándose la mezcla durante 30 min a temperatura ambiente en oscuridad. Los eritrocitos fueron posteriormente sedimentados a $10.000 \times \mathrm{g}$ durante $10 \mathrm{~s}$, y una vez eliminado el sobrenadante, suspendidos de nuevo en la disolución $\mathrm{HBS}_{2}+\mathrm{CaCl}_{2} 2,5 \mathrm{mM}$ al $0,04 \%$ de hematocrito.

Las muestras de eritrocitos no marcados y marcados con anexina V-FITC fueron analizadas en el Servicio de Citometría de Flujo de la Universidad de Salamanca, siguiendo procedimientos previos (Kuypers et al, 1996; LópezRevuelta et al, 2007) en un citómetro de flujo FACScalibur (Becton Dickinson, San José, CA, USA) con el programa de adquisición de datos CellQuest (Becton Dickinson). Se adquirieron un mínimo de 300.000 eventos por cada muestra, para asegurar una adecuada medida de los niveles de fluorescencia. El análisis de los datos se llevó a cabo usando el programa Paint-A-Gate (Becton Dickinson). La identificación de la población de eritrocitos intactos se realizó mediante el análisis de las características de dispersión de luz [side scatter (SSC)/forward scatter (FSC)] de muestras de eritrocitos frescos, marcados y sin marcar con anexina V-FITC. Una vez definidas las características de dispersión frontal de luz (FSC, que hace referencia al tamaño celular) y dispersión lateral de luz (SSC, que hace referencia a la complejidad celular) de los eritrocitos 
intactos, se definieron las características de FSC y SSC de los eritrocitos alterados (no viables), utilizando como control eritrocitos no tratados suspendidos en agua destilada al $0,04 \%$ de hematocrito. La identificación en el diagrama FSC/SSC de las regiones en las que aparecen los eritrocitos intactos y los eritrocitos alterados permitió calcular los resultados de integridad celular (viabilidad) de los eritrocitos diferentes tratados.

El porcentaje de eritrocitos positivos para anexina V-FITC se determinó en función del número de eventos del total que tenían un canal medio de fluorescencia (MFI) en el fotomultiplicador FL-1 superior a un determinado valor de marcaje negativo. Este umbral negativo se establecía en cada experimento mediante el análisis de la señal en FL-1 que se obtenía en una muestra de eritrocitos no marcados con anexina V-FITC (véase Fig. III. 1).

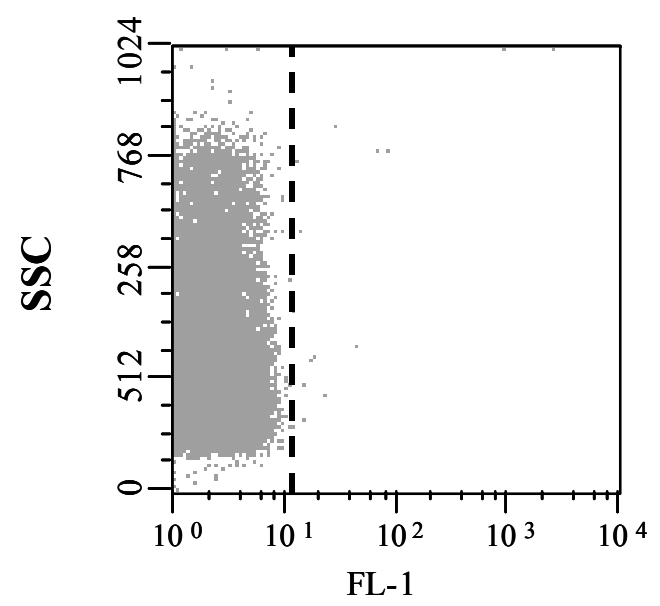

Fig. III. 1. Análisis de la señal de fluorescencia emitida por los eritrocitos controles no marcados con anexina V-FITC. La línea discontinua establece el umbral de marcaje negativo a partir del cual se considera a los eritrocitos positivos para anexina V-FITC.

El análisis de fluorescencia solamente fue considerado válido en aquellas muestras con poblaciones de eritrocitos que muestran una integridad $>92 \%$.

\subsection{DETERMINACIÓN DE LA ACTIVIDAD AMINOFOSFOLÍPIDO TRANSLOCÁSICA}

La enzima aminofosfolípido translocasa (APLT) dependiente de ATP, se encarga del mantenimiento de la asimetría de los aminofosfolípidos en las membranas biológicas, ya que transporta específicamente PS y PE hacia la 
cara interna de la membrana en contra del gradiente de concentración de estos fosfolípidos.

El procedimiento de determinación de esta actividad APLT se basa en el uso del sustrato fluorescente NBD-PS, que incorporado al eritrocito es transportado a su interior por acción de la enzima (Tyurina et al, 2004a; LópezRevuelta et al, 2007). El aumento del compuesto en el interior de la célula será proporcional a la actividad APLT presente. La fluorescencia emitida por el 1palmitoil-2-[6-[(7-nitro-2-1,3-benzoxadiazol-4-il)amino]hexanoil]-sn-glycero-3phosphoserine (NBD-PS) situado en el exterior de la célula es bloqueada por el ditionito sódico $\left(\mathrm{Na}_{2} \mathrm{~S}_{2} \mathrm{O}_{2}\right)$. Dicho reactivo debe ser usado en fresco, utilizando un tampón de elevado pH para su disolución, dada su gran inestabilidad en disoluciones amortiguadoras ligeramente ácidas (McIntyre y Sleight, 1991).

Los distintos tipos de eritrocitos fueron suspendidos al 0,8 \% de hematocrito en una disolución de incubación (Tris- $\mathrm{HCl} 10 \mathrm{mM}, \mathrm{KCl} 90 \mathrm{mM}, \mathrm{NaCl}$ $45 \mathrm{mM}$, sacarosa $44 \mathrm{mM}$ y glucosa $20 \mathrm{mM}, \mathrm{pH}$ 7.4, con PMSF $500 \mu \mathrm{M})$, manteniéndolos en hielo $10 \mathrm{~min}$. Posteriormente, se añadió NBD-PS $10 \mu \mathrm{M}$ (a partir de una disolución concentrada $320 \mu \mathrm{M}$ preparada en etanol) y se incubó la mezcla 10 min con agitación intermitente en un baño de hielo. Los eritrocitos marcados con la sonda NBD-PS fueron centrifugados a $2.500 \times \mathrm{g}, 5 \mathrm{~min}, \mathrm{y}$ posteriormente fueron suspendidos a la misma concentración de partida $(0,8 \%$ hematocrito) en la disolución de incubación. Las suspensiones de los eritrocitos marcados con la sonda fueron incubadas a $28^{\circ} \mathrm{C}$ durante diferentes tiempos para propiciar la actuación de la enzima sobre el sustrato (internado de la sonda), optándose como tiempo óptimo para la determinación los 10 min de incubación. La reacción se paró por enfriamiento rápido en hielo, y se tomaron alícuotas de $300 \mu \mathrm{l}$ que fueron diluidas con 2,2 ml de la disolución de incubación. A continuación se determinó la fluorescencia de esta mezcla en un fluorímetro Hitachi F-4010 a 540 nm, previa excitación a 470 nm, durante un intervalo de tiempo de $3 \mathrm{~min}$ en agitación continua. A los $10 \mathrm{~s}$ de iniciada la lectura se añadieron a la mezcla de reacción $40 \mu \mathrm{l}$ de $\mathrm{Na}_{2} \mathrm{~S}_{2} \mathrm{O}_{2} 0,5 \mathrm{M}$ disuelto en un tampón Tris- $\mathrm{HCl} 1 \mathrm{M}, \mathrm{pH} 10$, para llevar a cabo el bloqueo de la fluorescencia emitida por la sonda NBD-PS que permanece en la monocapa externa de la membrana. Las medidas de fluorescencia se realizaron tal como se especifica en la Fig. III. 2: 


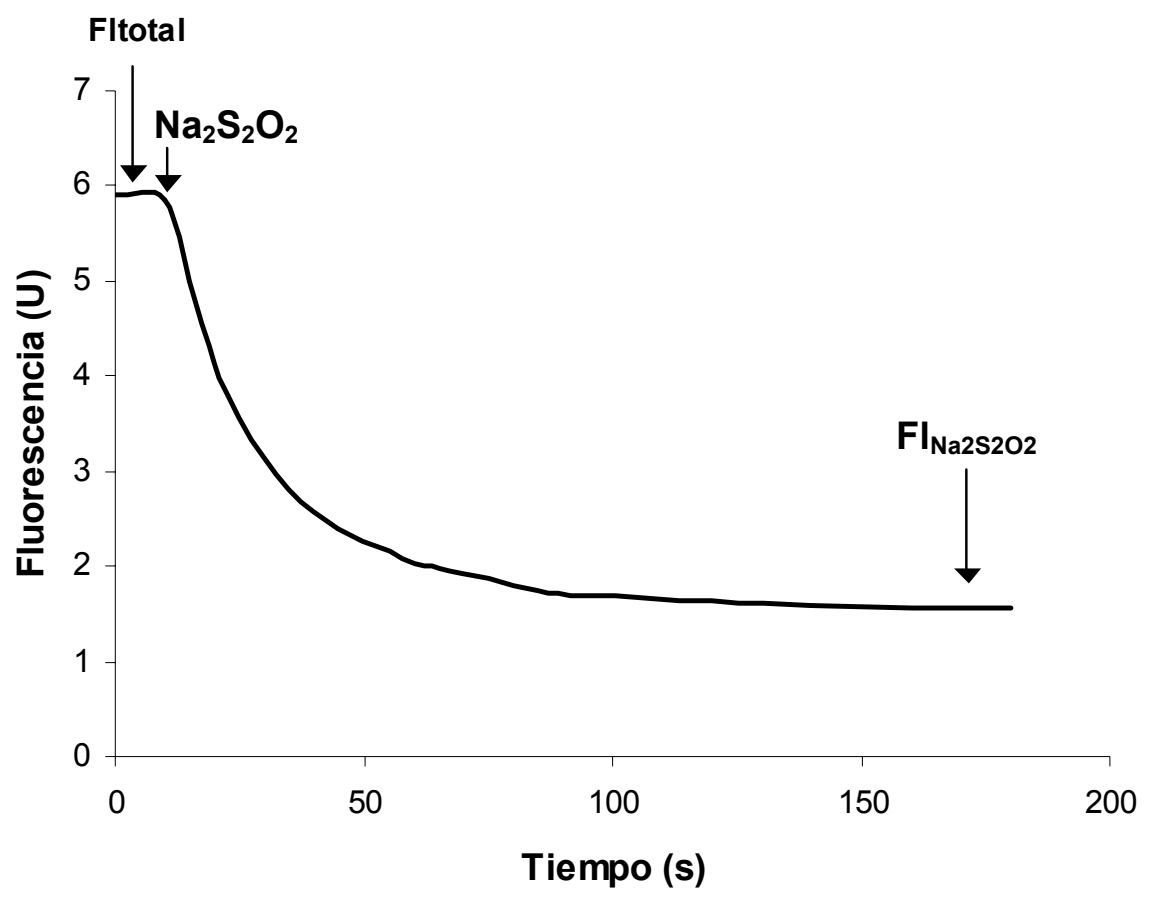

Fig. III. 2. Representación gráfica de la caída de fluorescencia que se produce cuando se adiciona ditionito sódico a una suspensión de eritrocitos controles marcados con NBD-PS. Fltotal, fluorescencia en ausencia de ditionito sódico; $\mathrm{FlNa}_{2} \mathrm{~S}_{2} \mathrm{O}_{2}$, fluorescencia en presencia de ditionito sódico.

i) Inmediatamente antes de la adición de ditionito sódico (Fluorescencia total, $\left.\mathrm{Fl}_{\text {total }}\right)$.

ii) Tres minutos después de la adición del ditionito sódico ( $\left.\mathrm{FlNa}_{2} \mathrm{~S}_{2} \mathrm{O}_{2}\right)$.

El porcentaje de NBD-PS internado se determina mediante la siguiente expresión:

$$
\% \text { NBD-PS internado }=\left(\mathrm{Fl}_{\mathrm{t}}-\mathrm{Fl}_{0}\right) /\left(\mathrm{Fl}_{\text {total }}-\mathrm{Fl}_{0}\right) \times 100
$$

donde, $\mathrm{Fl}_{\text {total }}$ corresponde a la fluorescencia total emitida por el NBD-PS unido al eritrocito internado más el no internado, al ser medido en ausencia de ditionito sódico; $\mathrm{Fl}_{0}$ es la fluorescencia basal emitida por el NBD-PS unido al eritrocito en ausencia de incubación tras la adición de ditionito sódico; $\mathrm{Fl}_{\mathrm{t}}$ es la fluorescencia emitida por el NBD-PS internado en el eritrocito por acción de la APLT después de la incubación a $28^{\circ} \mathrm{C}$ durante un tiempo $t$, con posterior adición de ditionito sódico.

El NBD-PS internado también se cuantificó llevando el valor $\mathrm{Fl}_{\mathrm{t}}-\mathrm{FL}_{0}$ a una recta de calibrado construida con hemolizados de eritrocitos que contenían concentraciones de NBD-PS comprendidas entre 2-40 pmoles (a partir de una disolución concentrada $40 \mu \mathrm{M}$ NBD-PS) en el medio de reacción, determinándose su fluorescencia en ausencia de ditionito sódico. 


\subsection{DETERMINACIÓN DE LA ERITROFAGOCITOSIS}

\subsubsection{Cultivos celulares de macrófagos de ratón}

Para los estudios de eritrofagocitosis se ha empleado la línea celular de macrófagos de ratón J774, suministrada por el Servicio de Cultivos de Células Animales del Centro de Investigaciones Biológicas (CSIC, Madrid). Esta línea celular se creció en frascos de $75 \mathrm{~cm}^{2}\left(5 \times 10^{5}\right.$ células $/ \mathrm{ml}$ de medio de cultivo) en el medio de cultivo RPMI 1640 suplementado con L-glutamina $4 \mathrm{mM}$, penicilina $100 \mathrm{U} / \mathrm{ml}$, estreptomicina $100 \mu \mathrm{g} / \mathrm{ml}$ y suero bovino fetal (SBF) al $10 \%$ (calentado previamente a $56^{\circ} \mathrm{C}$ durante $30 \mathrm{~min}$ ). Las células se mantuvieron en incubadores a $370 \mathrm{C}$ con una atmósfera húmeda $5 \%$ de $\mathrm{CO}_{2} / 95 \%$ de aire. Cuando los frascos alcanzaron un $80-90 \%$ de confluencia, las células se despegaron por raspado con rascadores para cultivos celulares. Se recogió el medio de cultivo con las células en un tubo falcon y se centrifugó a $600 \times \mathrm{g}, 5 \mathrm{~min}$, retirándose el sobrenadante y resuspendiéndose el sedimento celular en el volumen deseado de medio de cultivo.

El congelado de las células se llevó a cabo en nitrógeno líquido en un criogenizador a $-190^{\circ}$ C. Para ello, aproximadamente $3 \times 10^{6}$ células suspendidas en $1 \mathrm{ml}$ de medio de cultivo con $10 \%$ de SBF y $5 \%$ de DMSO, fueron depositadas en un criovial. Previamente a la criogenización, las células fueron sometidas a una congelación de $-1^{\circ} \mathrm{C} / \mathrm{min}$ en un contenedor con isopropanol mantenido a $-80^{\circ} \mathrm{C}$ durante al menos $4 \mathrm{~h}$.

La descongelación del criovial se realizó en un baño a 370 C lo más rápidamente posible. Para su crecimiento, las células descongeladas se traspasaron a un tubo falcon con medio de cultivo y se centrifugaron a $600 \mathrm{x} \mathrm{g}$, 5 min, lavándose nuevamente con el medio de cultivo y sembrándose en un frasco de $25 \mathrm{~cm}^{2}$ en las condiciones especificadas anteriormente.

\subsubsection{Ensayo de la fagocitosis de los eritrocitos por macrófagos de ratón}

El ensayo de fagocitosis está basado en el procedimiento de Pradhan et al (1994), Ilevándose a cabo como indican López-Revuelta et al (2007). Se sembraron $3 \times 10^{5}$ células de macrófago por pocillo $(18 \mathrm{~mm})$ en placas "multipocillo de 24", 12-24 horas antes del experimento de fagocitosis, 
consiguiéndose al cabo de este tiempo una monocapa de células con una confluencia del $90 \%$ aproximadamente. Para evitar interferencias de las proteínas del suero en la fagocitosis, las células fueron lavadas una vez con medio de cultivo libre de suero, y mantenidas $1 \mathrm{~h}$ a $37^{\circ} \mathrm{C}$ en este mismo medio. A continuación el medio de cultivo fue eliminado, y en cada pocillo se depositaron $15 \times 10^{6}$ eritrocitos suspendidos previamente en $450 \mu \mathrm{l}$ de medio libre de suero. Después de $1 \mathrm{~h}$ de incubación a $370 \mathrm{C}$, los eritrocitos no adheridos fueron eliminados mediante dos lavados con PBS. Los eritrocitos adheridos, pero no fagocitados por los macrófagos, fueron lisados con una disolución de Tris- $\mathrm{HCl} 17 \mathrm{mM}, \mathrm{pH}$ 7.2, con $\mathrm{NH}_{4} \mathrm{Cl} 140 \mathrm{mM}$, a temperatura ambiente durante $5 \mathrm{~min}$, y eliminados mediante dos lavados con PBS. Posteriormente, los macrófagos fueron fijados con metanol frío durante $3 \mathrm{~min}$. Los eritrocitos fagocitados fueron teñidos cubriendo los pocillos con una disolución de 3,3'-dimetoxibencidina al 0,0125\% (p/v) disuelta en Tris-HCl 0,1 $\mathrm{M}, \mathrm{pH} 7.6$, en presencia de $0,006 \%(\mathrm{v} / \mathrm{v})$ de $\mathrm{H}_{2} \mathrm{O}_{2}$, durante $10 \mathrm{~min}$. Los restos de 3,3'-dimetoxibencidina fueron eliminados mediante un lavado con Tris- $\mathrm{HCl}$ 0,1 M, pH 7.6. A continuación los macrófagos fueron teñidos con una disolución de azur-eosina-azul de metileno según Giemsa, diluida 1:10 con fosfato sódico 5 mM, pH 7.2, y lavados 3 veces con la disolución amortiguadora de la dilución. Los macrófagos teñidos fueron examinados en un microscopio óptico, contándose 300 macrófagos por pocillo (con un recuento de 2-4 pocillos por muestra) en diferentes campos elegidos al azar. Los macrófagos que tienen uno o mas eritrocitos internados se consideran macrófagos con fagocitosis eritrocitaria positiva (eritrofagocitosis), expresándose el índice de eritrofagocitosis en porcentajes.

\subsection{ESTUDIOS MORFOLÓGICOS}

Los eritrocitos ( $100 \%$ hematocrito) obtenidos de los diferentes tratamientos fueron fijados con 49 volúmenes de glutaraldehído al $1 \%(\mathrm{v} / \mathrm{v})$ en una disolución de fosfato salino (10 mM Na $2 \mathrm{HPO}_{4}, 150 \mathrm{mM} \mathrm{NaCl}, \mathrm{pH}$ 7.5) durante $15 \mathrm{~min}$ a $4^{\circ} \mathrm{C}$. Posteriormente, se lavaron una vez con la misma disolución exenta de glutaraldheído, para eliminar los restos de fijador, y se resuspendieron al $2 \%$ de hematocrito. A continuación, $10 \mu \mathrm{l}$ de la suspensión de eritrocitos se colocaron en un portaobjetos, se cubrieron con un cubreobjetos para su observación en el microscopio óptico, fotografiándose las imágenes obtenidas. Se contaron 200 eritrocitos por porta en diferentes 
campos elegidos al azar, expresándose los índices de alteración morfológica en porcentajes de eritrocitos que presentan una o más espículas en su superficie (Wolfs et al, 2003; López-Revuelta et al, 2007).

\section{TRATAMIENTO ESTADÍSTICO DE LOS DATOS}

Los datos son expresados como media aritmética de $\mathrm{n}$ experimentos individuales \pm D. E. (desviación estándar de la media). Para ver si existen diferencias estadísticamente significativas entre los parámetros estudiados de las distintas muestras analizadas, se ha aplicado la t-Student utilizando el programa de ordenador Quick/test para Macintosh y el análisis de la varianza con el programa SPSS 13.0.1 para Windows. Los resultados de los estudios se consideran estadísticamente significativos en aquellos pares de valores que presentan diferencias con un nivel de confianza de al menos el $95 \%$, es decir, con una significación en la muestra de $p \leq 0,05$.

\section{SOPORTES INFORMÁTICOS}

La redacción de este trabajo se ha realizado con el procesador de texto "Microsoft Word 2003". El procesamiento matemático de los datos, así como su representación gráfica, se ha efectuado con el programa "Microsoft Excel 2003". Las ilustraciones y esquemas se han construido con el programa "Microsoft Power Point 2003". Las fotografías de microscopía tomadas con una cámara de video digital Olympus DP170 acoplada al microscopio invertido Olympus IX51, han sido analizadas con los programas DPmanager y Adobe Photoshop 7.0. Así mismo, se ha empleado Internet para la búsqueda bibliográfica en las distintas bases de datos y revistas electrónicas disponibles en la red, utilizando como base de la búsqueda de bibliografía la página web Medline (National Library of Medicine), en la dirección http://www.ncbi.nlm.nih.gov/entrez. 
CAPÍTULO IV: Resultados 



\section{MODIFICACIÓN DE LOS CONTENIDOS DE COLESTEROL EN LOS ERITROCITOS}

La transferencia de colesterol a los eritrocitos está basada en el método de Shinitzky et al (1979), que utiliza la polivinilpirrolidona (PVP) como agente expansionante de la membrana para conseguir la incorporación del colesterol. Se ha seguido básicamente el procedimiento de Sánchez-Yagüe et al (1987), tal como se detalla en el apartado 4.2.1 del capítulo III. Los eritrocitos tratados incrementan su contenido en colesterol en un $89 \%$ con respecto a los eritrocitos no tratados (controles), alcanzándose un valor en la relación molar colesterol/fosfolípidos (Ch/PL) de $1,41 \pm 0,12$, con respecto a razones molares de $0,84 \pm 0,10$ detectadas en los eritrocitos controles. Este tratamiento provoca una hemólisis de $0,7 \pm 0,4 \%$.

El empobrecimiento de colesterol en el eritrocito se llevó a cabo por dos procedimientos diferentes, tal y como se detalla en el apartado 4.2.2 del capítulo III. La Fig. IV. 1 muestra los contenidos de colesterol de los eritrocitos tratados con diversas ciclodextrinas. La incubación de los eritrocitos con $3 \mathrm{mM}$ de $\beta$-ciclodextrinas (BCD) no provoca pérdidas de colesterol. En cambio, el tratamiento con $5 \mathrm{mM}$ de BCD consigue reducir en un $25 \%$ estos contenidos con respecto a los eritrocitos no tratados, alcanzándose una relación molar $\mathrm{Ch} / \mathrm{PL}$ de $0,77 \pm 0,07$. El tratamiento de los eritrocitos con $5 \mathrm{mM}$ de metil- $\beta$ ciclodextrinas (MBCD) logra un secuestro mayor del esterol, ya que se produce una pérdida del $65 \%(p \leq 0,001)$ en el contenido de colesterol, obteniéndose una relación molar Ch/PL de 0,43 $\pm 0,09$. 


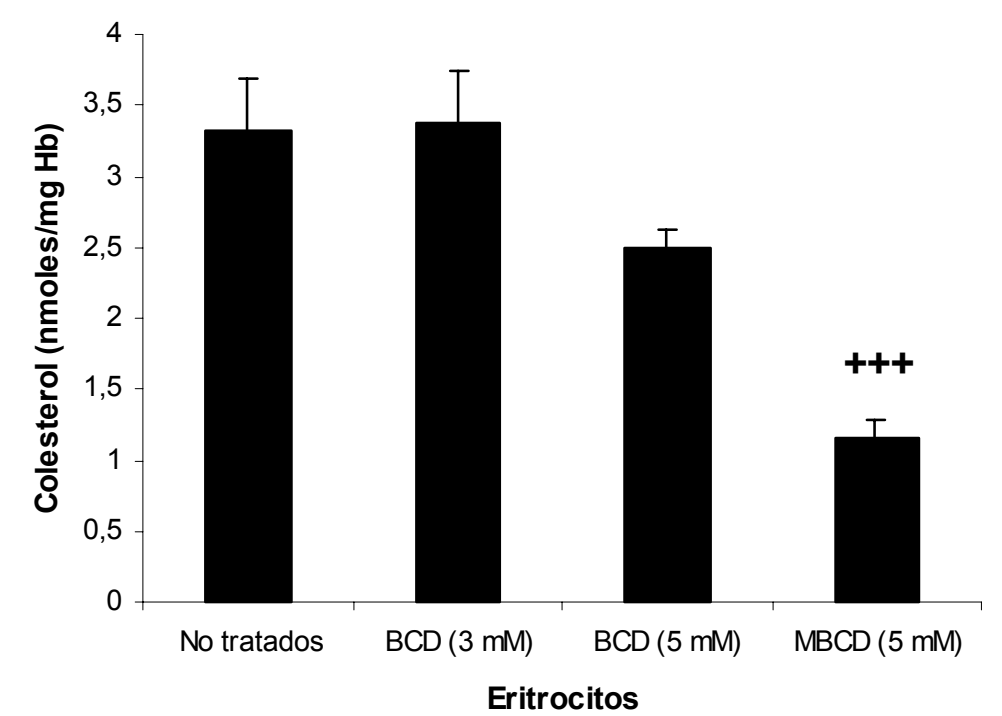

Fig. IV. 1. Contenidos de colesterol en los eritrocitos de conejo no tratados y tratados con ciclodextrinas ( $\beta$-ciclodextrinas, BCD 0 $\beta$-metilciclodextrinas, MBCD). Los resultados son la media aritmética \pm D.E. de 8 experimentos independientes. Comparaciones estadísticamente significativas: eritrocitos no tratados $v_{s}$ tratados, $+++p \leq 0,001$.

Se llevó a cabo un estudio de la hemólisis provocada por los tratamientos con las diferentes concentraciones de BCD. Las incubaciones de los eritrocitos con concentraciones $3 \mathrm{mM}$ y $5 \mathrm{mM}$ de $B C D$ producen un porcentaje de hemólisis $<5 \%(0,55 \pm 0,11 \%$ y $4,6 \pm 1,5 \%$, respectivamente). A concentraciones superiores de $\mathrm{BCD}$, la hemólisis producida aumenta rápidamente hasta alcanzar valores del $75 \%$ en los eritrocitos tratados con $\mathrm{BCD}$ $7 \mathrm{mM}$. El empobrecimiento de colesterol en los eritrocitos con $5 \mathrm{mM}$ de MBCD produce una hemólisis del 2,2 $\pm 0,7 \%$ (López-Revuelta, 2005).

Por tanto, la utilización de $5 \mathrm{mM}$ de MBCD como sistema de empobrecimiento en colesterol de los eritrocitos, resulta el método más indicado en la mayor parte de los estudios que se han llevado a cabo en este trabajo. 


\section{ENSAYO DE LA ACTIVIDAD ANTIOXIDANTE DE DIFERENTES COMPUESTOS FRENTE AL DAÑO OXIDATIVO INDUCIDO POR EL TBHP EN ERITROCITOS CONTROLES}

Se evaluó el grado de protección que aportan diversos compuestos (antioxidantes) frente al daño oxidativo inducido por el tBHP en los eritrocitos controles. Los eritrocitos fueron preincubados a $370 \mathrm{C}$ durante $10 \mathrm{~min}$ con diferentes concentraciones de cada compuesto (enzimas entre 1 y $100 \mathrm{mU} / \mathrm{ml}$, para el resto de compuestos entre 0,01 y $1 \mathrm{mM}$ ). A continuación se añadió tBHP $2 \mathrm{mM}$ al medio, manteniéndose la incubación durante 30 min más. Un tratamiento paralelo fue llevado a cabo, en la muestra control, cuya mezcla de reacción contenía $2 \mathrm{mM}$ de tBHP sin el antioxidante, y en el blanco correspondiente para cada compuesto, que en su medio de incubación contenía el antioxidante a la máxima concentración ( $1 \mathrm{mM}$ o $100 \mathrm{mU} / \mathrm{ml}$ ) en ausencia de tBHP. Tras el proceso de incubación, las reacciones fueron paradas con TCA al $28 \%$, valorándose a continuación los TBARS presentes en las mezclas. La capacidad antioxidante de cada compuesto se expresa como porcentaje de TBARS generados en su mezcla de reacción (\% TBARS), asignándose el 100\% de TBARS a los valores detectados en el control, previa sustracción a cada muestra de los valores de TBARS detectados en los blancos correspondientes. El valor porcentual restante corresponderá al porcentaje de capacidad antioxidante del compuesto.

En la Tabla IV. 1 se muestran los porcentajes de peroxidación que sufren los eritrocitos controles tratados con tBHP en presencia de diferentes compuestos. Los compuestos fenólicos son los que poseen un mayor poder antioxidante, que aumenta a medida que se incrementa la concentración del compuesto en el medio de reacción. Dentro de este grupo de compuestos, el más efectivo es el ácido tánico, ya que a concentraciones $1 \mathrm{mM}$ consigue más del $90 \%$ de protección frente a la peroxidación. El BHA, el BHT y la quercetina presentan porcentajes de protección similares (aproximadamente del $30 \%$ a $0,01 \mathrm{mM}$; del $60-70 \%$ a $0,1 \mathrm{mM}$ y del $82-87 \%$ a $1 \mathrm{mM}$ ). La rutina es un poco menos efectiva en dicha protección ( $60 \%$ a $1 \mathrm{mM})$, mientras que el $\alpha$-tocoferol no muestra prácticamente nada de capacidad antioxidante en estas condiciones. Por lo que se refiere a las hormonas esteroideas ensayadas, el $\beta$ estradiol presenta una capacidad antioxidante bastante alta, con protecciones del $45 \%$ a $0,1 \mathrm{mM}$ y del $54 \%$ a $1 \mathrm{mM}$, mientras que la DHEAS no impide el 
daño oxidativo generado por el tBHP a ninguna de las concentraciones ensayadas. Otros compuestos estudiados a la máxima concentración (1 mM), no tienen actividad protectora, como en el caso del manitol, o bien ésta es escasa, como sucede con la $\mathrm{N}$-acetil-L-cisteina, la astaxantina y la deferoxamina, mientras que el ácido ascórbico muestra una capacidad antioxidante bastante mayor (66\% de protección).

Tabla IV. 1. Porcentajes de peroxidación (expresados como \% TBARS) en eritrocitos controles tratados con $2 \mathrm{mM}$ de tBHP en presencia de diversos compuestos antioxidantes

\begin{tabular}{|c|c|c|c|}
\hline ANTIOXIDANTE & & EROXIDACIÓN & \\
\hline Enzimas & $1 \mathrm{mU} / \mathrm{ml}$ & $10 \mathrm{mU} / \mathrm{ml}$ & $100 \mathrm{mU} / \mathrm{ml}$ \\
\hline Glutation peroxidasa & $54,0 \pm 6,2(\mathrm{n}=3)$ & $52,4 \pm 7,5(\mathrm{n}=3)$ & $51,4 \pm 3,8(\mathrm{n}=3)$ \\
\hline Catalasa & $82,9 \pm 0,5(n=2)$ & $75,3 \pm 10,2(\mathrm{n}=2)$ & $73,2 \pm 9,8(\mathrm{n}=3)$ \\
\hline Comp. fenólicos & $0,01 \mathrm{mM}$ & $0,1 \mathrm{mM}$ & $1 \mathrm{mM}$ \\
\hline Acido tánico & $63 \pm 6,8(\mathrm{n}=5)$ & $20,8 \pm 2,4(\mathrm{n}=5)$ & $8,7 \pm 1,8(\mathrm{n}=5)$ \\
\hline BHA & $71,6 \pm 7(\mathrm{n}=5)$ & $31,0 \pm 5(n=5)$ & $13,3 \pm 2,1(\mathrm{n}=5)$ \\
\hline BHT & $68,0 \pm 8,8(\mathrm{n}=5)$ & $34,0 \pm 4,9(\mathrm{n}=5)$ & $17,8 \pm 3,2(\mathrm{n}=5)$ \\
\hline Quercetina & $69,9 \pm 6,7(n=5)$ & $41,4 \pm 12,6(n=7)$ & $17,0 \pm 5,9(\mathrm{n}=6)$ \\
\hline Rutina & $74,2 \pm 12,8(\mathrm{n}=8)$ & $57,5 \pm 13,6(\mathrm{n}=6)$ & $40,6 \pm 5,1(\mathrm{n}=7)$ \\
\hline a-tocoferol & $100 \pm 0(n=4)$ & $100 \pm 0(n=4)$ & $87,9 \pm 12,8(\mathrm{n}=4)$ \\
\hline Hormonas esteroideas & $0,01 \mathrm{mM}$ & $0,1 \mathrm{mM}$ & $1 \mathrm{mM}$ \\
\hline$\beta$-Estradiol & $83,8 \pm 13,6(\mathrm{n}=4)$ & $54,9 \pm 7,4(n=4)$ & $45,9 \pm 2,3(\mathrm{n}=4)$ \\
\hline $\begin{array}{l}\text { Dehidroisoandrosterona } \\
\text { 3-sulfato (DHEAS) }\end{array}$ & $100 \pm 0(n=4)$ & $100 \pm 0(\mathrm{n}=4)$ & $100 \pm 0(\mathrm{n}=4)$ \\
\hline Otros & $0,01 \mathrm{mM}$ & $0,1 \mathrm{mM}$ & $1 \mathrm{mM}$ \\
\hline Astaxantina & $94,5 \pm 11(\mathrm{n}=4)$ & $89,9 \pm 8,6(n=4)$ & $75,9 \pm 24,4(\mathrm{n}=4)$ \\
\hline Ac.Ascórbico & $94,5 \pm 4,4(\mathrm{n}=4)$ & $64,5 \pm 3,1(n=4)$ & $33,8 \pm 0,6(\mathrm{n}=4)$ \\
\hline $\mathrm{N}$-acetil-L-cisteina & $89,6 \pm 2,2(n=4)$ & $83,0 \pm 1,8(\mathrm{n}=4)$ & $79,9 \pm 4,7(n=4)$ \\
\hline Deferosamina & $100 \pm 0(n=4)$ & $100 \pm 0(n=4)$ & $64,6 \pm 3,2(n=4)$ \\
\hline Manitol & $98,5 \pm 1(n=4)$ & $96,9 \pm 3,9(n=4)$ & $99 \pm 1,2(n=4)$ \\
\hline
\end{tabular}

Los resultados son la media aritmética \pm D.E. de $\mathrm{n}$ experimentos independientes

Se ensayaron también dos enzimas que catalizan la descomposición de los peróxidos, y que podrían tener capacidad protectora en el sistema de oxidación empleado en este estudio. La catalasa, que descompone el $\mathrm{H}_{2} \mathrm{O}_{2}$ en agua y oxígeno, y la glutation peroxidasa, que degrada los peróxidos lipídicos en sus alcoholes correspondientes en presencia de glutation reducido. Esta última enzima se muestra más efectiva que la catalasa en la protección frente al daño oxidativo generado por el tBHP, con porcentajes de protección cercanos al $50 \%$ en las tres concentraciones ensayadas. La catalasa presenta aproximadamente la mitad de capacidad antioxidante que la glutation peroxidasa en nuestro sistema de peroxidación (véase Tabla IV. 1). 
De todos los compuestos anteriormente ensayados, se eligieron la quercetina y la rutina como antioxidantes para llevar a cabo nuestros posteriores estudios de protección frente al daño oxidativo en eritrocitos con diferentes contenidos de colesterol, al tratarse de compuestos naturales generados por organismos fotosintéticos, de gran abundancia en los alimentos (frutas y verduras), y que muestran un elevado poder antioxidante en nuestro modelo experimental, como acabamos de comentar anteriormente. Ambos compuestos se diferencian estructuralmente en la posición 3 del anillo $\mathrm{C}$ del flavonol, que en el caso de la quercetina lleva unido un grupo hidroxilo libre, mientras que en la rutina dicha posición se encuentra glicosilada con un disacárido constituido por ramnosa y glucosa, denominado rutinosa. Estas diferencias estructurales pueden generar un comportamiento antioxidante distinto de la quercetina con respecto a la rutina en nuestro sistema modelo frente al daño oxidativo, un motivo más por el cuál se han elegido ambos compuestos flavonoides para llevar a cabo nuestra investigación. 


\section{EFECTO PROTECTOR DE LOS ANTIOXIDANTES QUERCETINA Y RUTINA FRENTE AL DAÑO OXIDATIVO INDUCIDO POR EL TBHP EN LOS ERITROCITOS MODIFICADOS EN SUS CONTENIDOS DE COLESTEROL}

\subsection{Influencia sobre la producción de ROS}

Las especies reactivas del oxígeno (ROS, radicales libres) presentes en los diferentes tipos de eritrocitos fueron cuantificadas mediante el empleo de la sonda DCFDA, tal como se explica en el apartado 4.10 del capítulo III. Este compuesto penetra en las células, transformándose en la forma reducida no fluorescente de la $2^{\prime}, 7^{\prime}$-diclorofluresceina (DCF), la cuál al reaccionar con los ROS se oxida, generando la forma fluorescente.

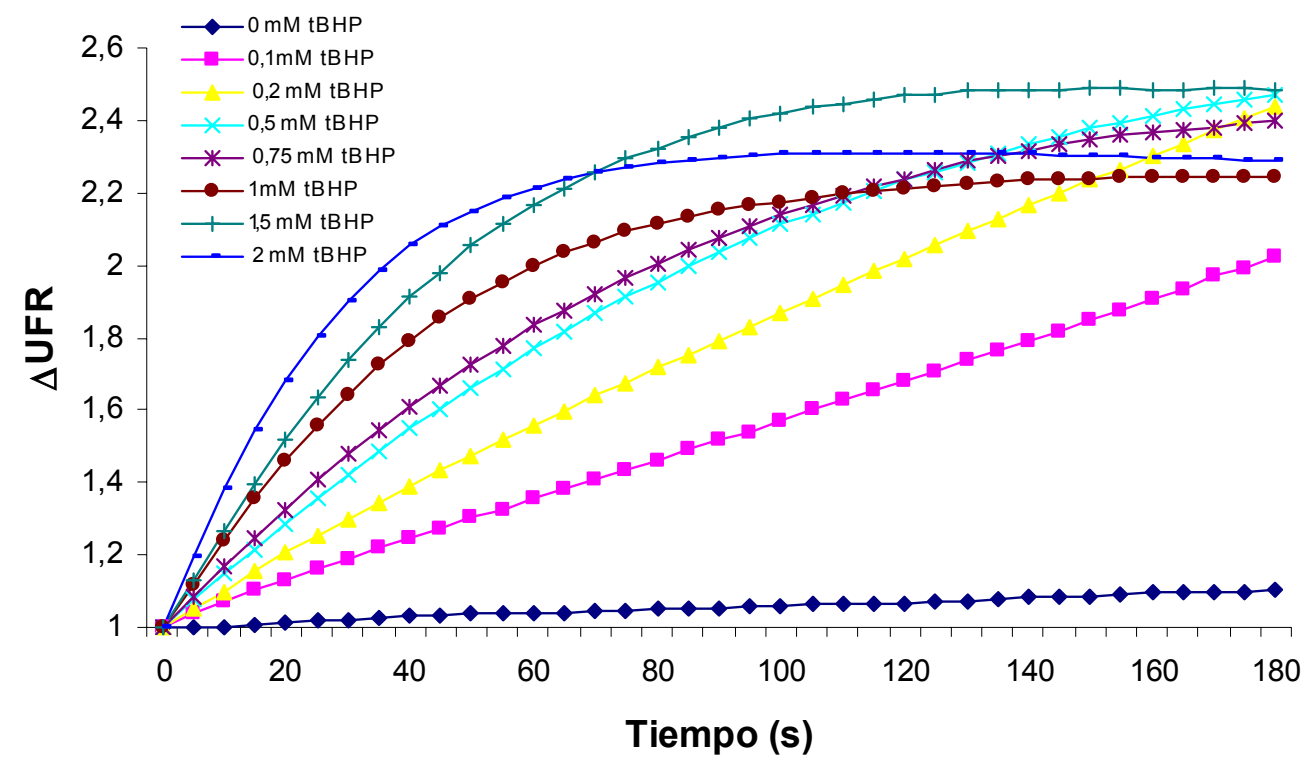

Fig. IV. 2. Producción de ROS a lo largo del tiempo en eritrocitos controles expuestos a diferentes concentraciones de tBHP. La formación de ROS fue medida como la variación de unidades de fluorescencia relativa ( $\triangle$ UFR) emitida por la DCF formada en los eritrocitos oxidados con concentraciones crecientes de tBHP $(0,1-2 \mathrm{mM})$. La gráfica mostrada corresponde a un experimento representativo de 10 ensayos realizados.

Los eritrocitos controles fueron oxidados con concentraciones crecientes de tBHP, midiéndose la producción de ROS tras el tratamiento a lo largo del tiempo. Como se observa en la Fig. IV. 2, la producción de ROS aumenta de forma significativa a medida que se incrementa la concentración de tBHP en el medio de reacción, hasta alcanzar valores máximos de 2,2-2,5 UFR (unidades de fluorescencia relativa). A concentraciones de oxidante $<0,5 \mathrm{mM}$, el 
incremento en la producción de ROS es directamente proporcional al tiempo de incubación en los 3 min de ensayo. A concentraciones superiores de oxidante se obtienen curvas hiperbólicas de formación, con cinéticas de primer orden en el primer tramo de la curva, cuya pendiente aumenta a medida que se incrementa la concentración del oxidante, alcanzándose los valores máximos de formación de radicales libres en tan sólo 1 min a concentración de tBHP 2 mM. Como se observa en la Fig. IV .3, la velocidad de formación de ROS en los eritrocitos controles en ausencia de oxidante es muy baja (0,027 UFR/min), aumentando progresivamente a medida que se incrementa la concentración de oxidante, desde $0,38 \mathrm{UFR} / \mathrm{min}(0,1 \mathrm{mM} \mathrm{tBHP})$ hasta $2,17 \mathrm{UFR} / \mathrm{min}$ (2 mM tBHP), lo que representa un aumento de 80 veces en la velocidad de formación de los ROS a concentraciones máximas de oxidante con respecto a los ROS detectados en los controles en ausencia del mismo.

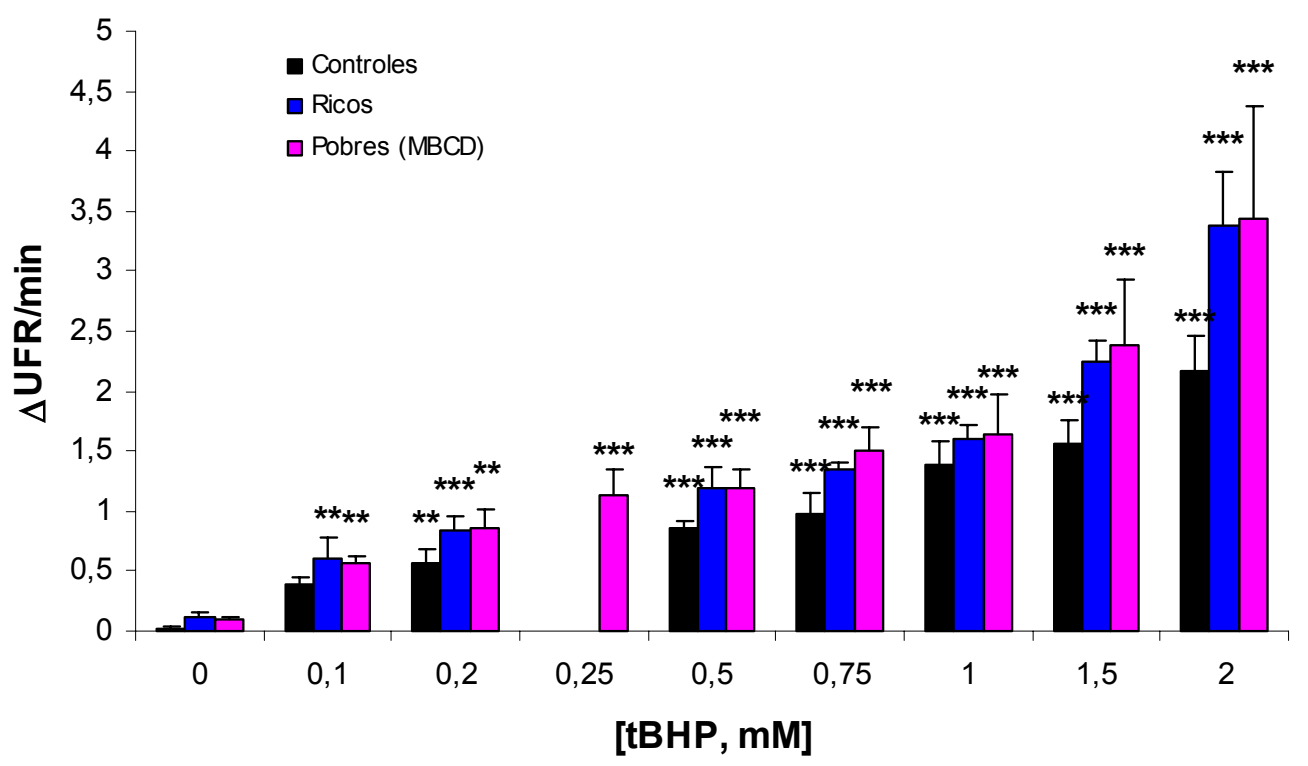

Fig. IV. 3. Velocidades de formación de ROS en eritrocitos controles y modificados (ricos y pobres en colesterol) expuestos a diferentes concentraciones de tBHP. La velocidad de formación de ROS fue medida como la variación de unidades de fluorescencia relativa por minuto $(\triangle \mathrm{UFR} / \mathrm{min})$ emitida por la DCF tras la adición de diferentes concentraciones del agente oxidante. Los resultados son la media aritmética \pm D.E. de 10 experimentos independientes. Comparaciones estadísticamente significativas: Por grupo de eritrocitos, eritrocitos no oxidados $(0 \mathrm{mM} \mathrm{tBHP}) \mathrm{v}_{\mathrm{s}}$ eritrocitos oxidados, $* *$ $\mathrm{p} \leq 0,01, * * * \mathrm{p} \leq 0,001$.

La Fig. IV. 3 muestra la velocidad de producción de ROS en los eritrocitos controles y modificados en sus contenidos de colesterol tras ser tratados con concentraciones crecientes de tBHP. La modificación de los contenidos de colesterol en los eritrocitos genera aumentos significativos en la velocidad de producción de ROS en ausencia de oxidante con respecto a los 
eritrocitos no modificados. Así, el enriquecimiento en colesterol provoca aumentos de 4,4 veces $(p \leq 0,001)$, mientras que el empobrecimiento en dicho esterol produce incrementos de 3,3 veces $(p \leq 0,001)$. La formación de ROS en los eritrocitos modificados en presencia del oxidante sigue un comportamiento similar al detectado en los eritrocitos controles, alcanzándose en estos casos siempre velocidades de formación de ROS superiores a los controles, con aumentos aproximados de 1.5 veces a las diferentes concentraciones de tBHP. Así, obtenemos velocidades de formación de ROS de 3,37 y 3,44 UFR/min en eritrocitos ricos y pobres en colesterol, respectivamente, tratados con $2 \mathrm{mM}$ de tBHP. Estos valores representan un incremento de 30-40 veces en la velocidad de formación de los ROS en los eritrocitos modificados tratados con la máxima concentración de oxidante con respecto a los eritrocitos modificados no oxidados.

Con el fin de averiguar cuál es la concentración idónea de antioxidante capaz de proteger de forma efectiva frente al daño oxidativo, a través del bloqueo de la formación de ROS, se llevaron a cabo oxidaciones de eritrocitos controles y modificados con tBHP 0,2 mM (Fig. IV. 4) o $2 \mathrm{mM}$ (Fig. IV. 5) en presencia de diferentes concentraciones de antioxidante, de forma que se alcanzaran las siguientes relaciones antioxidante: oxidante: 1:200, 1:100, 1:50, $1: 25,1: 20,1: 15,1: 10,1: 7,5,1: 5$ y $1: 2$. 


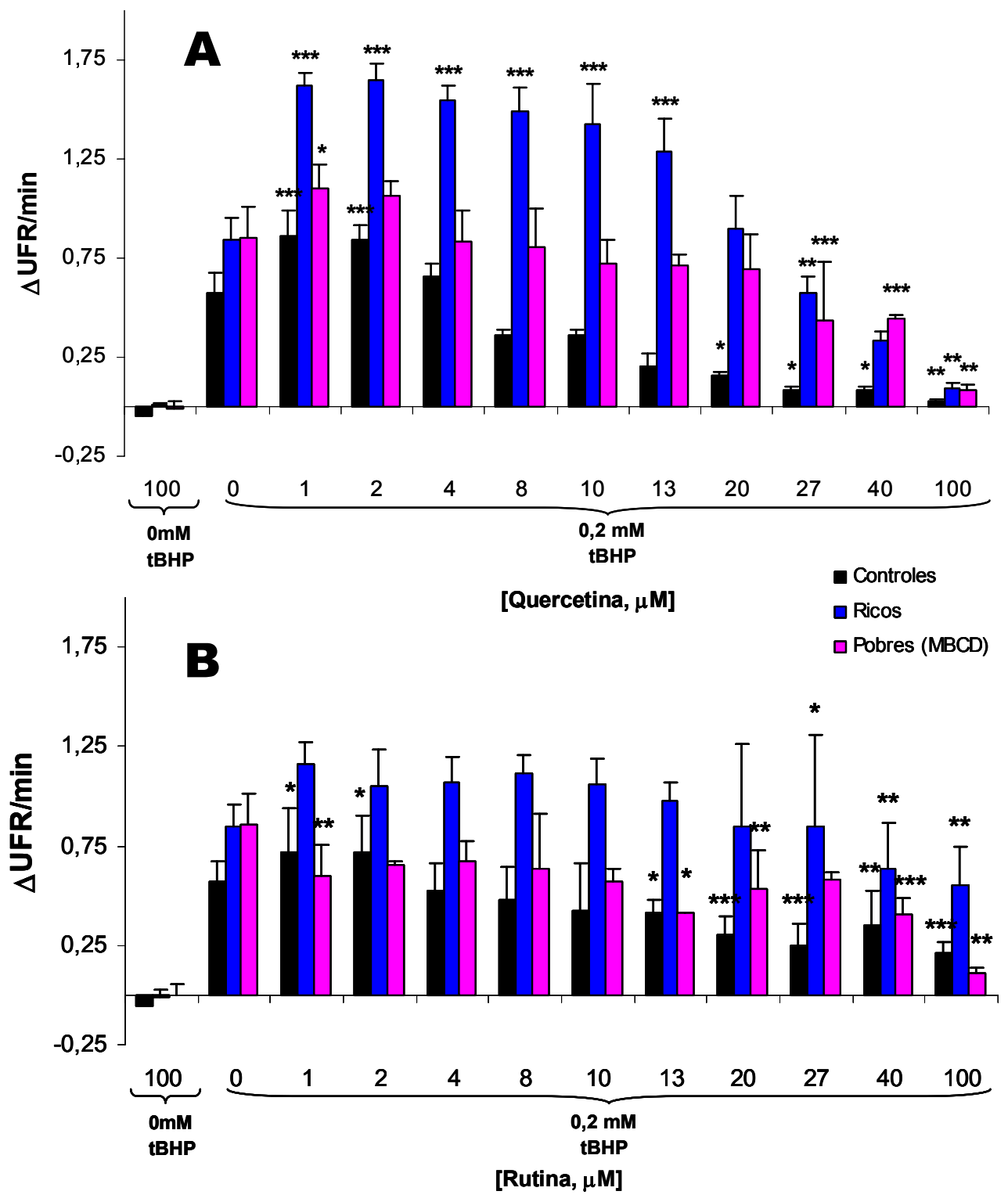

Fig. IV. 4. Velocidades de formación de ROS en eritrocitos modificados y controles peroxidados con $0,2 \mathrm{mM}$ de tBHP en presencia de distintas concentraciones de antioxidante. La formación de ROS fue medida como $\triangle \mathrm{UFR} / \mathrm{min}$ emitida por la DCF tras la adición de $0,2 \mathrm{mM}$ del agente oxidante, en presencia de distintas concentraciones de quercetina (Panel A) o de rutina (Panel B). Los resultados son la media aritmética \pm D.E. de 4 experimentos independientes. Comparaciones estadísticamente significativas: Por grupo, eritrocitos oxidados en presencia de antioxidante $\mathrm{v}_{\mathrm{s}}$ eritrocitos oxidados en ausencia de antioxidante, $* p \leq 0,05, * * p \leq 0,01, * * * p \leq 0,001$.

Cuando sometemos las diferentes clases de eritrocitos a la oxidación inducida por 0,2 mM de tBHP en presencia de las distintas concentraciones de antioxidante $(1,2,4,8,10,13,20,27,40$ y $100 \mu \mathrm{M})$, observamos que la máxima protección se obtiene siempre con la relación antioxidante:oxidante $1: 2$, siendo esta protección en presencia de quercetina del 94,88 y $90 \%$ en los eritrocitos controles, ricos y pobres en colesterol, respectivamente (Fig. IV. 4 A); y en presencia de rutina del $63 \%$ en controles, $35 \%$ en eritrocitos ricos y $88 \%$ en eritrocitos pobres en colesterol (Fig. IV. 4 B). También se consigue la 
máxima protección frente al daño oxidativo en los diferentes tipos de eritrocitos oxidados con tBHP $2 \mathrm{mM}$, cuando la relación antioxidante:oxidante es 1:2, con porcentajes de protección en presencia de quercetina del 92,95 y $99 \%$ en eritrocitos controles, ricos y pobres en colesterol, respectivamente (Fig. IV. 5 A), y mostrándose en presencia de rutina porcentajes de protección del $79 \%$ en controles, $96 \%$ en eritrocitos ricos y $93 \%$ en eritrocitos pobres en colesterol (Fig. IV. 5 B).

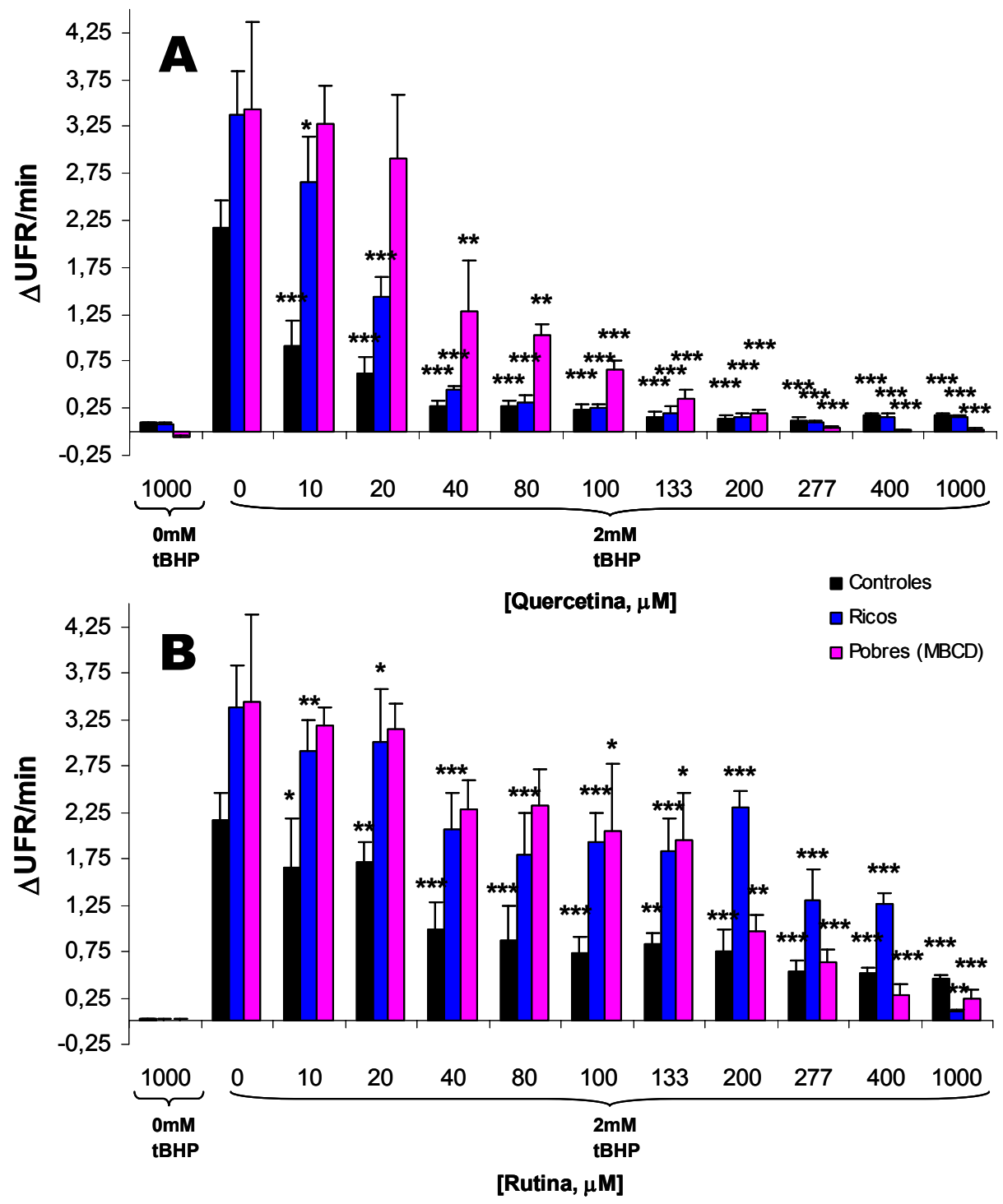

Fig. IV. 5. Velocidades de formación de ROS en eritrocitos modificados y controles peroxidados con $2 \mathrm{mM}$ de tBHP en presencia de distintas concentraciones de antioxidante. La formación de ROS fue medida como $\triangle U F R / m i n$ emitida por la DCF tras la adición de $2 \mathrm{mM}$ del agente oxidante, en presencia de distintas concentraciones de quercetina (Panel A) o de rutina (Panel B). Los resultados son la media aritmética \pm D.E. de 4 experimentos independientes. Comparaciones estadísticamente significativas: Por grupo, eritrocitos oxidados en presencia de antioxidante $v_{s}$ eritrocitos oxidados en ausencia de antioxidante, $* \mathrm{p} \leq 0,05, * * \mathrm{p} \leq 0,01, * * * \mathrm{p} \leq 0,001$. 
El efecto protector otorgado por la quercetina es siempre superior al que aporta la rutina, a cualquiera de las relaciones antioxidante:oxidante ensayadas en los distintos tipos de eritrocitos, especialmente a concentraciones de oxidante 0,2 $\mathrm{mM}$. Dichas diferencias son más acentuadas a bajas concentraciones de antioxidante.

Dado que el máximo grado de protección de ambos antioxidantes frente a los ROS se obtiene a la relación antioxidante:oxidante 1:2, dicha relación es la que se ha utilizado en los estudios posteriores para analizar la influencia de cada antioxidante sobre la estructura-función de los diferentes tipos de eritrocitos sometidos a estrés oxidativo.

La quercetina aporta un efecto pro-oxidante a bajas concentraciones, cuando los eritrocitos son tratados con concentraciones bajas de oxidante. El efecto es especialmente visible en los eritrocitos ricos en colesterol oxidados con tBHP $0,2 \mathrm{mM}$, donde se observan aumentos significativos $(p \leq 0,001)$ en la velocidad de formación de ROS de 1,93, 1,95, 1,83, 1,77, 1,69 y 1,52 veces para las relaciones antioxidante:oxidante de 1:200, 1:100, 1:50, 1:25, 1:20 y $1: 15$, respectivamente. Este efecto es menos pronunciado en los eritrocitos controles, que queda restringido a relaciones antioxidante:oxidante de 1:200 y $1: 100$, con aumentos en las UFR/min de 1,51 y 1,47 veces, respectivamente. En el caso de los eritrocitos pobres en colesterol, la actividad pro-oxidante de la quercetina es prácticamente inexistente (Fig. IV. 4 A).

En el caso de la rutina el efecto pro-oxidante es únicamente significativo $(p \leq 0,05)$ en los eritrocitos controles a relaciones antioxidante:oxidante 1:200 y 1:100 (Fig. IV. 4 B). El carácter pro-oxidante de ambos antioxidantes no se manifiesta en ningún caso cuando las oxidaciones de los eritrocitos se efectúan a concentraciones de tBHP $2 \mathrm{mM}$.

Para calcular las concentraciones a las que se alcanza el $50 \%$ de inhibición en la formación de ROS en presencia de cada uno de los antioxidantes, lo que se conoce como valor $\mathrm{IC}_{50}$, se realizaron las representaciones gráficas mostradas en la Fig. IV. 6. 

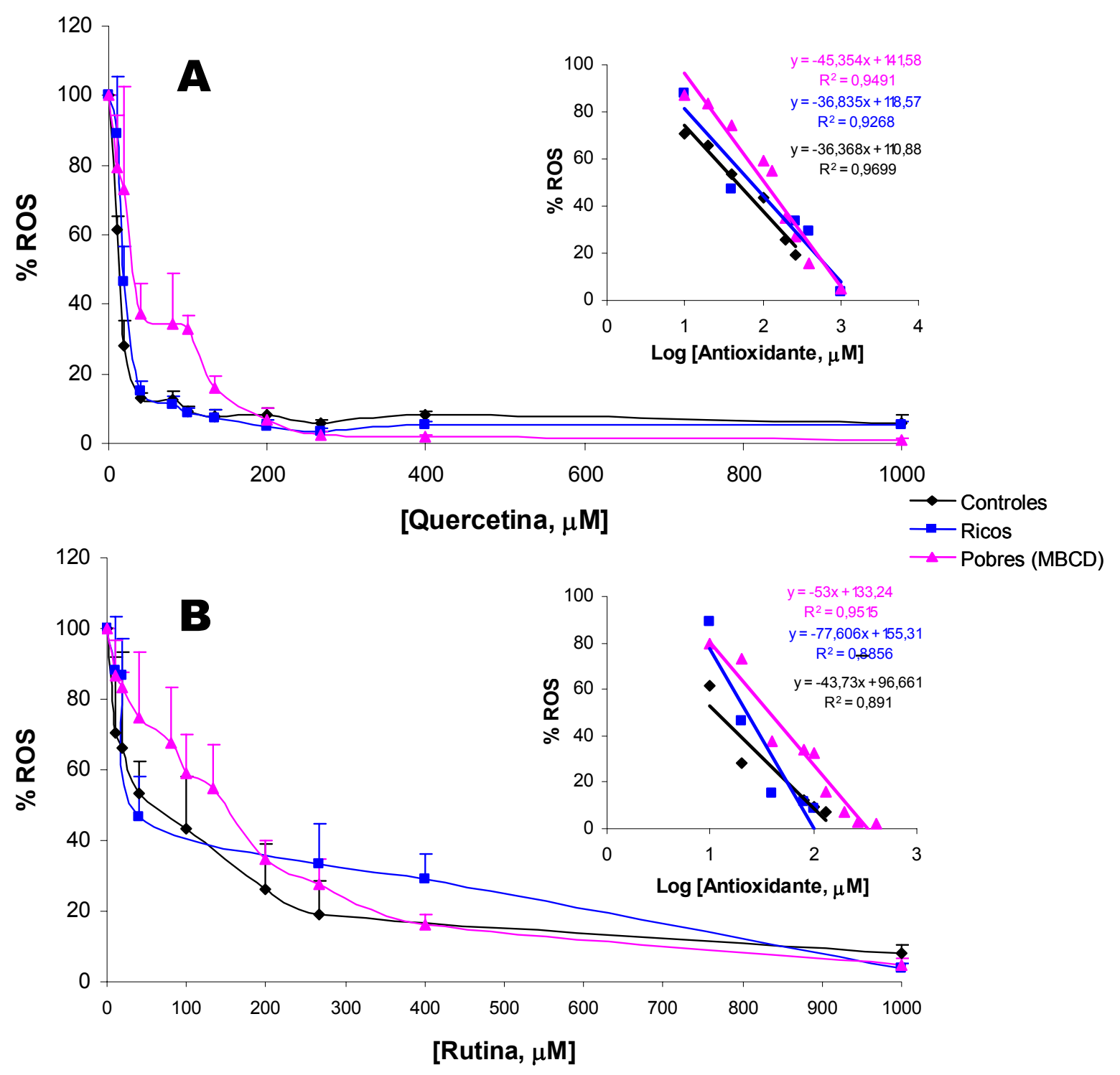

Fig. IV. 6. Efecto de la concentración de quercetina (panel A) o rutina (panel B) sobre la producción de ROS en eritrocitos modificados y controles oxidados con $2 \mathrm{mM}$ de TBHP. Se asignó el 100\% de producción de ROS a la fluorescencia emitida por el DCF en cada tipo de eritrocitos oxidados en ausencia de antioxidante. Los resultados son la media aritmética $\pm D$.E. de 4 experimentos independientes.

En dicha figura (Fig. IV. 6) se representan los porcentajes de ROS formados en los diferentes tipos de eritrocitos tras la oxidación con $2 \mathrm{mM}$ de tBHP, en presencia de distintas concentraciones de quercetina (panel A) o de rutina (panel B). Los valores de IC $_{50}$ obtenidos en cada caso se recogen en la Tabla IV. 2. 
Tabla IV. 2. Valores de IC $_{50}$ para quercetina y rutina en la formación de ROS en eritrocitos controles y modificados en colesterol, tras ser oxidados con $2 \mathrm{mM}$ de tBHP

\begin{tabular}{ccc}
\cline { 2 - 3 } Tipos de eritrocitos & \multicolumn{2}{c}{ Antioxidante IC $50(\mu \mathrm{M})$} \\
\cline { 2 - 3 } Controles & Quercetina & Rutina \\
Ricos & 12 & 47 \\
Pobres & 23 & 73 \\
& 37 & 104 \\
\hline
\end{tabular}

De los datos de la Tabla IV. 2 se deduce que la quercetina tiene un efecto protector más potente que la rutina frente a la generación de ROS, dado que sus valores de $\mathrm{IC}_{50}$ son inferiores en todos los casos a los valores que presenta la rutina. Esta conclusión es plenamente concordante con lo mostrado en estudios precedentes. Por otra parte, se observa que los eritrocitos controles son los mejor protegidos por ambos antioxidantes frente a los radicales libres, dado que muestran valores de $\mathrm{IC}_{50}$ siempre inferiores a los que presentan los eritrocitos modificados, siendo los eritrocitos pobres en colesterol los más sensibles al estrés oxidativo en presencia de ambos antioxidantes.

Los porcentajes de protección frente a la generación de ROS conseguidos en presencia de quercetina $1 \mathrm{mM}$ en los diferentes tipos de eritrocitos oxidados con $2 \mathrm{mM}$ de tBHP oscilan entre $96-99 \%$, mientras que en el caso de la rutina la protección es inferior $(85-95 \%, p \leq 0,001)$, como se puede deducir de los resultados mostrados en la Fig. 6. En todos los casos, los eritrocitos controles muestran mejor protección por los antioxidantes que los eritrocitos modificados.

\subsection{Influencia sobre la producción de TBARS}

La valoración de los contenidos de las sustancias reaccionantes con el ácido tiobarbitúrico (TBARS), que son expresadas en equivalentes de malonildialdehído (MDA)/mg $\mathrm{Hb}$, se ha llevado a cabo en las diferentes muestras tal como se detalla en el apartado 4.9 de Materiales y Métodos. 
Los contenidos de TBARS son prácticamente despreciables en las distintas clases de eritrocitos estudiados en ausencia de oxidante, con valores comprendidos entre 0,076 $\pm 0,002$ y 0,081 $\pm 0,005$ pmoles $\mathrm{MDA} / \mathrm{mg} \mathrm{Hb}$.

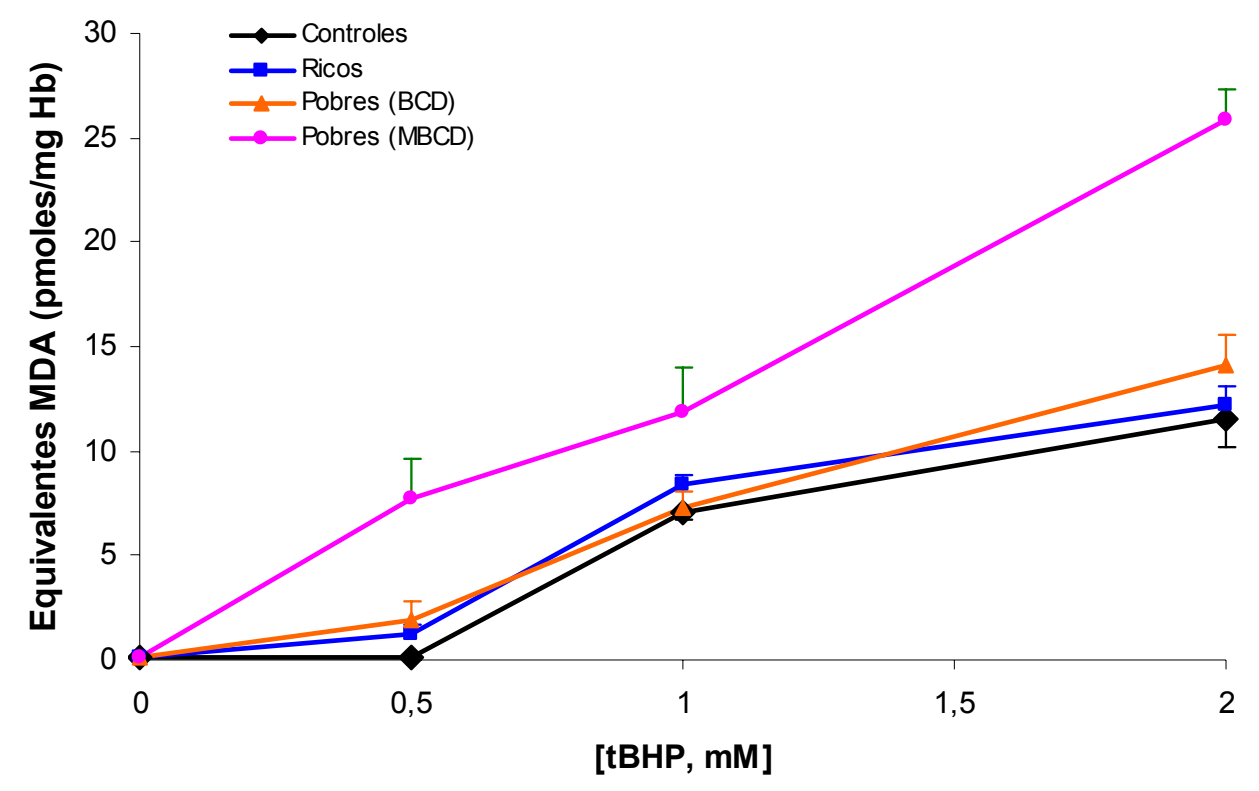

Fig. IV. 7. Producción de TBARS (expresados en equivalentes de MDA) en los eritrocitos controles, ricos y pobres en colesterol expuestos a diferentes concentraciones de tBHP. Los valores son la media \pm D.E. de 5 experimentos.

Los diferentes tipos de eritrocitos fueron incubados durante $30 \mathrm{~min}$ a $37{ }^{\circ} \mathrm{C}$ con diferentes concentraciones de tBHP, obteniéndose las producciones de TBARS que se muestran en la Fig. IV. 7. A medida que se aumenta la cantidad de agente oxidante se incrementan los equivalentes de MDA, alcanzándose un máximo de peroxidación a la concentración $2 \mathrm{mM}$ en los diferentes tipos de eritrocitos. Por ello, se ha elegido esta última concentración como la más apropiada para llevar a cabo la inducción del daño oxidativo. El tratamiento con esta concentración de agente oxidante produce una hemólisis aproximada del $86 \pm 8 \%$ en los eritrocitos controles, del $81 \pm 9 \%$ en los eritrocitos ricos, y del $84 \pm 13 \%$ (BCD) y $92 \pm 5 \%$ (MBCD) en los eritrocitos pobres en colesterol.

La valoración del grado de protección que ejercen los antioxidantes en la formación de TBARS, se llevó a cabo asignando el 100\% de peroxidación a los contenidos de TBARS presentes en cada grupo de eritrocitos oxidados con 2 $\mathrm{mM}$ de tBHP en ausencia de antioxidante, estableciéndose a partir de este valor el porcentaje de peroxidación que se obtiene en las muestras oxidadas en 
presencia del antioxidante. El valor porcentual restante corresponde a la capacidad protectora del antioxidante.

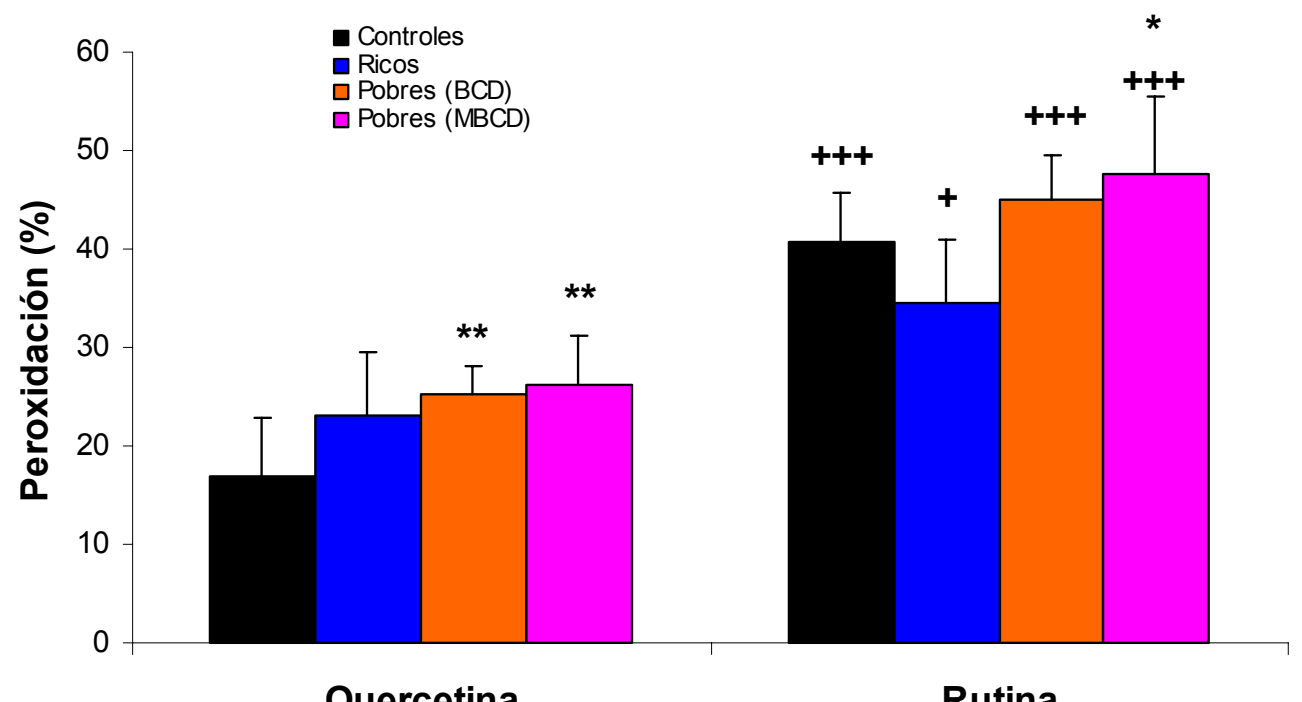

Fig. IV. 8. Porcentajes de peroxidación en presencia de antioxidantes (1 mM) en los eritrocitos controles y modificados en sus contenidos de colesterol al ser tratados con $2 \mathrm{mM}$ de tBHP. La relación antioxidante:oxidante fue siempre 1:2. Se asignó el $100 \%$ de peroxidación al contenido de TBARS (11-25 pmoles MDA/mg Hb) en los diferentes grupos de eritrocitos tratados con $2 \mathrm{mM}$ de tBHP en ausencia de antioxidante. Los valores son la media \pm D.E. de 6 experimentos. Cambios estadísticamente significativos: i) Por grupo de eritrocitos: quercetina $v_{s}$ rutina, $+p \leq 0,05$, $+++\mathrm{p} \leq 0,001$; ii) Por antioxidante: controles $\mathrm{v}_{\mathrm{s}}$ modificados, $* \mathrm{p} \leq 0,05, * *$ $\mathrm{p} \leq 0,01$.

Los efectos protectores que ejercen la quercetina y la rutina a concentraciones $1 \mathrm{mM}$ sobre la peroxidación lipídica inducida por $2 \mathrm{mM}$ de tBHP en los distintos tipos de eritrocitos se exponen en la Fig. IV. 8. En este caso, lo mismo que en la protección frente a la formación de ROS, la quercetina muestra siempre un poder antioxidante mayor (1,2-1,4 veces) que la rutina en los distintos grupos de eritrocitos oxidados. Sólo el empobrecimiento en colesterol de los eritrocitos modifica significativamente el efecto protector de ambos antioxidantes. En el caso de la quercetina, el tratamiento tanto con BCD como con MBCD provoca un descenso de su poder antioxidante de 1,1 veces $(p \leq 0,01)$; mientras que en la rutina sólo es el tratamiento de los eritrocitos con MBCD el que produce una disminución significativa $(1,1$ veces, $p \leq 0,05)$ de la eficacia protectora del antioxidante. 

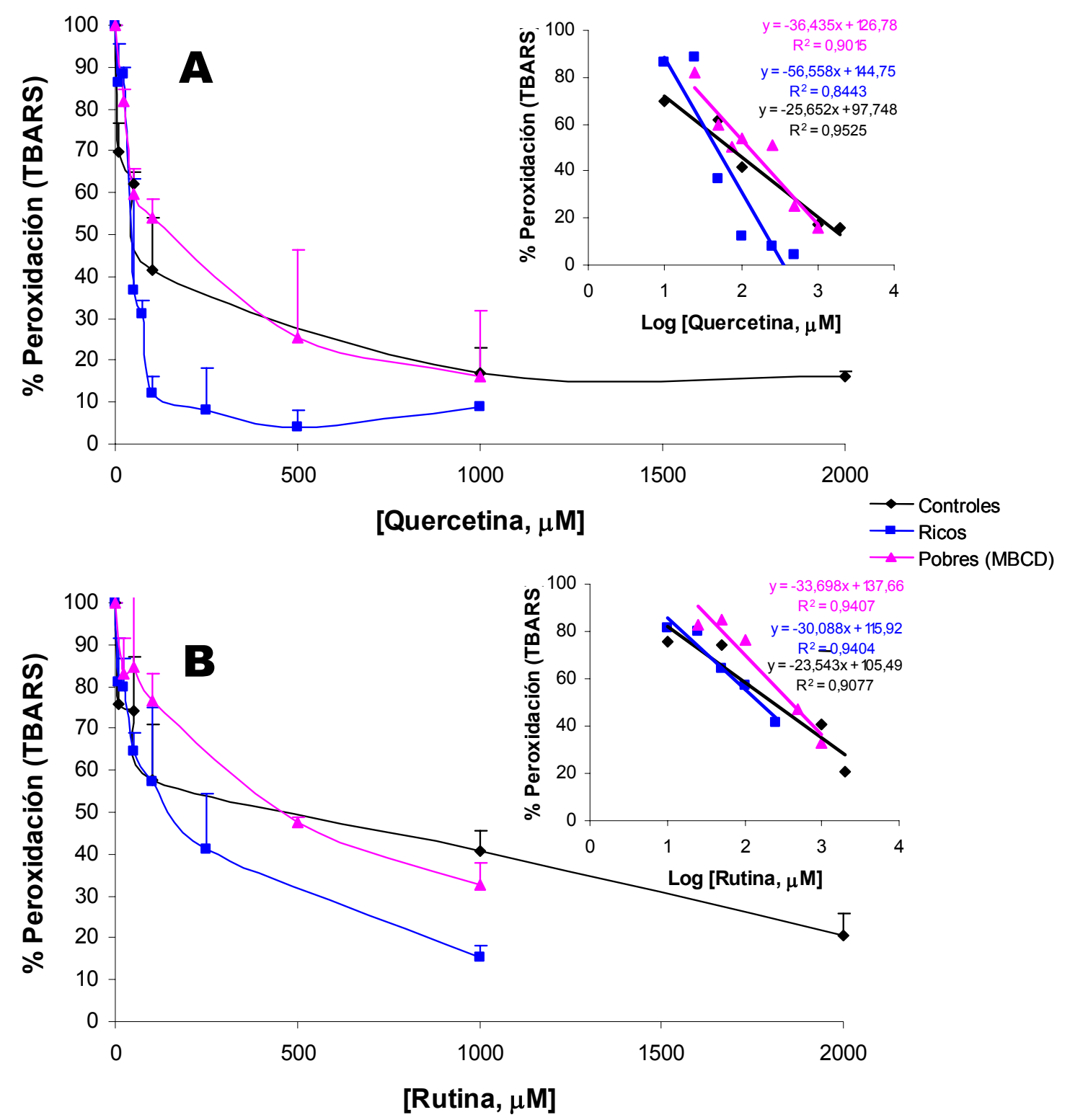

Fig .IV. 9. Efecto de la concentración de quercetina (Panel A) o rutina (Panel B) sobre la peroxidación en eritrocitos controles y modificados en sus contenidos de colesterol tratados con 2 mM de tBHP. Se asignó el $100 \%$ de peroxidación al contenido de TBARS en los diferentes grupos de eritrocitos tratados con $2 \mathrm{mM}$ de tBHP en ausencia de antioxidante. Los valores son la media \pm D.E. de 3 experimentos.

Los valores de IC $_{50}$ para ambos antioxidantes frente a la formación de TBARS en los tres tipos de eritrocitos oxidados con $2 \mathrm{mM}$ de tBHP, se obtuvieron a partir de las representaciones gráficas mostradas en la Fig. IV. 9, y se recogen en la Tabla IV. 3. 
Tabla IV. 3. Valores de IC 50 para quercetina y rutina en la formación de TBARS en los eritrocitos controles y modificados en sus contenidos de colesterol, tras ser oxidados con 2 mM de tBHP

\begin{tabular}{ccc}
\cline { 2 - 3 } Tipos de eritrocitos & \multicolumn{2}{c}{ Antioxidante IC50 $(\mu \mathrm{M})$} \\
\cline { 2 - 3 } Controles & Quercetina & Rutina \\
Ricos & 73 & 227 \\
Pobres & 47 & 155 \\
& 128 & 399 \\
\hline
\end{tabular}

A partir de los valores de $\mathrm{IC}_{50}$ se deduce una vez más que la quercetina ejerce siempre una mayor protección que la rutina, en este caso aproximadamente 3 veces superior frente a la formación de TBARS en los tres tipos de eritrocitos estudiados. La eficacia del poder antioxidante del compuesto se modifica en función del tipo de eritrocito, observándose de nuevo que los eritrocitos pobres en colesterol son los menos protegidos por los antioxidantes frente a la peroxidación, ya que son estos eritrocitos los que muestran los valores de $\mathrm{IC}_{50}$ mas elevados con ambos antioxidantes. 


\section{EFECTO PROTECTOR DE LOS FLAVONOIDES QUERCETINA Y RUTINA SOBRE LA OXIDACIÓN DE LA HEMOGLOBINA INDUCIDA POR +BHP}

La incubación de los distintos tipos de eritrocitos con concentraciones crecientes de tBHP durante 30 min genera un descenso exponencial de los contenidos de hemoglobina en los mismos, produciéndose una oxidación casi completa (>90\%) a la concentración de $2 \mathrm{mM}$ (Fig. IV. 10). La hemoglobina oxidada es expresada como porcentaje de metahemoglobina (MetHb). Concentraciones mayores de $0,25 \mathrm{mM}$ de tBHP inducen un apreciable grado de oxidación de la hemoglobina (> 5\%) en los cuatro tipos de eritrocitos analizados. Las concentraciones de tBHP que producen $50 \%$ de oxidación ( $\mathrm{IC}_{50}$ ) de la hemoglobina son de $1,5 \mathrm{mM}$ en los eritrocitos controles y pobres en colesterol tratados con $B C D$, y de $1,2 \mathrm{mM}$ en los eritrocitos ricos y pobres en colesterol tratados con MBCD.

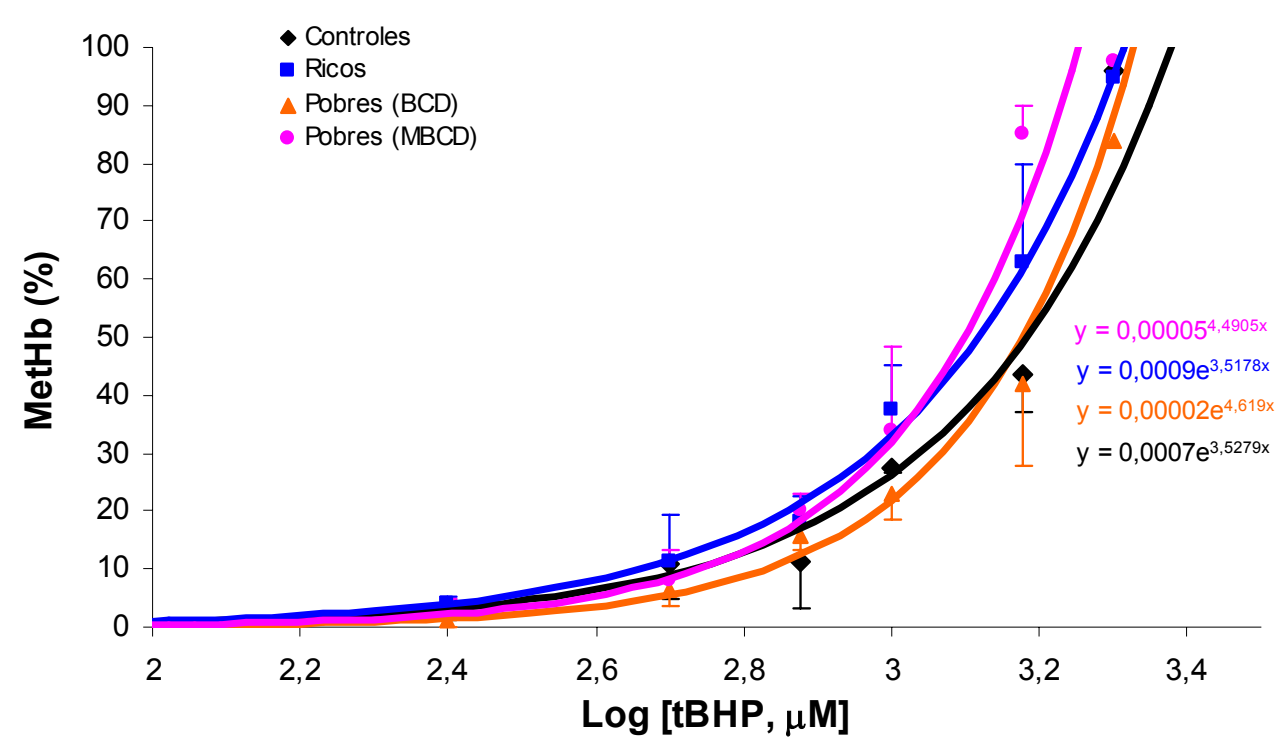

Fig. IV. 10. Oxidación de la hemoglobina en los eritrocitos controles y modificados en sus contenidos de colesterol expuestos a diferentes concentraciones de tBHP. Esta oxidación se expresa en porcentajes de metahemoglobina (MetHb) formada en el medio de oxidación. Los resultados son la media aritmética \pm D.E. de 4 experimentos independientes.

Los resultados del estudio de protección de la hemoglobina por antioxidantes frente al daño oxidativo generado por $2 \mathrm{mM}$ de tBHP (relación antioxidante:oxidante, 1:2) en los diferentes tipos de eritrocitos se exponen en la Fig. IV. 11. 


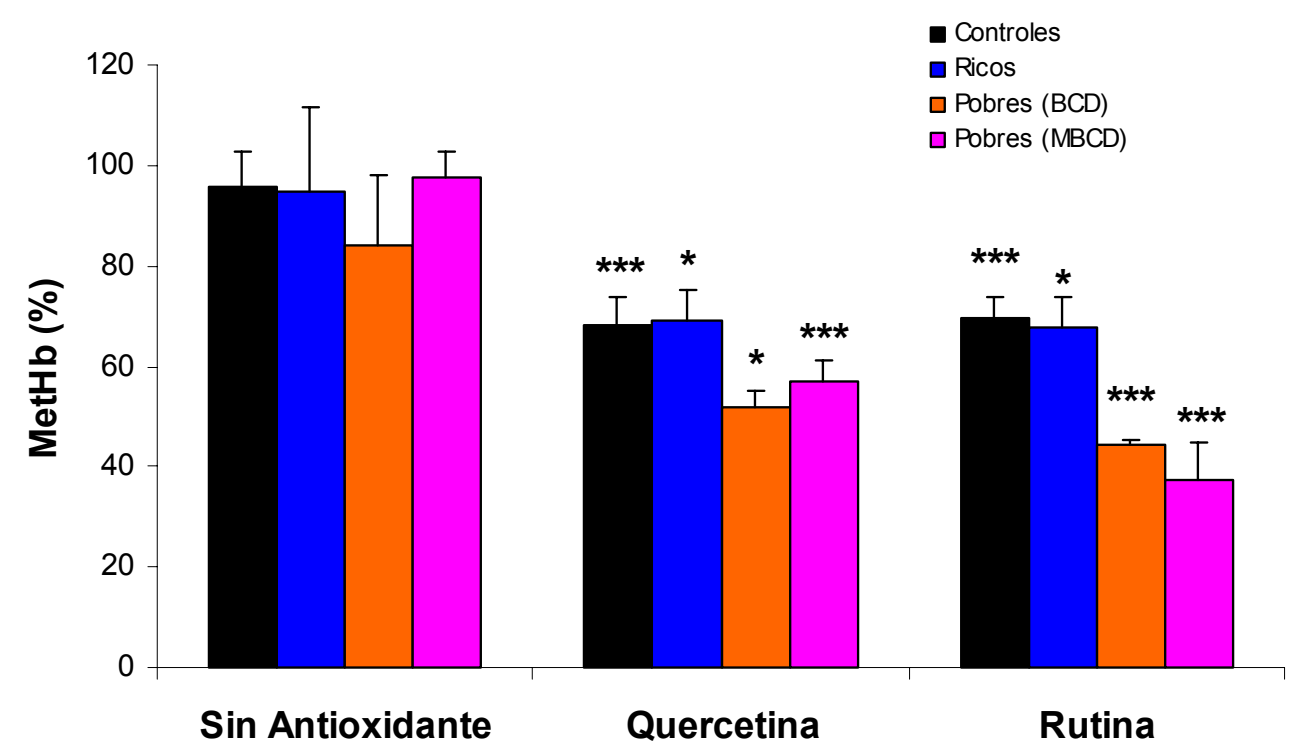

Fig. IV. 11. Efecto de la quercetina y de la rutina sobre la oxidación de la hemoglobina (\% MetHb) en los eritrocitos controles y modificados en sus contenidos de colesterol tras la exposición a 2 mM de tBHP, en una relación antioxidante: oxidante 1:2. Los resultados son la media aritmética \pm D.E. de 4 experimentos independientes. Comparaciones estadísticamente significativas: Por grupo, eritrocitos en presencia de antioxidante $\mathrm{v}_{\mathrm{s}}$ eritrocitos en ausencia de antioxidante, $* \mathrm{p} \leq 0,05, * * *$ $\mathrm{p} \leq 0,001$.

La presencia de los antioxidantes en el medio de reacción y en ausencia de daño oxidativo no provoca cambios significativos en los contenidos de hemoglobina de los distintos eritrocitos (datos no mostrados).

El máximo efecto protector de ambos antioxidantes frente a la oxidación de la hemoglobina por tBHP se observa en los eritrocitos empobrecidos en colesterol. La quercetina inhibe la oxidación de la hemoglobina un 38\% $(p \leq 0,05)$ en los eritrocitos tratados con $B C D$, y un $42 \%(p \leq 0,001)$ en los tratados con MBCD. Por su parte, la rutina inhibe de una forma más efectiva dicha oxidación, consiguiéndose porcentajes de inhibición del 47\% $(p \leq 0,001)$ en eritrocitos tratados con $B C D$ y del $62 \%(p \leq 0,001)$ en eritrocitos tratados con MBCD (Fig. IV. 11).

En eritrocitos controles y ricos en colesterol, el efecto protector de los flavonoides ensayados es menor. Se obtienen porcentajes de inhibición en la oxidación de la hemoglobina en eritrocitos controles del 29 y $28 \%(p \leq 0,001)$ para quercetina y rutina, respectivamente, y del $27 \%$ para quercetina y $29 \%$ para rutina $(p \leq 0,05)$ en los eritrocitos ricos en colesterol (Fig. IV. 11). 
Las comparaciones establecidas a partir de los datos recogidos en la Fig. IV. 12, que están en total consonancia con los resultados mostrados en la Fig. IV. 11, muestran claramente que la rutina tiene un mayor efecto protector frente a la oxidación de la hemoglobina que la quercetina en los eritrocitos pobres en colesterol $[1,3$ veces $(p \leq 0,05)$ más potente en los eritrocitos tratados con $B C D$ y 1,5 veces $(p \leq 0,05)$ en los eritrocitos expuestos a MBCD]. Sin embargo, la protección otorgada por ambos antioxidantes en el resto de los eritrocitos es muy similar, con porcentajes inferiores a los observados en los eritrocitos pobres en colesterol, y que en estos casos se aproximan al $30 \%$, sin que se aprecien diferencias estadísticamente significativas entre ambos antioxidantes (Fig. IV. 12).

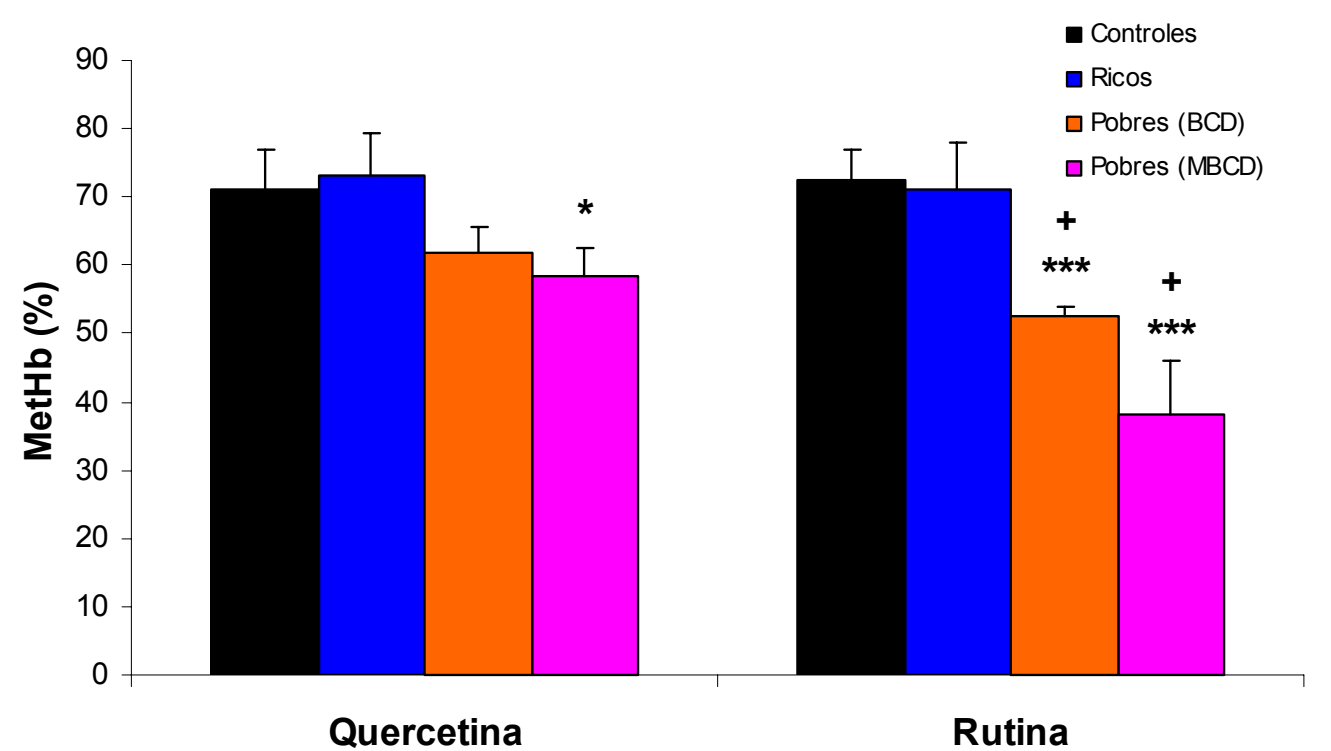

Fig. IV. 12. Comparación del efecto protector de la quercetina frente a la rutina en la oxidación de la hemoglobina (\% MetHb) en los eritrocitos controles y modificados en sus contenidos de colesterol tras la exposición a $2 \mathrm{mM}$ de tBHP, en una relación antioxidante:oxidante 1:2. Se asignó el $100 \%$ a los porcentajes de MetHb detectados en los diferentes grupos de eritrocitos oxidados en ausencia de antioxidante. Los resultados son la media aritmética \pm D.E. de 4 experimentos independientes. Comparaciones estadísticamente significativas: i) Por grupo de eritrocitos, quercetina $v_{s}$ rutina, $+p \leq 0,05$; ii) Por antioxidante: controles $v_{s}$ modificados, $* \mathrm{p} \leq 0,05, * * \mathrm{p} \leq 0,01, * * * \mathrm{p} \leq 0,001$. 


\section{EFECTO PROTECTOR DE LOS FLAVONOIDES QUERCETINA Y RUTINA SOBRE LA OXIDACIÓN DEL GSH INDUCIDA POR +BHP}

El contenido de glutation reducido (GSH) en los eritrocitos controles es similar al que presentan los eritrocitos ricos en colesterol. Sin embargo, el empobrecimiento en colesterol ocasiona aumentos de los contenidos de GSH de 1,25 veces en los tratados con $B C D$, y de 1,4 veces en los expuestos a MBCD $(p \leq 0,05)$ (Tabla IV. 4).

Tabla IV. 4. Contenido de GSH en los eritrocitos controles y modificados en colesterol en ausencia o presencia de $2 \mathrm{mM}$ de tBHP

Contenido de GSH total (nmol GSH/mg Hb)

\begin{tabular}{ccccc}
\hline & Controles & Ricos & Pobres (BCD) & Pobres (MBCD) \\
\hline No oxidados & $7,8 \pm 1,5$ & $8,0 \pm 1,3$ & $9,7 \pm 1,2$ & $10,6 \pm 1,4^{+}$ \\
Oxidados & $2,1 \pm 0,7^{\star \star \star}$ & $2,2 \pm 0,5^{\star \star \star}$ & $1,4 \pm 0,1^{\star \star}$ & $2,6 \pm 0,9^{\star \star \star}$ \\
\hline
\end{tabular}

Los resultados son la media aritmética \pm D.E. de 6 experimentos independientes. Comparaciones estadísticas: i) Eritrocitos no oxidados, control $v_{s}$ modificados, $+p<0,05$; ii) Por grupo de eritrocitos, no oxidados $v_{s}$ oxidados, ${ }^{\star \star} p \leq 0,01,{ }^{\star \star \star} p \leq 0,001$.

El tratamiento con $2 \mathrm{mM}$ de tBHP reduce los contenidos de GSH en un $73 \%$ en los eritrocitos controles y enriquecidos en colesterol $(p \leq 0,001)$, en un $75 \%$ en los eritrocitos pobres en colesterol expuestos a MBCD $(p \leq 0,001)$ y en un $85 \%$ en los eritrocitos pobres en colesterol tratados con $B C D(p \leq 0,01)$ (Tabla IV. 4).

La presencia de los antioxidantes en el medio de oxidación, a una relación antioxidante:oxidante $1: 2$, produce los efectos mostrados en las Fig. IV. 13 (contenidos de GSH total) y Fig. IV. 14 (\% de pérdidas de GSH). Observamos que la máxima protección en la preservación de los contenidos de GSH la ejerce la rutina en los eritrocitos pobres en colesterol, donde el antioxidante protege prácticamente el $100 \%$ de GSH total del eritrocito tras la oxidación, como muestra la Fig. IV. 13 ( $0 \%$ de pérdida de GSH en Fig. IV. 14). En cambio, la quercetina ejerce un efecto protector 1,5 veces menor que la rutina en este tipo de eritrocitos. En el resto de los eritrocitos, controles y enriquecidos en colesterol, ambos antioxidantes alcanzan niveles de protección similares (66-70\%), manteniendo los contenidos de GSH total entre el $70-75 \%$ (Fig. IV. 13), lo que equivale a pérdidas de GSH del 30-35\% (Fig. IV. 14). 


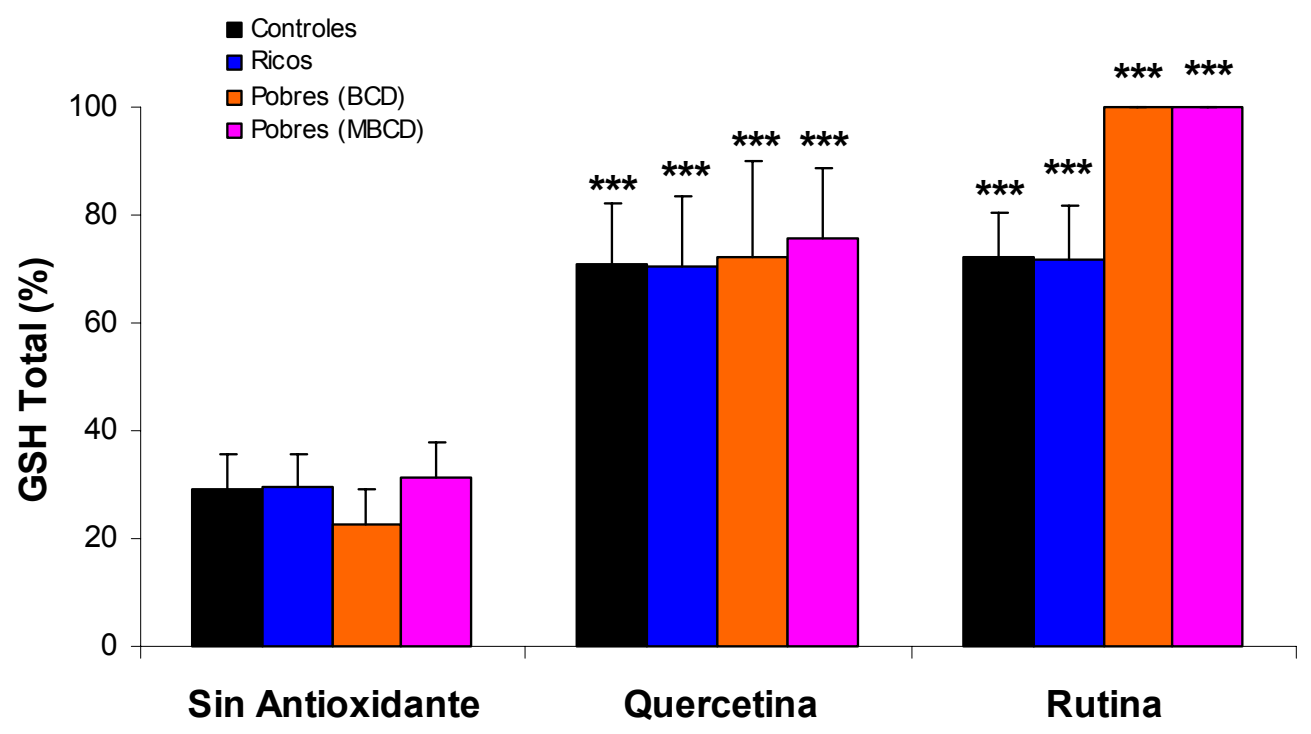

Fig. IV. 13. Efecto de la quercetina y de la rutina sobre la oxidación del GSH en los eritrocitos controles y modificados en sus contenidos de colesterol tras la exposición a $2 \mathrm{mM}$ de tBHP, con una relación antioxidante:oxidante 1:2. Los resultados son la media aritmética \pm D.E. de 7 experimentos independientes. Comparaciones estadísticamente significativas: Por grupo, eritrocitos en presencia de antioxidante $v_{s}$ eritrocitos en ausencia de antioxidante, $* * * p \leq 0,001$.

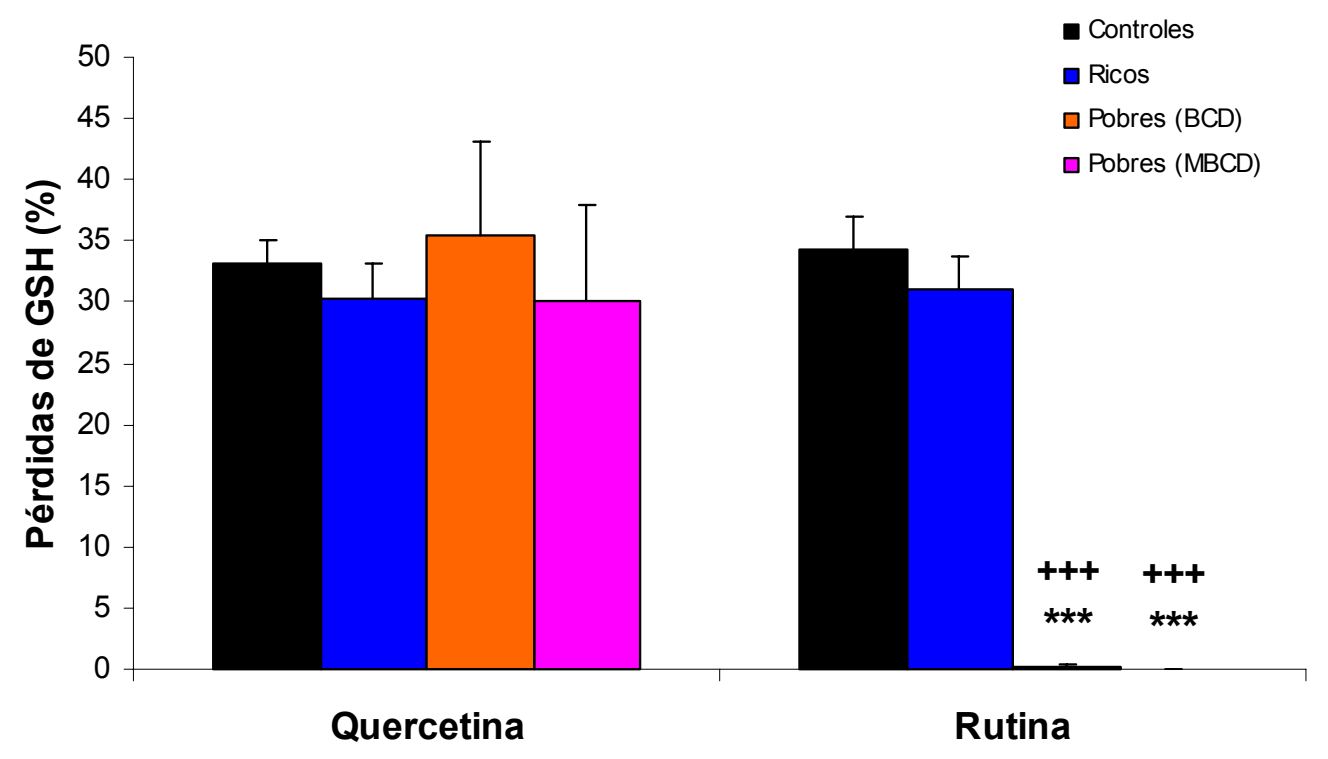

Fig. IV. 14. Comparación del efecto protector de la quercetina frente a la rutina en la oxidación del GSH en eritrocitos controles y modificados en colesterol oxidados con $2 \mathrm{mM}$ de tBHP, con una relación antioxidante:oxidante 1:2. Se asignó el $100 \%$ a los porcentajes de pérdida de GSH total detectados en los diferentes grupos de eritrocitos oxidados en ausencia de antioxidante. Los resultados son la media aritmética \pm D.E. de 7 experimentos independientes. Comparaciones estadísticamente significativas: Por grupo de eritrocitos, quercetina $v_{s}$ rutina, $+++p \leq 0,001$. Por antioxidante, controles $\mathrm{v}_{\mathrm{s}}$ modificados, $* * * \mathrm{p} \leq 0,001$. 


\section{PROTECCIÓN EJERCIDA POR LOS FLAVONOIDES QUERCETINA Y RUTINA SOBRE LA COMPOSICIÓN LIPÍDICA DE LOS DISTINTOS TIPOS DE ERITROCITOS TRAS LA OXIDACIÓN CON TBHP}

\subsection{Protección sobre el contenido en lípidos totales}

Los contenidos en colesterol y fosfolípidos fueron valorados en los extractos lipídicos de los diferentes tipos de eritrocitos, según se describe en los apartados 4.11 .2 y 4.11 .3 del capítulo III.

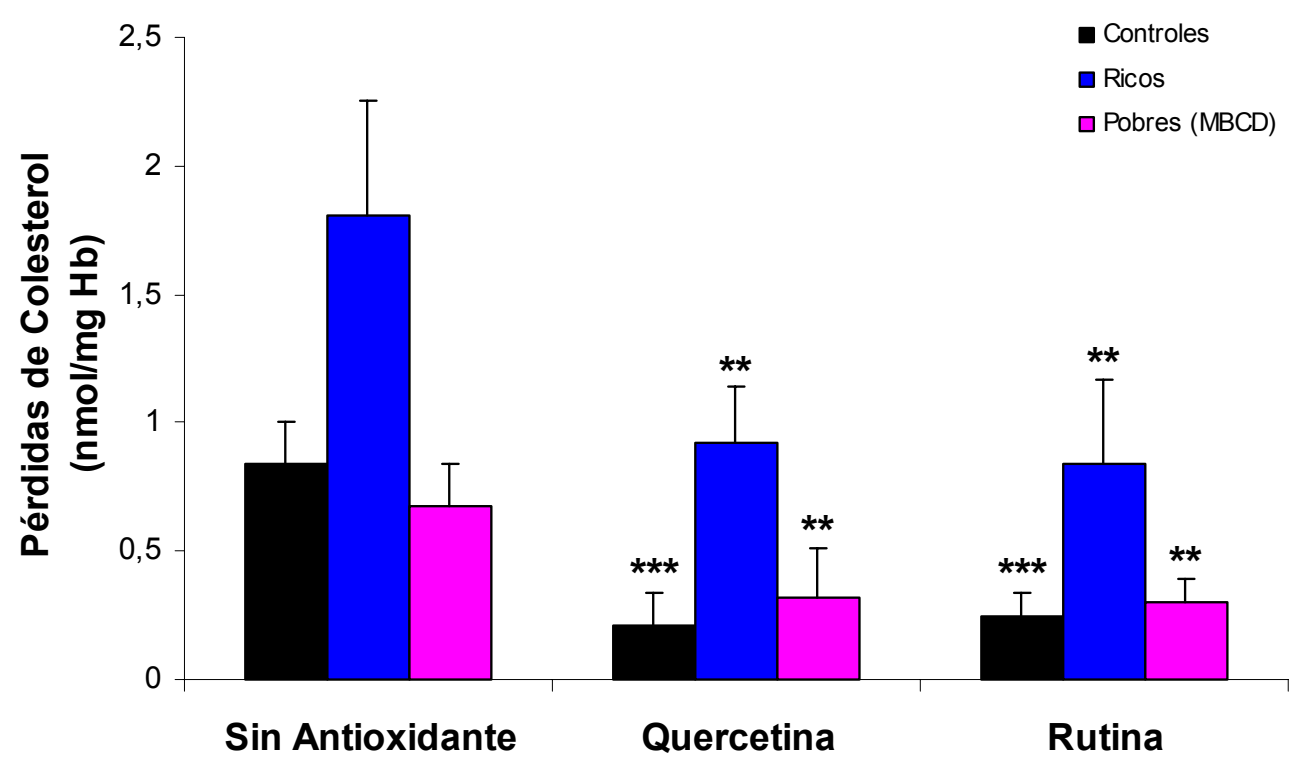

Fig. IV. 15. Pérdidas de colesterol ( $\mathrm{nmol} / \mathrm{mg} \mathrm{Hb}$ ) en eritrocitos controles y modificados oxidados con $\mathbf{2} \mathrm{mM}$ de tBHP en presencia 0 ausencia de $1 \mathbf{~ m M}$ de antioxidante. Los resultados son la media aritmética \pm D.E. de 4 experimentos independientes. Comparaciones estadísticamente significativas: Por grupo de eritrocitos oxidados: en ausencia de antioxidante $v_{s}$ presencia de antioxidante, $* * p \leq 0,01, * * * p \leq 0,001$.

Las pérdidas de colesterol (nmoles/mg $\mathrm{Hb}$ ) en los eritrocitos oxidados durante 30 min con $2 \mathrm{mM}$ de tBHP en ausencia de antioxidante se expresan en la Fig. IV. 15 , y representan pérdidas en dicho esterol del $24 \%$ en eritrocitos controles, $28 \%$ en eritrocitos ricos y $60 \%$ en eritrocitos pobres en colesterol con respecto a sus eritrocitos homólogos no oxidados (datos no mostrados, López-Revuelta et al, 2005).

La presencia tanto de quercetina como de rutina en el medio de reacción, en una relación antioxidante:oxidante 1:2, disminuye de un modo similar las pérdidas de colesterol causadas por el tratamiento con tBHP, 
consiguiéndose porcentajes de protección en torno al $70-75 \%(p \leq 0,001)$ en eritrocitos controles, $48-54 \%(p \leq 0,01)$ en eritrocitos ricos y $52-55 \%(p \leq 0,01)$ en eritrocitos pobres (Fig. IV. 15).

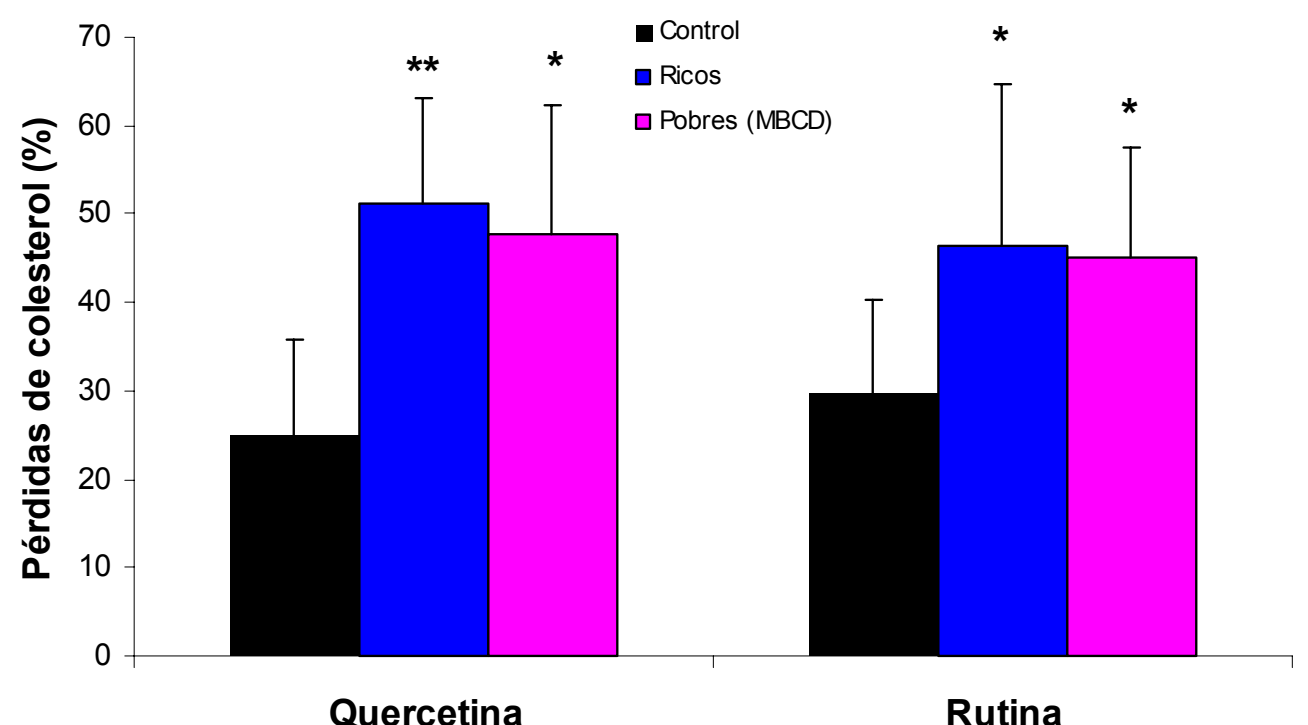

Fig. IV. 16. Estudio comparativo del efecto protector de quercetina y rutina frente a las pérdidas de colesterol en eritrocitos controles y modificados oxidados con $2 \mathrm{mM}$ de tBHP en presencia de $1 \mathrm{mM}$ de antioxidante. Se asignó el $100 \%$ a las pérdidas de colesterol detectadas en los diferentes grupos de eritrocitos oxidados en ausencia de antioxidante. Los resultados son la media aritmética \pm D.E. de 4 experimentos independientes. Comparaciones estadísticamente significativas: Por antioxidante, controles $\mathrm{v}_{\mathrm{s}}$ modificados, $* p \leq 0,05, * * p \leq 0,01$.

La quercetina es aproximadamente 1,5 veces más eficaz en la protección frente a la pérdida de colesterol en los eritrocitos controles con respecto a los modificados, mientras que la rutina alcanza valores de eficacia de 1,3 veces superiores en el mismo tipo de comparación. Los eritrocitos modificados muestran porcentajes de protección similares con ambos antioxidantes, pero siempre inferiores a los detectados en controles, como ya se ha comentado anteriormente (Fig. IV. 16).

Las pérdidas de fosfolípidos totales (nmoles/mg $\mathrm{Hb}$ ) en los eritrocitos oxidados durante $30 \mathrm{~min}$ con $2 \mathrm{mM}$ de tBHP en ausencia de antioxidante se expresan en la Fig. IV. 17, y representan descensos del $25 \%$ en eritrocitos controles, $30 \%$ en eritrocitos ricos y $45 \%$ en eritrocitos pobres en colesterol con respecto a sus eritrocitos homólogos no oxidados (López-Revuelta et al, 2005). 


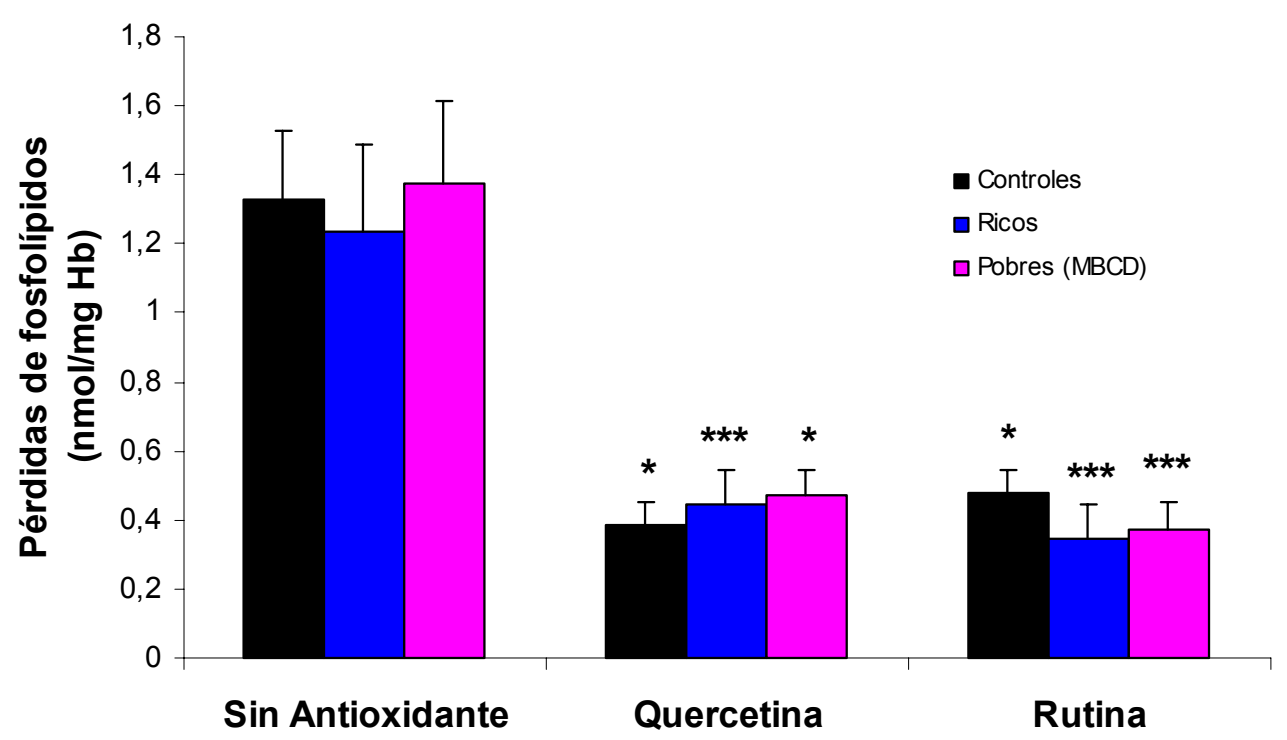

Fig. IV. 17. Pérdidas de fosfolípidos totales en eritrocitos controles $y$ modificados oxidados con $\mathbf{2} \mathbf{~ m M}$ de tBHP en presencia o ausencia de $1 \mathrm{mM}$ de antioxidante. Los resultados son la media aritmética \pm D.E. de 4 experimentos independientes. Comparaciones estadísticamente significativas: Por grupo, eritrocitos en presencia de antioxidante $v_{s}$ eritrocitos en ausencia de antioxidante, $* p \leq 0,05, * * p \leq 0,01, * * * p \leq 0,001$.

En presencia de ambos antioxidantes se observan porcentajes de protección frente a la pérdida de fosfolípidos del $64-71 \%(p \leq 0,05)$ en eritrocitos controles, del $64-72 \%(p \leq 0,001)$ en eritrocitos ricos y del $66-73 \%(p \leq 0,001)$ en eritrocitos pobres en colesterol (Fig. IV. 18).
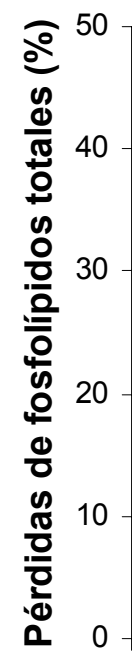

0

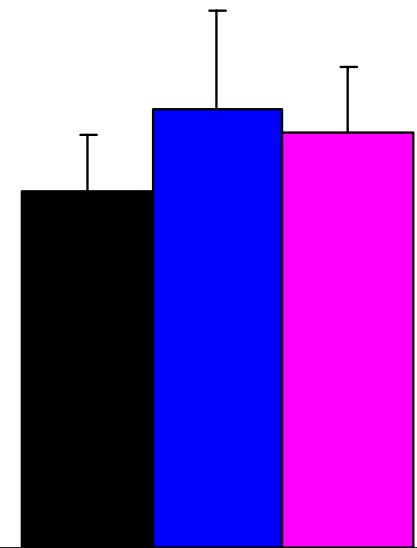

Quercetina
- Control

- Ricos

$\square$ Pobres (MBCD)

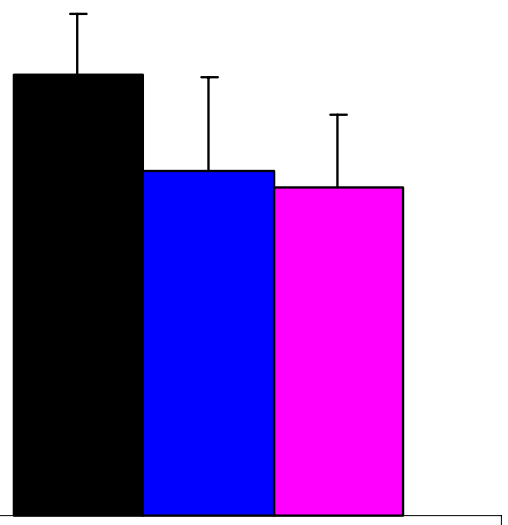

Rutina

Fig. IV. 18. Estudio comparativo del efecto protector de quercetina y rutina frente a las pérdidas de fosfolípidos totales en eritrocitos controles y modificados oxidados con $2 \mathrm{mM}$ de tBHP en presencia de $1 \mathrm{mM}$ de antioxidante. Se asignó el $100 \%$ a las pérdidas de fosfolípidos totales detectadas en los diferentes grupos de eritrocitos oxidados en ausencia de antioxidante. Los resultados son la media aritmética \pm D.E. de 4 experimentos independientes. 
La quercetina protege la pérdida de fosfolípidos tras la oxidación con una efectividad 1,1 veces superior en los eritrocitos controles con respecto a los eritrocitos modificados, mientras que es la rutina la que aporta una protección superior ( 1,1 veces) en los eritrocitos modificados, sin que en ningún caso se observen diferencias estadísticamente significativas.

Aunque los grados de protección otorgados por ambos antioxidantes son muy similares entre sí, sin embargo se observa una tendencia hacia un mayor poder protector de la quercetina con respecto a la rutina en los eritrocitos controles, mientras que en los eritrocitos modificados el proceso se invierte, y es la rutina la que tiene mayor poder antioxidante con respecto a la quercetina.

\subsection{Protección sobre las diferentes clases de fosfolípidos}

El proceso oxidativo inducido por tBHP provoca pérdidas significativas de las principales clases de fosfolípidos: $53 \%$ de fosfatidilcolina (PC) y fosfatidiletanolamina (PE), junto con $34 \%$ de fosfatidilserina/fosfatidilinositol (PS+PI) en los eritrocitos pobres en colesterol; $23-27 \%$ de PC y $28-34 \%$ de PE en los eritrocitos controles y ricos en colesterol (López-Revuelta et al, 2005).

En general, la rutina tiene un efecto protector superior a la quercetina para cada clase de fosfolípido en los eritrocitos modificados, mientras que el proceso se invierte en los eritrocitos controles, dónde la quercetina es mejor protector que la rutina (Fig. IV. 19). Estas conclusiones son concordantes con los perfiles de protección que aportan ambos antioxidantes en los fosfolípidos totales, aspecto ya comentado en el apartado anterior. 

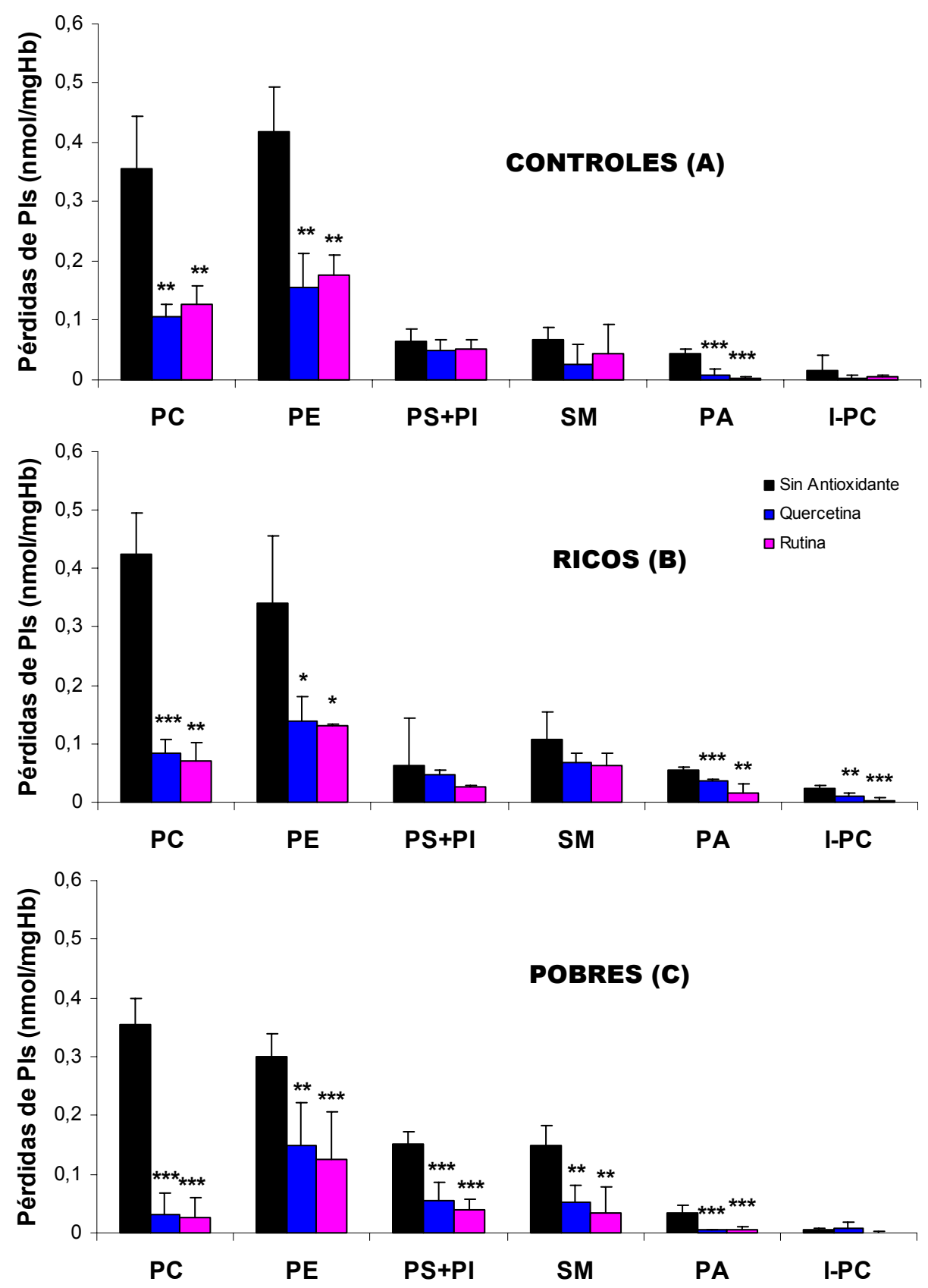

Fig. IV. 19. Protecciones ejercidas por los antioxidantes quercetina y rutina frente a las pérdidas de diferentes tipos de fosfolípidos en eritrocitos controles (panel A), ricos (panel B) y pobres en colesterol (MBCD) (panel C) oxidados con $2 \mathrm{mM}$ de tBHP en una relación antioxidante:oxidante 1:2. Los resultados son la media aritmética \pm D.E. de 4 experimentos independientes. Comparaciones estadísticamente significativas: Por grupo de fosfolípidos, eritrocitos en ausencia de antioxidante $v_{s}$ presencia de antioxidante, $* p \leq 0,05, * * p \leq 0,01$, $* * * \mathrm{p} \leq 0,001$. 
Un análisis individualizado de los fosfolípidos mayoritarios muestra lo siguiente:

1.- La PE presenta porcentajes similares de protección con ambos antioxidantes en los tres tipos de eritrocitos analizados, siendo todos ellos estadísticamente significativos. Con quercetina se consiguen protecciones del $63 \%$ en los controles, $60 \%$ en los ricos y $51 \%$ en los eritrocitos pobres en colesterol. Con la rutina se consiguen porcentajes de protección similares: $58 \%$ en los controles, $62 \%$ en los ricos y $58 \%$ en los eritrocitos pobres en colesterol.

2.- La PC muestra protecciones superiores a la PE en todos los casos analizados. Con la quercetina se consigue aproximadamente 1,1 veces más protección que con la rutina en los eritrocitos controles $\left(70 \% v_{\mathrm{s} .} 64 \%\right)$, mientras que en los eritrocitos modificados se alcanzan protecciones $>80 \%$, siendo siempre más elevados con la rutina ( $83 \%$ en ricos y $93 \%$ en pobres) que con la quercetina ( $80 \%$ en ricos y $91 \%$ en pobres).

3.- Las pérdidas de PS/PI y SM son también parcialmente evitadas en presencia de ambos antioxidantes en los eritrocitos modificados, especialmente en presencia de rutina, que aumenta la protección de forma significativa en los eritrocitos pobres en colesterol. En los eritrocitos controles, la quercetina ejerce una protección superior a la rutina frente al daño oxidativo.

4.- Las pérdidas de ácido fosfatídico (PA), tras la inducción del estrés oxidativo, son también contrarrestadas por la presencia de ambos antioxidantes de un modo significativo $(p \leq 0,001)$ en los distintos tipos de eritrocitos.

\subsection{Protección de los contenidos en ácidos grasos de los lípidos totales}

Los ácidos grasos de las distintas muestras fueron separados e identificados por cromatografía capilar en fase gaseosa acoplada a espectrometría de masas (GC-MS), previa obtención de sus correspondientes ésteres metílicos, tal como se describe en el apartado 4.11.5 del capítulo III.

La acción oxidativa del tBHP altera la composición en ácidos grasos de los lípidos totales procedentes de los eritrocitos modificados, como se ha puesto 
de manifiesto en los trabajos previos realizados por nuestro grupo (LópezRevuelta et al, 2005). Se observan cambios exclusivamente en los porcentajes de los ácidos linoleico $(18: 2, n-6)$ y araquidónico $(20: 4, n-6)$, que descienden significativamente, por lo que los estudios con antioxidantes se circunscriben solamente a estos dos ácidos grasos.

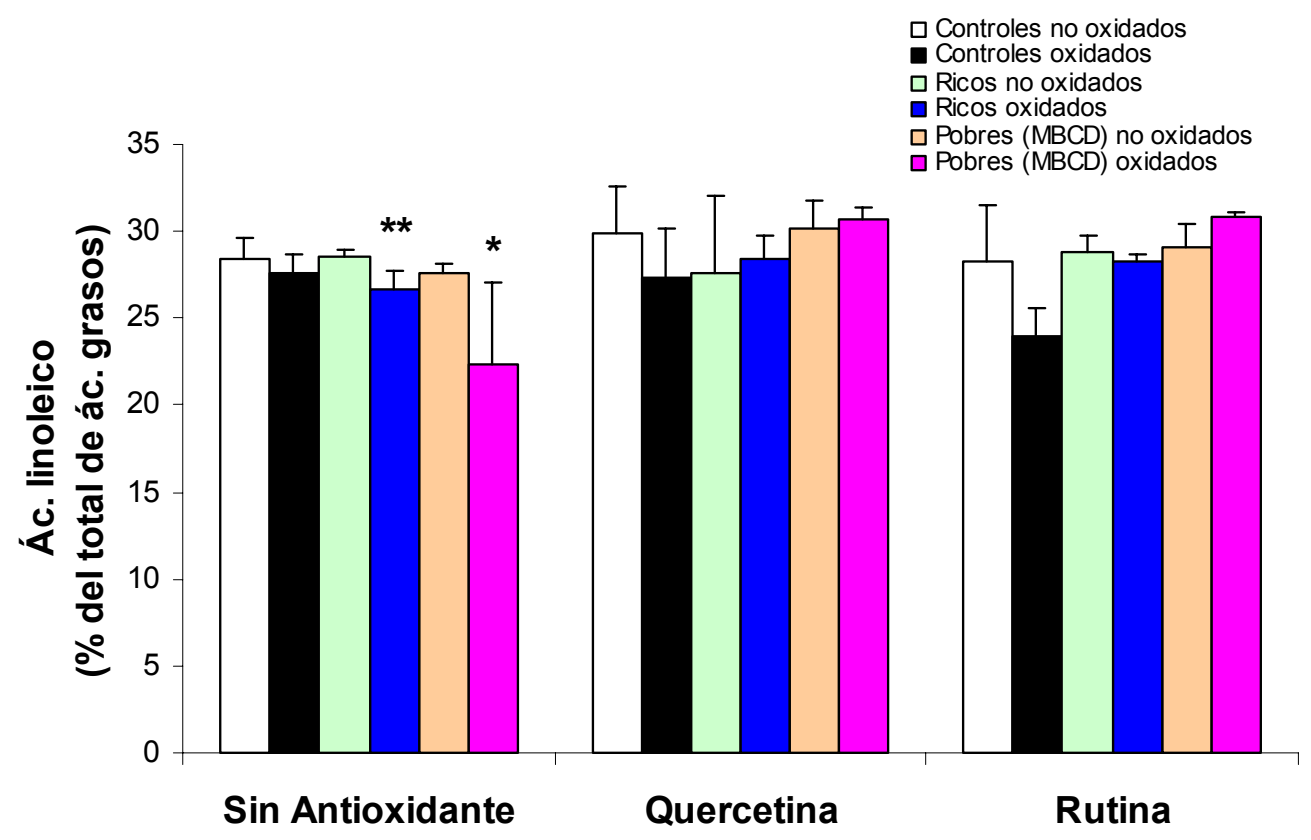

Fig. IV. 20. Protecciones ejercidas por los antioxidantes quercetina y rutina frente a los contenidos de ácido linoléico $(18: 2, n-6)$ de lípidos totales de eritrocitos controles y modificados oxidados con $\mathbf{2}$ mM de tBHP en una relación antioxidante:oxidante 1:2. Los resultados son la media aritmética \pm D.E. de 4 experimentos independientes. Comparaciones estadísticamente significativas: Por grupo de antioxidante, eritrocitos oxidados $v_{\mathrm{s} .}$ eritrocitos no oxidados, $* \mathrm{p} \leq 0,05, * * \mathrm{p} \leq 0,01$.

El daño oxidativo provoca pérdidas de $18: 2$ del $7 \%(p \leq 0,01)$ en eritrocitos ricos y del $19 \%(p \leq 0,05)$ en eritrocitos pobres en colesterol. La incubación de ambas clases de eritrocitos con $1 \mathrm{mM}$ de quercetina o rutina, evita totalmente ( $100 \%$ de protección) la pérdida de dicho ácido graso tras el proceso oxidativo, salvo en el caso de la rutina para los eritrocitos ricos en colesterol, donde sólo se alcanza el $69 \%$ de protección aunque con cambios no significativos (Fig. IV. 20). 


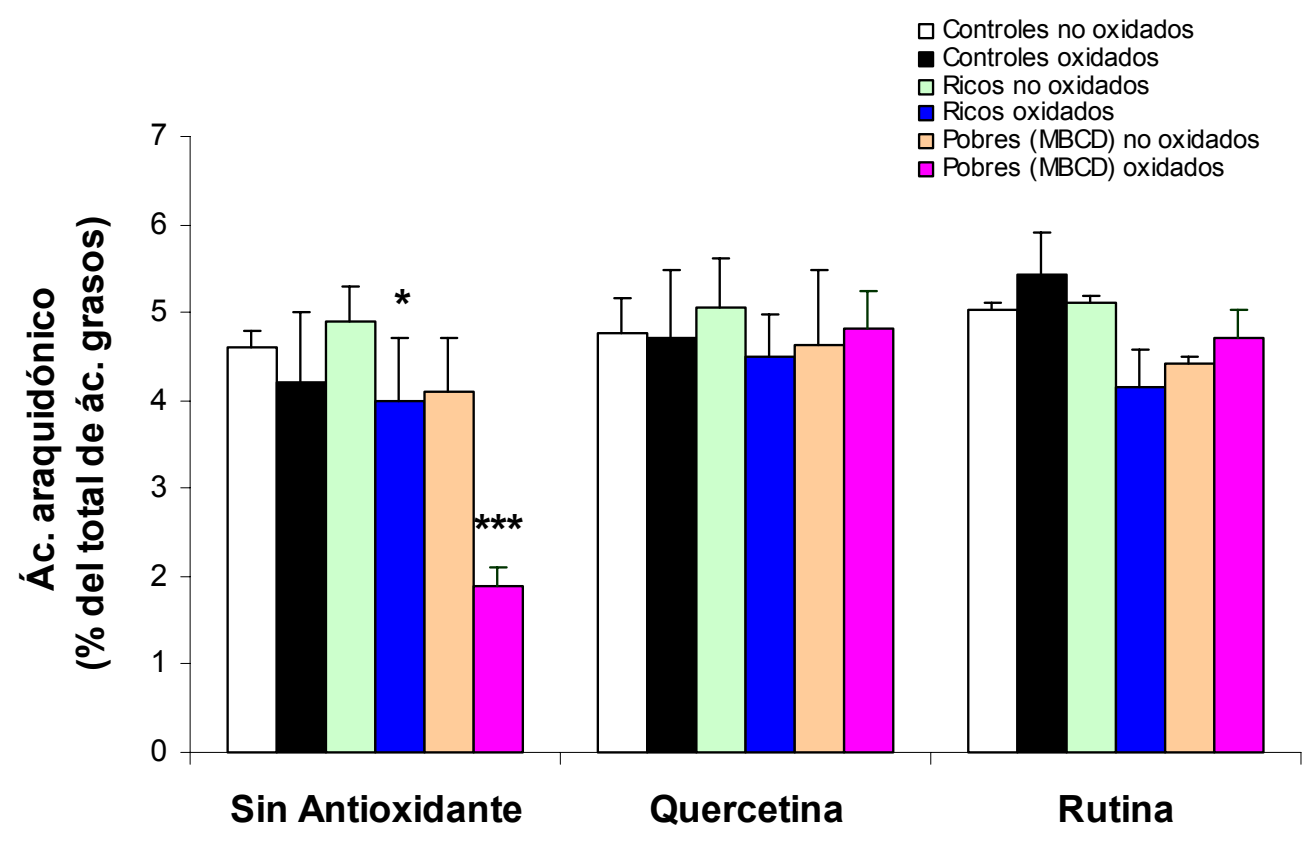

Fig. IV. 21. Protecciones ejercidas por los antioxidantes quercetina y rutina frente a los contenidos de ácido araquidónico $(20: 4, n-6)$ de lípidos totales de eritrocitos controles y modificados oxidados en una relación antioxidante:oxidante 1:2. Los resultados son la media aritmética \pm D.E. de 4 experimentos independientes. Comparaciones estadísticamente significativas: Por grupo de antioxidante, eritrocitos oxidados $\mathrm{v}_{\mathrm{s} .}$ eritrocitos no oxidados, $* \mathrm{p} \leq 0,05, * * * \mathrm{p} \leq 0,001$.

Por lo que respecta al 20:4, se aprecian pérdidas del $18 \%$ en eritrocitos ricos $(p \leq 0,05)$ y del $54 \%$ en eritrocitos pobres en colesterol $(p \leq 0,01)$ tras el proceso oxidativo. Ambos antioxidantes aportan el $100 \%$ de protección frente a la pérdida de este ácido graso tras la oxidación de los eritrocitos pobres en colesterol. Sin embargo en los eritrocitos ricos en colesterol oxidados, ambos antioxidantes aportan protecciones estadísticamente no significativas. La rutina apenas ejerce protección frente a la pérdida de 20:4, y la quercetina sólo consigue aportar el 38\% de protección (Fig. IV. 21). 


\section{ANÁLISIS DE LA PROTECCIÓN EJERCIDA POR QUERCETINA Y RUTINA SOBRE EL ESTADO FÍSICO DE LA MEMBRANA ERITROCITARIA SOMETIDA A OXIDACIÓN}

Los estudios se han realizado utilizando la técnica de polarización de fluorescencia, que permite determinar el grado de microviscosidad (inverso de fluidez) de un sistema, en este caso las membranas eritrocitarias, cuando a ellas se incorpora una sonda fluorescente. En el presente estudio se han empleado dos tipos de sondas fluorescentes que se localizan en distintas regiones de la bicapa lipídica. La sonda 1,6-difenil-1,3,5-hexatrieno (DPH) se sitúa en el núcleo de la bicapa, desplazándose entre las cadenas de ácidos grasos, lo que permite determinar el grado de fluidez de esta región mediante el cálculo de la anisotropía de fluorescencia $\left(r_{\mathrm{s}}\right)$ de esta sonda. La sonda 1-[4(trimetilamonio)-fenil]-6-fenil-1,3,5-hexatrieno (TMA-DPH), derivado catiónico del $\mathrm{DPH}$, que se sitúa en la superficie de la membrana, donde interacciona con las cabezas polares de los fosfolípidos aniónicos.

Las condiciones de medida empleadas en estos estudios de polarización de fluorescencia con las sondas DPH y TMA-DPH incorporadas a la membrana eritrocitaria, están descritas en el apartado 4.12.1 del capítulo III.

Se estudió el grado de fluidez de las membranas procedentes de los eritrocitos controles y modificados en sus contenidos de colesterol, previa incorporación de la sonda DPH o TMA-DPH, midiéndose posteriormente los valores de anisotropía de fluorescencia que presentaban estas sondas. La modificación de los contenidos de colesterol en la membrana eritrocitaria provoca cambios en su fluidez, aspecto puesto ya de manifiesto en estudios previos de nuestro grupo (López-Revuelta et al, 2005). El enriquecimiento en colesterol de la membrana eritrocitaria produce incrementos en los valores de $r_{s}$ del $\mathrm{DPH}$, que son sólo estadísticamente significativos a partir de los $30^{\circ} \mathrm{C}$ (incrementos del $10 \%, p \leq 0,05)$ (Tabla IV. 5), observándose también aumentos no significativos en los valores de $r_{s}$ del TMA-DPH (Tabla IV. 6). El secuestro de colesterol con MBCD provoca el efecto opuesto en los valores de $r_{s}$, obteniéndose descensos estadísticamente significativos para ambas sondas, a todas las temperaturas estudiadas (Tabla IV. 5 y Tabla IV. 6). 
Tabla IV. 5. Valores de anisotropía de fluorescencia $\left(r_{s}\right)$ del DPH incorporado a membranas no oxidadas y oxidadas con tBHP $2 \mathrm{mM}+\mathrm{FeSO}_{4} 0,5$ $\mathrm{mM}$, procedentes de eritrocitos controles $(n=6)$, ricos $(n=4)$ y pobres $(n=4)$ en colesterol

\begin{tabular}{ccccccc} 
& Controles & \multicolumn{2}{c}{ Ricos } & \multicolumn{2}{c}{ Pobres (MBCD) } \\
\cline { 2 - 7 } Temperatura $\left({ }^{\circ} \mathbf{C}\right)$ & No oxidados & Oxidados & No oxidados & Oxidados & No oxidados & Oxidados \\
\hline $\mathbf{1 0}$ & $0,302 \pm 0,004$ & $0,301 \pm 0,003$ & $0,302 \pm 0,005$ & $0,302 \pm 0,006$ & $0,296 \pm 0,003+$ & $0,291 \pm 0,009$ \\
$\mathbf{2 0}$ & $0,267 \pm 0,007$ & $0,261 \pm 0,007$ & $0,277 \pm 0,009$ & $0,268 \pm 0,007$ & $0,260 \pm 0,004$ & $0,257 \pm 0,004$ \\
$\mathbf{3 0}$ & $0,225 \pm 0,008$ & $0,223 \pm 0,001$ & $0,248 \pm 0,011+\boldsymbol{+}$ & $0,241 \pm 0,007$ & $0,212 \pm 0,007+$ & $0,212 \pm 0,004$ \\
$\mathbf{4 0}$ & $0,194 \pm 0,007$ & $0,191 \pm 0,004$ & $0,214 \pm 0,006+\boldsymbol{+}$ & $0,219 \pm 0,007$ & $0,180 \pm 0,007+$ & $0,179 \pm 0,005$ \\
\hline \hline
\end{tabular}

Los resultados son la media aritmética \pm D.E. de $n$ experimentos independientes analizados por triplicado. Por filas, cambios estadísticamente significativos, en eritrocitos no oxidados: controles $\mathrm{v}_{\mathrm{s}}$. modificados, $+p \leq 0,05,++p \leq 0,01$.

La acción oxidativa del tBHP sobre el estado físico de la membrana eritrocitaria no modifica significativamente los valores de $r_{s}$ del DPH en los distintos tipos de eritrocitos, aunque muestran una tendencia hacia el descenso de los valores de $r_{s}$ en los eritrocitos oxidados (Tabla IV. 5). Sin embargo, el proceso oxidativo sí produce descensos estadísticamente significativos en los valores de $r_{s}$ del TMA-DPH a temperaturas de $30^{\circ} \mathrm{C}(4 \%)$ y $40^{\circ} \mathrm{C}(5 \%)$, aunque únicamente en los eritrocitos controles (Tabla IV. 6).

Tabla IV. 6. Valores de anisotropía de fluorescencia $\left(r_{s}\right)$ del TMA-DPH incorporado a membranas no oxidadas y oxidadas con tBHP 2 mM $+\mathrm{FeSO}_{4} 0,5 \mathrm{mM}$, procedentes de eritrocitos controles $(n=4)$, ricos $(n=4)$ y pobres $(n=4)$ en colesterol

\begin{tabular}{|c|c|c|c|c|c|c|}
\hline \multirow[b]{2}{*}{ Temperatura $\left({ }^{\circ} \mathrm{C}\right)$} & \multicolumn{2}{|l|}{ Controles } & \multicolumn{2}{|c|}{ Ricos } & \multicolumn{2}{|c|}{ Pobres (MBCD) } \\
\hline & No oxidados & Oxidados & No oxidados & Oxidados & No oxidados & Oxidados \\
\hline 10 & $0,326 \pm 0,004$ & $0,325 \pm 0,004$ & $0,326 \pm 0,003$ & $0,326 \pm 0,005$ & $0,318 \pm 0,004$ • & $0,322 \pm 0,006$ \\
\hline 20 & $0,314 \pm 0,001$ & $0,313 \pm 0,001$ & $0,311 \pm 0,002$ & $0,315 \pm 0,005$ & $0,300 \pm 0,001++++$ & $0,302 \pm 0,001$ \\
\hline 30 & $0,289 \pm 0,004$ & $0,279 \pm 0,004^{*}$ * & $0,292 \pm 0,004$ & $0,294 \pm 0,003$ & $0,272 \pm 0,004+\boldsymbol{+}$ & $0,273 \pm 0,002$ \\
\hline 40 & $0,275 \pm 0,005$ & $0,260 \pm 0,014$ * & $0,279 \pm 0,002$ & $0,274 \pm 0,002$ & $0,254 \pm 0,004+\boldsymbol{+ +}$ & $0,260 \pm 0,006$ \\
\hline
\end{tabular}

Los resultados son la media aritmética \pm D.E. de $\mathrm{n}$ experimentos independientes analizados por triplicado. Por filas, cambios estadísticamente significativos en eritrocitos no oxidados: controles $\mathrm{v}_{\mathrm{s} .}$ modificados, $\boldsymbol{+} \mathrm{p} \leq 0,05, \boldsymbol{+ \boldsymbol { + }} \mathrm{p} \leq 0,01$, +++ $\mathrm{p} \leq 0,001$; por grupo de eritrocitos, no oxidados $\mathrm{v}_{\mathrm{s} .}$ oxidados, ${ }^{*} \mathrm{p} \leq 0,05,{ }^{*} \mathrm{p} \leq 0,01$.

Antes de analizar los efectos de los antioxidantes frente a los cambios que experimenta el estado físico de la membrana durante la oxidación, se han estudiado previamente los efectos que tiene la incorporación de los antioxidantes sobre el estado físico de las membranas de los diferentes tipos de eritrocitos, en ausencia de oxidación. Para ello, se han determinado los valores 
de $r_{s}$ de las sondas DPH (Fig. IV. 22) y TMA-DPH (Fig. IV. 23) incorporadas a las membranas eritrocitarias, las cuáles han sido previamente tratadas con 1 mM de antioxidante durante 10 min a $37^{\circ} \mathrm{C}$ en ausencia de oxidación.
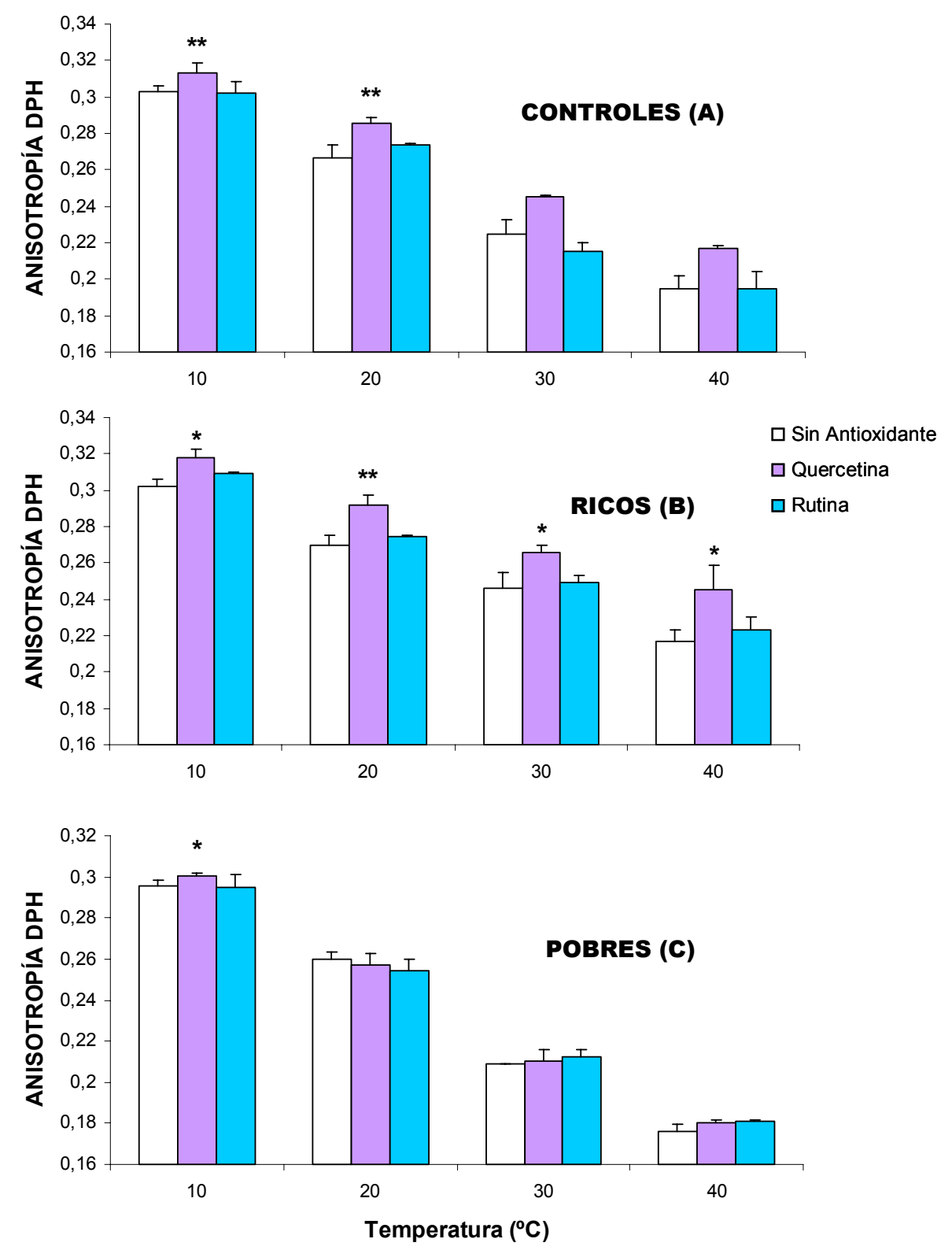

Fig. IV. 22. Efecto de la incorporación de $1 \mathrm{mM}$ de quercetina o rutina sobre los valores de $r_{s}$ del DPH presente en las membranas no oxidadas de eritrocitos controles $(n=5)$ (panel A), ricos $(n=3)$ (panel B) y pobres en colesterol $(\mathbf{n}=\mathbf{3})$ (panel $\mathbf{C})$. Los resultados son la media aritmética \pm D.E. de $\mathrm{n}$ experimentos independientes. Comparaciones estadísticamente significativas: Para una misma temperatura, eritrocitos $\sin$ antioxidante $\mathrm{v}_{\mathrm{s}}$. eritrocitos con antioxidante, $* p \leq 0,05, * * p \leq 0,01, * * * p \leq 0,001$.

Los valores de $r_{s}$ del DPH sólo se modificaban significativamente en las membranas de eritrocitos controles y ricos en colesterol en presencia de quercetina, exclusivamente, produciéndose aumentos alrededor del 3-13\% (Fig. 
IV. 22, paneles A y B). En los eritrocitos pobres en colesterol, la incorporación de uno $u$ otro antioxidante a la membrana apenas provocaba cambios en los valores de $r_{s}$ de la sonda (Fig. IV. 22, panel C).
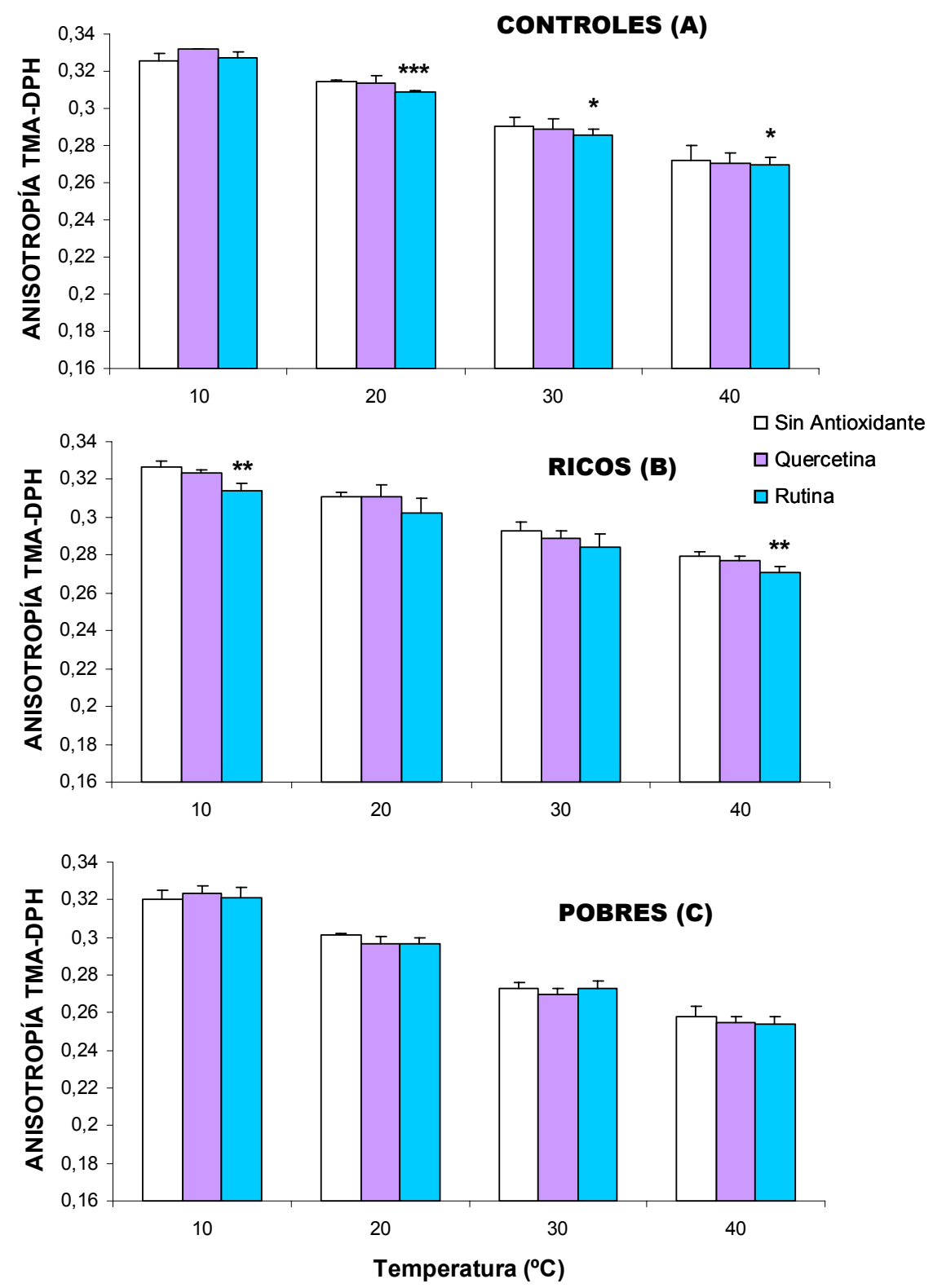

Fig. IV. 23. Efecto de la incorporación de $1 \mathrm{mM}$ de quercetina o rutina sobre los valores de $r_{s}$ del TMA-DPH presente en las membranas no oxidadas de eritrocitos controles $(n=5)$ (panel A), ricos $(n=3)$ (panel B) y pobres en colesterol $(\mathbf{n = 3}$ ) (panel C). Los resultados son la media aritmética \pm D.E. de $\mathrm{n}$ experimentos independientes. Comparaciones estadísticamente significativas: Por temperatura, eritrocitos sin antioxidante $v_{s .}$ eritrocitos con antioxidante, $* p \leq 0,05, * * p \leq 0,01, * * * p \leq 0,001$.

Los valores de $r_{s}$ del TMA-DPH incorporado a las membranas eritrocitarias que contienen los antioxidantes se representan en la Fig. IV. 23. 
En este caso, la quercetina no provoca cambios estadísticamente significativos en estos valores. Sin embargo, la rutina produce pequeños descensos (1-3\%) en los valores de $r_{s}$, circunscritos a las membranas de eritrocitos controles y ricos en colesterol.

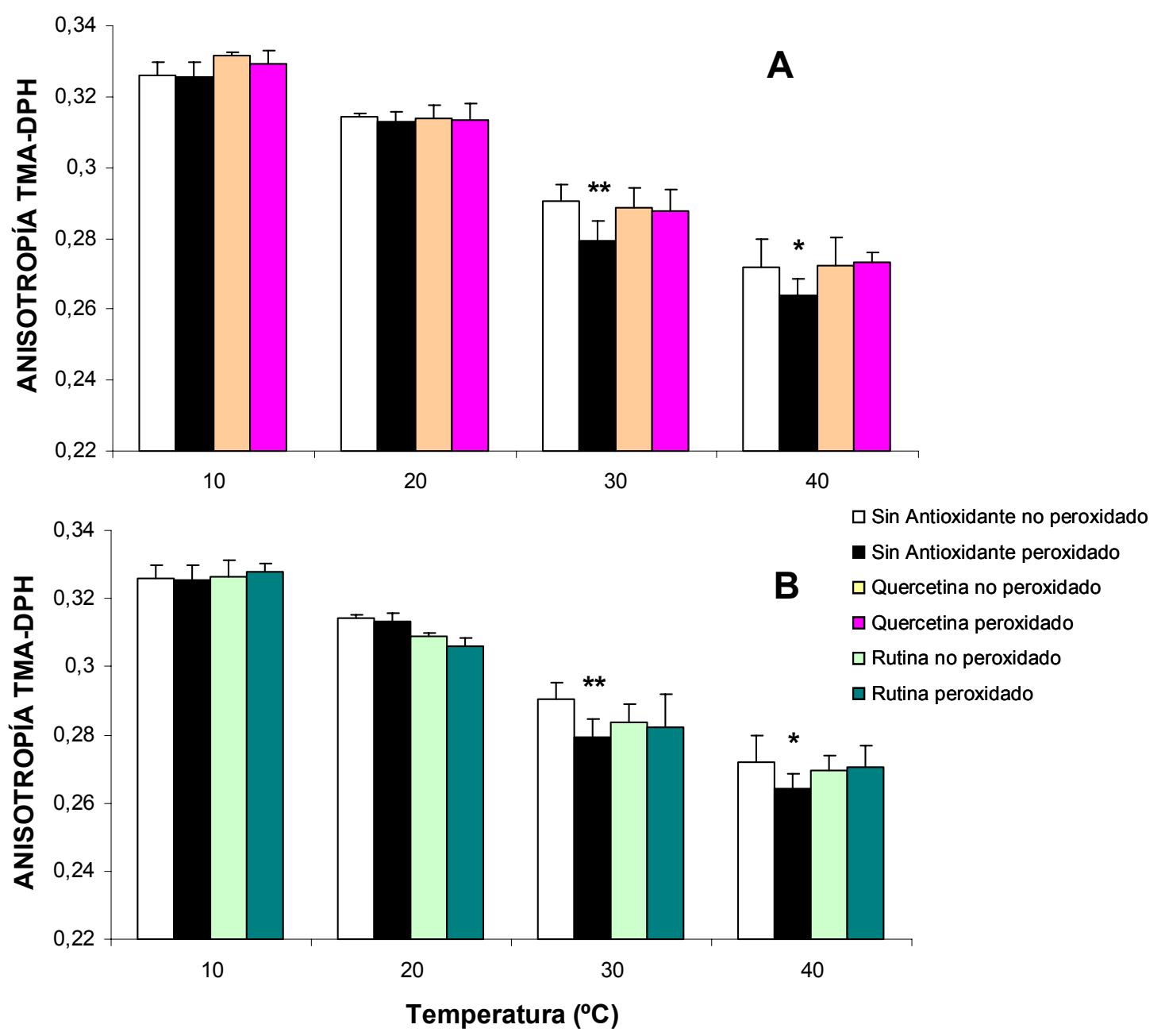

Fig. IV. 24. Análisis de la protección aportada por quercetina (panel A) o rutina (panel B) al estado físico (medido con TMA-DPH) de las membranas de eritrocitos controles, oxidadas dichas membranas en una relación antioxidante:oxidante 1:2. Los resultados son la media aritmética \pm D.E. de 6 experimentos independientes. Comparaciones estadísticamente significativas: Por temperatura, membrana no oxidada $\mathrm{v}_{\mathrm{s}}$. oxidada en ausencia o presencia de antioxidante, $* p \leq 0,05, * * p \leq 0,01$.

Dado que los eritrocitos controles son los únicos que manifiestan cambios en el estado físico de la bicapa lipídica frente al estrés oxidativo, y dichos cambios se limitan a la sonda TMA-DPH, los estudios de protección con antioxidantes se han restringido a este tipo de eritrocitos en presencia de TMADPH. Los resultados obtenidos se exponen en la Fig. IV. 24. 
El tratamiento con $2 \mathrm{mM}$ de tBHP provoca descensos significativos (4\%, $p<0,01$, a $30^{\circ} \mathrm{C} ; 5 \%, p<0,05$, a $40^{\circ} \mathrm{C}$ ) en los valores de $r_{s}$ del TMA-DPH en las membranas de eritrocitos controles. La presencia de quercetina o rutina a concentraciones $1 \mathrm{mM}$ en el medio de oxidación, impiden que se produzcan los descensos observados en la membrana eritrocitaria oxidada, lo que se interpreta como una protección total del estado físico de la membrana, cuando ésta es oxidada en presencia de antioxidante (Fig. IV. 24). 


\section{ANÁLISIS DE LA PROTECCIÓN EJERCIDA POR QUERCETINA Y RUTINA SOBRE LA DISPOSICIÓN ASIMÉTRICA DE LOS FOSFOLÍPIDOS EN LA MEMBRANA ERITROCITARIA OXIDADA}

\subsection{Análisis mediante hidrólisis con fosfolipasa $A_{2}$ de la disposición asimétrica de los fosfolípidos}

Para analizar la distribución de los glicerofosfolípidos en la membrana de los eritrocitos, se ha empleado un método enzimático basado en el tratamiento de la membrana con fosfolipasa $A_{2}$ de veneno de abeja. Esta enzima hidroliza exclusivamente el ácido graso en posición sn-2 de las especies moleculares de los glicerofosfolípidos situados en la cara externa de la bicapa lipídica, en condiciones de impermeabilidad celular. Por tanto, los glicerofosfolípidos situados en la cara externa de la membrana o aquellos que acceden a ella serán degradados, generando el correspondientes liso-glicerofosfolípido. La separación y cuantificación de los diferentes fosfolípidos y sus correspondientes formas liso tras el tratamiento con la fosfolipasa $A_{2}$, permiten estimar la distribución porcentual de cada glicerofosfolípido entre las monocapas externa e interna de la bicapa lipídica. Las condiciones experimentales empleadas para este estudio se recogen en el apartado 4.13.1 del capítulo III.

Estudios previos realizados en nuestro laboratorio ponen de manifiesto que el tratamiento idóneo para analizar la distribución de los fosfolípidos en la membrana, requiere tiempos de incubación con la fosfolipasa $A_{2}$ de 20 min. El tratamiento produce mínima destrucción celular, ya que los porcentajes de hemólisis obtenidos son inferiores al $2 \%$ en eritrocitos controles, del $5 \%$ en eritrocitos ricos y alrededor del $10 \%$ en eritrocitos pobres en colesterol (LópezRevuelta, 2005).

Los eritrocitos de conejo presentan el $78 \%$ de la fosfatidilcolina (PC), el $11 \%$ de la fosfatidiletanolamina (PE) y $<1 \%$ de la fosfatidilserina (PS) situadas en la cara externa de su membrana, localizándose los porcentajes restantes de estos fosfolípidos en la monocapa interna. La modificación de los contenidos de colesterol en su membrana provoca cambios en la disposición de los aminofosfolípidos, sin que ello conlleve un aumento de la lisis celular. El empobrecimiento en colesterol se llevó a cabo mediante tratamiento de los eritrocitos con $M B C D$, ya que es el procedimiento que mejor mantiene la 
integridad celular del eritrocito. Tanto el enriquecimiento como el empobrecimiento de la membrana en colesterol provocan la exteriorización de la PS, alcanzándose valores alrededor del $4 \%$ (aumentos de 11 veces, $p \leq 0,001$ ) en la monocapa externa. La PE solamente se exterioriza durante el empobrecimiento de la membrana en colesterol, situándose el $11 \%$ del fosfolípido en la cara externa de la membrana, lo que equivale a un incremento de 2,5 veces $(p \leq 0,01)$ en la exteriorización de la PE. Sin embargo, la PC no sufre alteraciones en su distribución tras modificarse los contenidos de colesterol en la membrana eritrocitaria (López-Revuelta et al 2007).

En este estudio, el daño oxidativo ha sido inducido con concentraciones de tBHP 0,5 mM en los eritrocitos controles y ricos en colesterol, mientras que los eritrocitos pobres en colesterol han sido oxidados con 0,25 mM de tBHP. Solamente las concentraciones de oxidante iguales 0 inferiores a las anteriormente citadas consiguen mantener la integridad celular (hemólisis $<12 \%$ ) del eritrocito oxidado y expuesto a la fosfolipasa $A_{2}$, condiciones necesarias para poder realizar los estudios proyectados en este apartado. Estos procedimientos fueron analizados en profundidad en estudios previos realizados por nuestro grupo (López-Revuelta, 2005).

El proceso oxidativo inducido por tBHP sólo provoca alteraciones en la disposición de los aminofosfolípidos en la membrana eritrocitaria, sin que se vea afectada la distribución de PC (López-Revuelta et al 2007). Por este motivo, los estudios llevados a acabo en este apartado se han ceñido al análisis exclusivo de la disposición de PE en las membranas de los distintos tipos de eritrocitos, tras ser oxidados en ausencia y presencia de los antioxidantes, dado que la localización de la PS se llevó a acabo mediante citometría de flujo, ya que es una técnica más sensible para detectar la exteriorización de PS. Los resultados obtenidos se muestran en las Fig. IV. 25. 


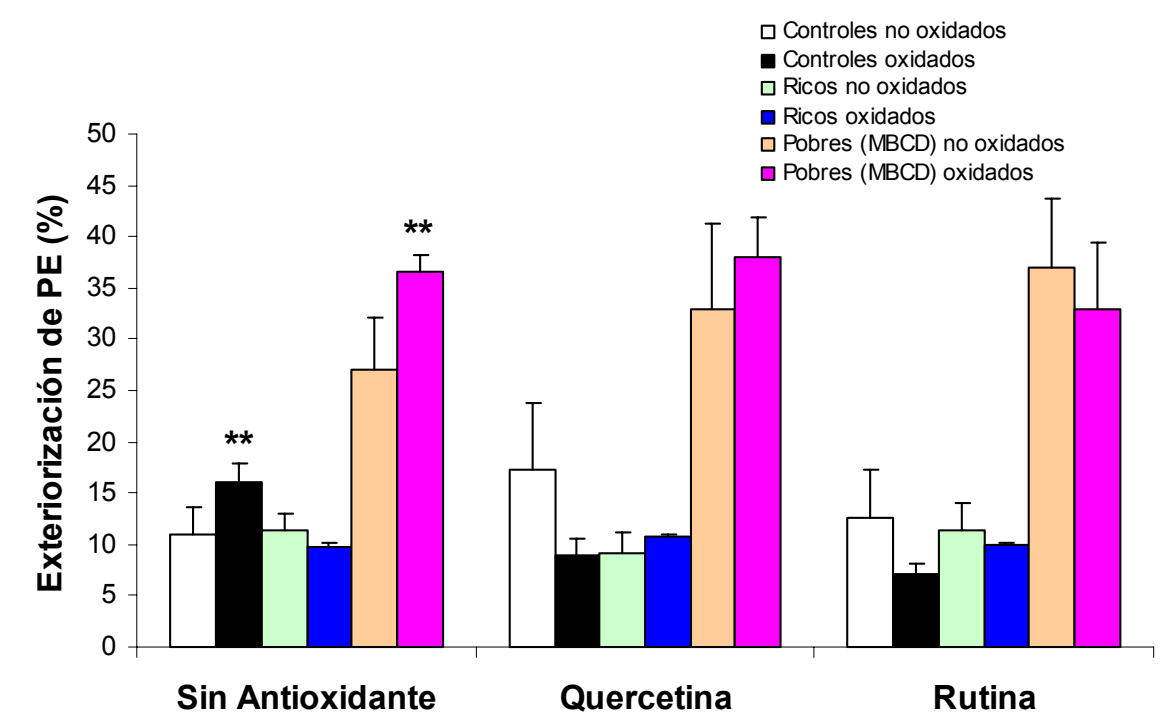

Fig. IV. 25. Distribución de la fosfatidiletanolamina (PE) en la monocapa externa de la membrana de los eritrocitos controles y modificados en colesterol, tras ser oxidados con $\mathrm{tBHP}$ en presencia $O$ ausencia de antioxidante en una relación antioxidante:oxidante 1:2. LOS resultados son la media aritmética \pm D.E. de 6 experimentos independientes. Comparaciones estadísticamente significativas: Por grupo, eritrocitos no oxidados $\mathrm{v}_{\mathrm{s} .}$ oxidados, $* * \mathrm{p} \leq 0,01$.

Como observamos en la Fig. IV. 25, la incorporación de los antioxidantes no provoca cambios significativos en la disposición de la PE en la membrana eritrocitaria de ninguno de los tres tipos de eritrocitos. Sin embargo el tratamiento con 0,5 mM de tBHP produce aumentos significativos en la exteriorización de PE en las membranas de los eritrocitos controles (1,5 veces, $p \leq 0,01)$ y pobres en colesterol $(1,3$ veces, $p \leq 0,01)$.

La presencia de los antioxidantes en el medio de incubación evita totalmente la salida de PE producida en la membrana del eritrocito control al ser oxidado. En los eritrocitos pobres, la rutina también impide dicha salida, mientras que la quercetina consigue una protección sólo del $46 \%$, aunque las diferencias encontradas no son estadísticamente significativas.

\subsection{Análisis mediante citometría de flujo de la exteriorización de fosfatidilserina}

La salida de PS hacia la cara externa de la membrana eritrocitaria ha sido investigada mediante citometría de flujo, aplicada a los distintos tipos de eritrocitos marcados con anexina V-FITC, proteína que lleva incorporada una sonda fluorescente. Esta proteína se une en presencia de $\mathrm{Ca}^{2+}$ a la fosfolípidos 
aniónicos, principalmente PS, presentes en la monocapa externa de la bicapa lipídica.

Las condiciones del marcaje con anexina $\mathrm{V}$ y el análisis por citometría de flujo se detallan en los apartados 4.13.2 del capítulo III.

\subsubsection{Estudio de la integridad celular de los eritrocitos}

Para determinar las poblaciones de células intactas, lo que se asocia con la viabilidad celular, y alteradas en las diferentes muestras tratadas, se analizó por citometría de flujo una muestra de eritrocitos de conejo recién aislados, sin haber sido sometidos a ningún tipo de tratamiento adicional, y otra muestra de eritrocitos hemolizados con agua destilada. La zona del diagrama SSC/FSC donde aparecen los eritrocitos hemolizados se considera la región de células alteradas (no viables) (López-Revuelta, 2005). Una vez establecidas las regiones correspondientes a los eritrocitos intactos y alterados, se procedió al estudio de la integridad celular de los diferentes tipos de eritrocitos tratados con distintas concentraciones de tBHP en presencia 0 ausencia de antioxidantes. Los eritrocitos controles, ricos y pobres en colesterol presentan una viabilidad $>99 \%$ en ausencia de agente oxidante (Tablas IV. 7 y 8 ).

Tabla IV. 7. Estimación por citometría de flujo de los porcentajes de integridad celular en eritrocitos controles y modificados en colesterol tras ser tratados con tBHP en presencia o ausencia de quercetina

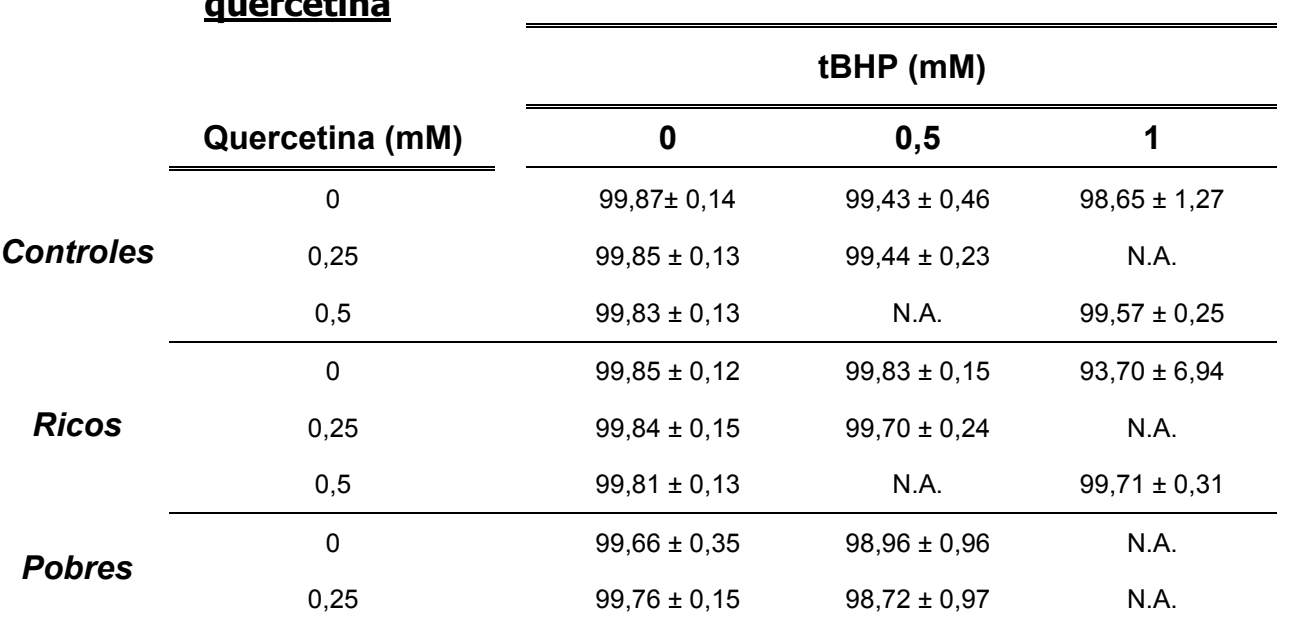

Los resultados son la media aritmética \pm D.E. de 3 experimentos independientes. N.A.: no analizado. 
Tabla IV. 8. Estimación por citometría de flujo de los porcentajes de integridad celular en eritrocitos controles $y$ modificados en colesterol tras ser tratados con tBHP en presencia o ausencia de rutina

\begin{tabular}{|c|c|c|c|c|}
\hline & & & \\
\hline & \multirow[b]{2}{*}{ Rutina (mM) } & \multicolumn{3}{|c|}{ tBHP (mM) } \\
\hline & & 0 & 0,5 & 1 \\
\hline \multirow{3}{*}{ Controles } & 0 & $99,87 \pm 0,14$ & $99,43 \pm 0,46$ & $98,65 \pm 1,27$ \\
\hline & 0,25 & $99,78 \pm 0,23$ & $99,48 \pm 0,41$ & N.A. \\
\hline & 0,5 & $99,87 \pm 0,08$ & N.A. & $98,98 \pm 0,74$ \\
\hline \multirow{3}{*}{ Ricos } & 0 & $99,85 \pm 0,12$ & $99,83 \pm 0,15$ & $93,70 \pm 6,94$ \\
\hline & 0,25 & $99,83 \pm 0,12$ & $99,85 \pm 0,13$ & N.A. \\
\hline & 0,5 & $99,86 \pm 0,11$ & N.A. & $99,68 \pm 0,19$ \\
\hline \multirow{2}{*}{ Pobres } & 0 & $99,66 \pm 0,35$ & $98,96 \pm 0,96$ & N.A. \\
\hline & 0,25 & $99,75 \pm 0,22$ & $99,32 \pm 0,52$ & N.A. \\
\hline
\end{tabular}

Los resultados son la media aritmética \pm D.E. de 3 experimentos independientes. N.A., no analizado.

Análisis previos realizados en nuestro laboratorio muestran que la integridad celular de los eritrocitos controles y ricos en colesterol tratados con 1 $\mathrm{mM}$ de tBHP oscila entre el 93 y $98 \%$, disminuyendo hasta el $51 \%$ con $1,5 \mathrm{mM}$ de tBHP; mientras que en los eritrocitos pobres (MBCD) en colesterol tratados con $0,5 \mathrm{mM}$ de tBHP la viabilidad es del $98 \%$, descendiendo hasta el $36 \%$ cuando son oxidados con 0,75 mM de tBHP (López-Revuelta, 2005; LópezRevuelta et al 2007). Por lo tanto, los estudios de citometría de flujo aquí realizados, se han efectuado con concentraciones $0,5 \mathrm{mM}$ de tBHP en los tres tipos de eritrocitos, y con $1 \mathrm{mM}$ de tBHP en eritrocitos controles y ricos en colesterol, con el fin de oxidarlos en presencia o ausencia de los antioxidantes.

La presencia de los antioxidantes no disminuye prácticamente la integridad celular en los diferentes tipos de eritrocitos, manteniéndola siempre $>98 \%$ en presencia o ausencia de agente oxidante (Tablas IV. 7 y 8 ). 


\subsubsection{Análisis porcentual de los eritrocitos marcados con anexina V-FITC}

Los estudios de exteriorización de la PS realizados en los distintos tipos de eritrocitos por citometría de flujo se efectuaron siempre sobre poblaciones de células intactas, es decir aquellas poblaciones que mostraron viabilidad $>98 \%$.

Nuestras condiciones experimentales de marcaje permitieron obtener un porcentaje de eritrocitos controles marcados con anexina V-FITC del 0,11 \pm $0,04 \%$. La modificación de los contenidos de colesterol no provoca cambios significativos en dicho valor.

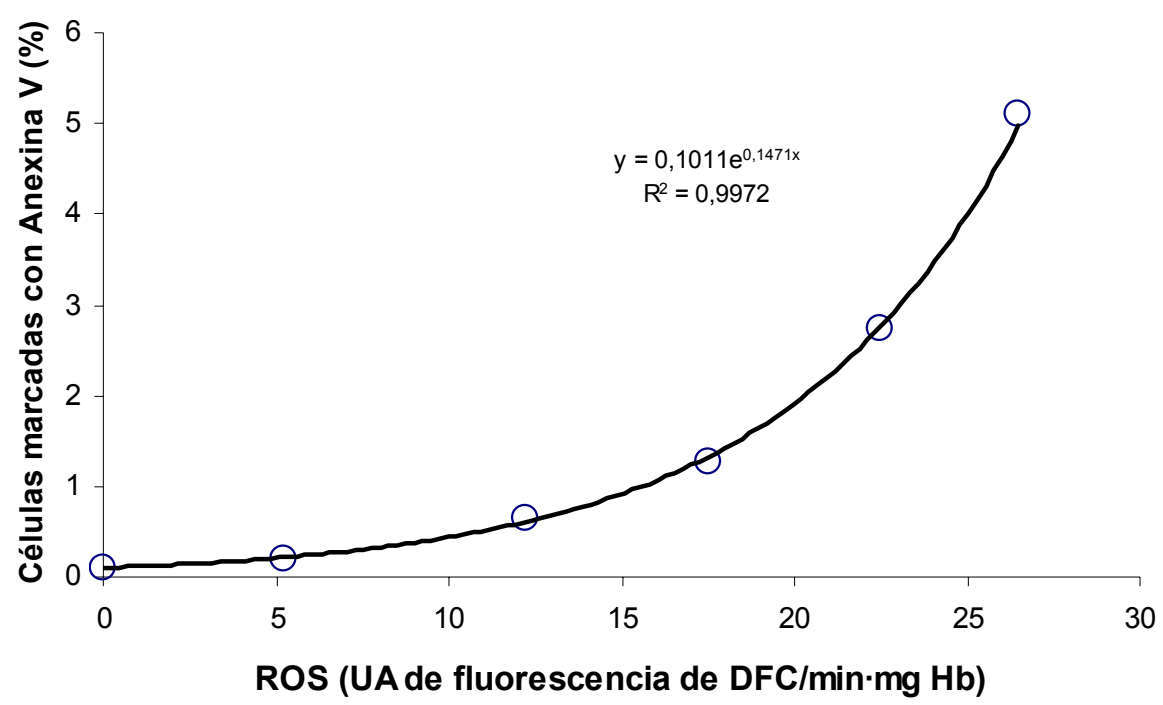

Fig. IV. 26. Relación entre la exteriorización de PS (expresada como \% de células marcadas con anexina V-FITC) y el estrés oxidativo (expresado como ROS generados en el eritrocito). Los eritrocitos controles fueron tratados con concentraciones progresivas de tBHP (0-1 $\mathrm{mM})$. Los resultados son la media aritmética \pm D.E. de 3 experimentos independientes.

Como puede observarse en la Fig. IV. 26, el aumento de la producción de ROS en el eritrocito genera un incremento exponencial del porcentaje de células marcadas con anexina V-FITC, lo que se asocia con una exteriorización progresiva de la PS hacia la superficie del eritrocito. 

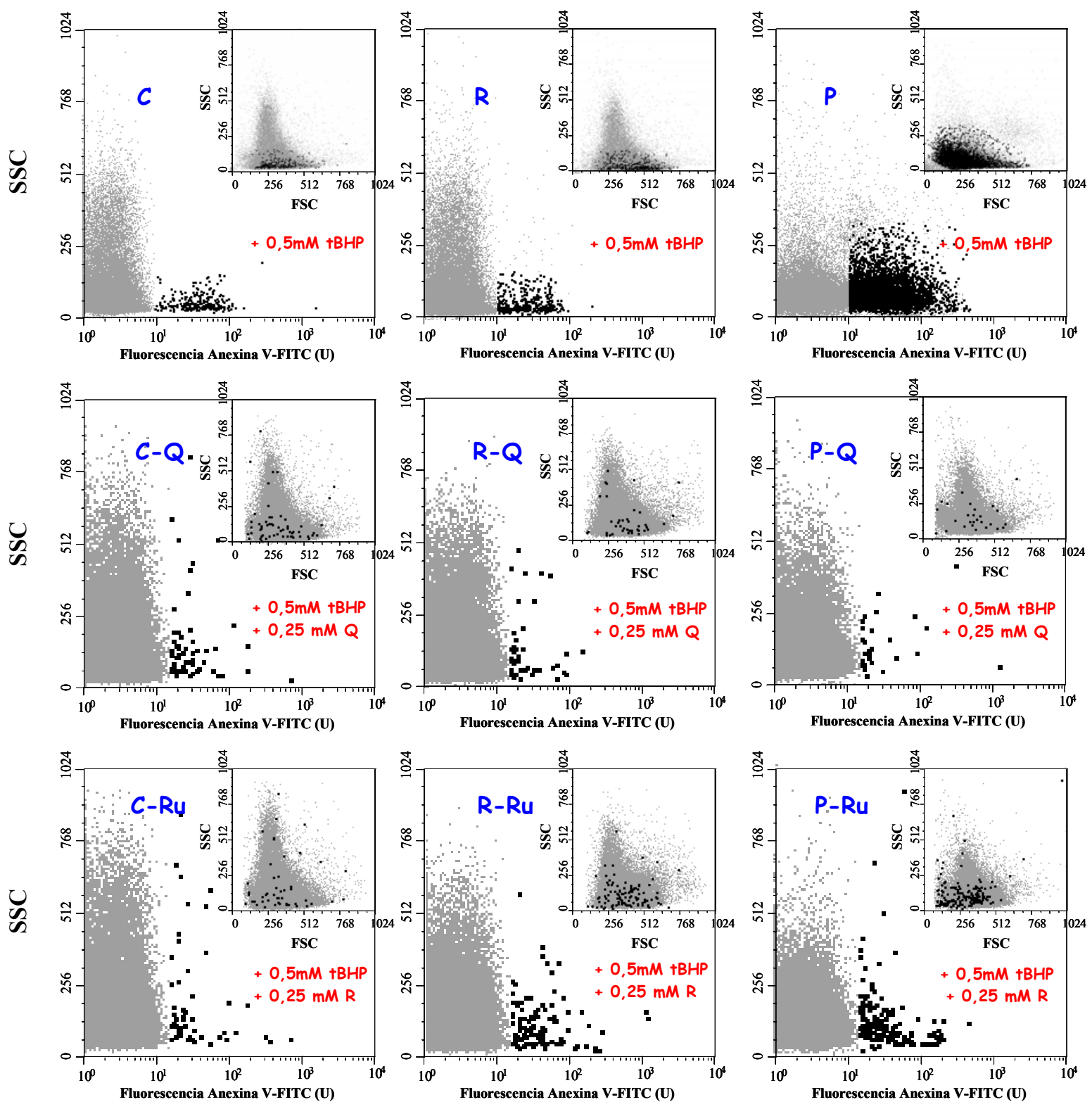

Fig. IV. 27. Análisis de la exteriorización de la PS por citometría de flujo en eritrocitos controles (C), ricos (R) y pobres en colesterol (P) oxidados con $0,5 \mathrm{mM}$ de tBHP, en ausencia 0 presencia de quercetina $(\mathbf{Q})$ o rutina $(\mathbf{R u})$. Imágenes representativas de uno de los 4 experimentos realizados. Las figuras grandes representan los diagramas de SSC/fluorescencia, a partir de los cuáles se cuantifican los porcentajes de células viables marcadas. Las figuras pequeñas (englobadas en las grandes) representan los diagramas de puntos SSC/FSC que determinan las poblaciones de eritrocitos intactos. Las células fluorescentes vienen representadas por las nubes de puntos negros y las no fluorescentes por las nubes de puntos grises. 
A partir de los diagramas de citometría de flujo, uno de cuyos experimentos se representa en la Fig. IV. 27, se han calculado los porcentajes de eritrocitos marcados con anexina V-FITC en cada caso, cuyos datos están representados en la Fig. IV. 28 (estudios con concentraciones de tBHP 0,5 mM) y en la Fig. IV. 29 (estudios con concentraciones de oxidante $1 \mathrm{mM}$ ).
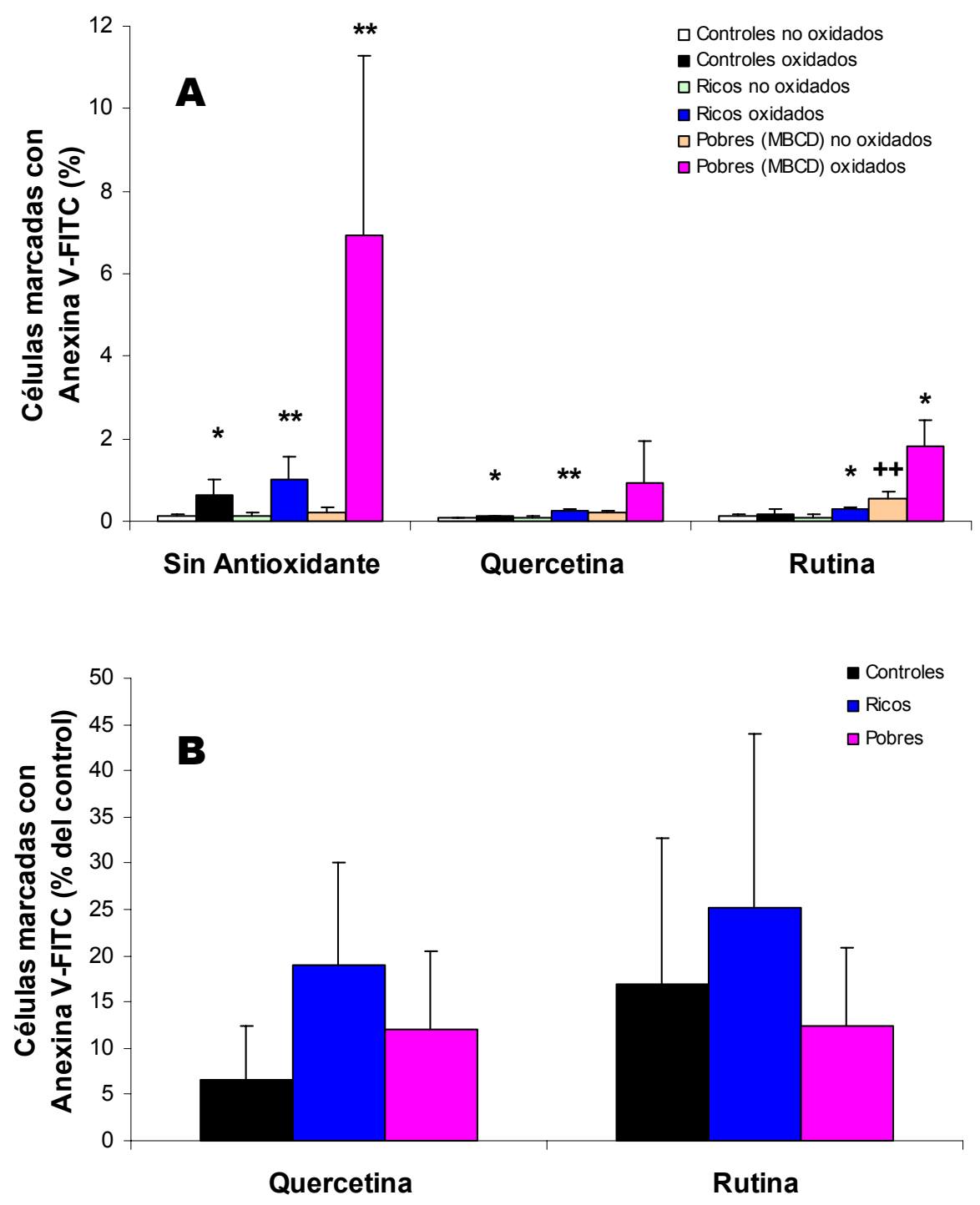

Fig. IV. 28. Efecto protector de los antioxidantes quercetina y rutina sobre la exteriorización de PS (expresada como \% de células unidas a anexina V-FITC) en los tres tipos de eritrocitos tratados con $0,5 \mathrm{mM}$ de tBHP. Panel A: En eritrocitos no oxidados y oxidados en ausencia y presencia de antioxidante $0,25 \mathrm{mM}$. Comparaciones estadísticamente significativas: i) Con o sin antioxidante, eritrocitos no oxidados $v_{s}$ oxidados, $* p \leq 0,05, * * p \leq 0,01$. ii) Entre eritrocitos del mismo tipo no oxidados, en ausencia $v_{s}$. presencia de antioxidante, $++p \leq 0,01$; Panel B: Se asignó el $100 \%$ a los porcentajes de células marcadas con anexina V-FITC detectados en los diferentes grupos de eritrocitos oxidados en ausencia de antioxidante (Control). Los resultados son la media aritmética \pm D.E. de 4 experimentos independientes. 
La incorporación de $0,25 \mathrm{mM}$ de los antioxidantes no provoca alteraciones en los valores de células marcadas con anexina V-FITC, porcentajes que son similares a los que muestran los diferentes tipos de eritrocitos no oxidados $(<0,2 \%)$, salvo en el caso de la rutina cuando se incorpora en eritrocitos pobres en colesterol, donde la presencia del flavonoide produce un aumento del porcentaje de células marcadas de 2,8 veces $(p \leq 0,01)$ (Fig. IV. 28 A). La oxidación inducida por tBHP 0,5 mM genera aumentos significativos en el porcentaje de células marcadas con anexina V-FITC en los eritrocitos controles $(6$ veces, $p \leq 0,05)$, ricos $(8$ veces, $p \leq 0,01)$ y pobres en colesterol (34 veces, $p<0,01$ ) (Fig. IV. $28 \mathrm{~A}$ ). La presencia de 0,25 mM de quercetina en el medio con $0,5 \mathrm{mM}$ de tBHP, reduce considerablemente los valores de eritrocitos marcados, alcanzándose protecciones del $93 \%$ en eritrocitos controles, del $81 \%$ en ricos y del $88 \%$ en eritrocitos pobres en colesterol. La rutina en condiciones idénticas a las anteriores, ejerce grados de protección algo inferiores a la quercetina, del $87 \%$ en controles, del $75 \%$ en ricos y del $88 \%$ en eritrocitos pobres en colesterol (Fig. IV. 28 B).

La presencia de 0,5 $\mathrm{mM}$ de antioxidante en el medio, en ausencia de oxidación, tampoco induce alteraciones en los porcentajes de eritrocitos marcados, ya que se observan valores porcentuales similares a los que presentan los eritrocitos controles y ricos en colesterol no oxidados $(<0,2 \%)$, excepto cuando se incorpora la rutina a los eritrocitos ricos en colesterol, que produce un aumento $(2,1$ veces, $p \leq 0,001)$ del porcentaje de eritrocitos marcados (Fig. IV. 29 A). Cuando estos eritrocitos se exponen a concentraciones $1 \mathrm{mM}$ de tBHP, en ausencia de antioxidantes, se producen aumentos significativos de los porcentajes de células marcadas, 45 veces $(p \leq 0,001)$ en los eritrocitos controles y 26 veces $(p \leq 0,01)$ en los eritrocitos ricos en colesterol. De nuevo la presencia de los antioxidantes en el medio de oxidación evita de un modo muy eficiente la exteriorización de la PS producida en el eritrocito oxidado. La quercetina consigue protecciones del $97 \%$ y $84 \%$ en los eritrocitos controles y ricos en colesterol, respectivamente, mientras que la rutina aporta protecciones algo inferiores, del $84 \%$ en eritrocitos controles y del $63 \%$ en eritrocitos ricos en colesterol. Los eritrocitos controles son significativamente $(p \leq 0,01)$ mejor protegidos frente a la exteriorización de PS por ambos antioxidantes que los eritrocitos modificados, demostrándose también que la quercetina es mejor protector que la rutina tanto en los eritrocitos controles $(p \leq 0,01)$, como en los ricos en colesterol (no significativo) (Fig. IV. 29 B). 

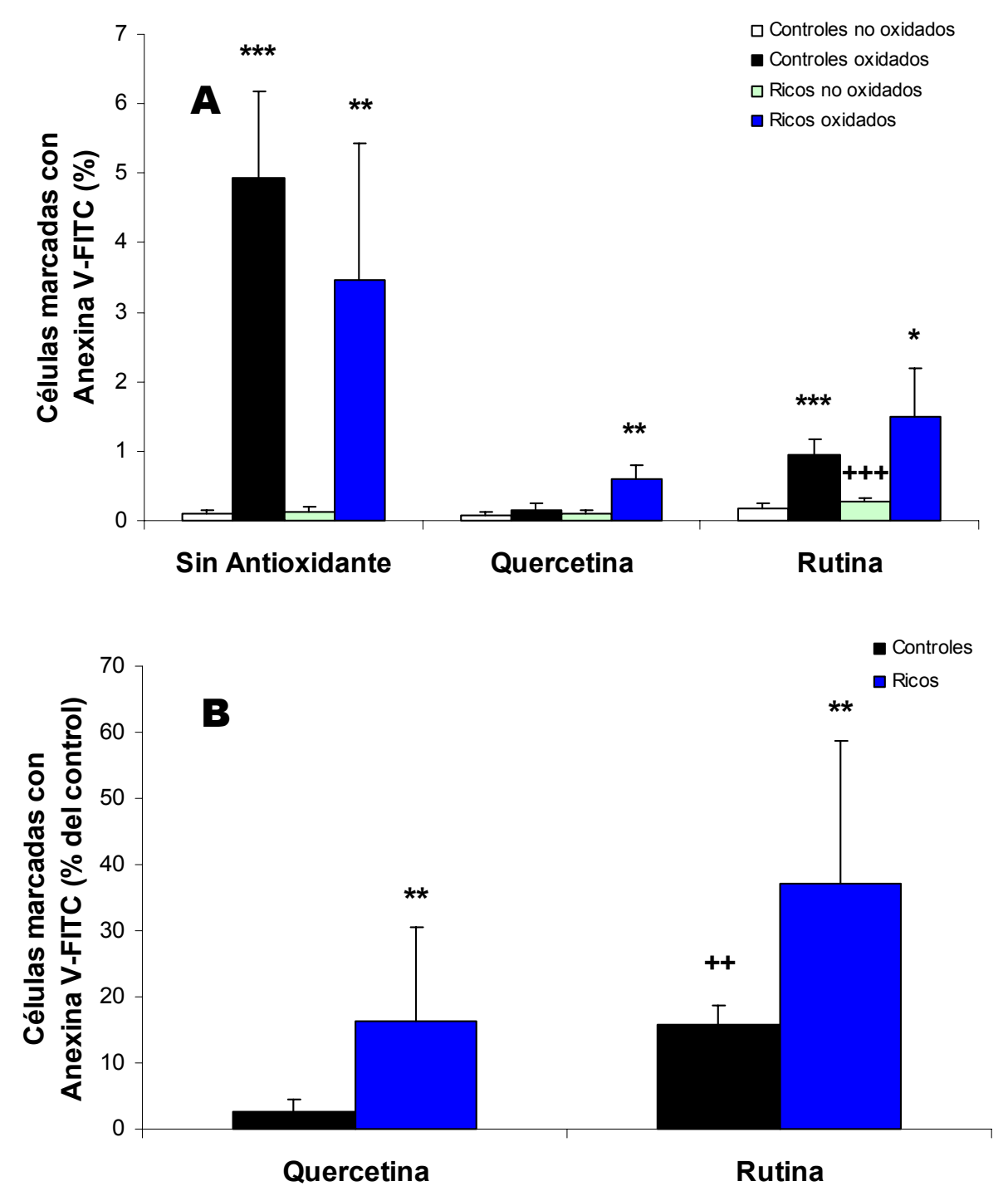

Fig. IV. 29. Efecto protector de los antioxidantes quercetina y rutina sobre la exteriorización de PS (expresada como \% de células unidas a anexina V-FITC) en los tres tipos de eritrocitos tratados con $1 \mathrm{mM}$ de tBHP. Panel A: En eritrocitos no oxidados y oxidados en ausencia y presencia de antioxidante $0,5 \mathrm{mM}$. Comparaciones estadísticamente significativas: i) Con o sin antioxidante, eritrocitos no oxidados $v_{\mathrm{s}}$ oxidados, $* p \leq 0,05, * * p \leq 0,01$. ii) Entre eritrocitos del mismo tipo no oxidados, en ausencia $v_{s}$. presencia de antioxidante, $++p \leq 0,01$; Panel B: Se asignó el $100 \%$ a los porcentajes de células marcadas con anexina V-FITC detectados en los diferentes grupos de eritrocitos oxidados en ausencia de antioxidante (Control). Comparaciones estadísticamente significativas: i) Por grupo de eritrocitos, quercetina $v_{s}$ rutina, $++p \leq 0,01$; ii) Por antioxidante: controles $v_{\mathrm{s} .}$ modificados, $* * \mathrm{p} \leq 0,01$. Los resultados son la media aritmética $\pm \mathrm{D}$.E. de 4 experimentos independientes. 


\subsection{Estudio de la fagocitosis en los diferentes tipos de eritrocitos tratados}

Una de las señales de reconocimiento de las células dañadas o envejecidas reside en la exteriorización de la PS, de forma que una salida gradual de este aminosfosfolípido hacia el exterior de la membrana es indicativo de que la célula no es viable, y será reconocida por los macrófagos, que la fagocitarán (Fadok et al, 2001). En nuestro estudio hemos utilizado macrófagos de ratón 3774 para llevar a cabo los ensayos de fagocitosis, que han sido efectuados en eritrocitos controles y modificados en colesterol oxidados con tBHP en presencia o ausencia de antioxidante.

El análisis se ha llevado a cabo tal como se detalla en el apartado 4.15.2 del capítulo III, realizándose un recuento de los macrófagos que han fagocitado uno o más eritrocitos (macrófagos positivos) y expresándose los resultados de fagocitosis en porcentajes de macrófagos positivos. Una imagen representativa de la fagocitosis de eritrocitos por macrófagos de ratón 3774 se observa en la Fig. IV. 30.

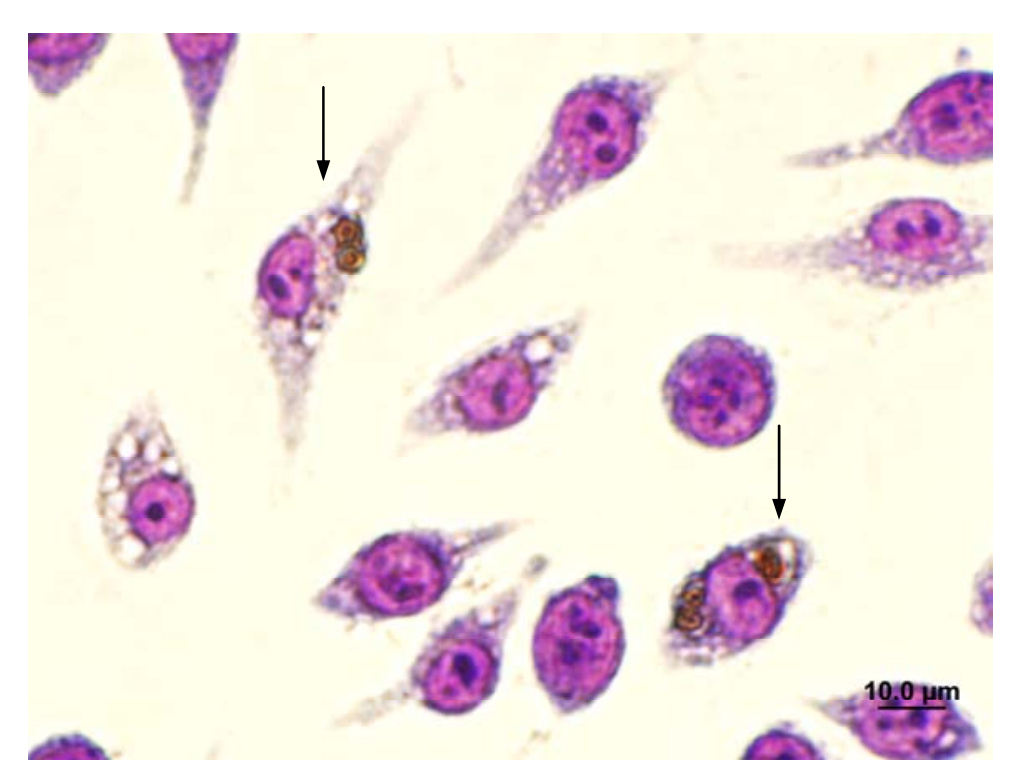

Fig. IV. 30. Imagen representativa de la fagocitosis de eritrocitos oxidados por macrófagos de ratón J774. Las flechas indican los macrófagos considerados positivos. Se muestra un experimento representativo de eritrocitos controles tratados con 0,5 mM de tBHP e incubados con los macrófagos durante $1 \mathrm{~h}$ a $37^{\circ} \mathrm{C}$. Los macrófagos son fijados, teñidos, observados al microscopio óptico (x 600). 
En la Fig. IV. 31 podemos observar como el número de macrófagos positivos aumenta de forma directamente proporcional al número de células marcadas con anexina V-FITC. De ello se deduce que existe una correlación positiva entre la exteriorización de la PS en la superficie del eritrocito y el número de eritrocitos fagocitados (macrófagos positivos), tanto en eritrocitos controles como modificados.

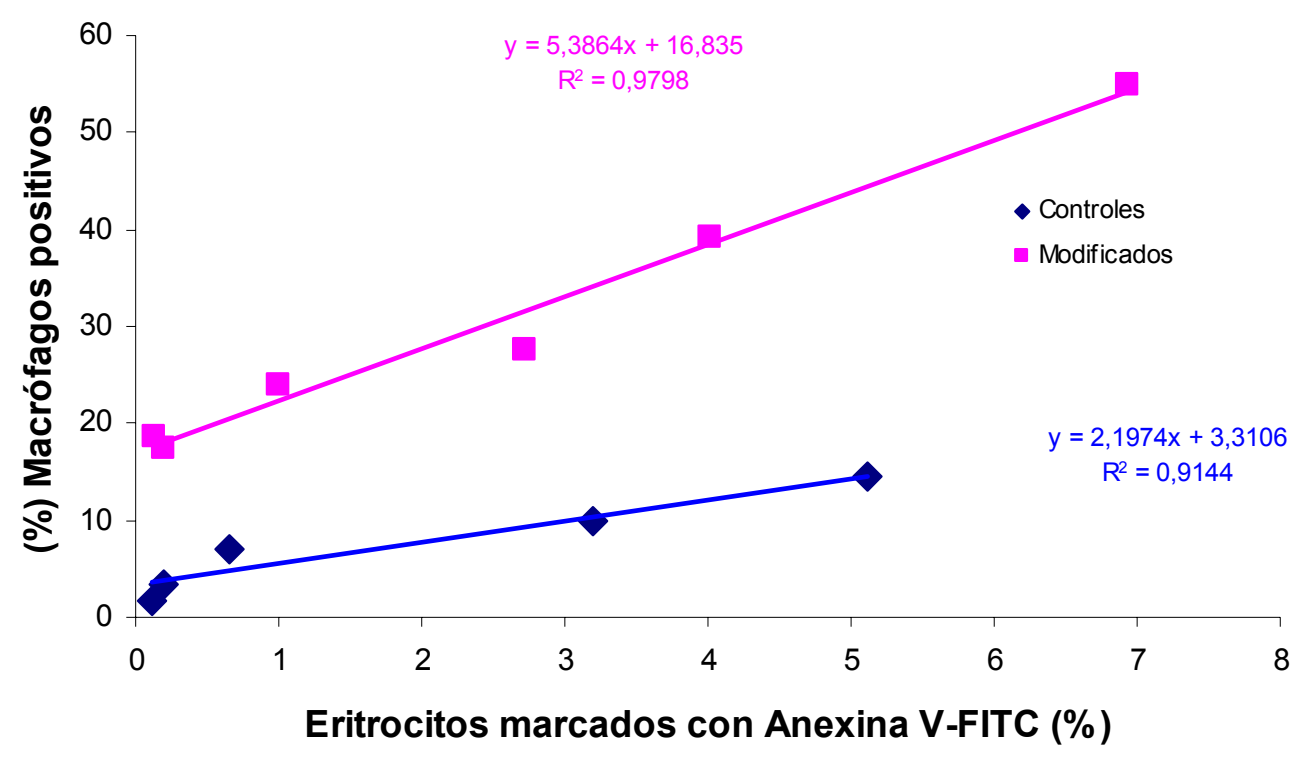

Fig. IV. 31. Correlación entre la exteriorización de PS (expresada como \% de células unidas con anexina V-FITC) y el grado de fagocitosis (\% de macrófagos positivos) tras la oxidación de eritrocitos controles y modificados. Cada punto es la media de 3 determinaciones independientes llevadas a cabo en eritrocitos controles y modificados tratados con concentraciones crecientes de tBHP (0-1 mM).

Los niveles de fagocitosis encontrados en eritrocitos controles no oxidados son muy bajos ( $<2 \%$ ). La modificación de los contenidos de colesterol en el eritrocito producen una salida de PS, que se refleja en un incremento de la fagocitosis eritrocitaria aproximadamente de 10 veces $(p \leq 0,001)$ con respecto a los eritrocitos controles (Figs IV. 31 y 32 ).

El tratamiento de los eritrocitos controles con concentraciones de tBHP 2 $\mathrm{mM}$ provoca un aumento significativo de 14 veces en el número de macrófagos positivos con respecto a los eritrocitos controles no oxidados (Fig. IV. 32). El proceso oxidativo también produce incrementos significativos en la fagocitosis tanto de los eritrocitos ricos ( 2 veces a $2 \mathrm{mM}$ de tBHP) como de los pobres en colesterol (1,6 veces a 0,25 mM de tBHP) (Fig. IV. 32). 
En ausencia de oxidación, los antioxidantes incorporados en los distintos eritrocitos sólo causan aumentos significativos del número de macrófagos positivos en los eritrocitos controles $(6,7$ veces, $p \leq 0,001$, con quercetina y 3,7 veces, $p \leq 0,001$, con rutina) (Fig. IV. 32).

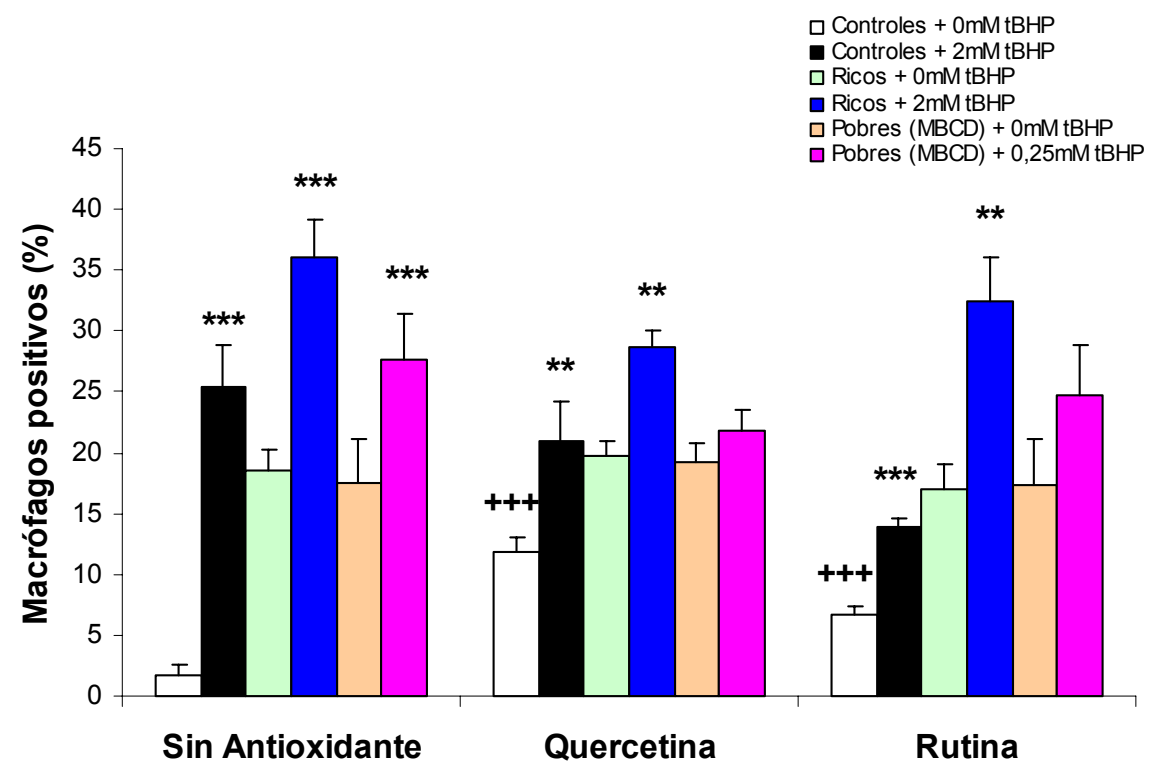

Fig. IV. 32. Efecto de la adición de quercetina y rutina sobre la fagocitosis experimentada por los eritrocitos controles y modificados tratados con tBHP en una relación antioxidante:oxidante 1:2. Los resultados son la media aritmética \pm D.E. de 4 experimentos independientes, y expresan los porcentajes de macrófagos $\mathrm{J774}$ que han fagocitado 1 o más eritrocitos (macrófagos positivos). Cambios estadísticamente significativos: i) por grupo de eritrocitos sin antioxidante o con antioxidante: no oxidados $\mathrm{v}_{\mathrm{s}}$. oxidados, $* * \mathrm{p} \leq 0,01, * * * \mathrm{p} \leq 0,001$; ii) en eritrocitos no oxidados: con antioxidante $\mathrm{v}_{\mathrm{s} .} \sin$ antioxidante, $+++\mathrm{p} \leq 0,001$.

La presencia de los flavonoides en el medio de oxidación evita parcialmente el aumento de los macrófagos positivos, principalmente en los eritrocitos controles, donde la quercetina otorga un $62 \%$ de protección y la rutina un $70 \%$ (Figs. IV. 32 y 33). Sin embargo, el grado de protección que aportan los flavonoides frente a la eritrofagocitosis en los eritrocitos modificados oxidados suele ser, en general, inferior al detectado en los eritrocitos controles, mostrándose los eritrocitos pobres en colesterol más sensibles a la protección por los antioxidantes que los eritrocitos ricos en colesterol. Así, en los eritrocitos pobres en colesterol los porcentajes de protección son del $74 \%$ en presencia de quercetina y del $27 \%$ con rutina, descendiendo hasta valores del $49 \%$ con quercetina y al $11 \%$ con rutina en los eritrocitos ricos en colesterol (Figs. IV. 32 y 33 ). 


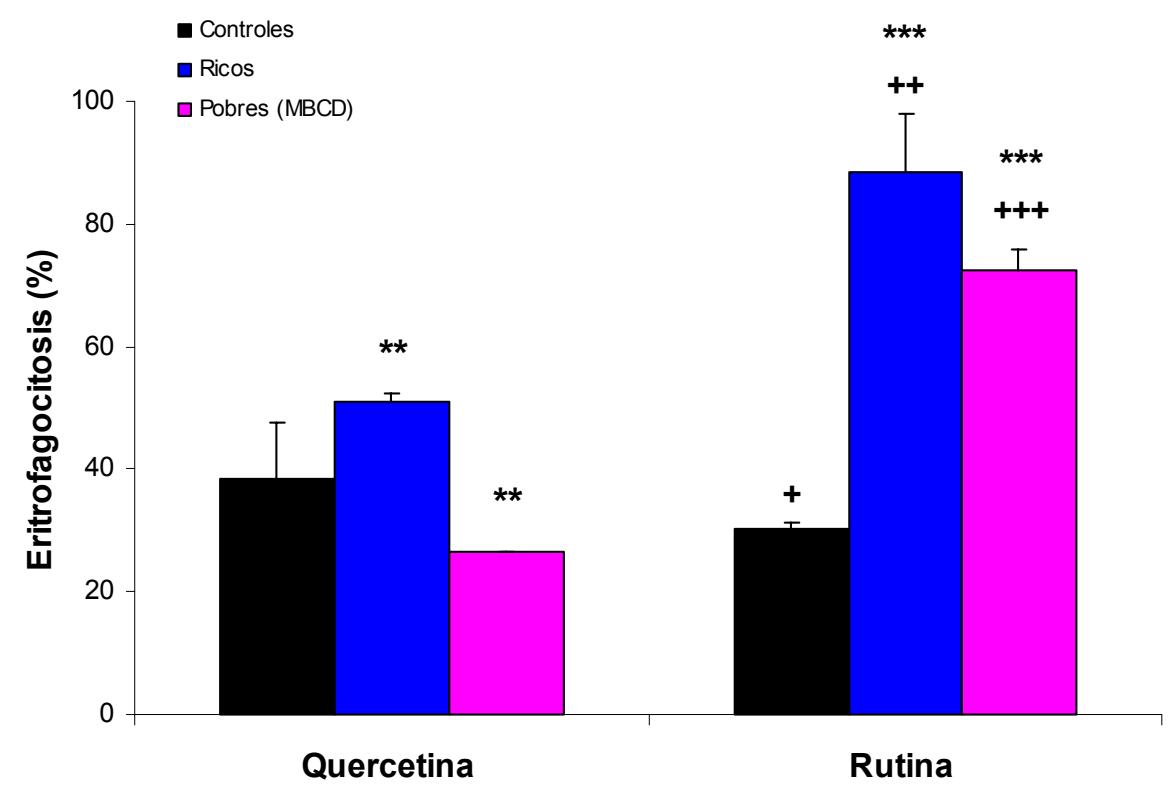

Fig. IV. 33. Comparación de los efectos protectores de quercetina y rutina sobre la fagocitosis experimentada por los eritrocitos controles y modificados oxidados. Se asignó el $100 \%$ a los porcentajes de macrófagos positivos detectados en los diferentes grupos de eritrocitos oxidados en ausencia de antioxidante. Los resultados son la media aritmética \pm D.E. de 4 experimentos independientes, y expresan los porcentajes de macrófagos que han fagocitado 10 más eritrocitos (macrófagos positivos). Por grupo de eritrocitos, quercetina $v_{s}$ rutina, $+++p \leq 0,001$. Por antioxidante, controles $\mathrm{v}_{\mathrm{s} .}$ modificados, $* * \mathrm{p} \leq 0,01 ; * * * \mathrm{p} \leq 0,001$

Como muestra la Fig. IV. 33, la quercetina tiene mayor poder de protección que la rutina en los eritrocitos modificados $(1,7$ veces en eritrocitos ricos, $p \leq 0,01$, y 2,7 veces en eritrocitos pobres en colesterol, $p \leq 0,001)$, mientras que en los eritrocitos controles la rutina aporta 1,3 veces más protección que la quercetina $(p \leq 0,05)$. 


\section{CUANTIFICACIÓN DE LA ACTIVIDAD AMINOFOSFOLÍPIDO TRANSLOCÁSICA}

La aminofosfolípido translocasa (APLT) es una enzima dependiente de ATP, responsable del mantenimiento de la distribución asimétrica de los aminofosfolípidos en la célula mediante el transporte hacia la cara interna de la bicapa lipídica de las moléculas de estos fosfolípidos que se sitúan en la superficie de la membrana plasmática.

La cuantificación de actividad enzimática de la APLT realizada en este estudio se basa en el empleo del sustrato fluorescente NBD-PS. El sustrato unido a la cara externa de la membrana eritrocitaria es transportado hacia la cara interna por acción de la APLT a lo largo del tiempo de incubación, expresándose la actividad enzimática como porcentaje de NBD-PS internado o en nmoles NBD-PS internado $\mathrm{min}^{-1} \cdot \mathrm{mg} \mathrm{Hb}^{-1}$. Las condiciones experimentales empleadas están descritas en el apartado 4.14 del capítulo III. La elección de los tiempos idóneos de incubación y los estudios de cinética de incorporación del sustrato NBD-PS se han llevado a cabo en estudios previos realizados en nuestro grupo (López-Revuelta et al, 2005).

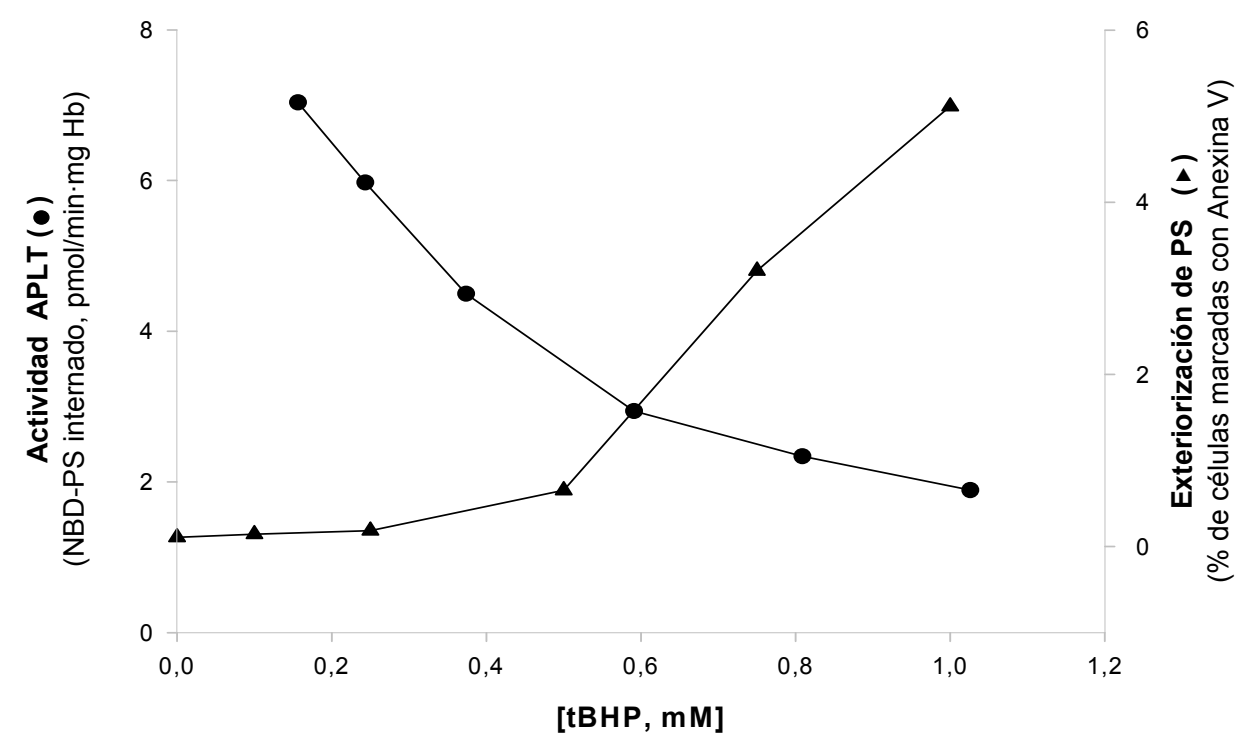

Fig. IV. 34. Análisis de la relación existente entre la actividad APLT y la exteriorización de PS por efecto de la oxidación inducida por tBHP. Cada punto representa la media aritmética de 3 determinaciones independientes. 
La Fig. IV. 34 muestra la correlación existente entre el descenso de la actividad enzimática de la APLT y el aumento de la PS en la monocapa externa a medida que se incrementa la concentración de tBHP.

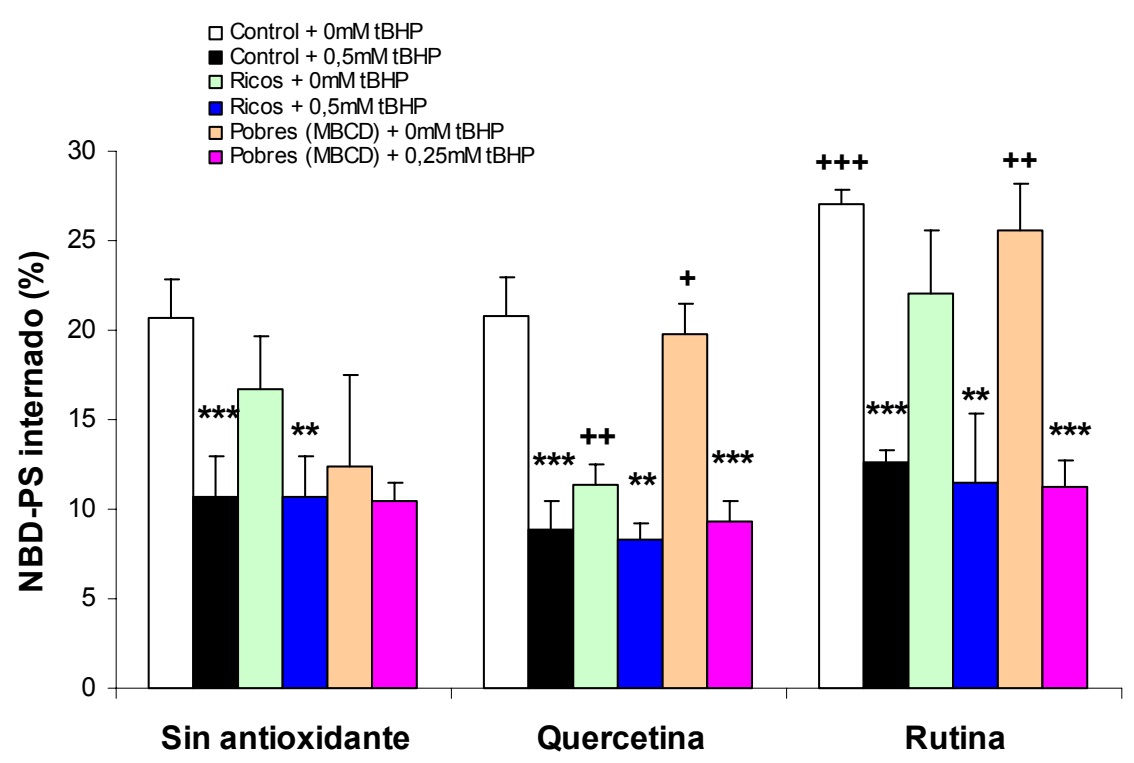

Fig. IV. 35. Efecto de quercetina y rutina sobre la actividad APLT (expresada en $\%$ de NBD-PS internado) en eritrocitos controles y modificados en colesterol oxidados con tBHP, en una relación antioxidante:oxidante 1:2. La actividad APLT fue determinada a los $10 \mathrm{~min}$ de incubación a $28^{\circ} \mathrm{C}$. Los resultados son la media aritmética \pm D.E. de 5 experimentos independientes. Comparaciones estadísticas: i) En los grupos de sin

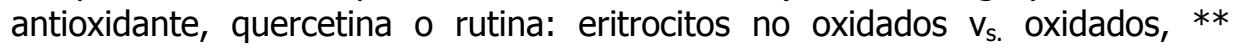
$\mathrm{p} \leq 0,01, * * * \mathrm{p} \leq 0,001$; ii) En eritrocitos de cada grupo: no oxidados sin antioxidante $\mathrm{v}_{\mathrm{s}}$. no oxidados con antioxidante, $+\mathrm{p} \leq 0,05++\mathrm{p} \leq 0,01,+++$ $\mathrm{p} \leq 0,001$.

Como se observa en la Fig. IV. 35, la incorporación de los flavonoides al medio de reacción en ausencia de oxidación provoca alteraciones significativas en la actividad APLT. Así la presencia de rutina induce un aumento en la actividad de la enzima de 1,31 veces $(p \leq 0,001)$ en eritrocitos controles, de 1,32 veces (aumento no significativo) en eritrocitos ricos y de 2,1 veces $(p \leq 0,01)$ en eritrocitos pobres en colesterol. En cambio, la quercetina ocasiona un aumento de 1,6 veces $(p \leq 0,05)$ en la actividad APLT de los eritrocitos pobres en colesterol no oxidados, mientras que en los eritrocitos ricos no oxidados provoca un descenso en dicha actividad enzimática del $32 \%(p \leq 0,01)$. La oxidación de los eritrocitos con tBHP produce una inactivación parcial de la enzima, como ya se ha descrito previamente, con descensos en su actividad del $48 \%(p \leq 0,001)$ en eritrocitos controles, del $36 \%(p \leq 0,01)$ en los eritrocitos ricos y del $16 \%$ (no significativo) en los eritrocitos pobres en colesterol. En presencia de ambos antioxidante, la actividad APLT detectada en los diferentes tipos de eritrocitos oxidados muestra valores similares a los cuantificados en los 
eritrocitos homólogos oxidados en ausencia del antioxidante, lo que indica que dichos antioxidantes no tienen prácticamente efecto protector sobre la actividad APLT en los distintos tipos de eritrocitos expuestos al tBHP (Fig. IV. 35). 


\section{ANÁLISIS MORFOLÓGICO Y DE ESTABILIDAD ISOTÓNICA}

\subsection{Efecto sobre la morfología celular}

Los eritrocitos controles y modificados en colesterol tratados con diferentes concentraciones de tBHP, fueron fijados con glutaraldehído al $1 \%$ para ser observados al microscopio óptico, tal como se detalla en el apartado 4.16 del capítulo III. Se contaron 200 eritrocitos por portaobjetos en diferentes campos elegidos al azar, calculándose el porcentaje de eritrocitos que presentan una o más espículas (u otras alteraciones) en su superficie celular (Fig. IV. 36).

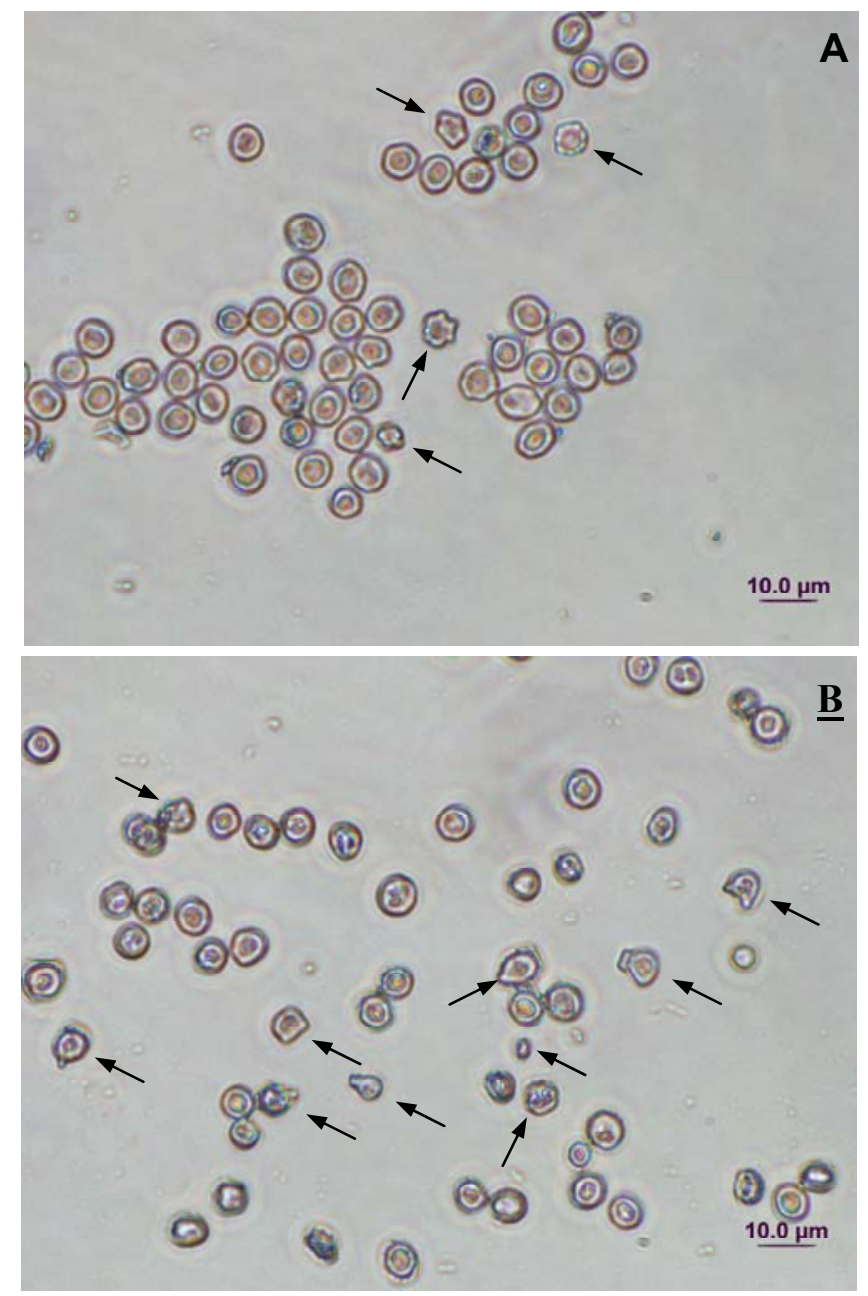

Fig. IV. 36. Morfología de los eritrocitos ricos en colesterol tratados sin (panel A) y con (panel B) $\mathbf{0 , 5} \mathbf{~ m M}$ de tBHP. Después del tratamiento, los eritrocitos fueron fijados con glutaraldehído al $1 \%$, observados al microscopio (x600) y fotografiados. Las flechas señalan los eritrocitos que se consideran alterados morfológicamente. 
Como se observa en la Fig. IV. 37, existe una correlación positiva entre la exposición de PS en la superficie de los diferentes tipos de eritrocitos y las alteraciones que se producen en dicha superficie celular.

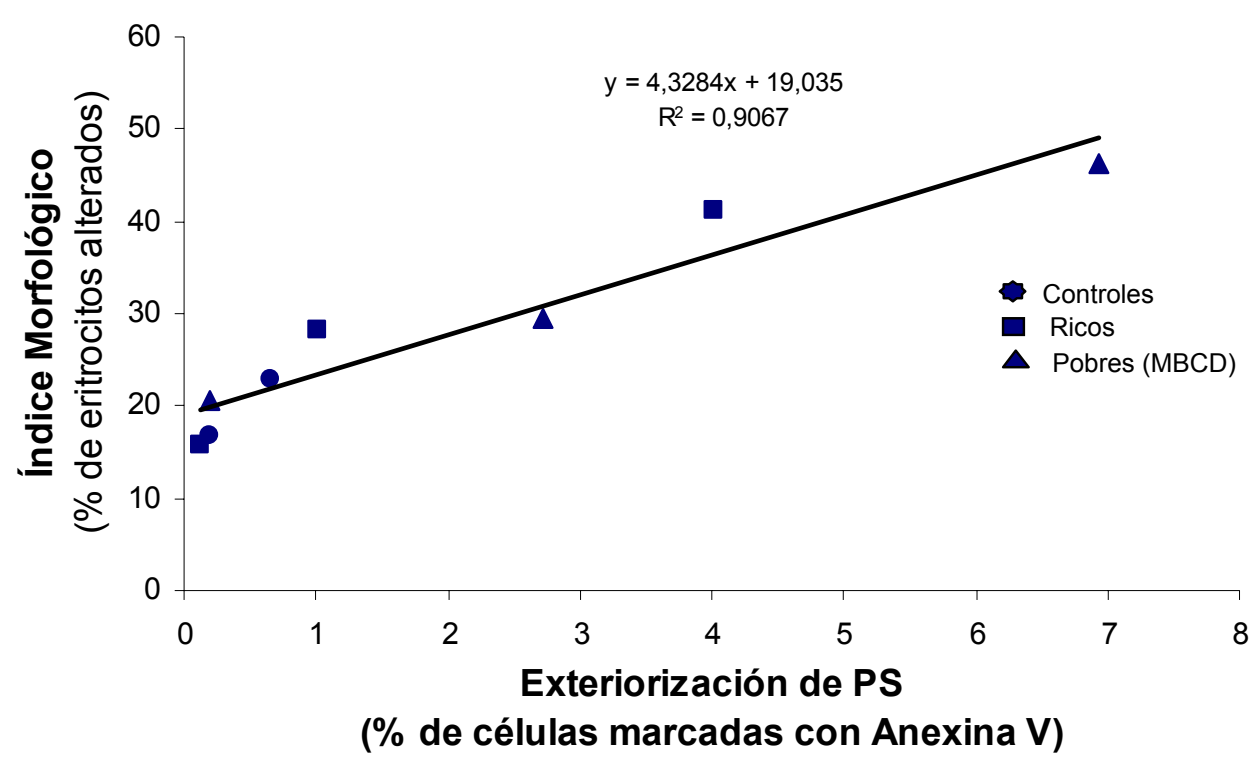

Fig. IV. 37. Relación entre la salida externa de PS y los cambios morfológicos observados en los distintos tipos de eritrocitos expuestos a concentraciones crecientes de tBHP $(0-0,5 \mathrm{mM})$. Cada punto representa la media aritmética de 3 determinaciones independientes. 
En ausencia de oxidación, los eritrocitos controles muestran aproximadamente un $10 \%$ de alteración morfológica, incrementándose hasta 1,5 y 3,2 veces $(p \leq 0,001)$ en los eritrocitos ricos y pobres en colesterol, respectivamente. El tratamiento con concentraciones crecientes de agente oxidante conlleva un deterioro de la morfología celular en todas las clases de eritrocitos estudiados. Así, la exposición de los eritrocitos a concentraciones 2 $\mathrm{mM}$ de tBHP provoca incrementos en los índices morfológicos de 6,1 veces en controles, 4,1 veces en ricos y 2,8 veces en pobres en colesterol con respecto a sus eritrocitos homólogos no oxidados (Fig. IV. 38).

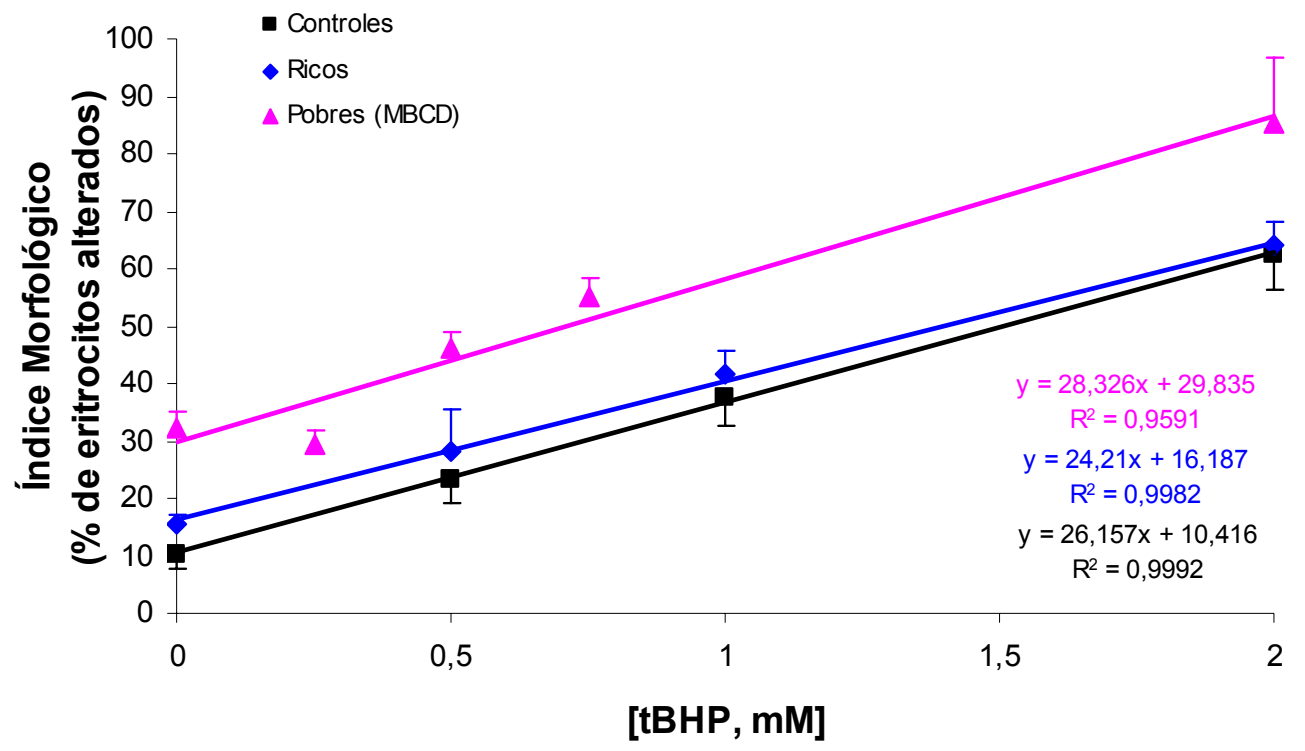

Fig. IV. 38. Estimación de los índices morfológicos (\% de eritrocitos alterados) de eritrocitos controles y modificados en colesterol tras el tratamiento con tBHP. Los eritrocitos fueron expuestos a distintas concentraciones de agente oxidante, posteriormente fueron fijados con glutaraldehído y observados al microscopio, realizándose el recuento de los eritrocitos alterados morfológicamente. Los resultados son la media aritmética \pm D.E. de 5 experimentos independientes.

La incorporación de los flavonoides a la membrana eritrocitaria provoca cambios estadísticamente significativos en los porcentajes de eritrocitos alterados. Así la presencia de quercetina induce un aumento de los índices morfológicos de 2,0 veces $(p \leq 0,01)$ en los eritrocitos controles y de 1,3 veces $(p \leq 0,05)$ en los eritrocitos ricos en colesterol. La rutina sólo provoca cambios en los eritrocitos ricos en colesterol, aumentando el porcentaje de eritrocitos alterados 1,5 veces $(p \leq 0,05)$ (Fig. IV. 39 A).

El aumento del porcentaje de eritrocitos alterados provocado por la acción del tBHP es parcialmente inhibido por la quercetina en eritrocitos controles y pobres en colesterol, con protecciones del 39 y $47 \%$, 
respectivamente. La rutina por su parte, otorga protecciones del $35 \%$ a los eritrocitos controles y del $22 \%$ a los eritrocitos pobres. Sin embargo, ninguno de los antioxidantes ensayados aporta protección a los eritrocitos ricos en colesterol contra las alteraciones morfológicas inducidas por el tBHP (Fig. IV. 39 B).

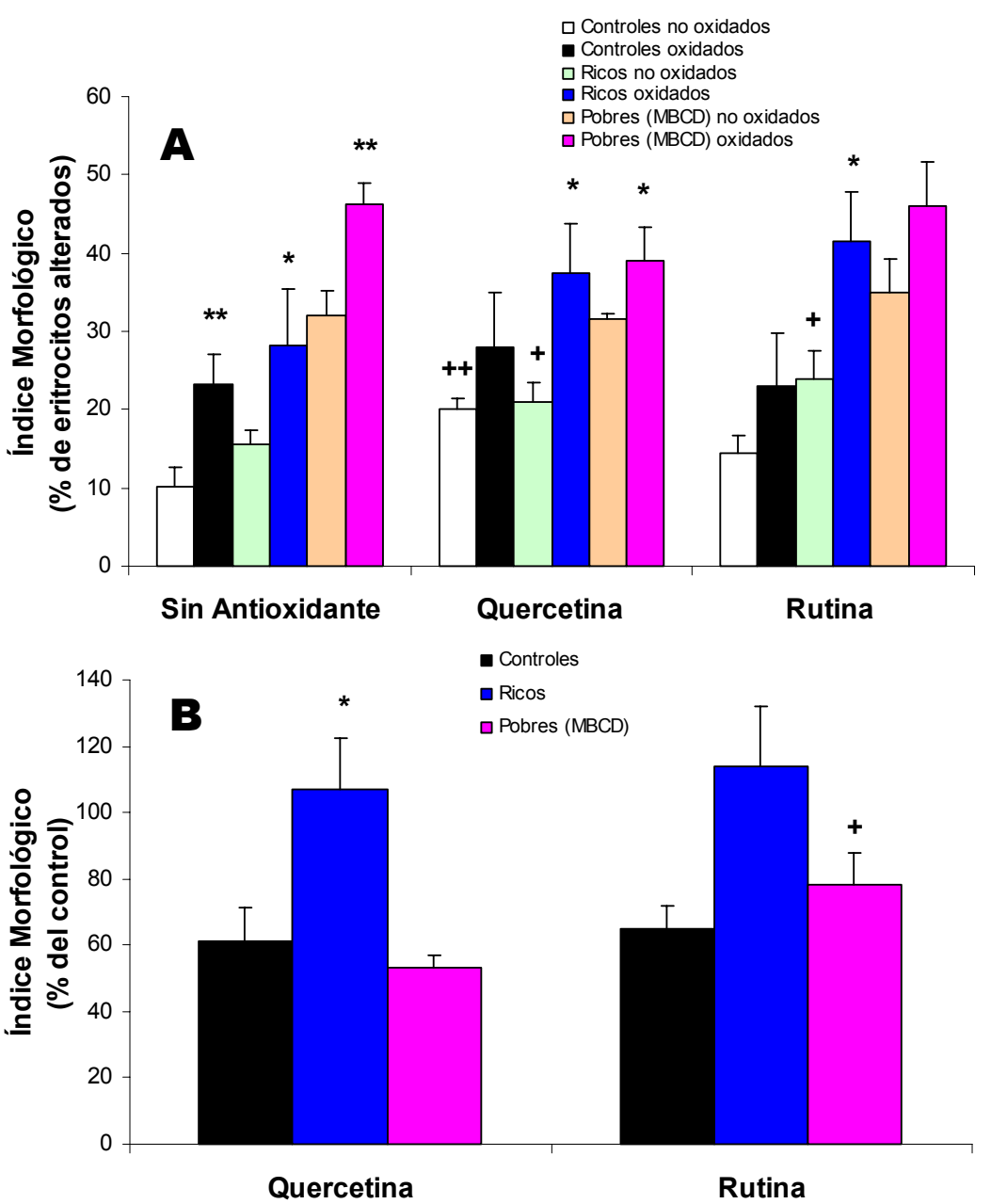

Fig. IV. 39. Efecto de la presencia de quercetina y de rutina sobre la morfología celular de los eritrocitos controles y modificados en colesterol al ser tratados con 0,5 mM de tBHP. Panel A: En eritrocitos no oxidados y oxidados en ausencia y presencia de antioxidante $0,25 \mathrm{mM}$. Comparaciones estadísticamente significativas: i) Con o sin antioxidante, eritrocitos no

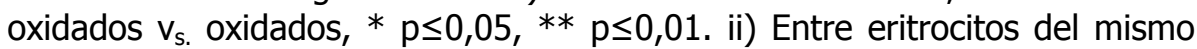
tipo no oxidados, en ausencia $v_{s}$. presencia de antioxidante, $+p \leq 0,05,++$ $\mathrm{p} \leq 0,01$; Panel B: Se asignó el $100 \%$ a los porcentajes de eritrocitos alterados detectados en los diferentes grupos de eritrocitos oxidados en ausencia de antioxidante (Control). Comparaciones estadísticamente significativas: i) Por grupo de eritrocitos, quercetina $v_{s}$ rutina, $+p \leq 0,05$; ii) Por antioxidante: controles $v_{s}$. modificados, $* p \leq 0,05$. Los resultados son la media aritmética \pm D.E. de 3 experimentos independientes. 


\subsection{Efecto sobre la estabilidad isotónica}

10.2.1. Análisis del grado de hemólisis en ausencia y presencia de antioxidante

Previamente al estudio de la estabilidad isotónica, se analizó el grado de hemólisis que produce el tratamiento con $2 \mathrm{mM}$ de tBHP en los eritrocitos controles y modificados en presencia o ausencia de antioxidantes. El análisis se llevó a cabo mediante la medida a $700 \mathrm{~nm}$ de la dispersión de luz que generan las suspensiones de eritrocitos intactos después de los tratamientos, tal como se detalla en el apartado 4.7.2 del capítulo III.

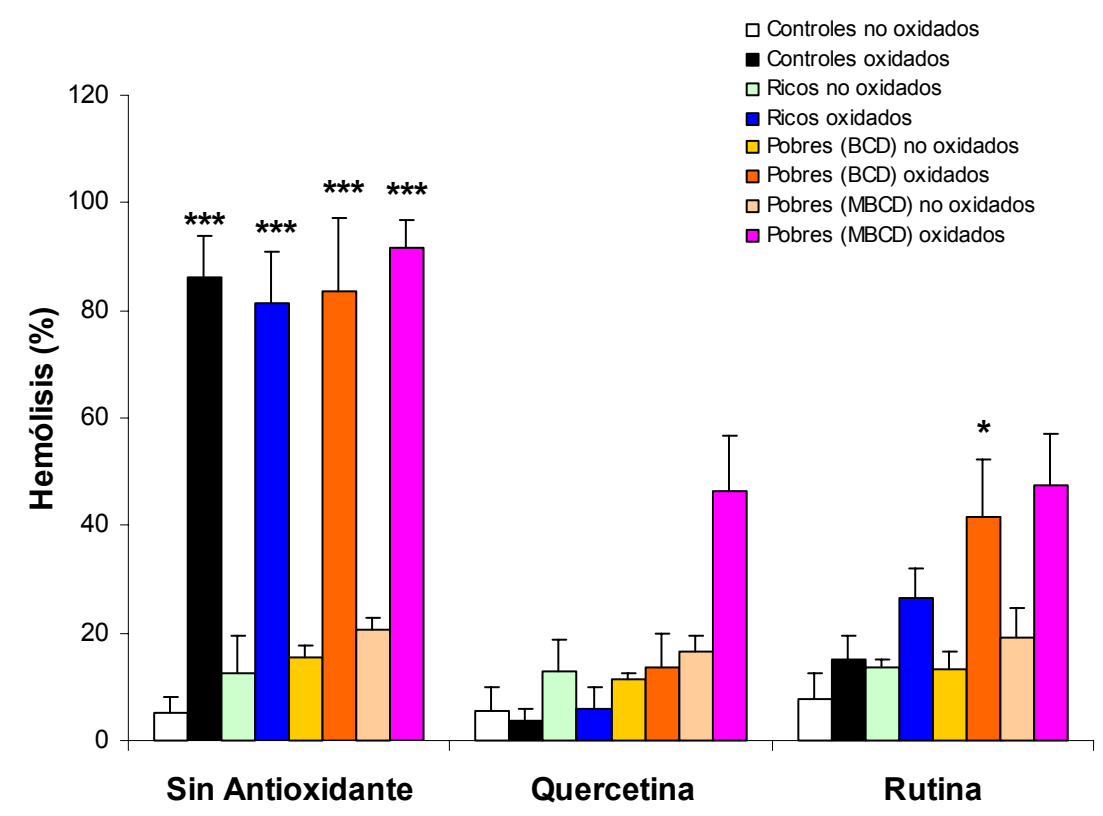

Fig. IV. 40. Efecto de la presencia de quercetina y rutina sobre la hemólisis producida en los eritrocitos controles y modificados en colesterol tratados con $2 \mathrm{mM}$ de tBHP, en relaciones antioxidante:oxidante 1:2. Los resultados son la media aritmética \pm D.E. de 4 experimentos independientes. Cambios estadísticamente significativos: Por grupo de eritrocitos sin o con antioxidante: no oxidados $\mathrm{v}_{\mathrm{s} \text {. }}$ oxidados, $* \mathrm{p} \leq 0,05, * * *$ $\mathrm{p} \leq 0,001$.

El tratamiento con el agente oxidante provoca aumentos estadísticamente significativos en los grados de hemólisis en todas las clases de eritrocitos tratados $(p \leq 0,001)$, alcanzándose porcentajes entre el $81-91 \%$ (Fig. IV. 40).

La presencia de antioxidante, tanto de quercetina como de rutina, en ausencia de oxidación no modifica significativamente el porcentaje de hemólisis en ninguno de los tipos de eritrocitos (Fig. IV. 40). 


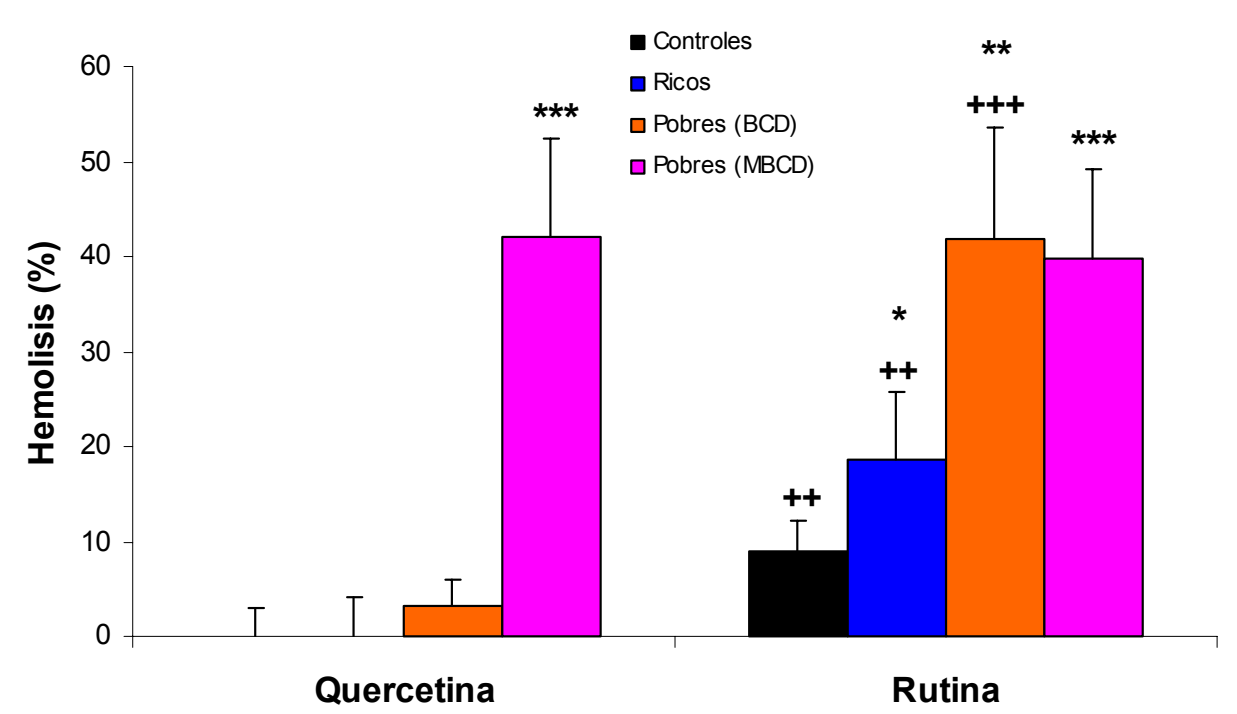

Fig. IV. 41. Comparación del efecto protector de la quercetina frente a la rutina sobre el grado de hemólisis producida en los eritrocitos controles y modificados en colesterol tratados con $2 \mathrm{mM}$ de tBHP, en una relación antioxidante:oxidante 1:2. En ausencia de antioxidante, la hemólisis fue considerada del $100 \%$ para cada grupo de eritrocitos oxidados. Los resultados son la media aritmética \pm D.E. de 4 experimentos independientes. Cambios estadísticamente significativos: i) Por grupo de eritrocitos, quercetina $v_{s}$. rutina, $++p \leq 0,01 ;+++p \leq 0,001$; ii) Por antioxidante, controles $\mathrm{v}_{\mathrm{s} .}$ modificados, $* \mathrm{p} \leq 0,05, * * \mathrm{p} \leq 0,01 ; * * * \mathrm{p} \leq 0,001$.

La quercetina en el medio de oxidación produce un bloqueo total de la hemólisis que induce el tBHP $(100 \%)$, siendo 9 veces $(p \leq 0,01)$ más eficaz que la rutina en eritrocitos controles, 18 veces $(p \leq 0,01)$ más en los ricos y 12 veces $(p \leq 0,001)$ más en los pobres $(B C D)$ en colesterol. Sin embargo, cuando el empobrecimiento de colesterol en los eritrocitos se lleva a cabo con MBCD, ambos antioxidantes aportan protecciones menores frente a la hemólisis inducida por el tBHP, alcanzándose porcentajes próximos al 60\% con ambos antioxidantes (Fig. IV. 41). Aunque la quercetina es el antioxidante más eficaz en la mayoría de los casos, la rutina aporta también elevadas protecciones frente a la hemólisis inducida por el daño oxidativo, consiguiéndose porcentajes de protección del $91 \%$ en eritrocitos controles, del $82 \%$ en ricos y del $59-60 \%$ en eritrocitos pobres en colesterol (Fig. IV. 41). 
10.2.2. Análisis de la estabilidad isotónica en ausencia y presencia de antioxidante

La estabilidad isotónica de los eritrocitos controles, ricos y pobres (BCD) en colesterol oxidados en ausencia o presencia de antioxidante ha sido analizada siguiendo el procedimiento descrito en el apartado 4.7.3 de Materiales y Métodos. Los resultados son expresados en porcentajes de hemólisis que muestran los eritrocitos tras $16 \mathrm{~h}$ de incubación con disoluciones $154 \mathrm{mM}$ de $\mathrm{NaCl}$, hemólisis que será inversamente proporcional a la estabilidad isotónica del eritrocito en el medio. El análisis del efecto de los antioxidantes sobre la estabilidad isotónica de los eritrocitos oxidados se ha restringido a los eritrocitos controles, ricos y empobrecidos en colesterol mediante tratamiento con $\mathrm{BCD}$, ya que son estos tres grupos los que muestran las máximas estabilidades isotónicas ( $6 \%$ de hemólisis en controles, $7,5 \%$ en ricos y $3 \%$ en pobres tratados con $\mathrm{BCD}$ ) en ausencia de oxidación al ser expuestos durante $16 \mathrm{~h}$ a disoluciones de $\mathrm{NaCl} 154 \mathrm{mM}$ (Fig. IV.42). Los eritrocitos empobrecidos en colesterol al ser tratados con MBCD muestran una estabilidad isotónica muy inferior ( $\sim 50 \%$ de hemólisis, datos no mostrados) en las condiciones anteriormente citadas.

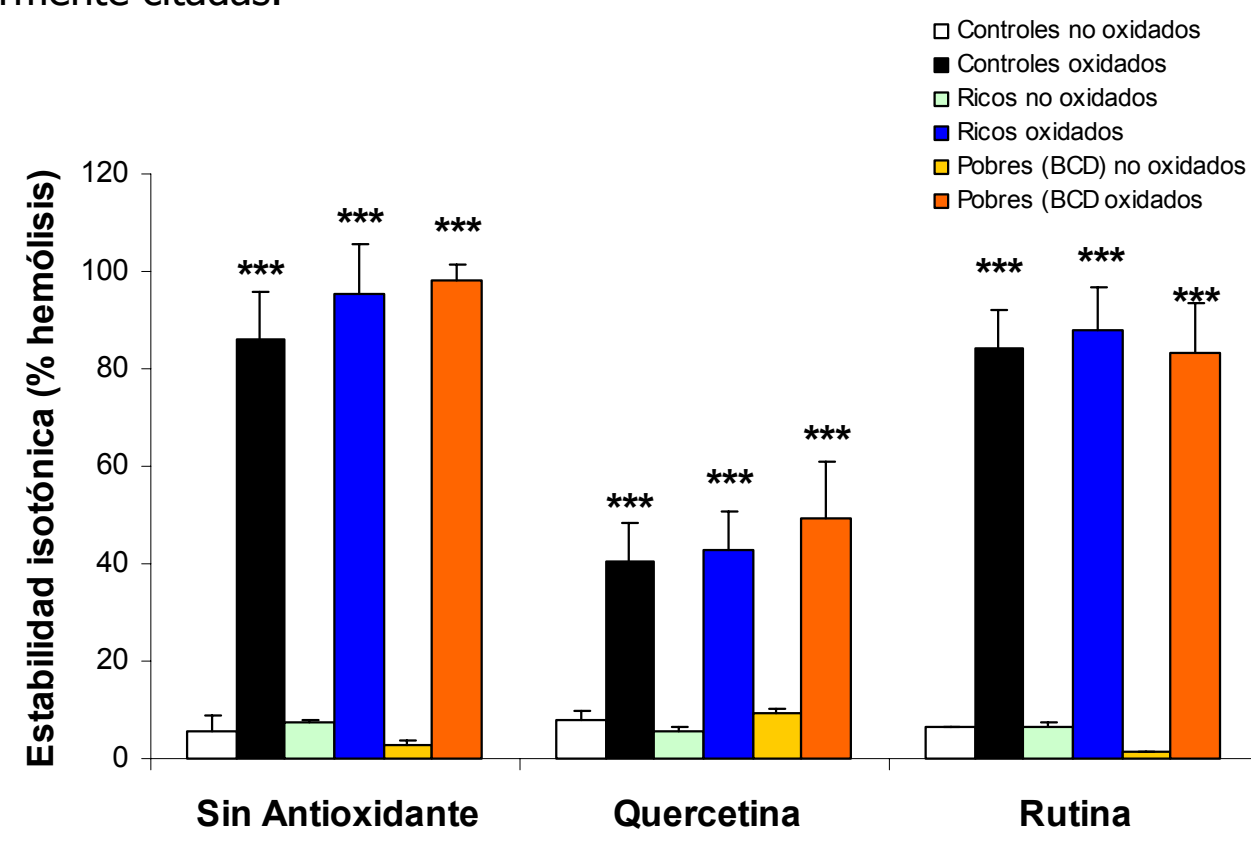

Fig. IV. 42. Efecto de la presencia de quercetina y rutina sobre la estabilidad isotónica en eritrocitos controles y modificados en colesterol oxidados con $2 \mathrm{mM}$ de tBHP, en relación antioxidante:oxidante 1:2. Los resultados son la media aritmética \pm D.E. de 6 experimentos independientes. Cambios estadísticamente significativos: i) Por grupo de eritrocitos sin antioxidante o con antioxidante: no oxidados $\mathrm{v}_{\mathrm{s} \text {. }}$ oxidados, $* * *$ $\mathrm{p} \leq 0,001$. 
El tratamiento de los eritrocitos con tBHP $2 \mathrm{mM}$ en ausencia de antioxidante disminuye de forma significativa $(p \leq 0,001)$ la estabilidad isotónica en los tres tipos de eritrocitos analizados, alcanzándose valores de hemólisis comprendidos entre 86-98\% (Fig. IV. 42). La incorporación de los antioxidantes a los eritrocitos no oxidados no altera la estabilidad isotónica de los distintos tipos de eritrocitos, que muestran porcentajes de hemólisis similares a sus eritrocitos homólogos no oxidados ( $<10 \%$ de hemólisis) (Fig. IV. 42).

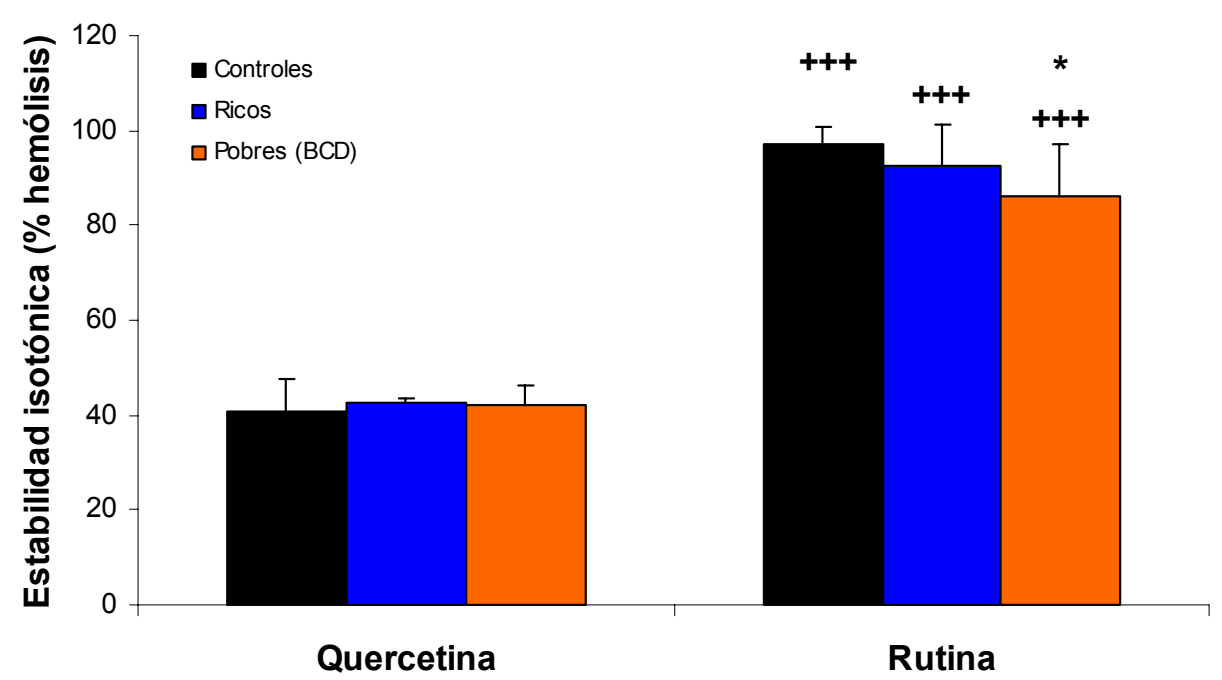

Fig. IV. 43. Análisis comparativo del efecto protector de la quercetina frente a la rutina sobre la estabilidad isotónica en eritrocitos controles y modificados en colesterol oxidados con $2 \mathrm{mM}$ de tBHP, en una relación antioxidante:oxidante 1:2. En ausencia de antioxidante, la hemólisis fue considerada del $100 \%$ para cada grupo de eritrocitos oxidados. Los resultados son la media aritmética \pm D.E. de 6 experimentos independientes. Cambios estadísticamente significativos: i) Por grupo de eritrocitos, quercetina $v_{s}$. rutina, $+++p \leq 0,001$; ii) Por antioxidante,



En todos los casos la quercetina ejerce un efecto protector significativamente mayor $(2,1-2,4$ veces, $\mathrm{p} \leq 0,001)$ que la rutina frente a la estabilidad isotónica en los diferentes tipos de eritrocitos. Con la quercetina se consiguen protecciones en la estabilidad isotónica del $58-59 \%$ en los tres tipos de eritrocitos oxidados (Fig. IV. 43). La rutina posee un poder de protección ostensiblemente inferior al de la quercetina, alcanzándose protecciones del 3\% en eritrocitos controles, $7 \%$ en los eritrocitos ricos y $14 \%$ en los eritrocitos pobres en colesterol (Fig. IV. 43). 
CAPÍTULO V: Discusión 

El eritrocito, debido a su alto contenido en ácidos grasos poliinsaturados (PUFA), a su contacto directo con el oxígeno y a la presencia de iones ferrosos formando parte de la hemoglobina, es muy susceptible al daño oxidativo en situaciones de deterioro tisular o cuando hay un predominio de los oxidantes con respecto a los antioxidantes intracelulares. En tales circunstancias, la oxidación de la hemoglobina en metahemoglobina se incrementa considerablemente, generando gran cantidad de radicales superóxido, que dan finalmente lugar a la formación de radicales sumamente reactivos como los radicales hidroxilo. Este radical o cualquier otra especie reactiva (ferrilhemoglobina, radicales peroxilo o alcoxilo) son capaces de oxidar diferentes componentes del eritrocito, hemoglobina, cadenas hidrocarbonadas de los ácidos grasos poliinsaturados, grupos tiólicos de proteínas y compuestos no proteicos, así como cualquier aminoácido susceptible de oxidación. Estas alteraciones generan cambios en la estructura de la membrana eritrocitaria, que ocasionan un descenso en la deformación del eritrocito, disminuyendo su estabilidad isotónica y aumentando las formas esferocíticas, con la consiguiente pérdida de la integridad celular y el acortamiento de su vida media (Clemens y Waller, 1987; Rice-Evans, 1990; López-Revuelta et al, 2005; López-Revuelta et al, 2007).

El colesterol es un esterol presente en las membranas biológicas de las células de mamíferos que juega un papel crucial en la organización, función y dinamismo celular. Este compuesto modula el estado físico de la membrana al interaccionar con las cadenas hidrocarbonadas de los fosfolípidos y glicolípidos, generando un efecto condensante o "fluidificante" de la bicapa lipídica en función de su temperatura de transición. El incremento de colesterol en la membrana produce aumentos en el parámetro de orden de los componentes de la bicapa lipídica por encima de la temperatura de transición, incrementando la microviscosidad de dicha bicapa, mientras que el descenso de los contenidos de colesterol provoca el efecto contrario, aumenta la fluidez de la membrana (Yeagle, 1985; Kucuk et al, 1992; Vélez et al, 1995; Tirosh et al, 1997; LópezRevuelta et al, 2005). El colesterol también modifica la carga superficial (Lupu y Calb, 1988) y la disposición asimétrica de los lípidos de la bicapa, produciéndose una salida gradual de los aminofosfolípidos hacia su cara externa a medida que se incrementa la concentración de colesterol, tanto en liposomas, como en membranas plasmáticas de plaquetas (Sánchez-Yagüe et al, 1987) y en eritrocitos (Manevich et al, 1985; López-Revuelta et al, 2007). El efecto modulador del colesterol sobre la estructura y estado físico de la bicapa lipídica 
de la membrana influye también sobre la movilidad y conformación de las proteínas ancladas en ella, modificando la actividad de canales iónicos, receptores y enzimas (Rooney et al, 1984; Yeagle, 1989; Ohvo-Rekila et al, 2002), lo que puede afectar de un modo determinante al funcionamiento (Yeagle, 1985; Yeagle, 1989; London y Brown, 2000) y a la morfología celular (Pessina et al, 1981; López-Revuelta et al, 2007), alterando en ciertos casos su estabilidad isotónica (Cooper et al, 1975; López-Revuelta et al, 2005; LópezRevuelta et al, 2007).

Con el presente estudio se trata de conocer la influencia que los contenidos de colesterol en las membranas ejercen sobre la capacidad protectora de los antioxidantes frente al daño oxidativo celular. Con el fin de elegir los antioxidantes que muestran un alto grado de protección en nuestro modelo experimental, y utilizarlos en el desarrollo posterior del estudio, se ha realizado una selección preliminar a partir de un grupo de compuestos descritos como antioxidantes, efectuándose la citada selección en base a la capacidad de dichos compuestos para bloquear la generación de TBARS en eritrocitos controles oxidados con tBHP $2 \mathrm{mM}$. El ácido tánico muestra el máximo poder de protección ( $90 \%)$, seguido de los compuestos fenólicos BHA, BHT y quercetina, que muestran grados de protección similares ( $\sim 85 \%)$. La rutina, junto con el ácido ascórbico, aportan porcentajes de protección alrededor del $65 \%$. Altas concentraciones de ascorbato pueden reducir los radicales peroxilo a hidroperóxidos en la superficie de las membranas celulares, y por tanto, interferir en las reacciones en cadena de la peroxidación (Halliwell y Gutteridge, 1999). En nuestro caso, ni el $\alpha$-tocoferol, ni el manitol, muestran prácticamente capacidad antioxidante, posiblemente porque la peroxidación inducida en nuestro estudio está provocada por radicales butoxilo, y el $\alpha$-tocoferol muestra baja protección frente a las peroxidaciones lipídicas inducidas por radicales alcoxilo (Martín et al, 2001). El manitol produce un secuestro específico de radicales hidroxilo (Souza-Santos et al, 2001), de lo que se deduce que nuestro sistema oxidativo, que contiene mayoritariamente radicales butoxilo, carece prácticamente de radicales hidroxilo. Las hormonas esteroides $\beta$-estradiol y dehidroandrosterona 3-sulfato (DHEAS), análogas estructurales del colesterol, no aportan protección en el caso del DHEAS (0\%), y solamente un $50 \%$ con el $\beta$-estradiol, a pesar de que a ambos compuestos se les atribuye la capacidad de interrumpir las reacciones en cadena de los procesos peroxidativos, así como quelar los iones metálicos en otros modelos experimentales (Martínez et al, 2002; van Rensburg et al, 2000). El colesterol también se ha descrito como un 
compuesto capaz de bloquear los procesos oxidativos (Smith, 1996). Sin embargo, nosotros hemos observado que los contenidos de TBARS en los eritrocitos controles oxidados con tBHP en presencia (relación molar oxidante:colesterol, 2:1) y en ausencia del esterol son similares (datos no mostrados), de lo que se deduce que el colesterol en nuestro caso no puede considerarse como un compuesto antioxidante. La enzima glutatión peroxidasa protege parcialmente al eritrocito del proceso oxidativo, con una efectividad superior a la catalasa, dado que la primera es capaz de descomponer el oxidante (tBHP), así como los peróxidos generados en el proceso en un medio dependiente de $\mathrm{GSH}$, mientras que la segunda descompone exclusivamente el $\mathrm{H}_{2} \mathrm{O}_{2}$ en agua y oxígeno. El resto de los compuestos ensayados (astaxantina, deferoxamina y $\mathrm{N}$-acetil-cisteina) muestran escasa actividad protectora.

De los datos anteriormente expuestos se deduce que los compuestos fenólicos son los que mayor protección otorgan frente al estrés oxidativo en nuestro modelo experimental. Por ello, se ha elegido el flavonoide quercetina como antioxidante para llevar a cabo el estudio aquí proyectado, dado su elevado poder antioxidante, además de tratarse de un compuesto natural abundante en frutas y verduras, que se ingiere en cantidades elevadas a través de la dieta. El estudio se ha completado con un análisis paralelo llevado a cabo con la rutina, un antioxidante que presenta analogías estructurales con la quercetina, de la que difiere solamente porque la rutina carece del grupo hidroxilo libre en posición 3 del anillo $C$, bloqueado por la presencia de un resto rutósido, lo que confiere a ambos antioxidantes distintas propiedades fiscoquímicas, con diferentes potenciales redox, y por tanto, efectos protectores distintos frente al estrés oxidativo (Halliwell y Gutteridge, 1999).

\section{Efecto de la incorporación de los antioxidantes quercetina y rutina en la estructura-función de los eritrocitos con diferentes contenidos de colesterol}

La modificación de los contenidos de colesterol en la membrana eritrocitaria se ha llevado a cabo por tratamiento de los eritrocitos con dispersiones de colesterol en polivinilpirrolidona (PVP), lo cuál provoca el enriquecimiento en colesterol, mientras que el empobrecimiento del esterol se produjo mediante tratamiento de los eritrocitos con $\beta$-ciclodextrinas. Ambos tratamientos producen baja hemólisis en el eritrocito $(<5 \%)$, con mínimas 
alteraciones estructurales y funcionales. El secuestro de colesterol provoca un incremento en la fluidez de la membrana eritrocitaria, mientras que el enriquecimiento produce el efecto contrario, descenso de su fluidez. Los tratamientos para el secuestro y el enriquecimiento de colesterol provocan en ambos casos una mínima exteriorización de los aminofosfolípidos en la superficie del eritrocito, más pronunciada en los eritrocitos pobres en colesterol, acompañada de un incremento en su fagocitosis, con pérdidas de su actividad basal aminofosfolípido translocásica y alteraciones en su morfología (LópezRevuelta et al, 2005; López-Revuelta et al, 2007).

La incubación de los diferentes tipos de eritrocitos con los antioxidantes quercetina o rutina en ausencia de oxidación y en idénticas condiciones a las empleadas durante los procesos oxidativos, provoca una hemólisis similar a la detectada en los procesos de modificación de los contenidos de colesterol $(<5 \%)$, detectándose porcentajes de viabilidad celular superiores al $98 \%$, sin que se modifique sensiblemente la estabilidad isotónica del eritrocito. Tampoco se alteran los contenidos de hemoglobina y GSH, ni cambia sensiblemente la composición lipídica del eritrocito. Sin embargo, se producen mínimas alteraciones en el estado físico de la membrana, con variaciones en la asimetría lipídica y en la morfología eritrocitaria, como consecuencia de la incorporación al eritrocito de los antioxidantes, que comentamos a continuación.

El efecto de la incorporación de los antioxidantes sobre el estado físico de la membrana eritrocitaria ha sido analizado mediante estudios de polarización de fluorescencia con las sondas DPH y TMA-DPH, incorporadas a los diferentes tipos de eritrocitos. Se han determinado los valores de anisotropía de fluorescencia $\left(r_{s}\right)$ en estado estacionario que muestran dichas sondas. El DPH se localiza en el núcleo hidrofóbico de la membrana, tanto en fases de gel como en estados líquido-cristal, interaccionando con las cadenas acílicas de los lípidos (Lentz, 1989; Wang et al, 1991), aportando por tanto información sobre el estado físico de esta zona de la bicapa. Mientras que su derivado catiónico TMA-DPH se sitúa preferentemente en las regiones periféricas de la membrana, interaccionando con las cabezas polares de los fosfolípidos aniónicos (Prendergast et al, 1981; Kaiser y London, 1998). El aumento de temperatura en el entorno provoca siempre descensos lineales en los valores de anisotropía de fluorescencia de ambas sondas, independientemente del tipo de eritrocitos y/o agente incorporado, lo que se interpreta como una fluidificación de la membrana por incremento de la temperatura, tanto en su región central como 
en su parte periférica. En todos los casos, los valores de anisotropía de fluorescencia que muestra el DPH son siempre inferiores a los que presenta el TMA-DPH, como consecuencia de la localización de las sondas en zonas de la membrana con diferente estado físico. El TMA-DPH se sitúa en zonas más rígidas de la bicapa lipídica que el DPH, como es la superficie celular, lo que provoca un menor desplazamiento del fluoróforo, y por tanto, un aumento de los valores de $r_{s}$ del TMA-DPH en todos los casos. La adición de los flavonoides solamente provoca alteraciones en el estado físico de la membrana en los eritrocitos controles y ricos en colesterol. La quercetina, molécula de carácter hidrofóbico, incrementa los valores de $r_{s}$ del $D P H$, sin que modifique los valores de $r_{s}$ del TMA-DPH. Estos datos indican que el antioxidante se incorpora preferentemente en la región hidrofóbica de la membrana, provocando una disminución en la fluidez de esta región de la bicapa. En cambio, la rutina, de carácter preferentemente hidrofílico, solamente produce descensos en los valores de $r_{s}$ del TMA-DPH en los mismos eritrocitos, lo que se asocia con una localización mayoritaria del antioxidante en la superficie de la membrana, dónde provoca una fluidificación de la zona. Diversos estudios han puesto de manifiesto también en otros tipos de membranas que los antioxidantes de carácter hidrofóbico se localizan en el centro de la bicapa lipídica de las membranas, mientras que los antioxidantes de naturaleza hidrofílica ocupan la superficie de dichas membranas, en interacción directa con su entorno acuoso (Saija et al, 1995b; Arora et al, 2000; Moridani et al, 2003; Dorta et al, 2005; Hendrich, 2006). En cambio, tanto la rutina como la quercetina parecen anclarse escasamente en las membranas de los eritrocitos pobres en colesterol, ya que dichos antioxidantes prácticamente no modifican los valores de $r_{s}$ del DPH y del TMA-DPH. Los descensos de colesterol en la membrana eritrocitaria podrían reducir drásticamente el volumen de la fase hidrofóbica de su bicapa lipídica, lo que ocasionaría un descenso apreciable en el anclaje del antioxidante.

La localización del antioxidante en la membrana viene impuesta fundamentalmente por sus características físicoquímicas, las cuáles dependen del pH del medio, influyendo en dicha distribución también la composición de la membrana y su estado físico (Hendrich, 2006). De hecho, el grupo de Pawlikowska-Pawlega describe una localización preferente de la quercetina a pH fisiológico en la interfase lípido-acuosa de las bicapas lipídicas en liposomas (Wójtowicz et al, 1996; Pawlikowska-Pawlega et al, 2007) y en membranas de eritrocitos humanos (Pawlikowska-Pawlega et al, 2003), provocando la 
incorporación del antioxidante un aumento en la fluidez de dicha región de la bicapa, sin que se aprecien cambios significativos en su región hidrofóbica. Sin embargo, en una línea celular de fibroblastos humanos, la quercetina muestra una amplia compartimentación subcelular (Pawlikowska-Pawlega et al, 2007), lo que demuestra el gran poder de penetración de este antioxidante en determinadas circunstancias. La acción de los polifenoles sobre la fluidez de la bicapa lipídica recuerda al efecto que ejerce el colesterol en la membrana, el cuál actúa como una molécula estabilizadora de la bicapa lipídica, aumentando o disminuyendo la rigidez de la membrana en función de la temperatura de transición de dicha bicapa lipídica (Hendrich, 2006).

Por lo que respecta a la distribución asimétrica de la PE en la membrana eritrocitaria, la incorporación de quercetina y rutina no provoca cambios en su distribución en los diferentes tipos de eritrocitos, como indican los estudios llevados a cabo mediante hidrólisis con fosfolipasa $A_{2}$.

En los eritrocitos controles tratados con ambos antioxidantes no se ha detectado exteriorización de la PS en los estudios con citometría de flujo, a través del marcaje con anexina V-FITC, lo que concuerda plenamente con la ausencia de cambios observados en la actividad APLT en presencia de quercetina en dichos eritrocitos. Sin embargo, la rutina provoca un incremento de dicha actividad enzimática en los diferentes tipos de eritrocitos, lo que afianzará la localización de los aminofosfolípidos en la cara interna de la membrana eritrocitaria. La enzima APLT es responsable de la interiorización de los aminofosfolípidos, principalmente de la PS, de forma que la pérdida de su actividad provoca la exteriorización de PS en los eritrocitos oxidados (Mandal et al, 2002; Banerjee y Kuypers, 2004; López-Revuelta et al, 2007) y células apoptóticas (Tyurina et al, 2004a; Tyurina et al, 2004b). A pesar de la no exteriorización de PS observada en los eritrocitos controles tratados con ambos antioxidantes, sin embargo se aprecia un incremento significativo de la fagocitosis en estos eritrocitos ( $\sim 7$ veces en presencia de quercetina y 4 veces en presencia de rutina), lo que podría justificarse en el caso de la quercetina por el incremento en el número de eritrocitos morfológicamente alterados. Cambios similares se han puesto también de manifiesto en eritrocitos humanos, dónde se describe que la quercetina se une a las proteínas del citoesqueleto, modificando así la forma del eritrocito (Pawlikowska-Pawlega et al, 2003). Otras señales de reconocimiento podrían ser responsables de la eritrofagocitosis observada en estos eritrocitos en presencia de los antioxidantes, tales como un 
posible descenso en su deformación, a la vista de las alteraciones físicas que experimenta la membrana, como hemos comentado anteriormente, o bien la aparición de determinados componentes en la superficie eritrocitaria, como restos $\beta$-galactosilados, banda 3 modificada, etc. (Bartosz, 1990; Kuypers y de Jong, 2004).

Los eritrocitos modificados en sus contenidos de colesterol no experimentan alteraciones en la exteriorización de PS mediante citometría de flujo en presencia de quercetina, proceso que va asociado al no aumento de la fagocitosis que muestran estos eritrocitos. La enzima APLT muestra cambios en su actividad que parecen ser insuficientes para modificar la asimetría aminofosfolípidica en la membrana. En cambio, la rutina provoca incrementos en la exteriorización de PS tanto en los eritrocitos ricos (concentraciones 0.5 $\mathrm{mM}$ de antioxidante) como en los eritrocitos pobres en colesterol (concentración $0.25 \mathrm{mM}$ de antioxidante), sin que ello implique un incremento en la fagocitosis eritrocitaria, lo que se interpreta como una señal de PS insuficiente para ser reconocida por los macrófagos. El tratamiento con rutina produce incrementos en la actividad APLT en todos los eritrocitos, que paradójicamente va asociado con un aumento en la exteriorización de PS en los eritrocitos modificados. Ello podría ser debido a una activación de las escramblasas, enzimas que inducen la distribución bidireccional de los lípidos a favor de gradiente de concentración, como se ha puesto de manifiesto en líneas celulares promielocíticas humanas NB4 tratadas con wogonina, donde se observa una exteriorización de PS que no puede ser contrarrestada por el incremento de actividad de la APLT (Zhang et al, 2008).

Por lo que respecta a la morfología de los eritrocitos modificados, los eritrocitos pobres en colesterol no experimentan cambios en presencia de ambos antioxidantes, mientras que sí se producen alteraciones morfológicas en los eritrocitos ricos en colesterol, aunque en ningún caso dichas alteraciones morfológicas van acompañadas de un aumento de la fagocitosis.

En conclusión, nuestros estudios demuestran que aunque la viabilidad celular siempre se mantiene alrededor del $98 \%$ en los diferentes tipos de eritrocitos no oxidados tratados con los antioxidante, los eritrocitos controles son los que muestran mayor alteración estructural, dado que sufren un aumento en su fagocitosis, que no manifiestan los eritrocitos modificados, así como cambios físicos en su membrana. Ello podría ser debido a que los 
eritrocitos modificados pueden incorporan menores cantidades de antioxidante como consecuencia de las alteraciones en la composición y estado físico de su membrana, especialmente en los eritrocitos pobres en colesterol, que precisamente son los que muestran menos alteraciones ante la incorporación de los antioxidantes.

\section{Efecto protector de los antioxidantes frente al daño oxidativo inducido por el TBHP en eritrocitos controles $y$ modificados en colesterol}

Estudios recientemente llevados a cabo en nuestro laboratorio han puesto de manifiesto que la modificación de los contenidos de colesterol en el eritrocito estimula la oxidación inducida por especies de oxígeno reactivas (ROS), lo que provoca un incremento del daño oxidativo celular, con oxidación casi completa de la hemoglobina y del glutation reducido, desestabilizando la bicapa lipídica por pérdidas de lípidos, especialmente en los eritrocitos pobres en colesterol. También se observan alteraciones en la fluidez de la membrana, con incrementos en la hemólisis y descenso en la estabilidad isotónica de los eritrocitos modificados (López-Revuelta et al, 2005). Los análisis sobre la distribución asimétrica de los fosfolípidos muestran un incremento en la exteriorización de fosfatidilserina en la membrana del eritrocito oxidado, lo que se correlaciona con aumentos en su fagocitosis e incrementos de las formas espiculadas, asociado todo ello con una pérdida de la actividad aminofosfolípido translocásica, que está en relación directa con el grado de estrés oxidativo que manifiesta el eritrocito (López-Revuelta et al, 2007). El incremento de colesterol en las membranas genera sistemas menos fluidos, en los que es posible observar microdominios que son más propensos a la peroxidación lipídica (McLean y Hagaman, 1992; Denisova et al, 2001). El empobrecimiento en colesterol produce también cambios estructurales en la célula, y una fluidificación de las bicapas lipídicas que favorecen la propagación de los radicales libres (McLean y Hagaman, 1992; Parasassi et al, 1995). La fosfatidilserina exteriorizada en la superficie del eritrocito como consecuencia de la modificación de sus contenidos de colesterol puede captar iones metálicos a través de su carga negativa, los cuáles pueden catalizar la descomposición de los peróxidos, ocasionando un incremento de los procesos oxidativos celulares (Tadolini et al, 1992; Gal et al, 2003). 
Análisis preliminares llevados a cabo en nuestro estudio indican que un gradiente creciente en la concentración de tBHP genera un aumento progresivo de ROS tanto en los eritrocitos controles como en los modificados, alcanzándose la máxima producción a concentraciones de oxidante $2 \mathrm{mM}$. Los antioxidantes quercetina y rutina bloquean en diferente grado la producción de ROS en función del tipo de eritrocito, así como de las concentraciones de oxidante y antioxidante, observándose en todos los casos la máxima protección (>65\%) a relaciones molares antioxidante:oxidante 1:2.

La quercetina aporta siempre mayor poder de protección que la rutina frente al estrés oxidativo en los diferentes tipos de eritrocitos, como se deduce de los valores de IC $_{50}$ determinados. La quercetina muestra una protección de 3-4 veces superior a la rutina frente a la producción de ROS, y alrededor de 3 veces superior frente a la generación de TBARS. Este mayor poder antioxidante de la quercetina ha sido también descrito en eritrocitos procedentes de pacientes con anemia falciforme (Cesquini et al, 2003), en células HepG2 expuestas a tBHP (Alía et al, 2006a; Alía et al, 2006b), así como en las membranas de eritrocitos de cabra tratadas con $\mathrm{Cu}^{2+}$ /ascorbato (Chaudhuri et al, 2007). Efectos protectores frente al estrés oxidativo de varios flavonoides, incluida la quercetina, han sido también observados en células Fao tratadas con $\mathrm{H}_{2} \mathrm{O}_{2}$ (Roig et al, 2002), en células de la retina expuestas a ascorbato/ $/ \mathrm{Fe}^{+2}$ (Areias et al, 2001) y en liposomas irradiados con luz ultravioleta (Gabrielska et al, 2006). El mayor poder antioxidante de la quercetina puede residir en: i) su mayor facilidad para incorporarse a la membrana (Kaneko et al, 1994; Saija et al, 1995a; Saija et al, 1995b; Moridani et al, 2003; Cesquini et al, 2003), lo que permite a la quercetina captar radicales libres situados en diferentes puntos de la bicapa lipídica; ii) su alta capacidad para captar iones metálicos a través del grupo orto-dihidroxifenólico y su poder para donar átomos de hidrógeno a los radicales alcoxilo y peroxilo, rompiendo así las reacciones de oxidación en cadena (Rice-Evans et al, 1996; Cao et al, 1997; Lien et al, 1999). Su glucósido rutina, que se sitúa principalmente en la interfase lípido-agua, es menos reactivo que la quercetina debido a la presencia de un disacárido que bloquea el grupo 3-OH de la molécula de hidroxiflavona (Saija et al, 1995b; Rice-Evans et al, 1996; Cesquini et al, 2003), y requerirá, por lo tanto, concentraciones mayores que la quercetina para aportar una protección similar frente al estrés oxidativo. 
La modificación de los contenidos de colesterol en la membrana no altera la mayor actividad antioxidante que muestra la quercetina con respecto a la rutina, pero sí modifica el grado de eficacia que aporta cada uno de estos antioxidantes. De forma tal, que el empobrecimiento en colesterol reduce la protección que otorgan los antioxidantes a los eritrocitos, observándose que la formación de TBARS en los eritrocitos pobres oxidados es significativamente menos bloqueada que en los controles, tanto en presencia de quercetina $(p \leq 0.01)$ como de rutina $(p \leq 0.05)$. Así mismo se observan valores superiores de $\mathrm{IC}_{50}$ en ambos antioxidantes en los eritrocitos pobres (3 veces en la protección frente a ROS y $\sim 2$ veces en la protección frente a TBARS) con respecto a los eritrocitos controles. Estas diferencias de comportamiento podrían ser debidas principalmente a los bajos niveles de flavonoide que pueden contener las membranas de eritrocitos pobres en colesterol, como consecuencia de la reducción del volumen hidrofóbico que experimenta la membrana durante el secuestro de colesterol. No se descarta también que la mayor facilidad de propagación y producción de ROS que se produce en los eritrocitos pobres en colesterol, como consecuencia de la desestabilización que sufre su membrana durante el secuestro del esterol, podría requerir un aporte mayor de antioxidante para lograr grados similares de protección. Incluso, las variaciones que experimenta el entorno del antioxidante por modificación de los contenidos de colesterol pueden también alterar el potencial redox del flavonoide, lo que ocasionará cambios en su actividad antioxidante.

La quercetina y la rutina en determinadas circunstancias presentan también poder oxidante. Así, la quercetina en un intervalo de concentración 13$1 \mu \mathrm{M}$, con bajas concentraciones de oxidante $(0.2 \mathrm{mM}$ tBHP), incrementa la producción de ROS de forma progresiva en los eritrocitos ricos en colesterol. Lo mismo sucede en los eritrocitos controles, dónde tanto la quercetina como la rutina a concentraciones 1 y $2 \mu \mathrm{M}$, en presencia de $0.2 \mathrm{mM}$ de tBHP, muestran también acción pro-oxidante. Este poder pro-oxidante que poseen los flavonoides se asocia con la presencia en su molécula de un grupo catecol, el cuál puede auto-oxidarse en presencia de metales de transición, transformándose la molécula a bajas concentraciones de antioxidante en una forma mayoritariamente oxidante, lo que provoca un aumento en los niveles de ROS. Este efecto pro-oxidante sólo es apreciable a bajas concentraciones de flavonoides, en cuyas condiciones hay predomino de los iones metálicos, produciéndose en tales circunstancias un descenso ostensible del potencial redox del complejo flavonoide-metal, que será el responsable de inducir la 
oxidación (Cao et al, 1997; Galati y O'brien, 2004; Teixeira et al, 2005). En nuestro caso, la presencia del $\mathrm{Fe}^{+2}$ procedente del grupo hemo puede acelerar el efecto pro-oxidante del flavonoide, especialmente en el caso de la quercetina, dado el alto poder quelante de dicha molécula, que es superior al de la rutina (Galati y O'brien, 2004; Teixeira et al, 2005).

La casi total oxidación de la hemoglobina y el $70 \%$ de disminución del GSH causados por el tBHP en los tres tipos de eritrocitos analizados (LópezRevuelta et al, 2005), son parcialmente inhibidos por ambos antioxidantes. Quercetina y rutina aportan porcentajes de protección similares en la oxidación de la hemoglobina (30\%) y del GSH (66-70\%), tanto en los eritrocitos controles como en los eritrocitos enriquecidos en colesterol. Sin embargo, en los eritrocitos pobres en colesterol, la rutina aporta una protección alrededor de 1,5 veces superior a la quercetina, inhibiendo en un 50-60\% la oxidación de la hemoglobina y en un $100 \%$ la pérdida de GSH. Estos resultados indican que el empobrecimiento en colesterol de los eritrocitos cambia el estado de oxidación intracelular después de la inducción del estrés oxidativo en presencia de los antioxidantes, incrementándose con la quercetina y disminuyendo con la rutina. Estas observaciones están en consonancia con estudios precedentes, en los que se observa que la quercetina causa descensos en la concentración de GSH en diferentes sistemas tras la inducción del estrés oxidativo (Metodiewa et al, 1999; Awad et al, 2001; Choi et al, 2003; Boots et al, 2003). Estas pérdidas de GSH en presencia de quercetina en los eritrocitos pobres en colesterol pueden explicarse, en parte, por la inhibición de la glutatión reductasa que se produce durante el proceso oxidativo, enzima que es responsable de la regeneración del GSH producida a partir de su forma oxidada (Roig et al, 2002; Choi et al, 2003). Los descensos en los niveles de GSH podrían también ser debidos a la formación de glutationilquercetin derivados, como se ha puesto de manifiesto en otros estudios, donde se observa que la oxidación de la quercetina da lugar a una orto-quinona con cuatro formas tautoméricas dotadas de actividad prooxidante a través de sus radicales fenoxilo, los cuáles reaccionan con el GSH produciendo su disminución, como consecuencia de la formación de los derivados mencionados (Awad et al, 2001; Boots et al, 2003). El mayor poder protector de la rutina frente a la oxidación del GSH en los eritrocitos pobres en colesterol puede residir en que su oxidación, como en el caso de la quercetina, previene el proceso oxidativo, pero en este casos se genera una forma oxidada que no parece reaccionar con el GSH. Los mayores contenidos de GSH y de hemoglobina en los eritrocitos pobres en colesterol oxidados en presencia de 
ambos antioxidantes sugieren una localización mayoritaria de los flavonoides en su citoplasma celular, en detrimento de su incorporación a la membrana.

El proceso oxidativo llevado a cabo por el tBHP provoca también perdidas significativas de colesterol (24-60\%) y de fosfolípidos totales (25-45\%) en los distintos grupos de eritrocitos, principalmente en los eritrocitos pobres en colesterol (López-Revuelta et al, 2005). Las pérdidas de colesterol son bloqueadas por ambos antioxidantes, con mayor eficacia en los eritrocitos controles (70-75\%) que en los modificados (50-55\%). La protección otorgada por los antioxidantes frente a la pérdida de fosfolípidos totales en los diferentes grupos de eritrocitos oxidados oscila alrededor del $64-73 \%$. Aunque el grado de protección otorgado por ambos antioxidantes es muy similar frente a las pérdidas de los diferentes tipos de lípidos en cada grupo de eritrocitos, la quercetina tiende a aporta una protección algo superior a la rutina en los eritrocitos controles, mientras que en los eritrocitos modificados es la rutina la más eficiente en dicha protección.

Las pérdidas de fosfolípidos se circunscriben a un descenso de los contenido de $\mathrm{PE}$, preferentemente, seguido de la pérdida de PC en todos los grupos de eritrocitos oxidados, detectándose también descensos en los contenidos de PS+PI solamente en los eritrocitos pobres en colesterol (LópezRevuelta et al, 2005). La PC y el PA son los fosfolípidos mejor protegidos (70$90 \%$ ) por ambos antioxidante frente a las pérdidas ocasionadas por el daño oxidativo, seguido de la $\mathrm{PE}$, con protecciones cercanas al $60 \%$. En general, la tendencia de protección que aporta cada antioxidante en las diferentes clases de fosfolípidos sigue la pauta marcada en los fosfolípidos totales.

El perfil de ácidos grasos de los lípidos totales sólo sufre cambios significativos tras el proceso oxidativo en los eritrocitos modificados, con descensos significativos en los porcentajes de ácido linoleico $(18: 2, n-6)$ y ácido araquidónico (20:4, n-6) (López-Revuelta et al, 2005). La presencia de quercetina $o$ rutina en el medio de oxidación evita las pérdidas de los citados ácidos grasos en los eritrocitos pobres en colesterol, consiguiéndose una protección total. Sin embargo, en los eritrocitos ricos en colesterol la quercetina es mejor protector ( $100 \%$ del $18: 2$ y $38 \%$ del $20: 4$ ) que la rutina (69\% del $18: 2$ y $0 \%$ del $20: 4$ ), siendo el ácido linoleico el mejor preservado por ambos antioxidantes. Las protecciones observadas frente a las pérdidas de lípidos y ácidos grasos en los diferentes tipos de eritrocitos oxidados concuerdan con la 
inhibición que experimentan los procesos oxidativos (descensos de formación de ROS y TBARS) en presencia de ambos antioxidantes. El descenso de radicales libres en el medio de oxidación por la presencia del antioxidante conllevará una disminución del proceso oxidativo, y por tanto, una disminución en la pérdida y oxidación de lípidos eritrocitarios. Diversos estudios han puesto de manifiesto que los polifenoles son capaces de prevenir la oxidación de lípidos y ácidos grasos poliinsaturados inducida en lipoproteínas de baja densidad (LDL) (Frémont et al, 1999) y en membranas celulares de rata (Frémont et al, 2000). Las pérdidas de lípidos se asocian con procesos de vesiculación que tienen lugar en la célula durante el proceso oxidativo, como consecuencia de la reorganización que experimenta el citoesqueleto, liberándose micropartículas que contienen parte de los componentes de la membrana (Martín-Valmaseda et al, 1998; Chen et al, 2000). La presencia de antioxidantes evita parcialmente dicho proceso de vesiculación, previniendo de este modo la pérdida de lípidos que se producen en la célula oxidada en ausencia de antioxidante (Chen et al, 2000).

Por lo que respecta al estado físico de la membrana eritrocitaria, la oxidación inducida por tBHP solamente altera la fluidez de la membrana en los eritrocitos controles, como se deduce de los estudios de anisotropía de fluorescencia llevados a cabo con DPH y TMA-DPH. Dichas membranas muestran descensos significativos exclusivamente en los valores de $r_{s}$ del TMADPH, asociándose dichos cambios con un incremento en la fluidez de la superficie de estas membranas (López-Revuelta et al, 2005). La adición de quercetina o rutina al medio de oxidación impide que se altere la fluidez de la membrana en los eritrocitos controles oxidados, ya que los valores de $r_{s}$ del TMA-DPH que muestran dichas membranas son prácticamente idénticos a los detectados en las membranas de eritrocitos controles no oxidados tratados con el antioxidante. Las procianidinas también aportan protección frente a los cambios físicos que experimentan las membranas de eritrocitos irradiados con luz ultravioleta (Carini et al, 2000), así como la catequina libre o el té negro, que restituyen los valores basales de microviscosidad en los eritrocitos humanos oxidados (Halder y Bhaduri, 1998). La situación del flavonoide en la membrana marca el modo de prevención del proceso oxidativos. Los flavonoides que se sitúan en la región hidrofóbica de la membrana, provocando un descenso significativo en la fluidez de dicha región, como sucede con la quercetina, lo que dificultará la difusión de los radicales libres en la célula, bloqueando así el proceso oxidativo (Arora et al, 2000; Saija et al, 1995b). Mientras que los 
flavonoides que se sitúan en la superficie de la membrana, como la rutina, pueden interaccionar con los radicales libres y otros tipos de moléculas, impidiendo de este modo la entrada de dichos radicales al interior de la célula (Saija et al, 1995b; Verstraeten et al, 2003).

El mantenimiento de la asimetría de la bicapa lipídica de la membrana eritrocitaria, con localización preferente de los aminofosfolípidos en la monocapa, es imprescindible para el correcto funcionamiento del eritrocito (Schroit y Zwaal, 1991; Balasubramanian y Schroit, 2003). Esta disposición asimétrica se ve alterada por el daño oxidativo inducido mediante el tratamiento de los eritrocitos controles y modificados con tBHP, produciéndose en todos los casos un incremento en la exteriorización de los aminofosfolípidos en la membrana eritrocitaria, acompañado de una inactivación de la APLT, especialmente en los eritrocitos pobres en colesterol (López-Revuelta et al, 2007). En el presente estudio se ha analizado el papel desempeñado por los antioxidantes en la preservación de la asimetría aminofosfolipídica basal en los diferentes tipos de eritrocitos tras el proceso oxidativo. Los análisis se han llevado a cabo mediante hidrólisis enzimática con fosfolipasa $A_{2}$, técnicas de citometría de flujo basadas en el empleo de anexina-V-FITC, y estudios de eritrofagocitosis, procedimientos todos ellos utilizados y ampliamente contrastados en estudios previos llevados a cabo en nuestro laboratorio (LópezRevuelta, 2007). El método enzimático permite conocer la distribución que adoptan los aminofosfolípidos en la membrana eritrocitaria (Roelofsen y Op den Kamp, 1988; Dumaswala et al, 1996), mientras que con los estudios de citometría de flujo, que es una técnica muy sensible, únicamente permite cuantificar las células que han exteriorizado la PS en la cara externa de la membrana. La anexina- $V$ es una proteína que se une a la PS situada en la superficie de la membrana en presencia de $\mathrm{Ca}^{+2}$, y su marcaje con el fluoróforo FITC permite, mediante citometría de flujo, cuantificar las poblaciones celulares que exteriorizan la PS (Kuypers et al, 1996; Kagan et al, 2002; Mandal et al, 2002). Diversas investigaciones también han demostrado que la presencia de la PS en la superficie celular constituye una de las principales señales de reconocimiento para la fagocitosis celular por parte de los macrófagos en células apoptóticas (FadoK et al, 1992; Kagan et al, 2002) y en los eritrocitos (Schroit et al, 1985; Kuypers y de Jong, 2004), eliminando mediante dicho proceso las células no viables. De hecho se ha demostrado que existe correlación entre la exteriorización de PS en la superficie celular y el aumento de fagocitosis que experimenta la célula (López-Revuelta et al, 2007). 
En los eritrocitos controles oxidados, la presencia de ambos antioxidantes en el medio bloquea de forma total la exteriorización de PE (100\% de protección), como demuestran nuestros estudios enzimáticos efectuados con fosfolipasa $A_{2}$. Los análisis realizados con la citometría de flujo muestran que ambos antioxidantes aportan una protección casi total ( $90 \%)$ frente a la exteriorización de PS producida durante el proceso oxidativo. Los porcentajes de fagocitosis ( $30 \%)$ que presentan los eritrocitos controles oxidados son superiores a lo esperado a la vista del grado de exteriorización de la PS. La eritrofagocitosis observada podría ser en parte imputable a las elevadas alteraciones morfológicas (60\%) que muestran dichos eritrocitos. Dicha fagocitosis podría también atribuirse a la presencia de otras señales de reconocimiento, siendo escasamente imputable a los bajos porcentajes de PS exteriorizada.

La salida de la PS hacia la cara externa de la membrana plasmática se produce a través de la inhibición de la APLT, asociado a la activación simultánea de escramblasas lipídicas dependientes de $\mathrm{Ca}^{+2}$ (Bevers et al, 1999; Zwaal et al, 2005; Smrz et al, 2008). Los procesos oxidativos provocan la activación de caspasas (Tyurina et al, 2004a; Tyurina et al, 2004b), que ocasionan la inhibición de la APLT por proteólisis (Mandal et al, 2002; Mandal et al, 2005) e incremento de calcio intracelular (Beleznay et al, 1997; Zwaal et al, 2005). En cambio, se activan las escramblasas por aumento de la concentración de ceramida y/o del calcio citosólico, lo que ocasiona la salida de PS hacia la cara externa de la membrana plasmática (Martínez et al, 1999; Lang et al, 2004). Nuestros estudios experimentales previos han demostrado que la correlación existente entre la pérdida de actividad APLT y el incremento de tBHP provoca también aumento de la salida de PS hacia la superficie de los eritrocitos controles y modificados, especialmente en los eritrocitos pobres en colesterol (López-Revuelta et al, 2007). En el presente estudio se demuestra que los antioxidantes no impiden la pérdida de actividad que sufre la enzima APLT en los tres tipos de eritrocitos oxidados, debido posiblemente a la presencia de ROS y otros productos de la oxidación. Dichos compuestos estarán presentes en el medio a bajas concentraciones, ya que la protección conseguida por los antioxidantes frente a la formación de ROS y TBARS no es total. La escasa exteriorización de PS observada en este estudio en los diferentes tipos de eritrocitos puede deberse a la inhibición de las escramblasas- $\mathrm{Ca}^{+2}$ dependientes, como consecuencia de la modificación de sus grupos sulfhidrilo a través del proceso oxidativo (de Jong y Kuypers, 2006), o bien por descensos del $\mathrm{Ca}^{2+}$ 
intracelular que debe producirse al disminuir la concentración de inositol-1,4,5trisfosfato ocasionado por inhibición de la actividad 1-fosfatidilinositol-4-quinasa en presencia de quercetina (Prajda et al, 1995). Estudios precedentes han puesto de manifiesto que el quercetín-3-O-galactósido previene el daño oxidativo y es capaz de bloquear la activación de caspasas en una línea celular de fibroblastos pulmonares tratados con peróxido de hidrógeno, lo que debe provocar una baja o nula salida de PS hacia la superficie celular (Piao et al, 2007). También se ha comprobado recientemente en timocitos de rata tratados con agua oxigenada que la quercetina inhibe parcialmente la salida de PS hacia el exterior de la membrana (Oyama et al, 1999; Sakanashi et al, 2008). Otros compuestos fenólicos como los ácidos cafeico y elágico bloquean también la exteriorización de la PS producida durante el tratamiento de células mononucleares de sangre periférica con $\mathrm{H}_{2} \mathrm{O}_{2}$ (Khanduja et al, 2006).

Ambos antioxidantes aportan protecciones similares tanto en la disposición que adoptan los aminofosfolípidos en la membrana eritrocitaria, como en la eritrofagocitosis y los cambios morfológicos que experimentan los eritrocitos controles oxidados.

La modificación de los contenidos de colesterol en el eritrocito produce una menor protección de los antioxidantes tanto frente a la exteriorización de la PS (78-89\%), como frente a la eritrofagocitosis (protecciones del $50 \%$ con quercetina y del $11-30 \%$ con rutina). Este menor poder de protección concuerda plenamente con la menor preservación en la formación de TBARS y en las pérdidas de colesterol que experimentan estos eritrocitos en presencia de ambos antioxidantes, siendo en general la quercetina mejor protector que la rutina. La alteración de la bicapa lipídica de la membrana eritrocitaria que se produce como consecuencia de la modificación de los contenidos de colesterol, conllevan un aumento en la salida de PS, con el consiguiente incremento de la carga eléctrica negativa (López-Revuelta et al, 2005), lo cuál debe restringir la incorporación del antioxidante, como se ha puesto de manifiesto en las membranas de liposomas que contienen PS e incorporan catequinas (Hendrich, 2006; Kajiya et al, 2002). El menor poder de preservación que muestran los antioxidantes frente al daño oxidativo en los eritrocitos modificados puede ser consecuencia del aumento de los procesos oxidativos que tienen lugar en este tipo de eritrocitos, junto con los bajos contenidos de antioxidante y los cambios de su potencial redox que deben producirse en sus membranas debido a la alteración de sus contenidos de colesterol. 
Por lo que respecta a la morfología, los antioxidantes muestran en general protecciones menores frente a los cambios morfológicos en los eritrocitos modificados oxidados que en los eritrocitos controles, siendo nula la preservación que otorgan a los eritrocitos ricos en colesterol. El aumento de dichas alteraciones justifica los incrementos de fagocitosis que experimentan estos eritrocitos, dada la baja exteriorización de PS producida en todos estos casos, que es próxima a los valores detectados en los eritrocitos controles oxidados en presencia de los antioxidantes.

El grado de hemólisis y la estabilidad isotónica son dos parámetros que se ven afectados de un modo considerable por el daño oxidativo inducido por el tBHP. La acción del agente oxidante eleva el grado de hemólisis hasta porcentajes de $81-91 \%$ en todos los tipos de eritrocitos, mientras que su estabilidad isotónica desciende hasta el $80-95 \%$. El tratamiento con los antioxidantes muestra que la quercetina protege más eficientemente que la rutina frente al aumento de hemólisis y el descenso de estabilidad isotónica, tanto en los eritrocitos controles y como en los modificados sometidos a oxidación. La acción antihemolítica de la quercetina, que es superior a la de sus glucósidos correspondientes, entre los que se incluye la rutina, ha sido también descrita en los eritrocitos humanos expuestos a radicales libres (Dai et al, 2006). Asimismo se observa que la estabilidad isotónica de los eritrocitos humanos (Bilto y Abdalla, 1998) y de cabra (Chaudhuri et al, 2007) aumenta en presencia de diferentes flavonoides. Estas protecciones pueden deberse a la estabilización producida en la membrana eritrocitaria por la incorporación de los antioxidantes, como demuestran nuestros estudios sobre el estado físico de la membrana, donde se observa que la quercetina disminuye la fluidez en la región hidrofóbica de la membrana, mientras que la rutina transforma la región superficial en una zona menos rígida. Diversos estudios han puesto de manifiesto que la incorporación de los flavonoides en las membranas celulares provoca cambios profundos en sus características físicas, modificando también su estructura y permeabilidad (Hendrich, 2006). La presencia de los antioxidantes impide la formación y dificulta la difusión de los radicales libres a través de la membrana, previniendo parcialmente la alteración estructural de la membrana eritrocitaria, así como su respuesta a los cambios osmóticos del entorno. La integridad celular de los eritrocitos pobres en colesterol es menos preservada por ambos antioxidantes que en el resto de eritrocitos oxidados, posiblemente debido a la menor presencia de los flavonoides en las membranas 
pobres en colesterol, lo que les hace más vulnerables al daño oxidativo, y por tanto, más susceptibles a los cambios osmóticos del medio.

En resumen, nuestro estudio demuestra que la quercetina ofrece mejor protección que la rutina frente a la peroxidación lipídica (TBARS) y la formación de ROS inducidos por tBHP, con una inhibición casi completa de la hemólisis y una estabilización isotónica parcial en los diferentes tipos de eritrocitos. Estas diferencias de comportamiento entre ambos tipos de compuestos residen en la mayor capacidad antioxidante que muestra la quercetina con respecto a la rutina, debido a sus características estructurales. La quercetina también incrementa la microviscosidad en la región central de la bicapa lipídica, lo que puede limitar la penetración de los radicales libres en la membrana, y por tanto, bloquear el proceso oxidativo. La rutina protege menos que la quercetina debido a la presencia de un resto glucosídico en su molécula, el cuál dificulta la difusión del compuesto dentro de la membrana, y a su vez bloquea el grupo hidroxilo de la posición 3, que cuando se encuentra en estado libre incrementa el poder antioxidante del flavonoide. Ambos antioxidantes suprimen con una eficacia similar, aunque con tendencia hacia una protección mayor por parte de la quercetina en la mayoría de los casos, las alteraciones en la fluidez y las pérdidas de lípidos, así como la exteriorización de la PS producidas por el estrés oxidativo en los diferentes tipos de eritrocitos, sin que se produzca protección alguna de la actividad APLT. Sin embargo existe baja o nula protección de los antioxidantes frente a la alteración morfológica que sufre el eritrocito oxidado, lo que se corresponde con la fagocitosis observada. La modificación de los contenidos de colesterol en la membrana eritrocitaria resta eficacia en general a los antioxidantes, posiblemente como consecuencia de su menor acceso a la membrana, especialmente durante el empobrecimiento en colesterol. El secuestro de colesterol produce una desestabilización de la membrana que puede ocasionar un descenso en la localización de los antioxidantes en la membrana, accediendo éstos de forma mayoritaria al citosol. Su mayor presencia en este compartimiento se corresponde con las elevadas protecciones de GSH y hemoglobina detectadas en los eritrocitos pobres en colesterol oxidados, especialmente en presencia de rutina.

A la vista de estos resultados pensamos que aquellas patologías donde la estructura de la membrana celular se encuentre alterada como consecuencia de cambios en su composición, la protección otorgada por el antioxidante frente al daño oxidativo celular puede verse sensiblemente disminuida. 
CAPÍTULO VI: Conclusiones 

1. La incorporación de quercetina o rutina en los eritrocitos controles y modificados no oxidados no altera su estabilidad isotónica, ni modifica su composición lipídica, ni los contenidos de GSH y hemoglobina. Sin embargo, sí provoca ciertos cambios estructurales en su superficie celular, que parecen más destacados en los eritrocitos controles, ya que éstos muestran incrementos en su fagocitosis que no presentan los eritrocitos modificados.

2. El bloqueo de la generación de ROS en presencia de ambos antioxidantes conlleva una protección casi total frente a la hemólisis en los eritrocitos controles y modificados, con preservación del estado físico de su membrana y un bloqueo mayoritario de la exteriorización de sus aminofosfolípidos. El proceso mantiene parcialmente la estabilidad isotónica del eritrocito, preservándolo frente a la peroxidación (formación de TBARS), con el consiguiente descenso en la pérdida de lípidos, acompañado de protecciones parciales frente a la eritrofagocitosis y los cambios morfológicos.

3. La quercetina ofrece mayor protección que la rutina frente al estrés oxidativo (formación de ROS y peroxidación) y la pérdida de integridad celular (hemólisis y estabilidad isotónica) en los tres grupos de eritrocitos oxidados, como consecuencia de su mayor capacidad antioxidante y su localización mayoritaria en la membrana.

4. La rutina aporta un efecto protector significativamente mayor que la quercetina frente a la oxidación de hemoglobina y GSH solamente en los eritrocitos pobres en colesterol, posiblemente como consecuencia de una distribución preferente de los antioxidantes en el citosol en este tipo de eritrocitos, asociado a la mayor reactividad de los derivados de quercetina en este compartimiento. Sin embargo, en los eritrocitos controles y ricos en colesterol oxidados, sus contenidos de GSH y 
hemoglobina son preservados con similar eficacia por ambos antioxidantes.

5. La modificación de los contenidos de colesterol en la membrana eritrocitaria provoca una disminución de la protección que aportan ambos antioxidantes frente a las alteraciones estructurales $y$ de integridad celular que se manifiestan en el eritrocito oxidado. El secuestro de colesterol acentúa dicho descenso, ya que produce cambios estructurales y físicos en la membrana eritrocitaria, que deben ocasionar una disminución en la localización de los antioxidantes en dicha membrana, con posible desplazamiento hacia el citosol. 
CAPÍTULO VII: Bibliografía 

> Abel, S., Smuts, C.M., de Villiers, C. y Gelderblom, W.C. (2001). Changes in essential fatty acid patterns associated with normal liver regeneration and the progression of hepatocyte nodules in rat hepatocarcinogenesis. Carcinogenesis 22, 795-804.

> Afanas'ev, I.B., Dorozhko, A.I., Brodskii, A.V., Kostyuk, A. y Potapovich, A.L. (1989). Chelating and free radical scavenging mechanisms of inhibitory action of rutin and quercetin in lipid peroxidation. Biochem. Pharmacol. 38, 1763-1769.

> Afanas'ev, I.B., Ostrachovitch, E.A., Abramova, N.E. y Korkina, L.G. (1995). Different antioxidant activities of bioflavonoid rutin in normal and iron-overloaded rats. Biochem.Pharmacol. 50, 627-637.

Ahmad, K.A., Clement, M.V. y Pervaiz, S. (2003). Pro-oxidant activity of low doses of resveratrol inhibits hydrogen peroxide-induced apoptosis. Ann. N.Y.Acad.Sci. 1010, 365-373.

> Ahmad, K.A., Clement, M.V., Hanif, I.M. y Pervaiz, S. (2004). Hydrogen peroxide-mediated cytosolic acidification is a signal for mitochondrial translocation of Bax during drug-induced apoptosis of tumor cells. Cancer Res. 64, 7867-7878.

> Ahmad, M.S., Fazal, F., Rahman, A., Hodi, S.M. y Parish, J.H. (1992) Activities of flavonoids for the cleavage of DNA in the presence of $\mathrm{Cu}(\mathrm{II})$ : correlation with generation of active oxygen species. Carcinogenesis 13, 605- 608.

> Ait-Si-Ali, S., Ramirez, S., Barre, F.X., Dkhissi, F., Magnaghi-Jaulin, L., Girault, J.A., Robin, P., Knibiehler, M., Pritchard, L.L., Ducommun, B., Trouche, D. y Harel-Ballau, A. (1998). Histone acetyl transferase activity of CBP is controlled by cycle-dependent kinases and oncoprotein E1A. Nature 396, 184- 186.

Alberts B, Johnson A, Lewis J, Raff M, Roberts K, Walter, P. (2002) En: Molecular Biology of the cell (4th edn). P. New York: Garland Science.

> Alía, M., Mateos, R., Ramos, S., Lecumberri, E., Bravo, L. y Goya L. (2006a). Influence of quercetin and rutin on growth and antioxidant defense system of a human hepatoma cell line (HepG2). Eur.J.Nutr. 45, 19-28.

Alía , M., Ramos, S., Mateos, R., Granado-Serrano, A.B., Bravo, L. y Goya, L. (2006b). Quercetin protects human hepatoma HepG2 against oxidative stress induced by tert-butyl Hudroperoxide. Toxicol.Appl.Pharmacol. 212, 110-118.

> Araya, J., Rodrigo, R., Orellana, M. y Rivera, G. (2001). Red wine raises plasma HDL and preserves long-chain polyunsaturated fatty acids in rat kidney and erythrocytes. Br.J.Nutr. 86, 189195.

> Areias, F.M., Rego, A.C., Oliveira, C.R. y Seabra, R.M. (2001). Antioxidant effect of flavonoids after ascorbate/Fe(2+)-induced oxidative stress in cultured retinal cells. Biochem. Pharmacol. 62, 111118.

> Arora, A., Nair, M. y Strasburg, G. (1998). Antioxidant activities of isoflavons and their biological metabolites in a liposomal system. Arch. Biochem.Biophys. 356, 133- 141.

> Arora, A., Byrem, T.M., Nair, M.G. y Strasburg, G.M. (2000). Modulation of liposomal membrane fluidity by flavonoids and isoflavonoids. Arch.Biochem.Biophys. 373, 102-109.

Arroyo, A., Modriansky, M., Serinkan, F.B., Bello, R.I., Matsura, T., Jiang, J., Tyurin, V.A., Tyurina, Y.Y., Fadeel, B. y Kagan, V.E. (2002). NADPH oxidase-dependent oxidation and externalization of phosphatidylserine during apoptosis in Me2SO-differentiated HL-60 Cells. J.Biol.Chem. 277, 49965-49975.

Arts, I.C., Sesink, A.L., Faassen-Peters, M. y Hollman, P.C. (2004). The type of sugar moiety is a major determinant of the small intestinal uptake and subsequent biliary excretion of dietary quercetin glycosides. Br.J.Nutr. 91, 841-847. 
> Aura, A.M., Martín-López, P., O'Leary, K.A., Williamson, G., Oksman-Caldentery, K.M., Poutaken, K. y Santos-Buelga, C. (2005). In vitro metabolism of anthocyanins by human gut microflora. Eur.J.Nutr. 44, 133-142.

> Awad, H.M., Boersma, M.G., Boeren, S., Van Bladeren, P.J., Vervoort, J. y Rietjens, I.M. (2001). Structure-activity study on the quinone/quinone methide chemistry of flavonoids. Chem.Res. Toxicol. 14, 398-408.

> Balasubramanian, K y Schroit, A.J. (2003). Aminophospholipid asymmetry: a matter of life and death. Annu.Rev.Physiol. 65, 701-734.

> Banerjee, T. y Kuypers, F.A. (2004). Reactive oxygen species and phosphatidylserine externalization in murine sickle red cells. Br.J.Haematol. 124, 391-402.

> Barber, A.J. y Jamieson, G.A. (1970). Isolation and characterization of plasma membranes from human blood platelets. J.Biol.Chem. 245, 6357-6365.

> Barenholz, Y., Moore, N.F. y Wagner, R.R. (1976). Enveloped viruses as model membrane systems: microviscosity of vesicular stomatitis virus and host cell membranes. Biochemistry 15, 35633570.

> Barros, M.P., Pinto, E., Colepicolo, P. y Pedersen, M. (2001). Astaxanthin and peridinin inhibit oxidative damage in $\mathrm{Fe}(2+)$-loaded liposomes: scavenging oxyradicals or changing membrane permeability? Biochem.Biophys.Res.Commun. 288, 225-232.

> Bartosz, G. (1990). Erythrocyte membrane changes during aging in vivo. En: Blood Cell Biochemistry (Harris, J.R. eds.) Vol.1, pp. 45-79, Plenum Press, New York.

> Beck, W.S. y Tepper, R.I. (1991) Hemolitic anemias III: Membrane disorders. En: Hematology (Beck, W.S. ed.) pp. 260, MIT Press, Cambridge.

Degum, A.N. y Terao, J. (2002). Protective effect of quercetin against cigarette tar extract-induced impairment of erythrocyte deformability. J.Nutr.Biochem. 13, 265-272.

$>$ Beleznay, Z., Zachowski, A., Devaux, P.F., Navazo, M.P. y Ott, P. (1993). ATP-dependent aminophospholipid translocation in erythrocyte vesicles: stoichiometry of transport. Biochemistry 32, 3146-3152.

> Beleznay, Z., Zachowski, A., Devaux, P.F. y Ott, P. (1997). Characterization of the correlation between ATP-dependent aminophospholipid translocation and Mg2+-ATPase activity in red blood cell membranes. Eur.J.Biochem. 243, 58-65.

> Bennett, M.R., Gibson, D.F., Schwartz, S.M. y Tait, J.F. (1995). Binding and phagocytosis of apoptotic vascular smooth muscle cells is mediated in part by exposure of phosphatidylserine. Circ.Res. 77, 1136-1142

> Bevers, E.M., Comfurius, P. y Zwaal, R.F. (1982). The nature of the binding for prothrombinase at the platelet surface as revealed by lipolytic enzymes. Eur.J.Biochem. 122, 81-85.

> Bevers, E.M., Comfurius, P., Dekkers, D.W. y Zwaal, R.F. (1999). Lipid translocation across the plasma membrane of mammalian cells. Biochim.Biophys.Acta 1439, 317-330.

> Billington, D., Coleman, R. y Lusak, Y.A. (1977). Topographical dissection of sheep erythrocyte membrane phospholipids by taurocholate and glycocholate. Biochim.Biophys.Acta 466, 526-530.

> Bilto, Y.Y. y Abdalla, S.S. (1998). Effects of selected flavonoids on deformability, osmotic fragility and aggregation of human erythrocytes. Clin.Hemorheol.Microcirc. 18, 165-173.

> Bitbol, M. y Devaux, P.F. (1988). Measurement of outward translocation of phospholipids across human erythrocyte membrane. Proc.Natl.Acad.Sci.U.S.A 85, 6783-6787. 
> Boggs, J.M. (1987). Lipid intermolecular hydrogen bonding: influence on structural organization and membrane function. Biochim.Biophys.Acta 906, 353-404.

Boots, A.W., Kubben, N., Haenen, G.R. y Bast, A. (2003). Oxidized quercetin reacts with thiols rather than with ascorbate: implication for quercetin supplementation. Biochem.Biophys.Res.Commun. 308, 560-565.

> Boots, A.W., Balk-J, M., Bast, A., Haenen-G, R.M.M. (2005). The reversibility of the glutathionylquercetin adduct spreads oxidized quercetin-induced toxicity. Biochem.Biophys.Res.Commun. 338, 923-929.

> Borisenko, G.G., Matsura, T., Liu, S.X., Tyurin, V.A., Jianfei, J., Serinkan, F.B. y Kagan, V.E. (2003). Macrophage recognition of externalized phosphatidylserine and phagocytosis of apoptotic Jurkat cells-existence of a threshold. Arch.Biochem.Biophys. 413, 41-52.

> Borochov, H., Zahler, P., Wilbrandt, W. y Shinitzky, M. (1977). The effect of phosphatidylcholine to sphingomyelin mole ratio on the dynamic properties of sheep erythrocyte membrane. Biochim.Biophys.Acta 470, 382-388.

> Borowitz, S.M. y Montgomery, C. (1989). The role of phospholipase A2 in microsomal lipid peroxidation induced with t-butyl hydroperoxide. Biochem.Biophys.Res.Commun. 158, 1021-1028.

> Bors, W., Heller, W., Michael, C. y Saran, M. (1990). Flavonoids as antioxidants: determination of radical scavenging efficiencies. Methods Enzymol. 186, 343-355.

> Bors, W., Michael, C. y Schikora, S. (1995). Interaction of flavonoids with ascorbate and determination of their univalent redox potentials: a pulse radiolysis study. Free Radic.Biol.Med. 19, 45-52.

$>$ Bratosin, D., Estaquier, J., Petit, F., Arnoult, D., Quatannens, B., Tissier, J.P., Slomianny, C., Sartiaux, C., Alonso, C., Huart, J.J., Montreuil, J. y Ameisen, J.C. (2001). Programmed cell death in mature erythrocytes: a model for investigating death effector pathways operating in the absence of mitochondria. Cell Death Differ. 8, 1143-1156.

> Bretscher, M.S. (1972). Asymmetrical lipid bilayer structure for biological membranes. Nat.New Biol. 236, 11-12.

> Broekhuyse, R.M. (1969). Quantitative two-dimensional thin-layer chromatography of blood phospholipids. Clin.Chim.Acta, 23, 457-461.

> Brouillard, R. y Cheminant, A. (1988). Flavonoids and plant color. En: Plant Flavonoids in Biology and Medicine: Biochemical, Cellular and Medicinal Properties (Cody V, Middleton E andHarborne JB eds), pp. 93-106, Alan R. Liss, Inc., New York.

$>$ Bruckheimer, E.M., Gillum, K.D. y Schroit, A.J. (1995). Colocalization of Rh polypeptides and the aminophospholipid transporter in dilauroylphosphatidylcholine-induced erythrocyte vesicles. Biochim.Biophys.Acta 1235, 147-154.

> Brusick, D. (1993). Genotoxicity of phenolic antioxidants. Toxicol. Ind. Health. 9, 223-230.

$>$ Buggisch, M., Atenghang, B., Ruhe, C., Strobel, C., Lange, S., Wartenberg, M. y Sauer, H. (2007). Stimulation of ES-cell-derived cardiomyogenesis and neonatal cell proliferation by reactive oxygen species and NADPH oxidase. J.Cell Sci. 120, 885-894.

$>$ Butler, L.G. (1992). Protein polyphenol interaction: nutritional aspects. En: Proceeding of the 16th International Conference of Grape Polyphenol, Part II, 11-18.

$>$ Cao, G., Sofic, E. y Prior, R.L. (1997). Antioxidant and prooxidant behavior of flavonoids: structureactivity relationships. Free Radic.Biol.Med. 22, 749-760.

$>$ Carini, M., Aldini, G., Bombardelli, E., Morazzoni, P. Y Maffei-Facino, R. (2000) UVB-induced hemolysis of rat erythrocytes: Protective effect of procyanidins from grape seeds. Life Sci. 67, 17991814. 
> Castelli, F., Uccella, N., Trombetta, D. y Saija, A. (1999). Differences between coumaric and cinnamic acids in membrane permeation as evidenced by time-dependent calorimetry. J.Agric.Food Chem. 47, 991-995.

> Cazzola, R., Rondanelli, M., Russo-Volpe, S., Ferrari, E. y Cestaro, B. (2004). Decreased membrane fluidity and altered susceptibility to peroxidation and lipid composition in overweight and obese female erythrocytes. J.Lipid Res. 45, 1846-1851.

> Cesquini, M., Torsoni, M.A., Stoppa, G.R. y Ogo, S.H. (2003). t-BOOH-induced oxidative damage in sickle red blood cells and the role of flavonoids. Biomed.Pharmacother. 57, 124-129.

> Chapman, D. y Hayward, J.A. (1985). New biophysical techniques and their application to the study of membranes. Biochem.J. 228, 281-295.

> Chattopadhyay, A., Choudhury, T.D., Bandyopadhyay, D. y Datta, A.G. (2000). Protective effect of erythropoietin on the oxidative damage of erythrocyte membrane by hydroxyl radical. Biochem. Pharmacol. 59, 419-425.

$>$ Chaudhuri, S., Banerjee, A., Basu, K., Sengupta, B. y Sengupta, P.K. (2007) Interaction of flavonoids with red blood cell membrana lipids and proteins: Antioxidative and antihemolytic effects. Intern J.Biol.Macromol. 41, 42-48.

$>\quad$ Chen, D., Landis-P, K.R., Chen, M.S. y Dou, Q.P. (2007). Inhibition of proteasome activity by the dietary flavonoid apigenin is associated with growth inhibition in cultured breast cancer cells and xenografts. Breast Cancer Res. 9(6), R8.

> Chen, H.W., Chiang, T., Wang, C.Y. y Lii, C.K. (2000). Inhibition of tert-butyl hydroperoxideinduced cell membrane bleb formation by alpha-tocopherol and glutathione. Food Chem.Toxicol. 38, 1089-1096.

$>$ Choi, E.J., Chee, K.M. y Lee, B.H. (2003). Anti- and prooxidant effects of chronic quercetin administration in rats. Eur.J.Pharmacol. 482, 281-285.

$>$ Choi, J.H. y Yu, B.P. (1995). Brain synaptosomal aging: free radicals and membrane fluidity. Free Radic.Biol.Med. 18, 133-139.

> Chung, W.Y. y Benzie, I.F. (2000). Probe-assisted flow cytometric analysis of erythrocyte membrane response to site-specific oxidant stress. Cytometry 40, 182-188.

> Clemens, M.R. y Waller, H.D. (1987). Lipid peroxidation in erythrocytes. Chem.Phys.Lipids 45, 251-268.

$>$ Colin, F.C., Gallois, Y., Rapin, D., Meskar, A., Chabaud, J.J., Vicariot, M. y Menez, J.F. (1992). Impaired fetal erythrocytes' filterability: relationship with cell size, membrane fluidity, and membrane lipid composition. Blood 79, 2148-2153.

> Comporti, M. (1993). Lipid peroxidation. Biopathological significance. Mol.Aspects Med. 14, 199-207.

$>$ Connor, J. y Schroit, A.J. (1987). Determination of lipid asymmetry in human red cells by resonance energy transfer. Biochemistry 26, 5099-5105.

> Connor, J., Pak, C.H., Zwaal, R.F. y Schroit, A.J. (1992). Bidirectional transbilayer movement of phospholipid analogs in human red blood cells. Evidence for an ATP-dependent and protein-mediated process. J.Biol.Chem. 267, 19412-19417.

$>$ Connor, J., Pak, C.C. y Schroit, A.J. (1994). Exposure of phosphatidylserine in the outer leaflet of human red blood cells. Relationship to cell density, cell age, and clearance by mononuclear cells. J.Biol.Chem. 269, 2399-2404.

$>$ Cooper, R.A., Arner, E.C., Wiley, J.S. y Shattil, S.J. (1975). Modification of red cell membrane structure by cholesterol-rich lipid dispersions. A model for the primary spur cell defect. J.Clin.Invest 55, 115-126. 
> Culebras, J.M. (1991) Transporte de bases en la sangre. En: Bioquímica. Biología Molecular y Bioquímica Fisiológica (Emilio Herrera, ed.) pp. 1344-1360, McGraw-Hill-Interamericana de España, Madrid.

> D'Archivio, M., Filesi, C., Di Benedetto, R., Gargiulo, R., Giovannini, C. y Masella, R. (2007). Polyphenols, dietary sources and bioavailability. Ann.Ist.Super Sanita 43, 348-361.

> Dai, F., Miao, Q., Zhou, B., Yang, L. y Liu, Z-L. (2006) Protective effects of flavonols and their glycosides against free radical-induced oxidative hemolysis of red blood cells. Life Sci. 78, 2488-2493.

$>$ Daleke, D.L. (2003) Regulation of transbilayer plasma membrane phospholipid asymmetry. J.Lipid Res. 44, 233-242.

> de Castro, J., Rodríguez, M.C., Martínez-Zorzano, V.S., Hernández-Hernández, A., Llanillo, M. y Sánchez-Yagüe, J. (2008). Erythrocyte and platelet phospholipid fatty acids as markers of advanced non-small cell lung cancer: comparison with serum levels of sialic acid, TPS and Cyfra 21-1. Cancer Invest. 26, 407-418.

> de Jong, K. y Kuypers, F.A. (2006) Sulphydryl modifications alter scramblase activity in murine sickle cell disease. Brit.J.Haematol. 133, 427-432.

$>$ de Jong, K., Geldwerth, D. y Kuypers, F.A. (1997). Oxidative damage does not alter membrane phospholipid asymmetry in human erythrocytes. Biochemistry 36, 6768-6776.

> Demel, R.A. y de Kruyff, B. (1976). The function of sterols in membranes. Biochim.Biophys.Acta 457, 109-132.

> Denisova, N.A., Cantuti-Castelvetri, I., Hassan, W.N., Paulson, K.E. y Joseph, J.A. (2001). Role of membrane lipids in regulation of vulnerability to oxidative stress in PC12 cells: implication for aging. Free Radic.Biol.Med. 30, 671-678.

> Deuticke, B., Heller, K.B. y Haest, C.W. (1986). Leak formation in human erythrocytes by the radical-forming oxidant t-butylhydroperoxide. Biochim.Biophys.Acta 854, 169-183.

$>$ Devaux, P.F. (1988). Phospholipid flippases. FEBS Lett. 234, 8-12.

$>$ Devaux, P.F. (1991). Static and dynamic lipid asymmetry in cell membranes. Biochemistry 30, 11631173.

Devaux, P.F. (1993). Lipid Transmembrane Asymmetry and Flip-Flop in Biological-Membranes and in Lipid Bilayers. Curr.Opinion Struct.Biol. 3, 489-494.

> Devaux, P.F., Herrmann, A., Ohlwein, N. y Kozlov, M.M. (2008) How flippases can modulate membrane structure. Biochim.Biophys.Acta 1778, 1591-1600.

> Dincer, Y., Akcay, T., Konukoglu, D. y Hatemi, H. (1999). Erythrocyte susceptibility to lipid peroxidation in patients with coronary atherosclerosis. Acta Med.Okayama 53, 259-264.

> Dinis, T.C., Almeida, L.M. y Madeira, V.M. (1993). Lipid peroxidation in sarcoplasmic reticulum membranes: effect on functional and biophysical properties. Arch.Biochem.Biophys. 301, 256-264.

$>$ Dise, C.A. y Goodman, D.B. (1986). t-Butyl hydroperoxide alters fatty acid incorporation into erythrocyte membrane phospholipid. Biochim.Biophys.Acta, 859, 69-78.

$>$ Dorta, D.J., Pigoso, A.A., Mingatto, F.E., Rodrigues, T., Prado, I.M.R., Helena, A.F.C., Uyemura, S.A., Santos, A.C. y Curti, C. (2005) The interaction of flavonoids with mitocondria: effects on energetic processes. Chem.Biol.Interact. 152, 67-78.

$>$ Dowhan, W. y Bogdanov, M (2002). Functional roles of lipids in membranes. En: Biochemistry of Lipids, Lipoproteins and Membranes (Vance, D.E. y Vance J.E. eds) pp. 1-35, Elsevier Science B.V., Amsterdam. 
$>$ Dufour, C., Loonis, M. y Dangles, O. (2007). Inhibition of the peroxidation of linoleic acid by the flavonoid quercetin within their complex with human serum albumin. Free Radic.Biol.Med. 43, 241-52.

> Dulloo, A.G., Duret, C., Rohrer, D., Girardier, L., Mensi, N., Fathi, M., Chantre, P. Y Vandermander, J. (1999). Efficacy of a green tea extract rich in catechin polyphenols and caffeine in increasing 24-h energy expenditure and fat oxidation in humans. Am.J.Clin.Nutr. 70, 1040-5.

> Dumaswala, U.J., Wilson, M.J., Jose, T. y Daleke, D.L. (1996). Glutamine- and phosphatecontaining hypotonic storage media better maintain erythrocyte membrane physical properties. Blood 88, 697-704.

> Dumaswala, U.J., Wilson, M.J., Jose, T. y Daleke, D.L. (1997). Effect of a glycerol-containing hypotonic medium on erythrocyte phospholipid asymmetry and aminophospholipid transport during storage. Biochim.Biophys.Acta 1330, 265-273.

> Dumaswala, U.J., Zhuo, L., Jacobsen, D.W., Jain, S.K. y Sukalski, K.A. (1999). Protein and lipid oxidation of banked human erythrocytes: role of glutathione. Free Radic.Biol.Med. 27, 10411049.

> Durbin, M.L., McCaig, B. y Clegg, M.T. (2000). Molecular evolution of the chalcone synthase multigene family in the morning glory genome. Plant.Mol.Biol. 42, 79-92.

DI Missiry, M.A. y Abou-Seif, M. (2000). Photosensitization induced reactive oxygen species and oxidative damage in human erythrocytes. Cancer Lett. 158, 155-163.

> Fabisiak, J.P., Tyurin, V.A., Tyurina, Y.Y., Sedlov, A., Lazo, J.S. y Kagan, V.E. (2000). Nitric oxide dissociates lipid oxidation from apoptosis and phosphatidylserine externalization during oxidative stress. Biochemistry 39, 127-138.

> Fadok, V.A., Voelker, D.R., Campbell, P.A., Cohen, J.J., Bratton, D.L. y Henson, P.M. (1992). Exposure of phosphatidylserine on the surface of apoptotic lymphocytes triggers specific recognition and removal by macrophages. J.Immunol. 148, 2207-2216.

> Fadok, V.A., de Cathelineau, A., Daleke, D.L., Henson, P.M. y Bratton, D.L. (2001). Loss of phospholipid asymmetry and surface exposure of phosphatidylserine is required for phagocytosis of apoptotic cells by macrophages and fibroblasts. J.Biol.Chem. 276, 1071-1077.

> Farquhar, J.W. y Ahrens, E.H. (1963). Effects of dietary fats on human erythrocyte fatty acid patterns. J.Clin.Invest. 42, 675-685.

> Formica, J.V. y Regelson, W. (1995). Review of the biology of Quercetin and related bioflavonoids. Food Chem. Toxicol. 33, 1061-1080.

> Frankel, E.N. (1993). In search of better methods to evaluate natural antioxidants and oxidative stability in food lipids. Trends Food Sci.Technol. 4, 220-225.

> Frémont, L., Belguendouz, L. y Delpal, S. (1999) Antioxidant activity of resveratrol and alcoholfree wine polyphenols related to LDL oxidation and polyunsaturated fatty acids. Life Sci. 64, 25112521.

> Frémont, L., Gozzelino, M.T. y Linard, A. (2000) Response of plasma lipids to dietary cholesterol and wine polyphenols in rats fed polyunsaturated fat diets. Lipids 35, 991-999.

> Gabrielska, J., Soczynska-Kordala, M., Hladyszowski, J., Zylka, R., Miskiewicz, J. y Przestalski, S. (2006). Antioxidative effect of quercetin and its equimolar mixtures with phenyltin compounds on liposome membranes. J.Agric.Food Chem. 54, 7735-7746.

$>$ Gaetani, G.F., Galiano, S., Canepa, L., Ferraris, A.M. y Kirkman, H.N. (1989). Catalase and glutathione peroxidase are equally active in detoxification of hydrogen peroxide in human erythrocytes. Blood 73, 334-339. 
$>$ Gal, S., Pinchuk, I. y Lichtenberg, D. (2003). Peroxidation of liposomal palmitoyllinoleoylphosphatidylcholine (PLPC), effects of surface charge on the oxidizability and on the potency of antioxidants. Chem.Phys.Lipids 126, 95-110.

> Galati, G. y O'brien, P.J. (2004). Potential toxicity of flavonoids and other dietary phenolics: significance for their chemopreventive and anticancer properties. Free Radic.Biol.Med. 37, 287-303.

$>$ Gomes, A., Fernandes, E. y Lima, J.L. (2005). Fluorescence probes used for detection of reactive oxygen species. J.Biochem.Biophys.Methods 65, 45-80.

> Gómez-Fernández, J.C. y Goñi F.M. (1983) Fluidez de las membranas celulares. Investigación y Ciencia 79, 127-158.

$>\quad$ Guo, L., Ogamo, A., Ou, Z., Shinozuka, T. y Nakagawa, Y. (1995). Preferential formation of the hydroperoxide of linoleic acid in choline glycerophospholipids in human erythrocytes membrane during peroxidation with an azo initiator. Free Radic.Biol.Med. 18, 1003-1012.

> Gutteridge, J.M. y Halliwell, B. (1990). The measurement and mechanism of lipid peroxidation in biological systems. Trends Biochem.Sci. 15, 129-135.

$>$ Guven, M., Ozturk, B., Sayal, A., Ozeturk, A. y Ulutin, T. (1999). Lipid peroxidation and antioxidant system in the blood of cancerous patients with metastasis. Cancer Biochem.Biophys. 17, 155-162.

> Halder, J. y Bhaduri, A.N. (1998) Protective role of black tea against oxidative damage of human red blood cells. Biochem.Biophys.Res.Commun. 244, 903-907.

$>$ Halliwell, B. (1992). Especies reactivas de oxígeno en los sistemas vivos: procedencia, bioquímica y papel patógeno en el hombre. En: GSH System. Glutation Eje de la Defensa Antioxidante (Crystal, R.J.y.R., J.R. eds.) pp. 42-47, Excerpta Médica, Amsterdam.

> Halliwell, B. y Gutteridge, J.M. (1984). Oxygen toxicity, oxygen radicals, transition metals and disease. Biochem.J. 219, 1-14.

$>$ Halliwell, B. y Gutteridge, J. M. C. (1999). Free Radicals in Biology and Medicine. Oxford University Press, Oxford.

> Halliwell, B., Aeschbach, R., Löliger, R. y Aruoma, O,I. (1995). The characterization of antioxidants. Food Chem. Toxicol. 33, 601-17.

> Han, K.S., Kim, M., Park, H.Y., Park, J.E. y Lee, H.J. (1992). Effect of lipid peroxidation on the fluidity of erythrocyte ghost and phopholipid liposomal membranes. Arch.Pharm.Res. 15, 309-16.

$>$ Hanasaki, Y., Ogawa, S. y Fukui, S. (1994). The correlation between active oxygen scavenging and antioxidative effects of flavonoids. Free Radic.Biol.Med. 16, 845-850.

> Harborne, J.B. y Williams, Ch.A. (2000). Advances in flavonoid research since 1992. Phytochemistry 55, 481-504.

$>$ Havsteen, B.H. (2002). The biochemistry and medical significance of the flavonoids. Pharmacol. Ther. 96, 67-202.

> Heim, K.E., Tagliaferro, A.R. y Bobilya, D.J. (2002). Flavonoid antioxidants: chemistry, metabolism and structure-activity relationships. J.Nutr.Biochem 13, 572-584.

$>$ Hendrich, A.B. (2006). Flavonoid-membrane interactions: possible consequences for biological effects of some polyphenolic compounds. Acta Pharma.Sinica. 27, 27-40.

> Hollman, P.C., de Vries, J.H., van Leeuwen, S.D., Mengelers, M.J. y Katan, M.B. (1995). Absorption of dietary quercetin glycosides and quercetin in healthy ileostomy volunteers. Am.J.Clin.Nutr. 62, 1276-1282. 
> Holst, B. y Williamson, G. (2008). 1,2 Nutrients and phytochemicals: from bioavailability to bioefficacy beyond antioxidants. Curr.Opin.Biotechnol. 19, 73-82.

> Hu M. (2007). Commentary: Bioavailability of Flavonoids and Polyphenols: Call to Arms. Mol.Pharm. 4, 803-806.

> Ioku, K., Tsushida, T., Takei, Y., Nakatani, N. y Terao, J. (1995). Antioxidative activity of quercetin and quercetin monoglucosides in solution and phospholipid bilayers. Biochim.Biophys.Acta 1234, 99-104.

$>$ Ivanov, I.T. (1999). Low pH-induced hemolysis of erythrocytes is related to the entry of the acid into cytosole and oxidative stress on cellular membranes. Biochim.Biophys.Acta 1415, 349-360.

$>$ Jain, S.K. y Shohet, S.B. (1984). A novel phospholipid in irreversibly sickled cells: evidence for in vivo peroxidative membrane damage in sickle cell disease. Blood 63, 362-367.

> Jiménez, R., López-Sepúlveda, R., Kadmiri, M., Romero, M., Vera, R., Sánchez, M., Vargas, F., Zarzuelo, A., Dueñas, M., Santos-Buelga, C. y Duarte, J. (2007). Polyphenols restore endotelial function in DOCA-salt hipertensión: rola of endothelin-1 and NADPH oxidase. Free Radic.Biol.Med. 43, 462-473.

> Jovanovic, S., SteenKen, S., Tosic, M., Marjanovic, B. y Simic, M.G. (1994). Flavonoids as antioxidants. J.Am.Chem.Soc. 116, 4846-51.

$>\quad$ Judd, W. S. Campbell, C. S. Kellogg, E. A. Stevens, P.F. Donoghue, M. J. (2002). Secondary Plant Compounds. En: Plant systematics: a phylogenetic approach, Second Edition. Sinauer Axxoc, USA.

> Kagan, V.E., Serbinova, E.A, Bakalova, R.A., Stoytchev, T.S., Erin, A.N., Prilipko, L.L. y Evstigneeva, R.P. (1990). Mechanisms of stabilization of biomembranes by alpha-tocopherol. The role of the hydrocarbon chain in the inhibition of lipid peroxidation. Biochem.Pharmacol. 40, 24032413.

$>\quad$ Kagan, V.E., Fabisiak, J.P., Shvedova, A.A., Tyurina, Y.Y., Tyurin, V.A., Schor, N.F. y Kawai, K. (2000). Oxidative signaling pathway for externalization of plasma membrane phosphatidylserine during apoptosis. FEBS Lett. 477, 1-7.

> Kaiser, R.D. y London, E. (1998). Location of diphenylhexatriene (DPH) and its derivatives within membranes: comparison of different fluorescence quenching analyses of membrane depth. Biochemistry 37, 8180-8190.

$>\quad$ Kajiya, K., Kumazawa, S. y Nakayama, T. (2002). Effects of external factors on the interaction of tea catechins with lipid bilayers. Biosci.Biotechnol.Biochem. 66, 2330-2335.

> Kaneko, T., Kaji, K. y Matsuo, M. (1994). Protection of linoleic acid hydroperoxide-induced cytotoxicity by phenolic antioxidants. Free Radic.Biol.Med. 16, 405-409.

> Kates, M. (1972). Techniques of lipidology: isolation, analysis and identification of lipids. En: Laboratory Techniques in Biochemistry and Molecular Biology. (Work, T. S. and Work, E. eds.) pp 360-361. North-Holland/American Elsevier.

> Kawai, Y., Ogamo, A. Y Nakagawa, Y. (1999). Formation of the aldehydic choline glycerophospholipids in human red blood cell membrane peroxidized with an azo initiator. J.Biochem.(Tokyo) 126, 115-120.

> Khanduja, K.L., Avti, P.K., Kumar, S., Mittal, N., Sohi, K.K. y Pathak, C.M. (2006) Antiapoptotic activity of caffeic acid, ellagic acid and ferulic acid in normal human peripheral blood mononuclear cells: a Bcl-2 independent mechanism. Biochim.Biophys.Acta 1760, 283-289.

$>$ Kohlwein, S.D. (1992). Biological-Membranes - Function and Assembly. J.Chem.Educ. 69, 3-9. 
> Kondo, K., Kurihara, M., Miyata, N., Suzuki, T. y Toyoda, M. (1999). Scavenging mechanisms of (-)-epigallocatechin gallate and (-)-epicatechin gallate on peroxyl radicals and formation of superoxide during the inhibitory action. Free Radic.Biol.Med. 27, 855-863.

> Koopman, G., Reutelingsperger, C.P., Kuijten, G.A., Keehnen, R.M., Pals, S.T. y van Oers, M.H. (1994). Annexin $V$ for flow cytometric detection of phosphatidylserine expression on $B$ cells undergoing apoptosis. Blood 84, 1415-1420.

> Krahling, S., Callahan, M.K., Williamson, P. y Schlegel, R.A. (1999). Exposure of phosphatidylserine is a general feature in the phagocytosis of apoptotic lymphocytes by macrophages. Cell Death.Differ. 6, 183-189.

> Kucuk, O., Lis, L.J., Dey, T., Mata, R., Westerman, M.P., Yachnin, S., Szostek, R., Tracy, D., Kauffman, J.W., y Gage, D.A. (1992). The effects of cholesterol oxidation products in sickle and normal red blood cell membranes. Biochim.Biophys.Acta 1103, 296-302.

> Kurata, M., Suzuki, M. y Agar, N.S. (1993). Antioxidant systems and erythrocyte life-span in mammals. Comp.Biochem. Physiol. 106B, 477-487.

$>$ Kuypers, F.A. y de Jong, K. (2004). The role of phosphatidylserine in recognition and removal of erythrocytes. Cell Mol.Biol. 50, 147-158.

> Kuypers, F.A., Lewis, R.A., Hua, M., Schott, M.A., Discher, D., Ernst, J.D. y Lubin, B.H. (1996). Detection of altered membrane phospholipid asymmetry in subpopulations of human red blood cells using fluorescently labeled annexin V. Blood 87, 1179-1187.

> Lakowicz, J.R. (1983). Principles of Fluorescence Spectroscopy. Plenum Press, New York.

> Lang, F., Birka, C., Myssina, S., Lang, K.S., Lang, P.A., Tanneur, V., Duranton, C., Wieder, T. y Huber, S.M. (2004) Erythrocyte ion channels in regulation of apoptosis. Adv.Exp.Med.Biol. 559, 211-217.

$>\quad$ Lang, F., Lang, K.S., Lang, P.A., Huber, S.M. y Wieder, T. (2006) Osmotic shock-induced suicidal death of erythrocytes. Acta Physiol. (Oxf) 187, 191-198.

> Laryea, M.D., Cieslicki, P., Diekmann, E. y Wendel, U. (1988). Analysis of the fatty acid composition of erythrocyte phospholipids by a base catalysed transesterification method--prevention of formation of dimethylacetals. Clin.Chim.Acta 171, 11-18.

$>\quad$ Lentz, B.R. (1989). Membrane "fluidity" as detected by diphenylhexatriene probes. Chem.Phys.Lipids 50, 171-190.

$>\quad$ Lien, E.J, Ren, S., Bui, H.H. y Wang, R. (1999) Quantitative structure-activity relationship analysis of phenolic antioxidants. Free Radic.Biol.Med. 26, 285-294.

> Llanillo, M., Sánchez-Yagüe, J., Martín-Valmaseda, E.M. y Hernández-Hernández, A. (1994). Erythrocyte storage as a model for lipid peroxidation studies. An experimental assay for students of Biochemistry and Molecular Biology. Biochem.Educ. 22, 158-161

> Llanillo, M., Sánchez-Yagüe, J., Checa, A., Martín-Valmaseda, E.M. y Felipe, A. (1995). Phospholipid and fatty acid composition in stored sheep erythrocytes of different densities. Exp.Hematol. 23, 258-264.

$>$ London, E. y Brown, D.A. (2000). Insolubility of lipids in triton X-100: physical origin and relationship to sphingolipid/cholesterol membrane domains (rafts). Biochim.Biophys.Acta 1508, 182195.

> López-Revuelta, A. (2001). Estudio de la peroxidación sobre la composición lipídica en eritrocitos de conejo enriquecidos en colesterol. Repercusiones funcionales. Trabajo de Grado de Salamanca. Univ. de Salamanca. 
$>$ López-Revuelta, A. (2005). Consecuencias del daño oxidativo sobre la estructura-función de eritrocitos con diferentes contenidos de colesterol. Tesis Doctoral. Univ. de Salamanca.

> López-Revuelta, A., Sánchez-Gallego, J.I., Hernández-Hernández, A., Sánchez-Yagüe, J. y Llanillo, M. (2005). Increase in vulnerability to oxidative damage in cholesterol-modified erythrocytes exposed to t-BuOOH. Biochim.Biophys.Acta 1734, 74-85.

> López-Revuelta, A., Sánchez-Gallego, J.I., García-Montero, A.C., Hernández-Hernández, A., Sánchez-Yagüe, J. y Llanillo, M. (2007). Membrane cholesterol in the regulation of aminophospholipid asymmetry and phagocytosis in oxidized erythrocytes. Free Radic.Biol.Med. 42, 1106-1118.

$>\quad$ Lotito, S.B. y Frei, B. (2006). Consumption of flavonoid-rich foods and increased plasma antioxidant capacity in humans: Cause, consequence, or epiphenomenon? Free Radic.Biol.Med. 41, 1727-1746.

$>$ Lupu, C. y Calb, M. (1988). Changes in the platelet surface charge in rabbits with experimental hypercholesterolemia. Atherosclerosis 72, 77-82.

> Mahfouz, M.M. y Kummerow, F.A. (2000). Cholesterol-rich diets have different effects on lipid peroxidation, cholesterol oxides, and antioxidant enzymes in rats and rabbits. J.Nutr.Biochem. 11, 293-302.

> Mandal, D., Moitra, P.K., Saha, S. y Basu, J. (2002). Caspase 3 regulates phosphatidylserine externalization and phagocytosis of oxidatively stressed erythrocytes. FEBS Lett. 513, 184-188.

> Mandal, D., Mazumder, A., Das, P., Kundu, M. y Basu, J. (2005). Fas-, caspase 8-, and caspase 3-dependent signaling regulates the activity of the aminophospholipid translocase and phosphatidylserine externalization in human erythrocytes. J.Biol.Chem. 280, 29460-39467.

> Manevich, E.M., Lakin, K.M., Archakov, A.I., Li, V.S., Molotkovsky, J.G., Bezuglov, V.V. y Bergelson, L.D. (1985). Influence of cholesterol and prostaglandin E1 on the molecular organization of phospholipids in the erythrocyte membrane. A fluorescent polarization study with lipid-specific probes. Biochim. Biophys.Acta 815, 455-460.

> Marín, M.S., Fernández, A., Sánchez-Yagüe, J., Cabezas, J.A. y Llanillo, M. (1990). Changes in the phospholipid and fatty acid composition in normal erythrocytes from sheep of different ages. Aminophospholipid organization in the membrane bilayer. Biochimie. 72, 745-750.

> Markwell, M.A., Haas, S.M., Bieber, L.L. y Tolbert, N.E. (1978). A modification of the Lowry procedure to simplify protein determination in membrane and lipoprotein samples. Anal.Biochem. 87, 206-210.

> Marsh, D. (1992) Role of lipids in membrane structure. Curr.Opinion Struct.Bio. 2, 497-02.

> Martín, C., Martínez, R., Navarro, R., Ruiz-Sanz, J.I., Lacort, M. y Ruiz-Larrea, M.B. (2001). tert-Butyl hydroperoxide-induced lipid signaling in hepatocytes: involvement of glutathione and free radicals. Biochem. Pharmacol. 62, 705-712.

$>$ Martin, D.W. y Jesty, J. (1995). Calcium stimulation of procoagulant activity in human erythrocytes. ATP dependence and the effects of modifiers of stimulation and recovery. J.Biol.Chem. 270, 1046810474.

> Martin, S.J., Reutelingsperger, C.P., McGahon, A.J., Rader, J.A., van Schie, R.C., LaFace, D.M. y Green, D.R. (1995). Early redistribution of plasma membrane phosphatidylserine is a general feature of apoptosis regardless of the initiating stimulus: inhibition by overexpression of Bcl- 2 and Abl. J.Exp.Med. 182, 1545-1556.

> Martin-Gallan, P., Carrascosa, A., Gussinye, M. y Dominguez, C. (2003). Biomarkers of diabetes-associated oxidative stress and antioxidant status in young diabetic patients with or without subclinical complications. Free Radic.Biol.Med. 34, 1563-1574. 
> Martín-Valmaseda, E.M. (1996). Estudio de las alteraciones producidas en las bicapas lipídicas de las membranas de las plaquetas durante el almacenamiento. Tesis Doctoral. Univ. de Salamanca.

> Martin-Valmaseda, E.M., Sanchez-Yague, J., Hernandez-Hernandez, A. y Llanillo, M. (1998). Vesiculation and changes in fluidity and lipid composition of platelet membranes after storage of sheep platelets in plasma or Seto solution. Thromb.Haemost. 80, 668-676.

> Martín-Valmaseda, E.M., Sánchez-Yagüe, J., Rodríguez, M.C., Gomez, F.P. y Llanillo, M. (1999). Comparison between in vitro lipid peroxidation in fresh sheep platelets and peroxidative processes during sheep platelet ageing under storage at 4 degrees C. Biochim.Biophys.Acta 1419, 313-324.

> Martínez, M.C., Martín, S., Toti, F., Fressinaud, E., Dachary-Prigent, J., Meyer, D. y Freyssinet, J.M. (1999) Significance of capacitative $\mathrm{Ca} 2+$ entry in the regulation of phosphatidylserine expresión at the surface os stimulated cells. Biochemistry 38, 10092-10098.

> Martínez, R., Quintana, K., Navarro, R., Martín, C., Hernández, M.L., Aurrekoetxea, I., Ruiz-Sanz, J.I., Lacort, M. y Ruiz-Larrea, M.B. (2002). Pro-oxidant and antioxidant potential of catecholestrogens against ferrylmyoglobin-induced oxidative stress. Biochim.Biophys.Acta 1583, 167175.

> Martínez-Flórez, S., González-Gallego, J., Culebras, J. M. y Tuñón, M.a J. (2002). LoS flavonoides: propiedades y acciones antioxidantes. Nutr. Hosp. XVII 6, 271-278.

> Martínez-Valverde, I., Periago, M.J. y Ros, G. (2000). Significado nutricional de los compuestos fenolicos en la dieta. Arch.Latinoam.Nutr. 50, 5-18.

$>$ Mathews, C.K., Van Holde, K.E. y Ahren, K.G. (2002) Bioquímica, 3a Ed., Pearson Educación, Madrid.

$>$ Matsura, T., Serinkan, B.F., Jiang, J. y Kagan, V.E. (2002). Phosphatidylserine peroxidation/externalization during staurosporine-induced apoptosis in HL-60 cells. FEBS Lett. 524, 25-30.

> Mawatari, S. y Murakami, K. (2001). Effects of ascorbate on membrane phospholipids and tocopherols of intact erythrocytes during peroxidation by t-butylhydroperoxide: comparison with effects of dithiothreitol. Lipids 36, 57-65.

> May, J.M., Qu, Z.C., Whitesell, R.R. y Cobb, C.E. (1996). Ascorbate recycling in human erythrocytes: role of GSH in reducing dehydroascorbate. Free Radic.Biol.Med. 20, 543-551.

> McGhie, T.K. y Walton, M.C. (2007). The bioavailability and absorption of anthocyanins: Towards a better understanding. Mol.Nutr.Food Res. 51, 702-713.

> McIntyre, J.C. y Sleight, R.G. (1991). Fluorescence assay for phospholipid membrane asymmetry. Biochemistry 30, 11819-11827.

> McLean, L.R. y Hagaman, K.A. (1992). Effect of lipid physical state on the rate of peroxidation of liposomes. Free Radic.Biol.Med. 12, 113-119.

> Metcalfe, L.V., Schmitz, A.A. y Pelke, J.R. (1966). Rapid preparation of fatty esters from lipids for gas chromatographic analysis. Anal.Chem. 38, 514-516.

> Metodiewa, D., Jaiswal, A.K., Cenas, N., Dickancaite, E. y Segura-Aguilar, J. (1999). Quercetin may act as a cytotoxic prooxidant after its metabolic activation to semiquinone and quinoidal product. Free Radic.Biol.Med. 26, 107-116.

> Montaña del Olmo, J.M. (1977) Heterósidos naturales. En: Tratados de Bioquímica (Palasi V., Cabezas Fdez. del Campo J.A. y Santos Ruiz A.) 89-100, Ed. Augusta, S.A., Barcelona.

> Moraleda, J.M. y Corral, M. (1996). Hematopoyesis. Hematíes: Estructura y función. En: Hematología. (Moraleda, J.M. eds) pp. 11-27, Luzán, S.A. de ediciones, Madrid. 
$>$ Morel, I., Lescoat, G., Cogrel, P., Sergent, O., Pasdeloup, N., Brissot, P., Cillard, P. y Cillard, J. (1993). Antioxidant and iron-chelating activities of the flavonoids catechin, quercetin and diosmetin on iron-loaded rat hepatocyte cultures. Biochem. Pharmacol. 45, 13-9.

> Moridani, M.Y., Pourahmad, J., Bui, H., Siraki, A. y O'Brien, P.J. (2003). Dietary flavonoid iron complexes as cytoprotective superoxide radical scavengers. Free Radic.Biol.Med. 34, 243-253.

$>$ Mouritsen, O.G. (2005). Life-as a matter of fat: the emerging science of lipidomics. Springer-Verlag New York, LLC.

$>$ Movileanu, L., Neagoe, I. y Flonta, M.L. (2000). Interaction of the antioxidant flavonoid quercetin with planar lipid bilayers. Int.J.Pharm. 205, 135-46.

> Moxness, M.S., Brunauer, L.S. y Huestis, W.H. (1996). Hemoglobin oxidation products extract phospholipids from the membrane of human erythrocytes. Biochemistry 35, 7181-7187.

$>$ Muller, C.P. y Krueger, G.R. (1986). Modulation of membrane proteins by vertical phase separation and membrane lipid fluidity. Basis for a new approach to tumor immunotherapy. Anticancer Res. 6, 1181-1193.

> Murray, R.K. (1993) Eritrocitos y leucocitos. En: Bioquímica de Harper (Murray, R.K, D.K., Mayes, D.A., Rodwell, V.W.eds) 13a Edición, pp. 823-841, El Manual Moderno, México D.F.

> Nakayama, T., Ono, K. y Hashimoto, K. (1998). Affinity of antioxidative polyphenols for lipid bilayers evaluated with a liposome system. Biosci.Biotechnol.Biochem. 62, 1005-1007.

$>\quad$ Nemeth, K., Plumb, G.W., Berrin, J.G., Juge, N., Jacob, R., Naim, H.Y., Williamson, G., Swallow, D.M. y Kroon, P.A. (2003). Deglycosylation by small intestinal epithelial cell betaglucosidases is a critical step in the absorption and metabolism of dietary flavonoid glycosides in humans. Eur.J.Nutr. 42, 29-42.

> Nigdikar, S.V., Williams, N.R., Griffin, B.A. y Howard, A.N. (1998). Consumption of red wine polyphenols reduces the susceptibility of low-density lipoproteins to oxidation in vivo. Am.J.Clin.Nutr. 68, 258-265.

$>$ Niki, E. (1996). $\alpha$-Tocopherol. En: Handbook of antioxidants. (L. Packer and E. Cadenas, eds) pp. 325, Marcel Dekker, New York.

> Niu, S.L., Mitchell, D.C. y Litman, B.J. (2002). Manipulation of cholesterol levels in rod disk membranes by methyl-beta-cyclodextrin: effects on receptor activation. J.Biol.Chem. 277, 2013920145.

$>\quad$ O'Brian, C.A., Ward, N.E. y Anderson, B.W. (1988). Role of specific interactions between protein kinase $\mathrm{C}$ and triphenylethylenes in inhibition of the enzyme. J.Natl.Cancer Inst. 80, 1628-1633.

> Ogiso, T., Iwaki, M., Takagi, T., Hirai, I. y Kashiyama, T. (1985). Increased sensitivity of aged erythrocytes to drugs and age-related loss of cell components. Chem.Pharm.Bull.(Tokyo) 33, 54045412.

$>\quad$ Ohtani, Y., Irie, T., Uekama, K., Fukunaga, K. y Pitha, J. (1989). Differential effects of alpha-, beta- and gamma-cyclodextrins on human erythrocytes. Eur.J.Biochem. 186, 17-22.

> Ohvo-Rekila, H., Ramstedt, B., Leppimaki, P. y Slotte, J.P. (2002). Cholesterol interactions with phospholipids in membranes. Prog.Lipid Res. 41, 66-97.

> Ollila, F., Halling, K., Vuorela, P., Vuorela, H. y Slotte, J.P. (2002). Characterization of flavonoid-biomembrane interactions. Arch. Biochem. Biophys. 399, 103-108.

$>$ Op den Kamp, J.A. (1979). Lipid asymmetry in membranes. Annu.Rev.Biochem. 48, 47-71.

$>$ Oteiza P.I., Erlejman A.G., Verstraeten, S.V., Keen, C.L. y Fraga C.G. (2005). Flavonoidmembrane interactions: A protective role of flavonoids at the membrane surface? Clin.Dev.Immunol. 12, 19-25. 
$>$ Oyama, Y., Noguchi, S., Nakata, M., Okada, Y., Yamazaki, Y., Funai, M., Chikahisa, L. y Kanemaru, K. (1999). Exposure of rat thymocytes to hydrogen peroxide increases annexin $\mathrm{V}$ binding to membranes: inhibitory actions of deferoxamine and quercetin. Eur.J.Pharmacol. 384, 47-52.

> Paganga, G., Al-Hashim, H., Khodr, H., Scott, B.C., Auroma, O.I. y Hider, R.C. (1996). Mechanisms of the antioxidant activities of quercetin and catechins. Redox Report 2, 359-364.

> Pantaleo, A., Giribaldi, G., Manuu, F., Arese, P. y Turrini, F. (2008) Naturally occurring antiband 3 antibodies and red blood cell removal under physiological and pathological conditions. Autoimmun.Rev. 7, 457-462.

> Parasassi, T., Giusti, A.M., Raimondi, M., Ravagnan, G., Sapora, O. y Gratton, E. (1995). Cholesterol protects the phospholipid bilayer from oxidative damage. Free Radic.Biol.Med. 19, 511516.

$>$ Pawlikowska-Pawlêga, B., Gruszecki, W.I., Misiak, L.E. y Gawron, A. (2003). The study of the quercetin action on human erythrocyte membranes. Biochem.Pharmacol. 66, 605-612.

$>$ Pawlikowska-Pawlêga, B., Gruszecki, W.I., Misiak, L.E. Paduch, R., Piersiak, T., Zarzyka, B., Pawelec, J. y Gawron, A. (2007) Modification of membranes by quercetin, a naturally occurring flavonoid, via its incorporation in the polar head group. Biochim.Biophys.Acta 1768, 2195-2204.

> Pessina, G.P., Paulesu, L. y Bocci, V. (1981). Red cell modifications in cholesterol-fed rabbits. Int.J.Biochem. 13, 805-810.

> Petkova, D.H., Momchilova-Pankova, A.B. y Koumanov, K.S. (1987). Effect of liver plasma membrane fluidity on endogenous phospholipase $A_{2}$ activity. Biochimie 69, 1251-1255.

Piao, M.J., Kang, K.A., Zhang, R., Ko, D.O., Wang, Z.H., You, H.J., Kim, H.S., Kim, J.S, Kang, S.S. y Hyun, J.W. (2008) Hyperoside prevents oxidative damage induced by hydrogen peroxide in lung fibroblast cells via an antioxidant effect. Biochim.Biophys.Acta 1780, 1448-1457.

$>$ Plumb, G.W., Price, K.R. y Williamson, G. (1999). Antioxidant properties of flavonol glycosides from tea. Redox Report 4 13-16.

> Porter, N.A., Caldwell, S.E. y Mills, K.A. (1995). Mechanisms of free radical oxidation of unsaturated lipids. Lipids 30, 277-290.

> Pradhan, D., Williamson, P. y Schlegel, R.A. (1994). Phosphatidylserine vesicles inhibit phagocytosis of erythrocytes with a symmetric transbilayer distribution of phospholipids. Mol.Membr.Biol. 11, 181-187.

> Pradja, N., Singhal, R.L., Yeh, Y.A., Olah, E., Look, K.Y. y Weber, G. (1995). Linkage of reduction in 1-phosphatidylinositol 4-kinase activity and inositol 1,4,5-trisphosphate concentration in human ovarian carcinoma cells treated with quercetin. Life Sci. 56, 1587-1593.

$>$ Prendergast, F.G., Haugland, R.P. y Callahan, P.J. (1981). 1-[4-(Trimethylamino) phenyl]-6phenylhexa-1,3,5-triene: synthesis, fluorescence properties, and use as a fluorescence probe of lipid bilayers. Biochemistry 20, 7333-7338.

> Ratty, A.K., Sunamoto, J. y Das, N.P. (1988).Interaction of flavonoids with 1,1-diphenyl-2picrylhydrazyl free radical, liposomal membranes and soybean lipoxigenase-1. Biochem.Pharmacol. 37, 989-995.

> Rausher, M.D., Miller, R.E. y Tiffin, P. (1999). Patterns of evolutionary rate variation among genes of the anthocyanin biosynthetic pathway. Mol. Biol.Evol 16, 266-274.

$>$ Raynal, P. y Pollard, H.B. (1994). Annexins: the problem of assessing the biological role for a gene family of multifunctional calcium- and phospholipid-binding proteins. Biochim.Biophys.Acta 1197, 6393.

> Rice-Evans, C. (1990). Iron-mediated oxidative stress and erythrocytes. En: Blood Cell Biochemistry (Harris, J.R. ed.) Vol. 1, pp. 429-453, Plenum Press, New York. 
> Rice-Evans, C. y Hochstein, P. (1981). Alterations in erythrocyte membrane fluidity by phenylhydrazine-induced peroxidation of lipids. Biochem.Biophys.Res.Commun. 100, 1537-1542.

> Rice-Evans, C.A. y Miller, N.J. (1998). Structure-antioxidant activity relationships of flavonoids. En: Flavonoids in health and disease. (Rice-Evans C A, Packer L, ed) pp. 541, Marcel Dekker,Inc., New York.

> Rice-Evans, C., Baysal, E., Pashby, D.P. y Hochstein, P. (1985). t-butyl hydroperoxide-induced perturbations of human erythrocytes as a model for oxidant stress. Biochim.Biophys.Acta 815, 426432.

> Rice-Evans, C.A., Miller, N.J. y Paganga, G. (1996). Structure-antioxidant activity relationships of flavonoids and phenolic acids. Free Radic.Biol.Med. 20, 933-956.

> Richter, C. (1987). Biophysical consequences of lipid peroxidation in membranes. Chem.Phys.Lipids 44, 175-189.

> Riemersma, R.A., Rice-Evans, C.A., Tyrrell, R.M., Clifford, M.N. y Lean, M.E.J. (2001). Tea flavonoids and cardiovascular health. Q.J.Med. 94, 227-282.

> Rivas-Gonzalo, J.C. y García-Alonso, M. (2002). Flavonoides en alimentos vegetales: estructura y actividad antioxidante. Alim.Nutri.Salud 9, 31-38.

$>$ Roelofsen, B. y van Deenen, L.L. (1973). Lipid requirement of membrane-bound ATPase. Studies on human erythrocyte ghosts. Eur.J.Biochem. 40, 245-257.

> Roelofsen, B. y Op den Kamp, J.A.F. (1988) Techniques to determine transbilayer organization and dynamics of membrane phospholipids. En: Membrane Biogenesis (Op den Kamp, J.A.F., ed.) Vol 16, pp. 37-58. NATO ASI Series H: Cell Biology. Springer.

$>$ Rogiers, V., Crokaert, R. y Vis, H.L. (1980). Altered phospholipid composition and changed fatty acid pattern of the various phospholipid fractions of red cell membranes of cystic fibrosis children with pancreatic insufficiency. Clin.Chim.Acta 105, 105-115.

$>\quad$ Rohn, T.T., Hinds, T.R. y Vincenzi, F.F. (1993). Inhibition of the Ca pump of intact red blood cells by t-butyl hydroperoxide: importance of glutathione peroxidase. Biochim.Biophys.Acta 1153, 67-76.

> Roig, R., Cascon, E., Arola, L., Blade, C. y Salvado, M.J. (2002). Procyanidins protect Fao cells against hydrogen peroxide-induced oxidative stress. Biochim.Biophys.Acta 1572, 25-30.

$>$ Rolfe, B.G. (1988). Flavones and isoflavones as inducing substances of legume nodulation. Biofactors 1, 3-10.

> Ronner, P., Gazzotti, P. y Carafoli, E. (1977). A lipid requirement for the (Ca2++ Mg2+) activated ATPase of erythrocyte membranes. Arch.Biochem.Biophys. 179, 578-583.

$>$ Rooney, M.W., Lange, Y. y Kauffman, J.W. (1984). Acyl chain organization and protein secondary structure in cholesterol-modified erythrocyte membranes. J.Biol.Chem. 259, 8281-8285.

> Rose, H.G. y Oklander, M. (1965). Improved procedure for the extraction of lipids from human erytrocytes. J.Lipid Res. 63, 428-431.

> Rouser, G., Fkeischer, S. y Yamamoto, A. (1970). Two dimensional then layer chromatographic separation of polar lipids and determination of phospholipids by phosphorus analysis of spots. Lipids 5, 494-496.

> Sadrzadeh, S.M., Graf, E., Panter, S.S., Hallaway, P.E. y Eaton, J.W. (1984). Hemoglobin. A biologic fenton reagent. J.Biol.Chem. 259, 14354-14356.

> Saija, A., Bonina, F. y Trombetta, D. (1995a). Flavonoid-biomembrane interactions: a calorimetric study on dipalmitoylohosphatidylcholine vesicles. Int.J.Pharm. 124, 1-8. 
> Saija, A., Scalese, M., Lanza, M., Marzullo, D., Bonina, F. y Castelli, F. (1995b). Flavonoids as antioxidants agents: importante of their interaction with biomembranes. Free Radic.Biol.Med. 19, 481-486.

> Sakanashi, Y., Oyama, K., Matsui, H., Oyama, T.B., Oyama, T.M., Nishimura, Y., Sakai, H. y Oyama, Y. (2008) Possible use of quercetin, an antioxidant, for protection of cells suffering from overload of intracellular Ca2+: a model experiment. Life Sci. 83, 164-169.

$>$ Salvati, A.M. y Tentori, L. (1981). Determination of aberrant hemoglobin derivatives in human blood. Methods Enzymol. 76, 715-731.

> Salzer, U. y Prohaska, R. (2001). Stomatin, flotillin-1, and flotillin-2 are major integral proteins of erythrocyte lipid rafts. Blood $\mathbf{9 7}, 1141-1143$.

$>$ Sambrano, G.R. y Steinberg, D. (1995). Recognition of oxidatively damaged and apoptotic cells by an oxidized low density lipoprotein receptor on mouse peritoneal macrophages: role of membrane phosphatidylserine. Proc.Natl.Acad.Sci.U.S.A. 92, 1396-1400.

> Sánchez-Yagüe, J., Cabezas, J.A. y Llanillo, M. (1987). Rearrangement of aminophospholipids in bilayers from sheep platelet plasma membranes and platelet liposomes by increasing their cholesterol levels. Biochem.Biophys.Res.Commun. 145, 1362-1367.

> Sarkadi, B., Ozvegy-Laczka, C., Német, K. y Váradi, A. (2004). ABCG2- a transporter for all seasons. FEBS Lett. 567, 116-120.

$>$ Sato, Y., Kamo, S., Takahashi, T. y Suzuki, Y. (1995). Mechanism of free radical-induced hemolysis of human erythrocytes: hemolysis by water-soluble radical initiator. Biochemistry 34, 89408949.

> Savill, J. (1997). Recognition and phagocytosis of cells undergoing apoptosis. Br.Med.Bull. 53, 491508.

> Scalbert, A. y Williamson, G. (2000). Dietary intake and bioavailability of polyphenols. J.Nutr. 130, 2073-2085.

$>$ Schachter, D. (1984). Fluidity and function of hepatocyte plasma membranes. Hepatology 4, 140151.

> Scheidt, H.A., Pampel, A., Nissler, L., Gebhardt, R. y Huster, D. (2004). Investigation of the membrane localization and distribution of flavonoids by high-resolution magic angle spinning NMR spectroscopy. Biochim.Biophys.Acta 1663, 97-107.

> Schlegel, R.A., Krahling, S., Callahan, M.K. y Williamson, P. (1999). CD14 is a component of multiple recognition systems used by macrophages to phagocytose apoptotic lymphocytes. Cell Death.Differ. 6, 583-592.

$>$ Schroeder, F. (1984). Role of membrane lipid asymmetry in aging. Neurobiol.Aging 5, 323-333.

> Schroeter, H., Boyd, C., Spencer, J.P.E., Williams, R.J., Cadenas, E. y Rice-Evans, C.A. (2002). MAPK signaling in neurodegeneration: influences of flavonoids and of nitric oxide. Neurobiol.Aging 23, 861-880.

Schroit, A.J. y Zwaal, R.F. (1991). Transbilayer movement of phospholipids in red cell and platelet membranes. Biochim.Biophys.Acta 1071, 313-329.

$>$ Schroit, A.J., Madsen, J.W. y Tanaka, Y. (1985). In vivo recognition and clearance of red blood cells containing phoshatidylserine in their plasma membranes. J.Biol.Chem. 260, 5131-5138.

> Schwartz, R.S., Tanaka, Y., Fidler, I.J., Chiu, D.T., Lubin, B. y Schroit, A.J. (1985). Increased adherence of sickled and phosphatidylserine-enriched human erythrocytes to cultured human peripheral blood monocytes. J.Clin.Invest 75, 1965-1972. 
> Scott, E.P. y Slichter, S.J. (1980). Viability and function of platelet concentrates stored in CPDadenine (CPDA-1). Transfusion 20, 489-497.

$>$ Seigneuret, M. y Devaux, P.F. (1984). ATP-dependent asymmetric distribution of spin-labeled phospholipids in the erythrocyte membrane: relation to shape changes. Proc.Natl.Acad.Sci.U.S.A. 81, 3751-3755.

> Shinitzky, M. (1984). Membrane fluidity in malignancy. Adversative and recuperative. Biochim.Biophys.Acta 738, 251-261

> Shinitzky, M. y Barenholz, Y. (1974). Dynamics of the hydrocarbon layer in liposomes of lecithin and sphingomyelin containing dicetylphosphate. J.Biol.Chem. 249, 2652-2657.

> Shinitzky, M. y Barenholz, Y. (1978). Fluidity parameters of lipid regions determined by fluorescence polarization. Biochim.Biophys.Acta 515, 367-394.

> Shinitzky, M., Skornick, Y. y Haran-Ghera, N. (1979). Effective tumor immunization induced by cells of elevated membrane-lipid microviscosity. Proc.Natl.Acad.Sci.U.S.A. 76, 5313-5316.

> Shiono, H., Yagi, Y., Chikayama, Y., Miyazaki, S. y Nakamura, I. (2003). Oxidative damage and phosphatidylserine expression of red blood cells in cattle experimentally infected with Theileria sergenti. Parasitol.Res. 89, 228-234.

$>$ Sies, H. (1993). Strategies of antioxidant defense. Eur.J.Biochem. 215, 213-219.

> Simons, K. y Vaz, W.L. (2004). Model systems, lipid rafts, and cell membranas. Annu.Rev.Biophys.Biomol.Struct. 33, 269-295

> Sindelar, P.J., Guan, Z., Dallner, G. y Ernster, L. (1999). The protective role of plasmalogens in iron-induced lipid peroxidation. Free Radic.Biol.Med. 26, 318-324.

$>$ Singer, S.J. (1974). The molecular organization of membranes. Annu.Rev.Biochem. 43, 805-833.

$>$ Slater, T.F. (1984). Free-radical mechanisms in tissue injury. Biochem.J. 222, 1-15.

$>$ Smeets, E.F., Comfurius, P., Bevers, E.M. y Zwaal, R.F. (1994). Calcium-induced transbilayer scrambling of fluorescent phospholipid analogs in platelets and erythrocytes. Biochim.Biophys.Acta 1195, 281-286.

$>$ Smith, L.L. (1996). Review of progress in sterol oxidations: 1987-1995. Lipids 31, 453-487.

$>$ Smrz, D., Lebduska, P., Dráberová, L., Korb, J. y Dráber, P. (2008). Engagement of phospholipid scramblase 1 in activated cells: implication for phosphatidylserine externalization and exocitosis. J.Biol.Chem. 283, 10904-10918.

> Souza-Santos, P., Ramos, R.S., Ferreira, S.T. y Carvalho-Alves, P.C. (2001). Iron-induced oxidative damage of corn root plasma membrane H(+)-ATPase. Biochim.Biophys.Acta 1512, 357-366.

> Spector, A.A. y Yorek, M.A. (1985). Membrane lipid composition and cellular function. J.Lipid Res. 26, 1015-1035.

$>$ Spiteller, G. (1996). Enzymic lipid peroxidation--a consequence of cell injury? Free Radic.Biol.Med. 21, 1003-1009.

$>$ Steck, T.L. y Kant, J.A. (1974). Preparation of impermeable ghosts and inside-out vesicles from human erythrocyte membranes. Methods Enzymol. 31, 172-180.

$>$ Sugihara, N., Arakawa, T., Ohnishi, M. y Furuno, K. (1999). Anti- and pro-oxidative effects of flavonoids on metal-induced lipid hydroperoxide-dependent lipid peroxidation in cultured hepatocytes loaded with alpha-linolenic acid. Free Radic.Biol.Med. 27, 1313-1323. 
> Tadolini, B., Fiorentini, D., Motta, P., Cabrini, L. y Sechi, A.M. (1992). The influence of phospholipid polar head on the lipid hydroperoxide dependent initiation of lipid peroxidation. Biochem.Int. 26, 275-285.

> Tarahovsky, Y.S., Muzafarov, E.N. y Kim, Y.A. (2008). Rafts making and rafts braking: how flavonoids may control membrane heterogeneity. Mol.Cell Biochem. 314, 65-71.

> Tedesco, I., I, Russo, M., Russo, P., Iacomino, G., Russo, G.L., Carraturo, A., Faruolo, C., Moio, L. y Palumbo, R. (2000). Antioxidant effect of red wine polyphenols on red blood cells. J.Nutr.Biochem. 11, 114-119.

> Teixeira, S., Siquet, C., Alvers, C., Boal, I., Marques, M.P., Borges, F., Lima, J.L.F.C. y Reis, S. (2005). Structure-property studies on the antioxidant activity of flavonoids present in diet. Free Radic.Biol.Med. 39, 1109-1118.

> Tentori, L. y Salvati, A.M. (1981). Hemoglobinometry in human blood. Methods Enzymol. 76, 707715.

> Thangasamy, T., Sittadjody, S., Lanza-Jacoby, S., Wachsberger, P.R., Limesand, K.H. y Burd, R. (2007). Quercetin selectively inhibits bioreduction and enhances apoptosis in melanoma cells that overexpress tyrosinase. Nutr.Cancer 59, 258-268.

> Thiagarajan, P. y Tait, J.F. (1990). Binding of annexin V/placental anticoagulant protein I to platelets. Evidence for phosphatidylserine exposure in the procoagulant response of activated platelets. J.Biol.Chem. 265, 17420-17423.

> Thompson, M. y Williams, C.R. (1976). Stability of flavonoid complexes of copper(II) and flavonoid antioxidant activity. Anal.Chim.Acta 85, 375-381.

$>$ Tirosh, O., Kohen, R., Katzhendler, J., Alon, A. y Barenholz, Y. (1997). Oxidative stress effect on the integrity of lipid bilayers is modulated by cholesterol level of bilayers. Chem.Phys.Lipids 87, $17-22$.

> Tozzi-Ciancarelli, M.G., D'Alfonso, A., Tozzi, E., Troiani-Sevi, E. y De Matteis, G. (1989). Fluorescence studies of the aged erythrocyte membranes. Cell Mol.Biol. 35, 113-120.

> Tsatmali, M., Walcott, E.C., Makarenkova, H. y Crossin, K.L. (2006). Reactive oxigen species modulate the differentiation of neurons in clonal cortical cultures. Mol.Cell Neurosci. 33, 345-357.

> Tyurina, Y.Y., Tyurin, V.A., Zhao, Q., Djukic, M., Quinn, P.J., Pitt, B.R. y Kagan, V.E. (2004a). Oxidation of phosphatidylserine: a mechanism for plasma membrane phospholipid scrambling during apoptosis? Biochem.Biophys.Res.Commun. 324, 1059-1064.

$>\quad$ Tyurina, Y.Y., Serinkan, F.B., Tyurin, V.A., Kini, V., Yalowich, J.C., Schroit, A.J., Fadeel, B. y Kagan, V.E. (2004b). Lipid antioxidant, etoposide, inhibits phosphatidylserine externalization and macrophage clearance of apoptotic cells by preventing phosphatidylserine oxidation. J.Biol.Chem. 279, 6056-6064.

$>$ Uchida, K. (2003). 4-Hydroxy-2-nonenal: a product and mediator of oxidative stress. Prog.Lipid Res. 42, 318-343.

> van Deenen, L.L.M. y de Gier, J. (1964). The Red Blood Cell, Academic Press, New York.

> van den Berg, J.J., Op den Kamp, J.A., Lubin, B.H. y Kuypers, F.A. (1993). Conformational changes in oxidized phospholipids and their preferential hydrolysis by phospholipase A2: a monolayer study. Biochemistry 32, 4962-4967.

> van den Boom, M.A., Wassink, M.G., Roelofsen, B., De Fouw, N.J. y Op den Kamp, J.A. (1996). The influence of a fish oil-enriched diet on the phospholipid fatty acid turnover in the rabbit red cell membrane in vivo. Lipids 31, 285-293. 
> van der Woude, H., Boersma, M.G., Alink, G.M., Vervoort, J. y Rietjens, I.M.C.M. (2006). Consequences of quercetin methylation for its covalent glutathione and DNA adduct formation. Chem.Biol.Interact. 160, 193-203.

> van Ginkel, G., van Langen, H. y Levine, Y.K. (1989). The membrane fluidity concept revisited by polarized fluorescence spectroscopy on different model membranes containing unsaturated lipids and sterols. Biochimie 71, 23-32.

$>\quad$ van Ginkel, G. y Sevanian, A. (1994). Lipid peroxidation-induced membrane structural alterations. Methods Enzymol. 233, 273-288.

> van Kuijk, F.J.G.M., Sevanian, A., Handelman, G.J. y Dratz, E.A. (1987). A New Role for Phospholipase-A2 - Protection of Membranes from Lipid-Peroxidation Damage. Trends Biochem.Sci. 12, 31-34.

> van Rensburg, S.J., Daniels, W.M., van Zyl, J.M. y Taljaard, J.J. (2000). A comparative study of the effects of cholesterol, beta-sitosterol, beta-sitosterol glucoside, dehydroepiandrosterone sulphate and melatonin on in vitro lipid peroxidation. Metab.Brain Dis. 15, 257-265.

> Velamakanni, S., Wei, S.L. Janvilisri, T. y van Veen, H.W. (2007). ABCG trasporters: structure, substrate specificities and physiological roles: a brief overview. J.Bioener.Biomembr. 39, 465-471.

> Vélez, M., Lillo, M.P., Acuna, A.U. y González-Rodríguez, J. (1995). Cholesterol effect on the physical state of lipid multibilayers from the platelet plasma membrane by time-resolved fluorescence. Biochim.Biophys.Acta 1235, 343-350.

> Verstraeten, S.V., Keen, C.L., Schimtz, H.H., Fraga, C.G. y Oteiza, P.I. (2003). Flavan-3-ols and procyanidins protect liposomes against lipid oxidation and disruption of the bilayer structure. Free Radic.Biol.Med. 34, 84-92.

> Visioli, F., Borsani, L. y Galli, C. (2000). Diet and prevention of coronary heart disease: the potential role of phytochemicals. Cardiovasc.Res. 47, 419-425.

Vladimirov, Y.A., Olenev, V.I., Suslova, T.B. y Cheremisina, Z.P. (1980). Lipid-Peroxidation in mitochondrial-membrane. Adv.Lipid Res. 17, 173-249.

$>$ Wang, H. y Joseph, J.A. (1999). Quantifying cellular oxidative stress by dichlorofluorescein assay using microplate reader. Free Radic.Biol.Med. 27, 612-616.

> Wang, S., Beechem, J.M., Gratton, E. y Glaser, M. (1991). Orientational distribution of 1,6diphenyl-1,3,5-hexatriene in phospholipid vesicles as determined by global analysis of frequency domain fluorimetry data. Biochemistry 30, 5565-5572.

> Williams, J.W., Beutler, E., Erslev, J.A. y Rundless, R.W. (1975). Hematología Vol.1, Salvat Editores, S.A., Barcelona.

Dilliams, R.J., Spencer, J.P.E. y Rice-Evans, C.A. (2004). Flavonoids: antioxidants or signalling molecules? Free Radic.Biol.Med. 36, 838-849.

> Wills, E.D. (1987). Evaluation of lipid peroxidation in lipids and biological membranes. En: Biochemical Toxicology, A Practical Approach. (Snell, K.y.M., B. ed.) pp. 127-152, IRL Press Limited, Oxford.

> Winkel-Shirley, B. (2001). Flavonoid Biosynthesis. A Colorful Model for Genetics, Biochemistry, Cell Biology, and Biotechnology. Plant Physiol. 126, 485-493.

> Wójtowicz, K., Pawlikowska-Pawlega, B., Gawron, A., Misiak, L.E. y Gruszecki, W.I. (1996). Modifing effect of quercetin on the lipid membrane. Folia Histochem.Cytobiol. 34, 49-50.

$>$ Wolfs, J.L., Comfurius, P., Bevers, E.M. y Zwaal, R.F. (2003). Influence of erythrocyte shape on the rate of $\mathrm{Ca} 2+-$ induced scrambling of phosphatidylserine. Mol.Membr.Biol. 20, 83-91. 
$>\quad$ Yanagawa, K., Takeda, H., Egashira, T., Sakai, K., Takasaki, M. y Matsumiya, T. (1999). Agerelated changes in alpha-tocopherol dynamics with relation to lipid hydroperoxide content and fluidity of rat erythrocyte membrane. J.Gerontol.A Biol.Sci.Med.Sci. 54, B379-B383.

> Yang, C.S., Sang, S., Lambert, J.D. y Lee, M.J. (2008). Bioavailability issues in studying the health effects of plant polyphenolic compounds. Mol.Nutr.Food Res. 52, 139-151.

> Yeagle, P.L. (1985). Cholesterol and the cell membrane. Biochim.Biophys.Acta 822, 267-287.

$>$ Yeagle, P.L. (1989). Lipid regulation of cell membrane structure and function. FASEB J. 3, 18331842.

> Zachowski, A. (1993). Phospholipids in animal eukaryotic membranes: transverse asymmetry and movement. Biochem.J. 294 (Pt 1), 1-14.

> Zhang, J., Stanley, R.A., Adaim, A., Melton, L.D. y Margot, A. (2006). Skinner Free radical scavenging and cytoprotective activities of phenolic antioxidants. Mol.Nutr.Food Res. 50, 996-1005.

$>\quad$ Zhang, K., Guo, Q.L., You, Q.D., Yang, Y., Zhang, H.W., Yang, L., Gu, H.Y., Oi, Q., Tan, Z. y Wang, X. (2008) Wogonin induces the granulocitic differentiation of human NB4 promyelocytic leukemia cells and up-regulates phospholipid scramblase 1 gene expresión. Cancer Sci., 99, 689-695.

> Zwaal, R.F. y Schroit, A.J. (1997). Pathophysiologic implications of membrane phospholipid asymmetry in blood cells. Blood 89, 1121-1132.

> Zwaal, R.F., Roelofsen, B. y Colley, C.M. (1973). Localization of red cell membrane constituents. Biochim.Biophys.Acta 300, 159-182.

> Zwaal, R.F., Roelofsen, B., Comfurius, P. y Van Deenen, L.L. (1975). Organization of phospholipids in human red cell membranes as detected by the action of various purified phospholipases. Biochim.Biophys.Acta 406, 83-96.

Z Zwaal, R.F., Comfurius, P. y Bevers, E.M. (2005). Surface exposure of phosphatidylserine in pathological cells. Cell Mol.Life.Sci. 62, 971-988. 